\title{
TAXONOMIA DO GÊNERO Trichogramma WESTWOOD, 1833 (HYMENOPTERA: TRICHOGRAMMATIDAE) NA AMÉRICA DO SUL
}

\section{RANYSE BARBOSA QUERINO DA SILVA}

Engenheiro Agrônomo

\section{Orientador: Prof. Dr. ROBERTO ANTONIO ZUCCHI}

\begin{abstract}
Tese apresentada à Escola Superior de Agricultura "Luiz de Queiroz", Universidade de São Paulo, para obtenção do título de Doutor em Ciências, Área de Concentração: Entomologia.
\end{abstract}

PIRACICABA

Estado de São Paulo - Brasil

Janeiro - 2002 


\section{Dados Internacionais de Catalogação na Publicação (CIP) DIVISÃO DE BIBLIOTECA E DOCUMENTAÇĀO - ESALQ/USP}

Silva, Ranyse Barbosa Querino da

Taxonomia do gênero Trichogramma Westwood, 1833 (Hymenoptera :

Trichogrammatidae) na América do Sul / Ranyse Barbosa Querino da Silva. - . Piracicaba, 2002.

214 p. : il.

Tese (doutorado) - Escola Superior de Agricultura Luiz de Queiroz, 2002. Bibliografia.

1. Controle biológico 2. Entomologia agricola 3. Hymenoptera 4. Insetos parasitas Classificação 5. Tricogramatideo I. Título

- CDD 595.79

Termitida a copia total ou parcial destedocumento, desde que citada a fonte- O autor? 
"É cam a caraçãa que de enxerga correlsmente.

O essencial é invisúvel aos olhos".

Intanie de Saint-Exupery 
À minha avó Eulália Barbosa de Souza,

Aos meus pais Armando e Rany,

Aos meus irmãos Márcio, Emmanuel e Denise,

À minhas tias e tios,

\section{Dedico}




\section{AGRADECIMENTOS}

Com muita admiração e gratidão, ao Prof. Dr. Roberto Antonio Zucchi, que pelos seus ensinamentos, dedicação e distinto exemplo, contribuiu de forma relevante em meu desenvolvimento profissional.

À FAPESP pela concessão da bolsa e o importante apoio financeiro.

Ao Prof. Dr. José Roberto Postali Parra, pelo incentivo nos trabalhos e cessão de material e espaço nos laboratórios de Biologia de Insetos.

A todos os professores do setor de Entomologia da ESALQ, pelos ensinamentos transmitidos. Em especial, ao Prof. Dr. Sinval Silveira Neto, pelas valiosas idéias, sugestões e convivência durante a realização deste trabalho. Ao Prof. Dr. Evôneo Berti Filho e Prof. Dr. Celso Omoto pelo apoio constante. Ao Prof. Dr. Luís Carlos Marchini, pelo uso de equipamento microscópico e fotográfico do Laboratório de Apicultura.

Ao Prof. Dr. Elliot W. Kitajima, pelo apoio e uso dos equipamentos de microscopia eletrônica do NAP/MEPA da ESALQ/USP.

Ao Prof. Dr. John D. Pinto (University of Califórnia, USA) pelo envio de material e ajuda na confirmação de espécies de Trichogramma.

Ao Dr. Aristóbulo Lopez-Ávila (Colômbia), Dr. Carlos Alberto D. Silva (Embrapa Algodão), Dr. César Basso (Uruguai), Prof. Cjeslavo Korytkowski (Panamá), Prof. Dirceu 
Pratissoli (UFES), Dr. Eduardo Botto (Argentina), Dr. Francisco Ferrer (Venezuela), Prof. Geraldo A. Carvalho (UFLA), Profa. Iracilda M.M. Lima (UFAL), Prof. José Morales Sánchez (Venezuela), Dra. Líbia Judith Garzon (Colombia), Prof. Lino B. Monteiro (UFPR), Prof. Luis A. Foerster (UFPR), Dra. Mary Whu P. (Peru), Dr. Mauro S. Garcia (UFPEL), Prof. Paulo E. Degrande (UFMS) e Prof. Orlando Sales Jr. (UFMT), pelas amostras de Trichogramma que foram de fundamental importância neste trabalho.

Ao Biológo João A. Cerignoni pelo auxílio nas coletas.

Ao Dr. Américo I. Ciociola Jr. e ao Dr. Raul P. Almeida pela ajuda na confirmação de espécie por meio das análises moleculares.

À Bióloga Dra. Teresinha A. Giustolin e as Eng as Agrônomas M.Sc. Marina R. Frizzas e Rosangela C. Marucci, pelas valiosas discussões profissionais e correções na redação tese.

Ao Biólogo M.Sc. Jorge A. Guimarães pelas críticas e sugestões no transcorrer do trabalho.

À Analista de Sistemas Regina Célia Botequio de Moraes (CPD-Entomologia/ESALQ) pelo auxílio na elaboração do banco de dados e no uso de softwares.

Ao Biólogo Heraldo Negri de Oliveira pela ajuda na criação de Trichogramma.

Aos colegas da ESALQ pela amizade e por todos os momentos compartilhados, indispensáveis durante o Programa de Doutorado (ressalvo-me a não citar nomes pelo carinho que tenho a todos).

A todos os funcionários do setor de Entomologia da ESALQ/USP, sempre disponíveis para ajudar nos trabalhos. 


\section{SUMÁRIO}

Página

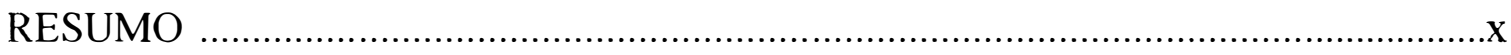

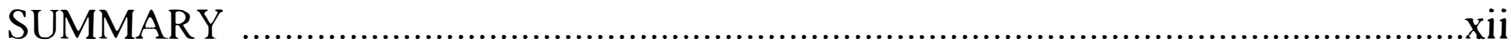

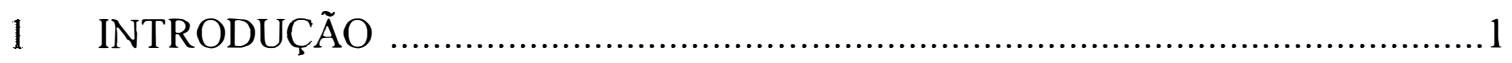

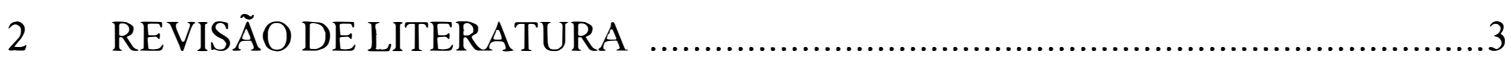

2.1 Família Trichogrammatidae ........................................................... 3

2.2 Gênero Trichogramma .................................................................

2.3 Espécies de Trichogramma na América do Sul ............................................ 7

2.4 Diversidade de espécies e hospedeiros .................................................. 9

2.5 Métodos para a identificação das espécies ...................................................11

3 MATERIAL E MÉTODOS ............................................................... 18

3.1 Coleção de Trichogramma ..................................................................... 18

3.2 Obtenção das amostras ......................................................................... 18

3.3 Preparação dos espécimes para identificação ................................................20

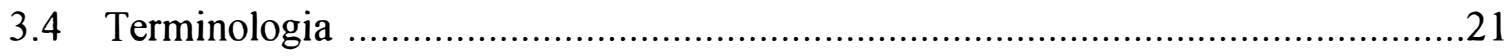

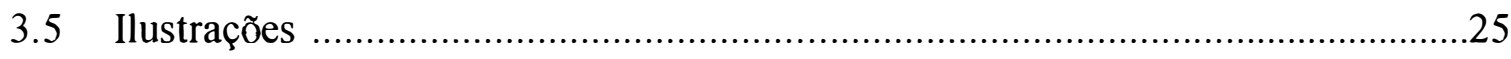

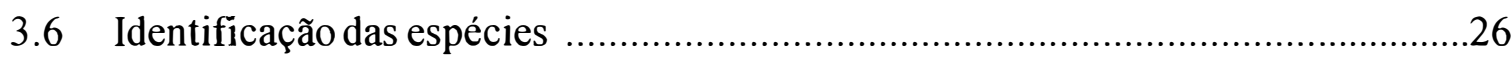

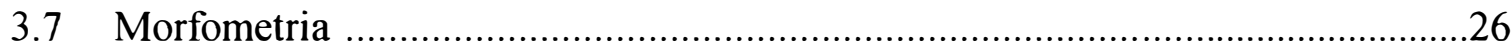

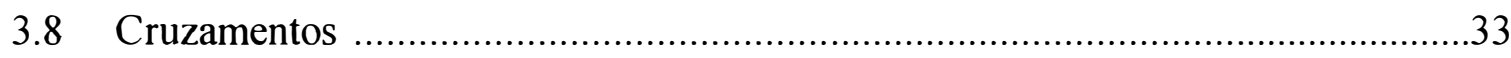

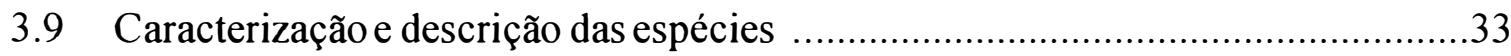

3.10 Chave ilustrada para as espécies de Trichogramma da América do Sul .............34

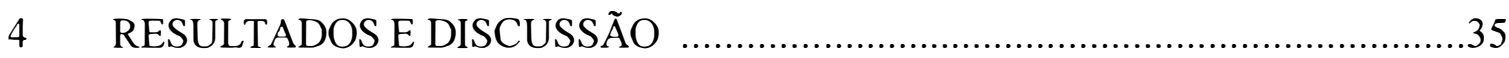

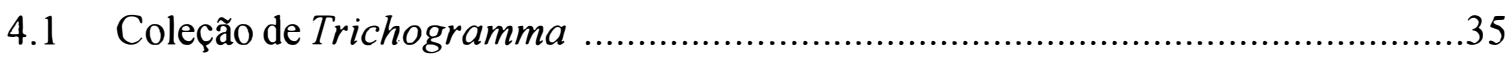

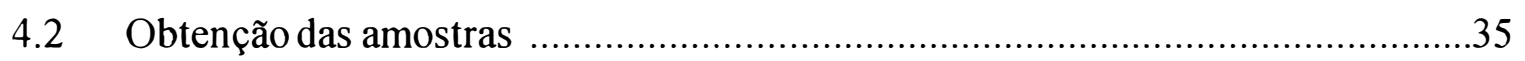




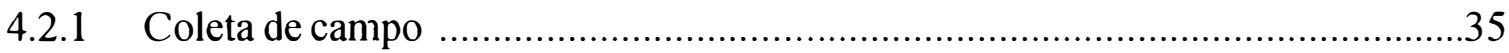

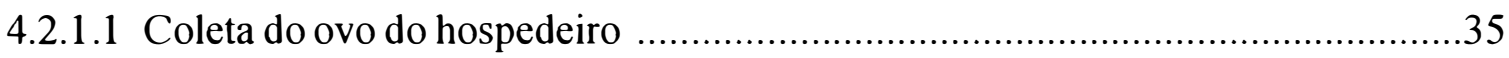

4.2.1.2 Armadilha com ovos do hospedeiro alternativo ………..................................37

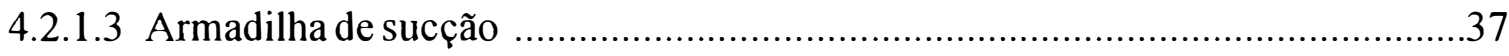

4.3 Caracterização de espécies de Trichogramma registradas na América do Sul.....41

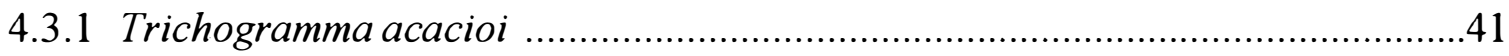

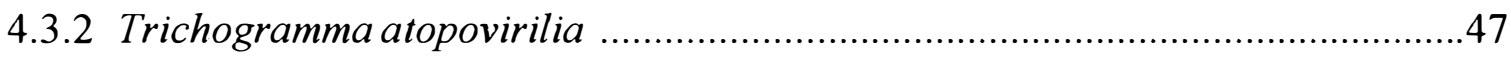

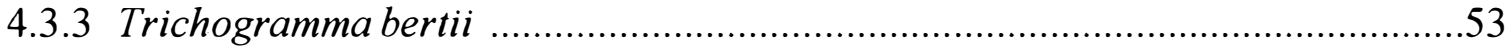

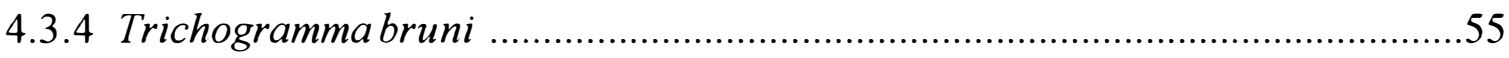

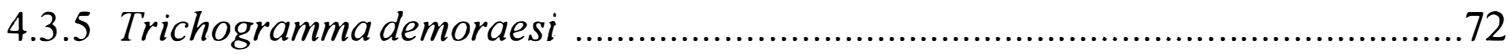

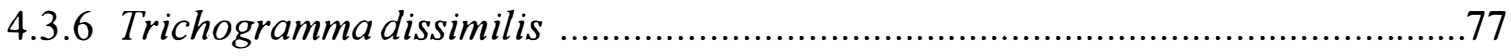

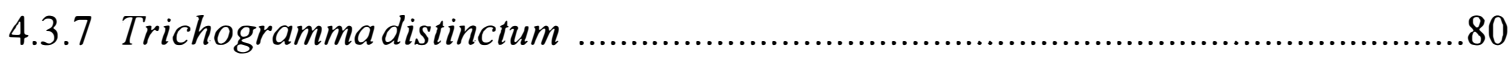

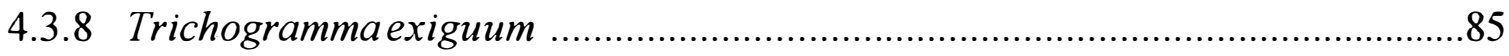

4.3.9 Trichogramma fasciatum ……….........................................................92

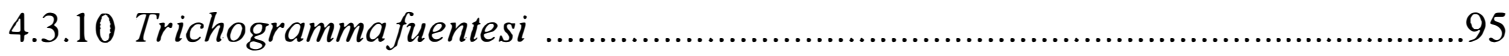

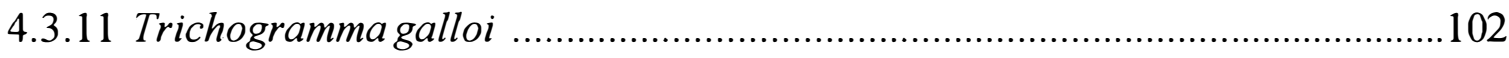

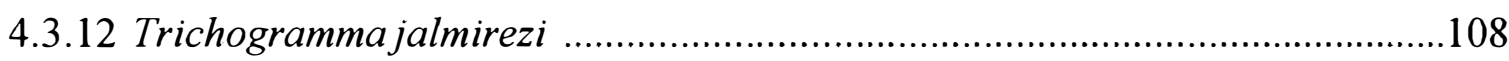

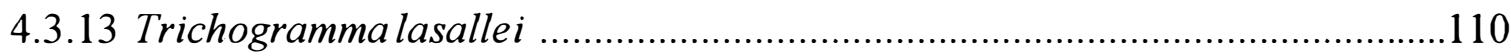

4.3.14 Trichogramma lopezandinensis ...........................................................114

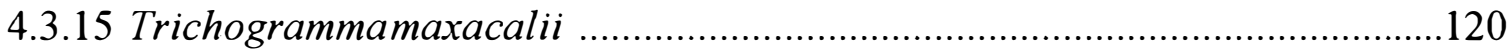

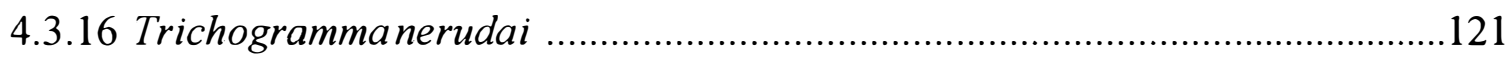

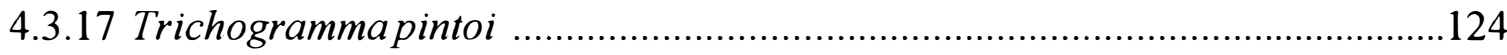

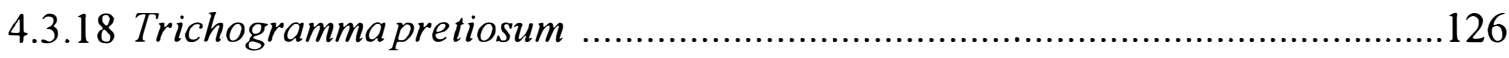

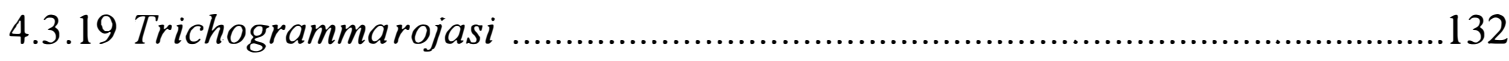

4.4 Descrị̧ão das novas espécies .....................................................................135

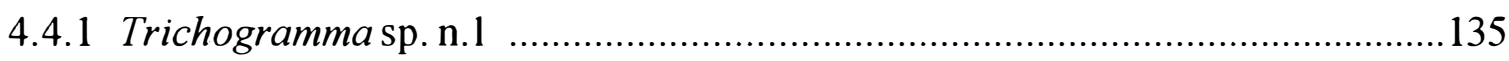

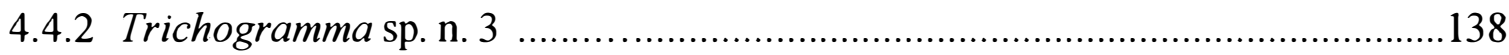

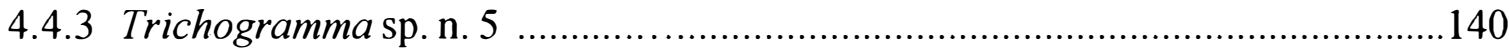

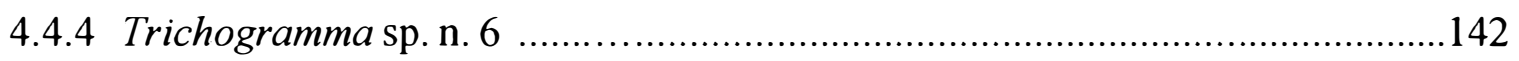

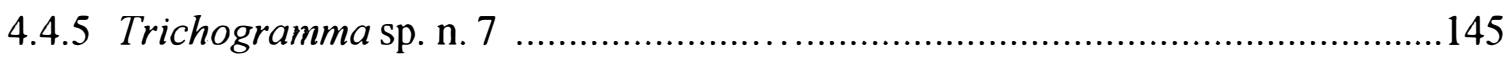




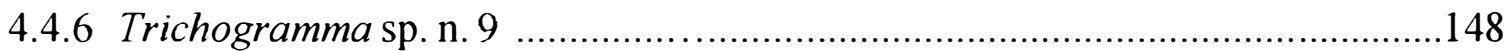

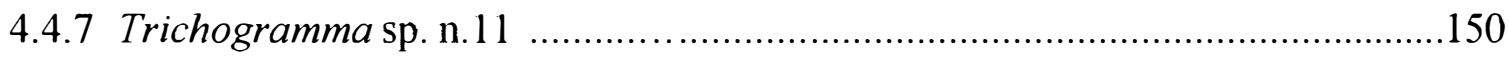

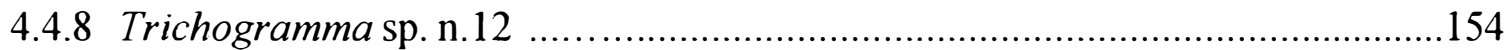

4.5 Chave ilustrada para as espécies de Trichogramma da América do Sul ...........157

4.6 Adendo ao catálogo de espécies de Trichogramma da América do Sul ...........174

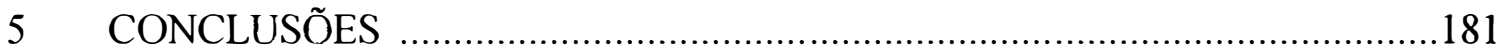

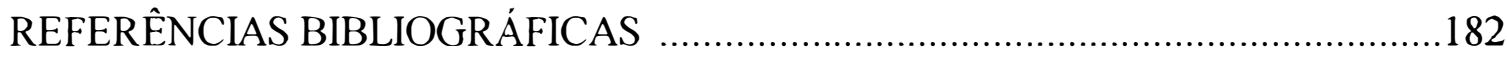

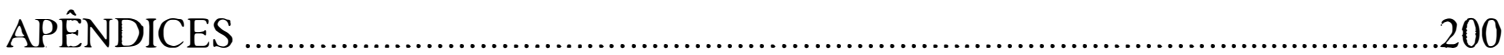




\title{
TAXONOMIA DO GÊNERO Trichogramma WESTWOOD, 1833 (HYMENOPTERA: TRICHOGRAMMATIDAE) NA AMÉRICA DO SUL
}

\author{
Autora: RANYSE BARBOSA QUERINO DA SILVA \\ Orientador: Prof. ROBERTO ANTONIO ZUCCHI
}

\section{RESUMO}

Aproximadamente 180 espécies de Trichogramma são conhecidas em todo o mundo, mas apenas 28 espécies estão registradas na América do Sul e a maioria dos registros para esta região refere-se às espécies associadas com pragas agrícolas. Além disso, os estudos taxonômicos de Trichogramma na América do Sul estão limitados a alguns paises. Este é o primeiro estudo no qual a maioria das espécies registradas na América do Sul é discutida em conjunto. Neste estudo, foram caracterizadas 19 espécies e oito novas espécies são descritas. Baseando-se nos estudos morfológicos e biológicos (cruzamentos e progênies de isofềmeas) foi possivel determinar as variações de intraespecificas de $T$. bruni Nagaraja, 1983. Análises estatísticas multivariadas foram também usadas para auxiliar na caracterização da maioria das espécies. Espécimes de $T$. pretiosum Riley, 1879 obtidos de 10 espécies de lepidópteros, foram analisados por meio da morfometria geométrica. Baseando-se nos espécimes examinados e nas informações da literatura, foi elaborada uma chave ilustrada para 35 espécies da América do Sul (T. castrensis de Velasquez de Rios \& Teran, 1995 não foi incluída na chave). Nas coletas de ovos de lepidópteros, foram obtidas as seguintes espécies: $T$. acacioi Brun, Moraes \& Soares, 1984, T. bruni Nagaraja, 1983, T. demoraesi Nagaraja, 
1983, T. pretiosum Riley, 1879 e Trichogramma sp.n.l1. Com o uso de uma armadilha de sucção, foram coletados 551 espécimes pertencentes a T. bruni, Trichogramma sp. aff. pintoi, $T$. pretiosum e a seis espécies novas. Espécimes depositados na coleção da ESALQ foram incluídos em um banco de dados e o catálogo das espécies de Trichogramma para a América do Sul foi atualizado. Considerando-se as espécies novas descritas neste trabalho, 36 espécies de Trichogramma são conhecidas na América do Sul. A maioria das espécies está registrada para o Brasil (23 espécies), seguido pela Venezuela (9 espécies), Colômbia ( 7 espécies) e Peru (6 espécies). Não há registros de espécies de Trichogramma na Guiana Francesa e no Suriname. Trichogramma pretiosum é a espécie mais amplamente distribuída na América do Sul. 


\title{
TAXONOMY OF THE GENUS Trichogramma WESTWOOD, 1833 (HYMENOPTERA: TRICHOGRAMMATIDAE) ON SOUTH AMERICA
}

\author{
Author: RANYSE BARBOSA QUERINO DA SILVA \\ Adviser: Prof. ROBERTO ANTONIO ZUCCHI
}

\section{SUMMARY}

Approximately 180 Trichogramma species are known, however, only 28 species are recorded in South America, and most of these records for this region refer to species associated with agricultural pests. In addition, the taxonomic studies of Trichogramma in South America are limited to species recorded in some countries. This is the first study in which most species recorded in South America are discussed together. In this study, nineteen species were characterized and eight are described as new ones. Based on morphological and biological studies (crossings and isofemale progenies), it was possible to determine intraspecific variations of $T$. bruni Nagaraja, 1983. A multivariate statistic analysis approach was also used to characterize most species, including the new ones. Specimens of $T$. pretiosum Riley, obtained from 10 lepidopterous species, were analyzed by geometry morphometric. Based on examined specimens studied herein and those reported in literature, an illustrated key to 35 species from South America (only T. castrensis Velasquez de Rios \& Teran, 1995 was not included in the key) was elaborated. From a survey of lepidopterous eggs, the following species were collected: Trichogramma species: T. acacioi Brun, Moraes \& Soares, 1984, T. bruni Nagaraja, 1983, T. demoraesi Nagaraja, 1983, T. pretiosum Riley, 1879 
and Trichogramma sp.n.11. With the use of a suction trap, a total of 551 specimens belonging to $T$. bruni, Trichogramma sp. aff. pintoi, T. pretiosum and to six new species were collected. Specimens deposited at ESALQ collection were included in a database, and the catalogue of the species recorded in South America was updated. Considering the new species described herein, 36 species of Trichogramma are known in South America. Most species are recorded in Brazil (24 species), following by Venezuela (9 species), Colombia ( 7 species) and Peru (6 species). There is no record of Trichogramma species from French Guyana and Suriname. Trichogramma pretiosum is the most widely distributed species in South America. 


\section{INTRODUÇÃO}

Trichogramma é o maior gênero da família Trichogrammatidae, com aproximadamente 180 espécies reconhecidas (Pinto, 1998). As espécies de Trichogramma são microimenópteros parasitóides de ovos, usualmente associadas a Lepidoptera e utilizadas como agentes de controle biológico de pragas de importância econômica em todo o mundo.

A Taxonomia deste gênero na América do Sul foi pouco estudada, mesmo sendo esse parasitóide de grande importância nos programas de controle biológico. Portanto, os estudos taxonômicos com Trichogramma são de fundamental importância, tanto com relação às espécies existentes, quanto no conhecimento da diversidade de espécies. As espécies nativas podem ser potencialmente importantes no controle biológico e, em alguns casos, com altos índices de parasitismo (e.g. Monje, 1995).

Um dos problemas no estudo desse gênero é a sua complexidade taxonômica. Muitas espécies utilizadas no controle biológico têm sido erroneamente identificadas, pois o seu reconhecimento era baseado em caracteres variáveis, como coloração e cerdas das asas. Esses caracteres eram comumente utilizados até a descoberta do valor taxonômico da genitália do macho na identificação taxonômica. Ressalta-se ainda que a falta de voucher specimens sugere incertezas quanto aos dados de literatura anteriores à década de 70. Além disso, a ocorrência de variação intra-específica e a presença de espécies crípticas dificultam a identificação das espécies. Assim, muitos insucessos ocorridos em programas de controle biológico com Trichogramma foram devidos à identificação incorreta deste parasitóide.

A identificação das espécies de Trichogramma baseia-se principalmente em caracteres morfológicos. Nesse caso, é de grande utilidade a morfologia da genitália do 
macho. Outros caracteres das antenas, asas e coloração também são usados. Aliados aos estudos morfológicos, os métodos morfométricos têm sido importantes ferramentas na Taxonomia. Entretanto, as análises morfométricas multivariadas e mais recentemente a morfometria geométrica, são pouco utilizadas no estudo de Trichogramma. O uso dessas análises é particularmente útil para detectar diferenças sutis e no estudo das variações de diversos caracteres quantitativos.

Os métodos bioquímicos, moleculares e reprodutivos são também utilizados na identificação, principalmente, para os casos de espécies crípticas não distinguidas morfologicamente. Estudos de cruzamento são usados para resolver problemas com espécies de Trichogramma, complementando as características morfológicas (Nagarkatti \& Nagaraja, 1968; Pinto et al., 1978; Nagaraja, 1987). Da mesma forma, os resultados obtidos com os métodos moleculares são promissores e de grande utilidade na Taxonomia, mas devem ser realizados em conjunto com os morfológicos e reprodutivos.

Os estudos taxonômicos e o melhor conhecimento desses parasitóides na região Neotropical, isto é, a diversidade de espécies, os hospedeiros e o habitat, são passos iniciais para o desenvolvimento da Taxonomia do gênero Trichogramma e o avanço no uso desse parasitóide em programas de controle biológico na América do Sul e, particularmente, no Brasil. Assim, os objetivos deste trabalho são: 1) a caracterização morfológica de espécies já registradas; 2) descrição de novas espécies; 3) estudos biológicos (cruzamentos); 4) atualização do catálogo de Trichogramma e 5) elaboração de uma chave ilustrada para as espécies de Trichogramma da América do Sul. 


\section{REVISÃO DE LITERATURA}

\subsection{Família Trichogrammatidae}

A família Trichogrammatidae constitui um dos grupos menos numerosos de Chalcidoidea (Hymenoptera), que reúne microimenópteros que parasitam ovos de insetos. A posição dessa família dentro de Chalcidoidea ainda não está bem esclarecida. Dout \& Viggiani (1968) consideraram Trichogrammatidae um grupo separado e distinto de himenópteros parasíticos e relacionado à família Eulophidae. Evidências recentes apontam para um relacionamento próximo a Aphelinidae, particularmente ao gênero Eretmocerus (Heraty et al.,1997 e Yousuf \& Shafee citado por Pinto, 1998).

Doutt \& Viggiani (1968) realizaram um amplo estudo sobre Trichogrammatidae e Viggiani (1971) apresentou a classificação da família, reconhecendo duas subfamílias, Oligositinae com as tribos Oligositini e Chaetostrichini, e Trichogrammatinae com as tribos Paracentrobiini e Trichogrammatini, sendo nesta última incluído o gênero Trichogramma.

A família Trichogrammatidae, constituída por 80 gêneros e cerca de 600 espécies, está distribuída por todo o mundo e ocorre em todos os hábitats terrestres (Pinto, 1997a). Muitos dos gêneros são pouco conhecidos e sua importância se deve quase que exclusivamente ao gênero Trichogramma, o maior da família, que tem recebido muitas atenções na Entomologia Aplicada, por que seus membros parasitam numerosas pragas da ordem Lepidoptera e podem ser multiplicados e liberados com relativa facilidade (Pinto, 1997a, 1997b).

Os Trichogrammatidae são solitários ou gregários endoparasitóides primários de ovos de insetos. Certos gêneros, como Trichogramma, são conhecidos por parasitar ovos 
de várias ordens de insetos. No entanto, outros gêneros são aparentemente restritos, pois parasitam uma única ordem de insetos (Pinto, 1997a). Por exemplo, Oligosita tem sido registrado em Hemiptera (incluindo Homoptera), Orthoptera e Coleoptera, e, embora Trichogramma seja usualmente associado a Lepidoptera, existem registros de parasitismo de ovos de Coleoptera, Diptera, Hemiptera (incluindo Homoptera), Hymenoptera (Symphyta) e Neuroptera. Indicações iniciais sugerem uma maior fidelidade ao microhábitat do que ao táxon hospedeiro. Assim, membros de Lathromeroidea têm sido associados com ovos de Odonata e Hemiptera que ocorrem em ambientes aquáticos, e certas espécies de Trichogramma parasitam ovos de Lepidoptera, Neuroptera e Hymenoptera que ocorrem em uma mesma planta (Pinto \& Stouthamer, 1994).

As principais características utilizadas para $o$ reconhecimento de Trichogrammatidae são (Pinto, 1997b): tarsos 3-segmentados, que os distingui de qualquer outro Chalcidoidea; corpo compacto, sem distinta constrição entre o mesossoma e metassoma; cutícula lisa, raramente esculturada; dimorfismo sexual na antena em vários gêneros; tórulo na margem inferior do olho; pronoto curto; asa anterior variando de extremamente estreita a muito larga, ocasionalmente podem ser ápteros ou braquípteros; distribuição das cerdas discais variável nas asas anteriores e posteriores, comumente distribuída em linhas distintas.

Zerova \& Fursov (1989) publicaram um catálogo para espécies de Trichogramma do mundo. Na América do Sul, a família Trichogrammatidae é pouco conhecida. A maior parte dos registros referem-se aos gêneros Trichogramma e Trichogrammatoidea, que são os de importância para o controle biológico. Segundo Ruiz \& Korytkowski (1979), 27 gêneros são encontrados na região Neotropical. De Santis (1980) citou em seu catálogo, 7 gêneros para o Brasil.

\subsection{Gênero Trichogramma}

Após a criação do gênero Trichogramma por Westwood, 1833, sucederam-se diversas descrições de espécies e vários trabalhos, como os Ashmead (1904), Girault 
(1911 e 1912) e Perkins (1910 e 1912) (Nagarkatti \& Nagaraja, 1977). Quednau (1960) publicou um estudo sobre o efeito da temperatura na pigmentação, ciclo de vida, partenogênese e incluiu uma chave com ilustrações para seis espécies. Flanders \& Quednau (1960) identificaram e descreveram seis espécies de Trichogramma. Comentaram que para a validação das espécies, essas deveriam ser caracterizadas pelo modo de reprodução, variação de cor, comprimento do ciclo de vida e diferenças nas cerdas. Doutt \& Viggiani (1968) publicaram um importante trabalho sobre a família Trichogrammatidae e apresentaram uma lista das espécies de cada gênero.

O avanço na Taxonomia de Trichogramma, ocorreu a partir dos trabalhos de Nagarkatti \& Nagaraja (1968, 1971), que demonstraram a importância do estudo morfológico da genitália do macho. A partir de então, no mundo todo, surgiram novos trabalhos com descrições de espécies baseadas na morfologia da genitália do macho. Novas espécies foram identificadas e outras tantas designadas como sinonímias e posteriormente, muitos problemas taxonômicos esclarecidos.

As espécies do gênero Trichogramma ocorrem em todos os hábitats terrestres, desde o norte, na tundra do círculo ártico, no deserto, em ilhas e hábitats montanhosos, em áreas tropicais e até no ponto mais ao sul, na ilha de Auckland, na costa da Nova Zelândia (Pinto \& Stouthamer, 1994; Pinto \& Oatman, 1996).

Nagarkatti \& Nagaraja (1977) apresentaram uma distribuição mundial de Trichogramma, com registros dos insetos e plantas associadas. Comentaram que, devido ao reduzido tamanho (alguns milímetros), espécimes de Trichogramma podem ser transportados pelo vento e muitas vezes, intencionalmente de um país para outro, em curto espaço de tempo, sendo, portanto, difícil, às vezes, determinar sua região natural de distribuição.

As espécies de Trichogramma ocorrem nas seis regiões biogeográficas do mundo: Paleártica (50 espécies), Oriental (35 espécies), Neártica (28 espécies), Neotropical (24 espécies), Afrotropical (8 espécies) e Austrália (7 espécies). Esses números são altamente correlacionados com a intensidade de coletas nas diferentes regiões e a utilização na Agricultura (Pinto \& Stouthamer, 1994). Várias espécies são relativamente comuns em diferentes regiões, decorrentes de distribuições naturais. 
Outras com ampla distribuição, como T. pretiosum Riley, 1879 na Austrália (e talvez na América do Sul) e $T$. chilonis Ishii, 1941 no Havaí, talvez tenham sido disseminadas pelo homem (Oatman et al., 1982; Pinto et al., 1993).

Apesar da ausência de uma sólida classificação, sabe-se que o gênero é morfologicamente homogêneo e que espécies correlacionadas ocorrem em todo o mundo. Parece haver um conjunto monofilético de espécies que são virtualmente cosmopolitas. Por exemplo, no Novo Mundo, $T$. pretiosum e a espécie asiática $T$. ostriniae Pang \& Chen, 1974; a norte-americana T. nubilale Ertle \& Davis, 1975 e a paleártica T. brassicae Bezdenko, 1968; a norte-americana T. parkeri Nagarkatti, 1975 e a paleártica $T$. principium Sugonjaev \& Sorokina, 1976 são todas muito próximas, pares de espécies alopátricas (Pinto, 1997a).

O gênero Trichogramma, com cerca de 180 espécies em todo o mundo, é o maior da família Trichogrammatidae (Pinto, 1998). Atualmente, está dividido em três subgêneros: o nominativo, Trichogramma Westwood, espécie-tipo Trichogramma evanescens Westwood, 1833 é cosmopolita e possui a maior parte das espécies; Trichogrammanza Carver, 1978 é um subgênero pequeno, restrito a Austrália e Nova Zelândia, e tem como espécie-tipo Trichogramma (Trichogrammanza) funiculatum Carver, 1978 sendo conhecidas apenas três espécies (T. carverae Oatman \& Pinto, 1987, T. funiculatum e T. tenebrosum Oatman \& Pinto, 1987) e o subgênero Vanlisus Pinto, 1998 que ocorre na Austrália e no Novo Mundo, e tem com espécie-tipo Trichogramma lachesis Pinto, 1992 sendo conhecidas 4 espécies, 3 incluídas no grupo lachesis ( $T$. atropos Pinto, 1992, T. clotho Pinto, 1992, T. lachesis) e uma no grupo primaevum (T. primaevum Pinto, 1992).

Várias tentativas de dividir o gênero Trichogramma em grupos de espécies foram feitas (Nagarkatti \& Nagaraja, 1977; Voegelé \& Pintureau, 1982; Pintureau, 1993; Viggiani \& Laudonia, 1989; Pinto, 1992 e Sorokina, 1993). Todos os grupos foram definidos feneticamente. Contudo, esses grupos não têm sido usados, pois várias espécies recentemente descobertas não se enquadram em nenhum grupo e/ou não apresentam limites definidos. A estrutura desse gênero foi examinada filogeneticamente por Pintureau (1994), que com base em caracteres enzimáticos e morfológicos dividiu as 
espécies européias em oito grupos. Pinto (1998) analisou o relacionamento filogenético do gênero Trichogramma e das espécies norte-americanas pertencentes ao subgênero nominativo, dividindo as espécies em seis seções (Arcanum, Drepanophorum, Exiguum, Parkeri, Retorridum e Thalense).

Chaves para as espécies de Trichogramma do mundo foram publicadas por Voegelé \& Pintureau (1982) e Sorokina (1993). Na região Neotropical por Ruiz \& Korytkowski (1979), Zucchi (1985, 1988) e Velasquez de Rios \& Teran (1995). Recentemente, Pinto (1998) publicou uma revisão para as espécies norte-americanas, incluindo também algumas espécies registradas na América do Sul.

\subsection{Espécies de Trichogramma na América do Sul}

Os estudos taxonômicos com Trichogramma na América do Sul são escassos e relativamente recentes, havendo problemas de nomenclatura e de distribuição geográfica das espécies. Grande parte das informações anteriores à décadas de 70 é duvidosa, já que as espécies eram reconhecidas principalmente com base na coloração e nas cerdas das asas, não permitindo uma correta identificação. Aliado a esse fato, a falta de voucher specimens não permite a confirmação de muitos dados na literatura.

A primeira descrição de uma espécie de Trichogramma da América do Sul, realizada com base na genitália masculina, foi feita por Nagaraja \& Nagarkatti (1973), que descreveram $T$. rojasi coletado no Chile e comentaram indícios da presença de $T$. bennetti Nagaraja \& Nagarkatti, 1973, nas Guianas.

Ruiz \& Korytkowski (1979) elaboraram uma revisão do gênero Trichogramma para o Peru e um catálogo das espécies da região Neotropical. Contudo, devido às escassas e confusas referências existentes na época, aquele trabalho apresenta denominações errôneas das espécies e dúvidas na origem das espécies listadas, se nativas ou introduzidas no continente sul-americano. Por exemplo, confundiram $T$. fasciatum (Perkins, 1912) com T. fuentesi Torre, 1990 e com T. exiguum Pinto \& Platner, 1978. 
Pinto et al. (1978, 1983) esclareceu problemas na identificação de várias espécies de Trichogramma norte-americanas, e também para algumas espécies registradas na América do Sul, tais como as designações de T. fasciatum, T' perkinsi Giraul, 1912, $T$. retorridum (Girault, 1911), T. semifumatum (Perkins, 1978), que na realidade são, $T$. fuentesi, T. exiguum, T. brevicapillum Pinto \& Platner, 1978 e T. pretiosum, respectivamente. Outro caso está relacionado a $T$. brasiliense, como mencionado por Zucchi \& Monteiro (1997). Essa espécie tem sido registrada em vários países sulamericanos, apesar de ter sido descrita com base em uma fềmea, cujos caracteres morfológicos não permitem a identificação específica. Entretanto, Pinto (1997c), estudando o material-tipo, revelou que a espécie T. brasiliense Ashmead não pertence ao gênero Trichogramma, mas ao gênero Trichogrammatoidea. Esta nova combinação foi baseada no exame do holótipo remontado. O autor, comentou ainda que algumas espécies criadas em laboratório, pertenciam, a $T$. fuentesi e dados da literatura sugerem que o nome $T$. brasiliense tenha sido aplicado para outras espécies, como $T$. pretiosum e populações telítocas.

De Santis (1980) em seu catálogo, fez a primeira referência de Trichogramma no Brasil, relacionando duas espécies, T. brasiliense (sic) e T. minutum (sic). De Santis (1981), no catálogo de himenópteros calcidóideos da América do Sul, citou 13 espécies de Trichogramma (nativas e introduzidas), entretanto, muitas designações das espécies estão incorretas, não correspondendo às descrições originais.

As primeiras descrições do gênero no Brasil, baseadas no estudo da genitália, foram feitas por Voegelé \& Pointel (1980) para T. maxacalii e por Nagaraja (1983) para T. bruni e $T$. demoraesi.

As espécies de Trichogramma associadas às pragas agrícolas no Brasil foram estudadas por Zucchi (1985, 1988), Zucchi et al. (1991) e Zucchi \& Monteiro (1995). No Chile, T. nerudai foi recentemente descrito por Pintureau et al. (1999). Na Colômbia, Sarmiento (1993) descreveu T. lopezandinensis. Whu \& Valdivieso (1999) comentaram a distribuição das espécies de Trichogramma no Peru e mencionaram as espécies nativas (T. fuentesi, T. exiguum, T. pretiosum, T. rojasi), além das introduzidas. No Uruguai, estão registradas 4 espécies: T. distinctum Zuchi, 1988, T. exiguum, T. galloi Zucchi, 1988 e $T$. 
pretiosum (Basso et al., 1999). Na Venezuela, Velasquez de Rios \& Teran (1995) descreveram três novas espécies: T. castrensis, T. colombiensis e T. guariquensis.

O catálogo das espécies de Trichogramma, seus hospedeiros e respectivas plantas hospedeiras publicado por Zucchi \& Monteiro (1997), lista 24 espécies para a América do Sul e cita inúmeros hospedeiros e plantas associadas com esse parasitóide. Pinto (1998) também mencionou informações sobre distribuição geográfica e hospedeiros de espécies que ocorrem na América do Sul.

O conhecimento atual do padrão de distribuição de Trichogramma na América do Sul é ainda muito incipiente, dificultado ainda pela introdução de espécies sem o prévio estudo das espécies nativas.

\subsection{Diversidade de espécies e hospedeiros}

As espécies de Trichogramma, especialmente aquelas adaptadas a hábitats agrícolas e a outros hábitats modificados, estão amplamente distribuídas na América do Sul. T. pretiosum, por exemplo, está amplamente distribuído no Novo Mundo (Pinto \& Stouthamer, 1994). Segundo esses autores, comparações biogeográficas são complicadas pelas amplas introduções realizadas nos últimos 100 anos. Assim, há poucas evidências quanto às liberações atuais, se estas resultam em permanentes adições às faunas regionais, por causa do pequeno conhecimento sobre a fauna e dos raros levantamentos realizados pré e pós-liberações.

A diversidade de espécies de Trichogramma na região Neotropical ainda é pouco conhecida. Muitos levantamentos são realizados visando programas de controle biológico e, portanto, o conhecimento dos hospedeiros está altamente correlacionado com as coletas e suas aplicações na Agricultura.

$\mathrm{Na}$ América do Sul, espécies que ocorrem predominantemente em ambientes agrícolas apresentam uma lista de hospedeiros conhecidos, como é o caso de $T$. pretiosum com cerca de 240 registros (Pinto, 1998) e essa espécie não é normalmente encontrada em hábitats naturais. Em cana-de-açúcar, estão assinaladas 7 espécies de Trichogramma associadas à broca-da-cana-de-açúcar, Diatraea saccharalis Fabricius, 
1799 (Lep., Crambidae), sendo que 4 (T. dissimilis Zucchi, 1988, T. distinctum, T. galloi e $T$. jalmirezi Zucchi, 1988) somente foram coletadas nesse hospedeiro. Os registros da ocorrência de espécies de Trichogramma associados à broca-da-cana no Novo Mundo foram apresentados por Zucchi et al., 1996.

As espécies de Trichogramma que ocorrem em hábitats de mata, parasitando hospedeiros silvestres de pouca importância econômica, são pouco conhecidas, como é o caso de T. bruni.

O escasso conhecimento da fauna local tem retardado o sucesso na utilização de Trichogramma em programas de controle biológico. Em quase todas áreas amostradas estão presentes espécies nativas, mas levantamentos populacionais raramente precedem as introduções de parasitóides em programas de liberação inundativa, assim, essas formas nativas permanecem desconhecidas e não utilizadas (Pinto, 1998). Segundo LaSalle (1993), é de fundamental importância conservar um grande reservatório de parasitóides nativos, independentemente dos conhecimentos taxonômicos ou biológicos desse reservatório, já que não se pode prever quais as espécies que podem se tornar pragas no futuro. O mesmo autor comentou ainda que os parasitóides de uma determinada praga (ou praga potencial) são importantes para outras também, já que os parasitóides podem mudar de hospedeiro passando de um nativo para um introduzido, com resultados notáveis.

Embora não amplamente estudado, os níveis de parasitismo natural por Trichogramma nos agroecossistemas são relativamente altos (Pinto, 1998) e, em alguns casos, as espécies nativas apresentam um volume maior de parasitismo (Monje, 1995). Assim, é de fundamental importância o conhecimento da diversidade local para preservá-la. Além disso, muitas espécies exóticas de parasitóide podem ser similares às espécies nativas, que são preteridas, e nem sempre o estabelecimento das espécies introduzidas é efetivo (Pinto \& Stouthamer, 1994).

A preferência do hábitat (culturas agrícolas, árvores frutíferas, florestas, etc.) pelas espécies de Trichogramma é outro ponto importante na escolha da espécie a ser usado no controle biológico (Hassan, 1994). 


\subsection{Métodos para a identificação das espécies}

\subsubsection{Morfológicos}

Inicialmente, os caracteres utilizados para identificação das espécies baseavamse na coloração, cerdas da asa e antenas. Quednau (1960) observou que esses caracteres variavam com o tamanho do corpo do inseto e com fatores ambientais. O mesmo autor, afirmou que o problema da identificação poderia ser resolvido apenas com estudos biológicos e reprodutivos, visto a não confiabilidade dos caracteres morfológicos até, então, conhecidos. Com os estudos de Nagarkatti \& Nagaraja $(1968,1971)$, mostrando o valor da genitália do macho na identificação das espécies, verificou-se um aumento expressivo no número de espécies descritas. A morfologia da genitália do macho e outros caracteres morfológicos utilizados na identificação de Trichogramma podem ser encontrados em Pinto (1997a, 1998).

Variação intra-específica tem sido observada em várias espécies de Trichogramma, mostrando que os caracteres são plásticos. Pinto et al. (1989) encontraram uma significativa plasticidade dos caracteres, mas observaram que a genitália do macho, comumente usada em estudos com Trichogramma, parece ser particularmente resistente à variação ecofenotípica.

Assim, a morfologia desse parasitóide depende das variações ambientais e da influência do hospedeiro (Marston \& Ertle, 1973; Bai et al., 1992; Kazmer \& Luck, 1991 e Grenier, 2001). É importante considerar todos esses fatores nos estudos morfológicos com Trichogramma.

\subsubsection{Morfometria multivariada tradicional}

Aliada à morfologia, os métodos morfométricos podem detectar diferenças sutis entre populações (Reyment et al., 1981) e, portanto, são importantes ferramentas na taxonomia. Entretanto, a morfometria multivariada foi pouco utilizada no estudo de Trichogramma.

O termo "Morfometria Multivariada" foi definido por Blackith \& Reyment (1971) para o uso de análises multivariadas em morfometria. Os complexos padrões de 
variação morfométrica dos organismos requerem o uso de análises multivariadas, que permitam considerar simultaneamente a variação de diversos caracteres quantitativos (Cavalcanti \& Lopes, 1993). Essas análises, sobretudo a análise de componentes principais, das variáveis canônicas e das funções discriminantes, são extremamente úteis na ordenação dos dados morfométricos, permitindo que parâmetros biológicos subjacentes às relações morfológicas entre indivíduos ou grupos possam ser mais facilmente detectados e interpretados (Blackith \& Reyment, 1971; Reis, 1988).

$\mathrm{Na}$ análise dos componentes principais (ACP), cada componente é uma combinação linear dos caracteres morfométricos. O número de componentes principais pode ser igual ao número dos caracteres selecionados, no entanto, somente os dois ou três primeiros deverão ser interpretados em um senso biológico, pois normalmente eles explicam a maior porcentagem de variação nos dados (Reyment et al., 1981). Assim, na ACP, como sugerido por Humphries et al. (1981) e Bookstein et al. (1985), o primeiro componente é interpretado como um fator de tamanho e os outros como fatores de forma. Essa análise não requer a priori um agrupamento dos espécimes, pois é uma técnica de ordenação exploratória. Conseqüentemente, revela o padrão total, mas não distingue variações dentro dos grupos das variações entre grupos (Thorpe, 1976).

Para distinguir as variações dentro dos grupos é utilizada a análise das variáveis canônicas, que é similar à análise de componentes principais, exceto pelo fato dos grupos serem definidos a priori e as correlações entre as variáveis não serem consideradas (Cavalcanti \& Lopes, 1993). Isso pode limitar a utilização deste método em biologia evolutiva, onde as correlações entre os caracteres são importantes (Reis, 1988). Contudo, a análise das variáveis canônicas mostra-se bastante apropriada para estudos taxonômicos por permitir maximizar a separação entre grupos e indicar caracteres que mais contribuem para a discriminação das espécies ao longo de cada variável canônica (Blackith \& Reyment, 1971).

Pintureau (1993b) analisou morfometricamente dez espécies européias de Trichogramma. As análises multivariadas permitiram a estimativa das divergências interespecíficas e todas as espécies analisadas foram distinguidas, à exceção de $T$. brassicae e T. voegelei Pintureau. Galán \& Rodríguez (1993) fizeram a caracterização 
morfométrica de cinco espécies cubanas de Trichogramma e os resultados da análise discriminante fatorial permitiram identificar quais as estruturas e as razões responsáveis pela separação destas espécies. Velásquez de Rios \& Colmenares (1999) utilizaram a análise dos componentes principais como um método estatístico para separação de $T$. pretiosum e $T$ atopovirilia Oatman \& Platner, 1983. Concluíram que das variáveis incluídas nas análises, as relacionadas com a genitália do macho foram as que mais contribuíram para separar essas duas espécies.

\subsubsection{Morfometria geométrica}

Recentemente, a introdução da morfometria geométrica no estudo da forma, causou uma revolução nas análises biométricas (Bookstein, 1996; Rohlf \& Marcus, 1993), provocando no início da década de 90, um avanço no conhecimento e na utilização destas técnicas (Monteiro \& Reis, 1999). Estes novos métodos morfométricos ainda são pouco usados, tanto pelas dificuldades metodológicas quanto, em alguns casos, pela dificuldade em identificar os marcos anatômicos de certos organismos.

Os métodos da morfometria geométrica foram desenvolvidos para analisar as diferenças de forma entre organismos com base nos marcos anatômicos, definidos por coordenadas cartesianas (x e y). Essas coordenadas são comparadas após a remoção de qualquer efeito que não relacionado à forma, ou seja, tamanho, posição e orientação, permitindo estudar as diferenças somente quanto à forma. Assim, a forma do objeto a ser estudado está contida em propriedades geométricas que não se alteram com mudanças na escala, translação e rotação (Rohlf, 1996). Esses procedimentos estão detalhados em Bookstein, 1989, 1991, 1996; Rohlf, 1998a; Rohlf \& Slice, 1990; Rohlf \& Bookstein, 1991; Marcus et al., 1993 e Monteiro \& Reis, 1999. Abordagem comparativa entre a "morfometria tradicional", termo definido por Marcus (1990), e a geométrica é discutida por Bookstein, 1993; Zelditch et al., 1995; Stone, 1998.

As aplicações da morfometria geométrica por meio de análises de deformações (Thin-plate spline) são ilimitadas. Adams \& Funk (1997) documentaram a eficiência da função "thin-plate spline" na identificação de sutis, mas informativas variações na forma de Neochlamisus bebbianae (Brown, 1943) (Coleoptera, Chrysomelidae). Estas análises 
endossaram o reconhecimento de espécies crípticas dentro da espécie nominal, na qual os métodos da taxonomia tradicional não discerniram. Nascimento (2000) estudou espécies crípticas pertencentes ao complexo Anastrepha fraterculus (Wiedemann, 1830) (Diptera: Tephritidae), demonstrando que as espécies estudadas apresentam diferenças quanto à forma de asa, quantificada por deformações relativas e independentes do sexo comparado. Poucos grupos foram estudados com essa nova metodologia e não há registro na literatura do seu uso no gênero Trichogramma.

\subsubsection{Reprodutivos}

Os estudos de cruzamento, complementando características morfológicas, são utilizados para resolver problemas taxonômicos de espécies de Trichogramma (Nagarkatti \& Nagaraja, 1968; Pinto et al., 1978; Nagaraja, 1987). A espécie norteamericana T. platneri Nagarkatti, 1975, por exemplo, foi distinguida de T. minutum Riley, 1871, depois que duas culturas morfologicamente idênticas não se cruzaram em laboratório (Nagarkatti, 1975).

O valor dos dados reprodutivos para a taxonomia tem sido justificado pelo importante papel do isolamento reprodutivo na especiação e a necessidade de reconhecer formalmente populações distintas para uso no controle biológico (e.g. DeBach, 1969).

Pinto et al. (1991), estudando a variação na compatibilidade reprodutiva em $T$. deion Pinto \& Oatman, 1986, T. minutum e T. pretiosum e sua significância taxonômica, observaram complexos modelos de compatibilidade reprodutiva. Esses autores notaram uma completa compatibilidade, variados níveis de incompatibilidade parcial (em uma ou nas duas direções) e completa incompatibilidade. Comentaram que o relacionamento reprodutivo está correlacionado às variações geográficas do complexo T. minutum, mas não de $T$. pretiosum ou de $T$. deion. Detalharam ainda os procedimentos para os cruzamentos de espécies de Trichogramma.

O modo de reprodução mais comum em Trichogramma é a arrenotoquia, como nos Hymenoptera em geral, ou seja, ovos fertilizados produzem fềmeas diplóides e ovos não-fertilizados produzem machos haplóides. Outro modo menos comum é a telitoquia ou partenogênese completa, em que ovos fertilizados e não-fertilizados produzem 
fềmeas diplóides. Em Trichogramma, existem duas formas de telitoquia: reversível (associada a infecções microbianas) e a não-reversível (Stouthamer et al., 1990). Evidências citológicas apontam para uma completa correlação entre a presença de microorganismos em ovos e a incidência de partenogênese (telitoquia) reversível em espécies do gênero Trichogramma (Stouthamer \& Werren, 1993). Em várias espécies desse parasitóide, a telitoquia é causada por bactérias do gênero Wolbachia ( $\alpha$ Proteobacteria, Rickettsia) (Stouthamer et al., 1993), inclusive em algumas espécies de Trichogramma (Stouthamer \& Luck, 1993). Segundo Van Meer (1999), essas bactérias induzem a incompatibilidade citoplasmática, telitoquia, feminização ou aumento na fecundidade em seus hospedeiros.

Fêmeas telítocas, ocorrendo em população arrenótoca (não-infectada), podem receber e usar esperma dos machos. Não há isolamento genético. Essas fềmeas podem ser tratadas com antibiótico ou temperaturas altas e se transformarem em formas arrenótocas normais. Por essa razão, é importante estudar o tipo de telitoquia envolvida antes de considerar populações unissexuais como espécies distintas ou subespécies (Pinto, 1997a).

A modificação no modo de reprodução poderia interferir com a dinâmica da população hospedeira e causar conseqüências no processo de especiação (Breeuweer \& Werren, 1990). As vantagens e desvantagens para o controle biológico no uso de fềmeas telítocas versus fềmeas arrenótocas foram discutidas por Stouthamer (1993). Van Meer (1999) estudou as implicações ecológicas para o controle biológico do uso de fềmeas telítocas.

Wolbachia é conhecida por induzir partenogênese em mais de 10 espécies de Trichogramma (Pinto \& Stouthamer, 1994). Os primeiros casos de reprodução partenogenética completa induzida por Wolbachia na América do Sul, mais especificamente no Brasil, foram registradas por Almeida et al. (2001) em T. pretiosum e Ciociola Jr. et al. (2001) em T'. atopovirilia. 


\subsubsection{Moleculares}

As primeiras técnicas moleculares utilizadas para a identifícą̧ão de espécies de Trichogramma foram as isoenzimas. Pintureau \& Babault (1981) usaram três sistemas enzimáticos (esterases, malato desidrogenase e tetrazólio oxidade) na distinção de $T$. evanescens e T. maidis Pintureau \& Voegelé, 1980. Pintureau (1993a), trabalhando com espécies européias de Trichogramma, mostraram que as esterases podem ser utilizadas na identificação de algumas espécies. Pinto et al. (1992) observaram que as variações aloenzímicas encontradas em 14 locos de 22 culturas do complexo T. minutum estão correlacionadas significativamente aos níveis de compatibilidade reprodutiva, previamente observadas (e.g. Pinto et al., 1991). Os dados enzimáticos suportaram o reconhecimento de três formas morfologicamente similares, duas de T. platneri e uma de T. minutum. Aqueles autores mencionaram ainda que considerável variação aloenzímica foi encontrada dentro dessas morfoespécies. Por isso, um protocolo com extensa amostragem é necessário na utilização dos dados aloenzímicos para caracterizar e relacionar espécies desse gênero.

Os estudos moleculares com DNA (mais precisos) passaram a serem aplicados à Taxonomia de Trichogramma. Vários trabalhos foram realizados mostrando a utilidade das técnicas de RAPD, RFLP, microssatélites e seqüenciamento da região ITSI e ITS2 do r-DNA (Orrego \& Agudelo-Silva, 1993; Vanlerberghe-Masutti, 1994; Silva et al., 1995; Pinto et al., 1997; Silva et al., 1995).

Stouthamer et al. (1999) demonstraram a utilidade do seqüenciamento da região ITS2 do r-DNA, como nova técnica de identificação de Trichogramma. Utilizando as informações produzidas por essas técnicas, por exemplo, o comprimento do seqüenciamento e o auxílio de enzimas de restrição, é possível diferenciar as espécies, como observado por Silva (1999) para cinco espécies de Trichogramma, que ocorrem em Portugal. Além disso, utilizando as enzimas é possível elaborar uma chave molecular de espécies de Trichogramma seqüenciadas. Por exemplo, Ciociola Jr. (2001) elaborou uma chave molecular para 7 espécies brasileiras de Trichogramma, usando seqüências da região ITS2 e análises de restrição. 
Os resultados obtidos com os métodos moleculares são promissores e de grande utilidade na Taxonomia, mas devem ser realizados em conjunto com os morfológicos e reprodutivos. Assim, as maiores vantagens da identificação molecular são: a) possibilidade para identificar fêmeas, pois até agora todas as identificações são baseadas nos machos; b) identificação de variantes intra-específicos, os quais são geralmente indistinguíveis morfologicamente mas potencialmente importantes para o controle biológico (Landry et al., citado por Pinto, 1998). 


\section{MATERIAL E MÉTODOS}

\subsection{Coleção de Trichogramma}

Inicialmente, realizou-se um levantamento do acervo da coleção de Trichogramma da ESALQ (Entomologia) para catalogação de todas as lâminas. Isto foi necessário para ter-se conhecimento do material já existente a ser utilizado nos estudos. As lâminas foram examinadas e colocadas em caixas numeradas. As informações sobre espécies, insetos hospedeiros e plantas associadas, locais de coleta, data de coleta e coletores foram adicionadas a um banco de dados (programa Access) para facilitar o acesso e obter as informações disponíveis na Coleção Entomológica.

\subsection{Obtenção das amostras}

As amostras de Trichogramma foram solicitadas a instituições e pesquisadores de diferentes regiões do Brasil e de vários países da América do Sul, visando-se obter uma maior diversidade no material em estudo para permitir comparações das espécies em razão das variações geográficas ou até mesmo dos hospedeiros. Foram examinadas todas as amostras recebidas, de coletas de campo e as lâminas da coleção da ESALQ que conta com material coletado em diferentes regiões do Brasil e de outros países da América do Sul. Foram examinados T. bruni da Argentina, Costa Rica, Trinidad e Venezuela da coleção da University of California (Riverside, Tx, USA), designados como "nr. bruni". 


\subsubsection{Coleta de campo}

\subsubsection{Coleta de ovos do hospedeiro}

Foram realizadas, coletas ocasionais de ovos de prováveis insetos-hospedeiros em áreas agrícolas, reservas florestais e plantas nativas, como também em hábitats adjacentes (áreas nativas e vegetação de sub-bosque e espontânea) nos municípios de Anhembi, Campinas, Itatinga, Lins, Piracicaba e Sorocaba, no Estado de São Paulo. Os ovos dos insetos hospedeiros foram coletados diretamente nas plantas e acondicionados em frascos de vidro, onde permaneceram até a emergência dos adultos do parasitóide. Era oferecida uma pequena quantidade de ovos do hospedeiro alternativo (Anagasta kuehniella Zeller, 1879), visando a multiplicação do parasitóide. Para a identificação do inseto hospedeiro, quando possível, foi realizada a criação das formas imaturas até o estágio adulto para a identificação.

\subsubsection{Armadilha com ovos do hospedeiro alternativo}

Ovos de A. kuehniella foram colocados em cartelas (aproximadamente $3 \times 3 \mathrm{~cm}$ ) de cartolina azuis e instaladas em plantas na ESALQ. Após 48h eram levadas ao laboratório, para observação do parasitismo e identificação dos parasitóides. As cartelas foram enviadas também para os Estados do Mato Grosso do Sul e Tocantins.

\subsubsection{Armadilha de sucção}

Uma armadilha de sucção estacionária, contendo recipiente de coleta abastecido com uma solução de álcool + glicerina (3:1), foi instalada em uma reserva florestal, no Horto Florestal de Tupi (Piracicaba, SP). As coletas foram realizadas pelo período de um ano (setembro/1999 a setembro/2000). Semanalmente, a amostra era retirada, colocada em um frasco com tampa e a solução de álcool + glicerina substituída. A amostra coletada era armazenada em freezer.

O material coletado na armadilha de sucção era triado para a separação dos espécimes de Trichogramma para identificação específica. Voucher specimens foram depositados na ESALQ (Entomologia). 
Os dados foram agrupados mensalmente e a quantificação dos exemplares foi feita por meio de contagem direta. Com base no programa ANAFAU (ESALQ, Entomologia) foram calculadas as seguintes medidas da fauna:

1) Abundância: número de indivíduos por unidade de superfície ou volume e varia no espaço e tempo, calculada por meio do desvio padrão e do intervalo de confiança (IC) da média aritmética a $1 \%$ e $5 \%$ de probabilidade;

2) Freqüência: porcentagem de indivíduos de uma espécie com relação ao total de indivíduos, calculada segundo Silveira Neto et al. (1976);

3) Constância: porcentagem de espécies presentes no levantamento, calculada por meio do intervalo de confiança (IC) da média aritmética a $5 \%$ de probabilidade;

4) Dominância: definida como a ação exercida pelos organismos dominantes de uma comunidade. O método utilizado foi o de Kato et al. citado por Laroca \& Mielke (1975);

5) Índice de diversidade $(\alpha)$ : riqueza em espécies de uma comunidade (índice proposto por Shannon-Weaner, citado por Southwood, 1992).

\subsection{Preparação dos espécimes para identificação}

Os espécimes recebidos de outras instituições e os coletados em campo foram preparados para a montagem em lâminas de microscopia para a identificação. Os espécimes conservados em álcool $70 \%$ foram transferidos para ácido acético glacial, por um período mínimo de $24 \mathrm{~h}$. Aqueles que apresentavam pigmentação mais escura passaram por um processo de clarificação utilizando-se solução de $\mathrm{NaOH} 10 \%$, neste caso, eram deixados em temperatura ambiente por no máximo $24 \mathrm{~h}$. Posteriormente, os exemplares eram montados, um por lâmina, em meio de Hoyer's, em posição dorsoventral, utilizando-se um microscópio estereoscópico com aumento de 40x. As lâminas assim preparadas foram mantidas numa estufa a $50 \pm 5{ }^{\circ} \mathrm{C}$ por um período de uma semana e em seguida lutadas e etiquetadas. 


\subsection{Terminologia}

A terminologia das estruturas anatômicas foi baseada em Pinto (1998). As estruturas utilizadas na caracterização e descrição estão na Figura 1.

\section{Antena:}

- Cerdas flageliformes: cerdas alongadas que cobrem a superfície do flagelo.

- Cerdas com base indistinta: cerdas muito curtas e menos conspícuas do que as flageliformes, rígidas e apicalmente direcionadas (semelhante a pêlos).

- Sensilo basicônico: estrutura bulbosa, ocorrendo em seis posições no flagelo da antena do macho. A fórmula dos sensilos basicônicos é usada para indicar a presença e o número do sensilo nessas posições (e.g. 1-2-2-0-1-1). Na fórmula, quando um número estiver entre parênteses, indica que ambos estados são igualmente freqüentes (e.g. 12(1)-2-0-1-1).

- Sensilo placóideo: são alongados e estreitos presentes na metade apical do flagelo da antena do macho.

\section{Escutelo:}

- Esclerito posterior do mesonoto. Usou-se o termo adotado por Vincent \& Goodpasture (1986), segundo o qual "escutelo" é preferível a "mesoescutelo" para Trichogramma e outros calcidóideos, já que o pronoto e metanoto são placas segmentais não diferenciadas. Como somente o mesonoto mostra diferenciação nos dois escleritos, é desnecessário o uso do prefixo meso- associado ao escutelo, quando este indicar o esclerito posterior do mesonoto. $\mathrm{O}$ termo mesoescuto refere-se ao esclerito anterior do mesonoto. Por outro lado, mesoescuto refere-se ao esclerito anterior do mesonoto.

\section{Asa anterior:}

- Cerdas da franja: encontradas ao longo da margem póstero-lateral da asa.

- Número de cerdas: contadas entre a quarta e quinta fileira de cerdas. A contagem não inclui as cerdas da franja da primeira fileira de cerdas imediatamente após a franja. 


\section{Asa posterior:}

- Formada por três fileiras de cerdas, a primeira é chamada de anterior e a terceira de posterior, ambas são úteis na identificação. A segunda é a fileira mediana que alcança o ápice da asa em todas as espécies.

Genitália do macho: composta por várias estruturas nas superfícies dorsal e ventral.

- Distância apical: da base do processo intervolselar ao ápice dos parâmeros, grosseiramente equivalente ao comprimento dos parâmeros.

- Distância basal: da base do processo intervolselar à base da cápsula genital.

- Largura apical: largura da cápsula genital ao nível do processo intervolselar.

- Abertura dorsal: seção do dorso da cápsula genital que não é coberta pela lâmina dorsal.

- Lâmina dorsal: estrutura que se origina próxima à metade do comprimento da cápsula genital e estende-se posteriormente e, em geral, estreitando-se apicalmente.

- Processo intervolselar: estrutura tipicamente pontiaguda ou subtriangular que ocorre ventralmente ao longo da linha mediana da cápsula genital, entre as volselas.

- Carena ventral: estende-se anteriormente da base do processo volselar ao longo da linha mediana da cápsula genital.

- Carena dorsal (carena interna na vista dorsal): estende-se posteriormente da base da cápsula genital ao longo da linha mediana da superfície dorsal.

- Processos ventrais: duas pequenas estruturas situadas ao lado da carena ventral, geralmente, próxima à base do processo intervolselar.

- Parâmeros: define a distância apical da cápsula genital; estrutura mais lateral do ápice da cápsula genital.

- Volselas: duas estruturas digitiformes situada lateralmente ao processo intervolselar.

- Edeago: uma estrutura separada, posicionada entre a lâmina dorsal e a região ventral da cápsula genital. 


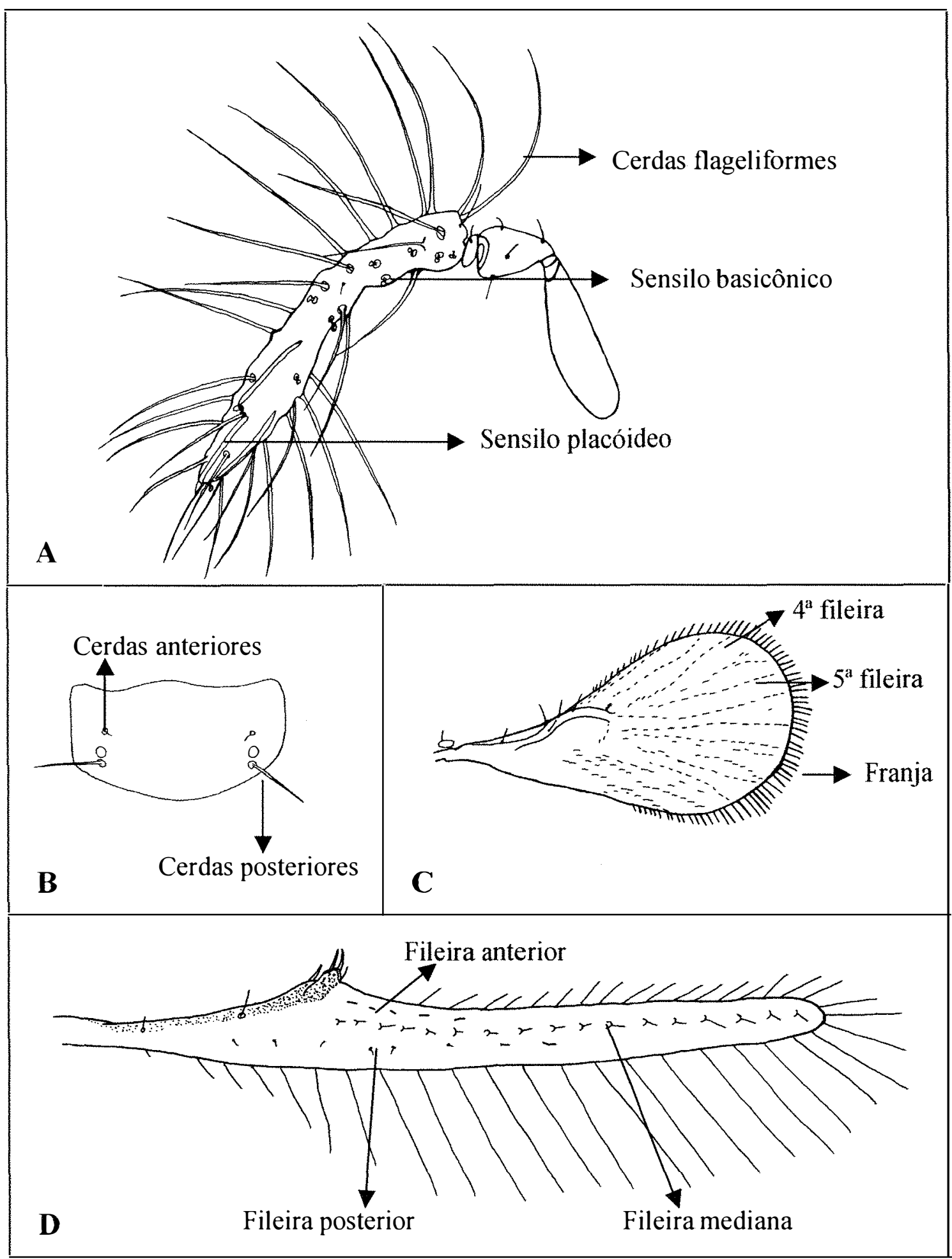

Figura 1 - Morfologia de Trichogramma. A - Antena do macho; B - Escutelo; C - Asa anterior; D - Asa posterior. 


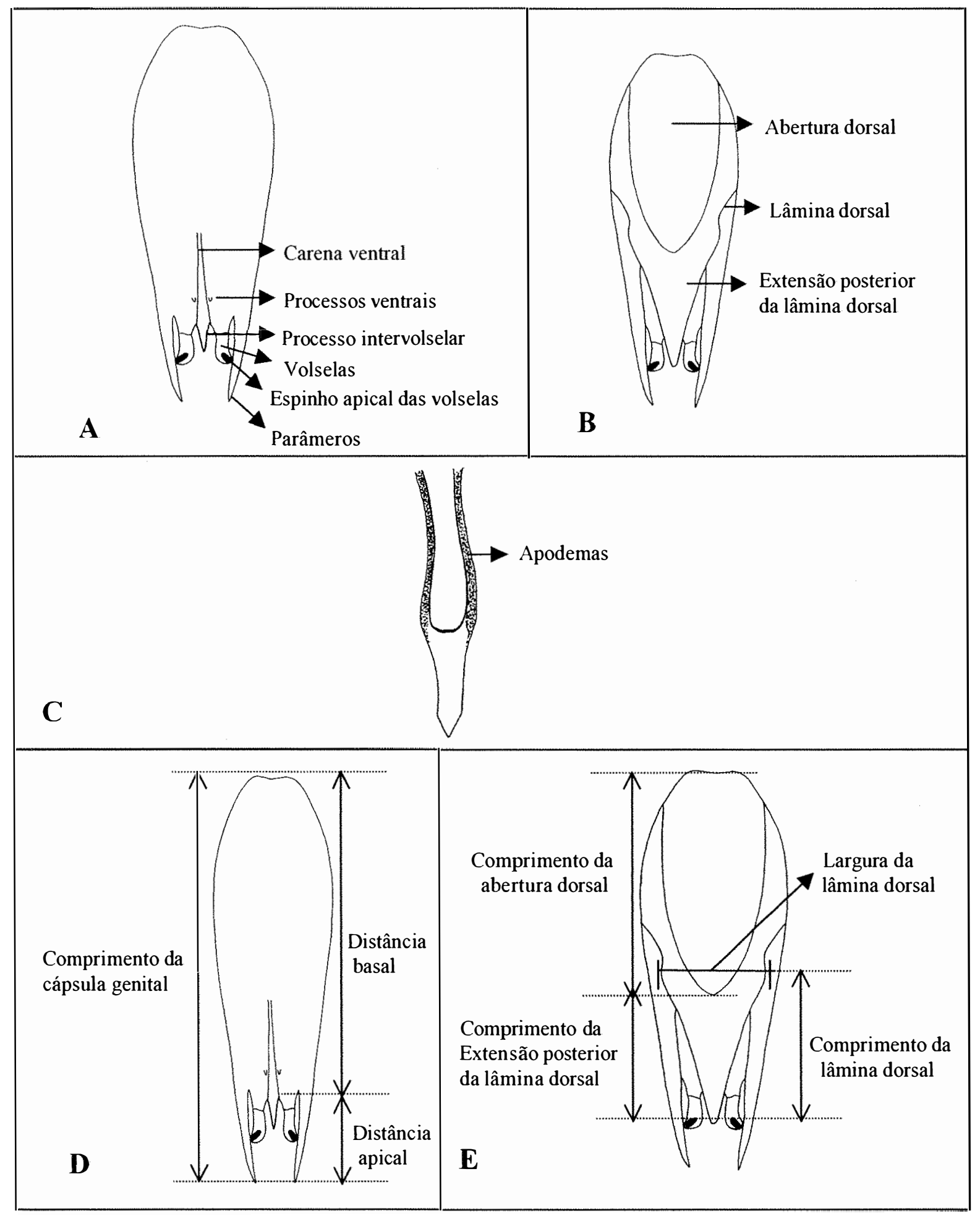

Figura 2 - Morfologia da genitália do macho de Trichogramma. A e D - Cápsula genital (ventral); B e E - Cápsula genital dorsal; C - Edeago. 


\subsection{Ilustrações}

Foram realizados desenhos em câmara clara e fotografias com câmera acoplada ao microscópio óptico, das estruturas de importância taxonômica. Microfotografias em microscopia eletrônica de varredura foram também utilizadas na caracterização e descrição das espécies de Trichogramma. Os procedimentos utilizados na microscopia eletrônica de varredura constam das seguintes etapas:

\section{Morte dos exemplares}

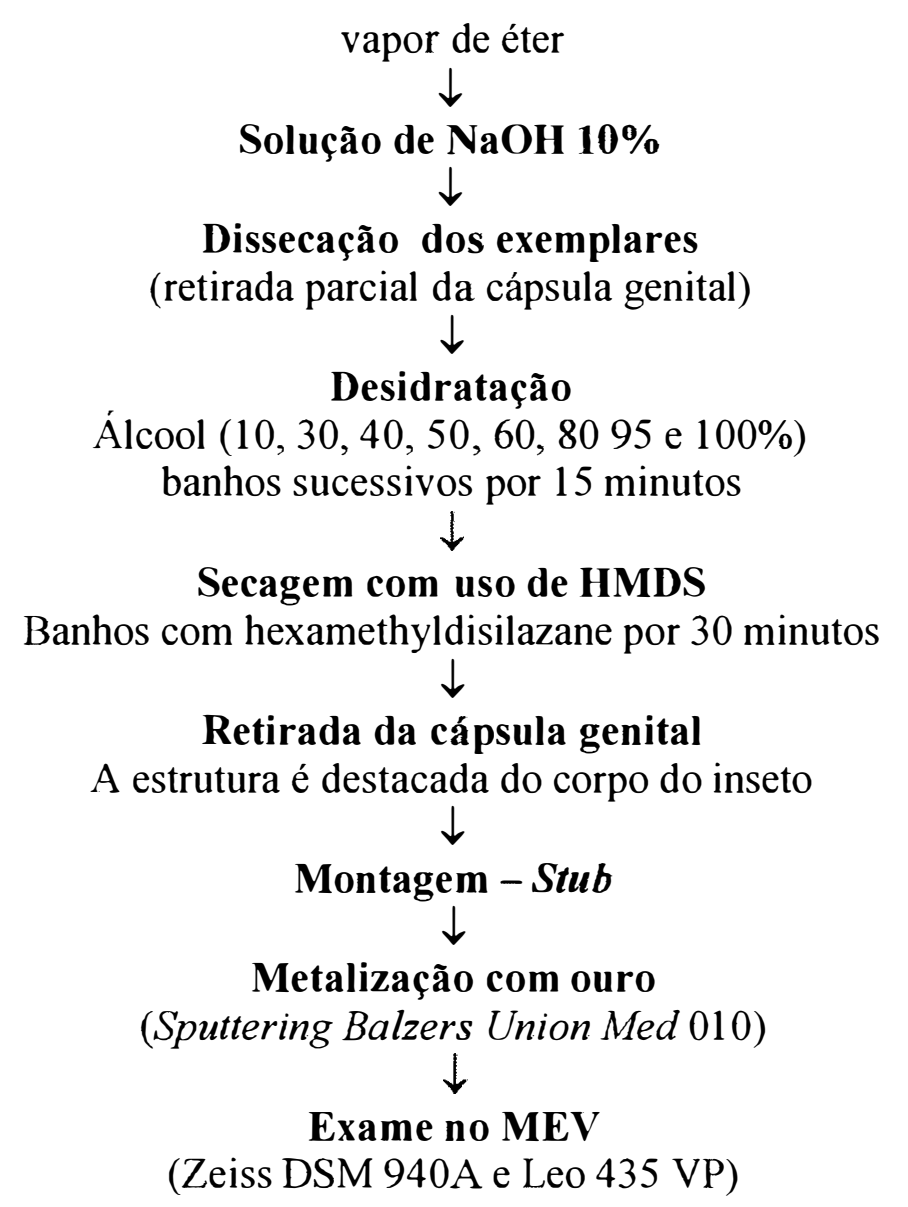

O tempo de permanência dos espécimes na solução de $\mathrm{NaOH} 10 \%$ variou segundo o grau de esclerotização e a origem do material. Os espécimes de Trichogramma usados: eram recém-emergidos, criados em ovos de A. kuehniella esterilizados em luz ultravioleta; exemplares conservados em álcool e secos. 
Para a dissecação e manipulação das estruturas, utilizaram-se estiletes de microalfinetes. A cápsula genital era extrovertida, mas permanecia unida ao corpo do inseto, para que não se perdesse nas outras fases. Após a secagem com HMDS (durante toda noite), os espécimes eram colocados em uma lâmina de vidro, onde se retirava a cápsula genital e eram montados sobre os stubs, juntamente com o restante do corpo do inseto.

\subsection{Identificação das espécies}

A identificação foi realizada somente em machos, baseada principalmente nos caracteres da genitália, das antenas e das asas. As lâminas eram observadas em microscópio óptico com aumento entre 400 a 1000x. A identificação específica foi obtida por meio das descrições originais e também por comparações com espécimes da coleção da ESALQ. Espécimes também foram enviados ao Dr. John Pinto, University of California, Riverside, Tx., USA, para confirmação das identificações específicas.

Os insetos hospedeiros da ordem Lepidoptera foram identificados por comparação na coleção da ESALQ e pelo Dr. Victor Becker.

\subsection{Morfometria}

As medidas dos caracteres taxonômicos das espécies de Trichogramma foram realizadas em microscópio óptico sob ocular reticulada, com aumentos de 400-1000x. A morfometria foi utilizada para auxiliar na caracterização das espécies de Trichogramma. As estruturas medidas foram:

1. Comprimento do flagelo (CF);

2. Maior largura do flagelo (LF);

3. Comprimento da maior cerda do flagelo (CCF);

4. Comprimento da maior cerda da franja da asa anterior (CCFAA);

5. Número de cerdas da fileira anterior da asa posterior (NCFAAP);

6. Número de cerdas da fileira posterior da asa posterior (NCFPAP); 
7. Comprimento das cerdas anteriores do mesoescuto (CCAM);

8. Comprimento das cerdas posteriores do mesoescuto (CCAM);

9. Comprimento das cerdas anteriores do escutelo (CCAE);

10. Comprimento das cerdas posteriores do escutelo (CCPE);

11. Comprimento do edeago (CE);

12. Comprimento dos apódemas (CA);

13. Comprimento da carena ventral (CCV);

14. Comprimento da cápsula genital (CCG);

15. Largura da cápsula genital (LCG);

16. Distância basal (DB);

17. Distância apical (DA);

18. Largura apical (LA);

19. Comprimento da abertura dorsal (CAD);

20. Largura da lâmina dorsal (LLD);

21. Comprimento da lâmina dorsal (CLD);

22. Comprimento da extensão posterior da lâmina dorsal (CEPLD);

23. Número de cerdas na asa anterior ( $\mathrm{NC}$ );

24. Distância dos processos ventrais para a base do processo intervolselar (DVP);

25. Comprimento da projeção do sensilo placóideo (CPSP);

26. Comprimento da tíbia posterior (CTP);

27. Comprimento do escapo da antena (CEA);

28. Largura da asa anterior (LAA)

29. Comprimento da asa anterior (CAA).

Foram determinadas a partir destas medidas as relações entre as seguintes estruturas:

1. Comprimento do flagelo/Largura do flagelo;

2. Comprimento do flagelo/Comprimento das tíbias posteriores;

3. Comprimento da maior cerda do flagelo/Largura do flagelo;

4. Comprimento da maior cerda da franja da asa anterior/Comprimento da tíbia posterior;

5. Comprimento da maior cerda da franja da asa anterior/Largura da asa anterior; 
6. Largura da asa anterior/Comprimento da asa anterior;

7. Comprimento das cerdas anteriores do escutelo/Comprimento das cerdas posteriores do escutelo;

8. Largura da cápsula genital/Comprimento da cápsula genital;

9. Distância apical/Comprimento da cápsula genital;

10. Largura apical/Largura da cápsula genital;

11. Comprimento da lâmina dorsal/Comprimento da cápsula genital;

12. Comprimento da lâmina dorsal/Largura da lâmina dorsal;

13. Comprimento da abertura dorsal/Comprimento da lâmina dorsal;

14. Comprimento da extensão posterior da lâmina dorsal/Comprimento lâmina dorsal;

15. Comprimento da carena ventral/Distância basal;

16. Distância basal/Comprimento da cápsula genital;

17. Comprimento do Edeago/Comprimento da cápsula genital;

18. Comprimento dos Apodemas/Comprimento do Edeago.

\subsubsection{Multivariada tradicional}

Os caracteres morfológicos foram examinados por meio da Análise dos Componentes Principais (ACP) e Análise Discriminante Canônica (ADC). Esta análise teve como objetivo encontrar as duas variáveis canônicas que melhor separam as espécies de Trichogramma e examinar o padrão de discriminação entre as espécies, bem como comparar os resultados obtidos na ACP. As análises foram realizadas utilizando o programa SAS (1990).

\subsubsection{Morfometria geométrica}

Os métodos de morfometria geométrica foram utilizados no estudo de $T$. pretiosum. Optou-se por essa espécie pela disponibilidade de espécimes provenientes de vários hospedeiros e por ser uma espécie já muito estudada por outros métodos. Avaliou-se, assim, o uso de técnicas de morfometria geométrica e estudaram-se as variações em $T$. pretiosum associado a diferentes hospedeiros. 
Os espécimes utilizados foram provenientes da Coleção de Trichogramma da da Escola Superior de Agricultura Luiz de Queiroz - ESALQ (Entomologia). Foram utilizados espécimes de $T$. pretiosum provenientes de 10 espécies da ordem Lepidoptera (Tabela 1). As lâminas foram selecionadas a partir de espécimes que apresentavam as estruturas intactas e em condições adequadas para serem desenhadas. $\mathrm{O}$ número de espécimes foi definido em função da disponibilidade de material da coleção. Foram estudados somente os machos, já que a identificação de Trichogramma é baseada exclusivamente nas estruturas morfológicas dos indivíduos desse sexo.

Tabela 1. Hospedeiros, locais de coleta e número de espécimes de Trichogramma pretiosum.

\begin{tabular}{|c|c|c|}
\hline Insetos hospedeiros (Lepidoptera) & Locais da coleta & $\mathrm{N}^{\circ}$ de espécimes \\
\hline Alabama argilaceae (Noctuidae) & Juarez Távora-PB & 05 \\
\hline Anagasta kuehniella** (Pyralidae) & Piracicaba-SP & 14 \\
\hline Anticarsia gemmatalis (Noctuidae) & Curitiba-PR & 06 \\
\hline Bonagota cranaodes (Tortricidae) & Vacaria-RS & 08 \\
\hline Danaus plexippus* (Nymphalidae) & Piracicaba-SP & 05 \\
\hline Diaphania sp. (Pyralidae) & Viçosa-MG & 03 \\
\hline Diatraea saccharalis (Crambidae) & Rio Brilhante-MS & 10 \\
\hline Hamadryas feronia* (Nymphalidae) & Piracicaba-SP & 03 \\
\hline Helicoverpa zea (Noctuidae) & Lavras-MG & 12 \\
\hline Spodoptera frugiperda (Noctuidae) & Piracicaba-SP & 06 \\
\hline
\end{tabular}

As cápsulas genitais dos espécimes de T. pretiosum foram desenhadas por meio de uma câmara clara (16x) acoplada a um microscópio óptico (400x). Os desenhos foram realizados da maneira tradicional, com a extremidade posterior da genitália voltada para a margem inferior do papel. Os desenhos foram digitalizados usando-se um "scanner". Uma escala foi utilizada para padronizar as figuras. Foram assinalados 15 
marcos anatômicos (representando pontos homólogos) em cada figura da cápsula genital (Figura 3), em regiões que melhor definiam as diferenças morfológicas observadas nesta estrutura. As coordenadas cartesianas ( $\mathrm{x}$ e $\mathrm{y}$ ) dos marcos foram registradas em cada figura por meio do programa Tpsdig Rohlf (2000). Os tipos dos marcos anatômicos foram baseados em Bookstein (1991) (Tabela 2).

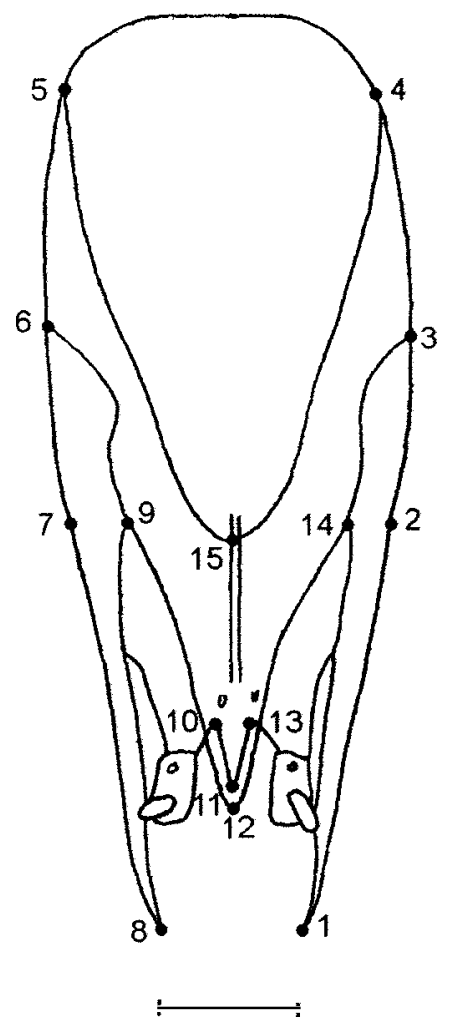

Figura 3 - Localização dos marcos anatômicos na cápsula genital masculina de Trichogramma pretiosum. 
Tabela 2. Descrições e tipos dos marcos anatômicos na cápsula genital masculina de Trichogramma pretiosum.

\begin{tabular}{clc}
\hline $\begin{array}{c}\text { Marcos } \\
\text { anatômicos }\end{array}$ & \multicolumn{1}{c}{ Descrições } & Tíos \\
\hline 01 & Ápice do parâmero direito & II \\
02 & Projeção perpendicular na lateral direita da cápsula genital da junção da extensão & I \\
& posterior da lâmina dorsal com o parâmero direito & \\
03 & Inserção da lâmina dorsal na lateral direita da cápsula genital & I \\
04 & Extremidade anterior direita da abertura dorsal & II \\
05 & Extremidade anterior da abertura dorsal & II \\
06 & Inserção da lâmina dorsal na lateral esquerda da cápsula genital & I \\
07 & Projeção perpendicular na lateral esquerda da cápsula genital da junção da & I \\
& extensão posterior da lâmina dorsal com o parâmero esquerdo & II \\
08 & Ápice do parâmero esquerdo & I \\
09 & Junção da extensão posterior da lâmina dorsal com o parâmero esquerdo & II \\
10 & Base esquerda do processo intervolselar & II \\
11 & Ápice do processo intervolselar & II \\
12 & Ápice da lâmina dorsal & II \\
13 & Base direita do processo intervoselar & I \\
14 & Junção da extensão posterior da lâmina dorsal com o parâmero direito & I \\
15 & Extremidade posterior da abertura dorsal &
\end{tabular}

\subsubsection{Análise de morfometria geométrica}

Para a quantificação do tamanho da variação na forma das cápsulas genitais dos espécimes de $T$. pretiosum foi utilizado o programa Tpssmall (Rohlf, 1997). Esse procedimento foi adotado, pois quando a variação na forma entre um conjunto de espécimes é muito grande, os métodos estatísticos baseados na aproximação no espaço tangente não podem ser usados.

As configurações dos marcos anatômicos das cápsulas genitais dos espécimes de T. pretiosum foram sobrepostas pelo método de quadrados mínimos. Este método transforma uma configuração de marcos, superpondo-a em uma configuração de referência (consenso), transladando, normalizando e rotacionando uma das configurações 
de modo que a soma dos quadrados das distâncias entre os pontos correspondentes entre configurações seja a menor possível (Monteiro \& Reis, 1999). Os consensos dos espécimes por hospedeiro foram combinados para analisar apenas as diferenças entre as médias.

Em seguida, foram determinadas as deformações, representadas pela função "thin-plate splines" e decompostas em descritores de forma. Os descritores podem ter componentes uniformes que descrevem estiramentos, compressões ou cisalhamento (variação global) e componentes localizados, correspondentes às mudanças que acontecem em regiões localizadas. As deformações principais são os autovetores da matriz de energia de deformação e cada um descreve uma possível mudança na forma aplicável à configuração média.

Os espécimes superpostos foram então projetados nas deformações principais descrevendo as diferenças de forma como desvios da configuração média (Bookstein, 1989; Rohlf, 1993). As projeções ou escores gerados indicaram quanto de cada deformação principal foi necessário para realizar as deformações. Os escores, chamados de deformações parciais, descreveram cada cápsula genital dos espécimes como uma combinação linear entre deformações principais e as coordenadas padronizadas x e y para cada marco anatômico. Esses escores podem ser usados em análise multivariada (Rohlf, 1993; Rohlf et al., 1996).

Por meio da matriz dos escores das deformações parciais foram obtidas as deformações relativas, que são componentes principais da matriz que combina escores de deformações parciais e componentes uniformes. Foram elaborados gráficos de ordenação das populações de $T$. pretiosum e grades das deformações associadas a cada eixo computado. Para que todas as deformações parciais apresentassem a mesma escala de variação foram estabelecidos valores de $\alpha=0$ no cálculo dos escores das deformações parciais. Esse procedimento é o mais indicado para os casos de estudos exploratórios e taxonômicos (Rohlf, 1993), pois os valores de $\alpha$ deslocam o eixo de maior variação no espaço de forma para as regiões com maior ou menor localização (Monteiro \& Reis, 1999). As análises de superposição e deformações relativas foram 
realizadas usando o programa "Tpsrelw" (Rohlf, 1998b). Todos os programas da série "TPS" utilizados neste trabalho são "freeware" (http://life.bio.sunysb.edu/morph).

\subsection{Cruzamentos}

Os cruzamentos foram conduzidos segundo a metodologia de Pinto et al. (1991). Cruzamentos bidirecionais (homogâmicos e heterogâmicos), bem como o modo de reprodução foi testado para algumas espécies de Trichogramma. Inicialmente, isofềmeas dessas espécies foram criadas por várias gerações em tubos de vidro $(13 \times 75 \mathrm{~mm})$. Foram isolados cerca de 100 ovos de A. kueniella parasitados por T. bruni e T. lasallei, que foram individualizados em tubos de vidro. Após a emergência, foram separados os machos e as fêmeas, quando emergiam indivíduos de sexos diferentes no mesmo tubo, estes eram descartados. Formaram-se 20 repetições de cada combinação heterogâmica e como controle, 10 repetições de cada combinação homogâmica. Dez fềmeas virgens de cada espécie foram individualizadas e isoladas dos machos, para controle do modo de reprodução das espécies. Os cruzamentos foram conduzidos em B.O.D., à $25^{\circ} \mathrm{C}$ e fotofase de $14 \mathrm{~h}$. As repetições se constituíram de um único macho e fêmea virgem, colocados em recipientes de vidro fechados com filme plástico com abundância de hospedeiro. Para confirmar a não ocorrência de contaminação das espécies, machos de cada cruzamento foram montados em lâminas, identificados e mantidos como voucher specimens na coleção de Trichogramma da ESALQ (Entomologia). Avaliou-se a produção da progênie através da contagem de machos e fềmeas e verificou-se também a fertilidade das fêmeas.

\subsection{Caracterização e descrição de espécies}

Foram baseadas na morfologia e morfometria. O número de indivíduos utilizados por espécie variou de acordo com a disponibilidade de material. 


\subsection{Chave ilustrada para as espécies de Trichogramma da América do Sul}

Foi elaborada uma chave ilustrada para a identificação das espécies de Trichogramma que ocorrem na América do Sul. Foram incluídas na chave, 6 espécies para as quais não foi examinado nenhum exemplar. Nesse caso, os caracteres da chave foram baseados na literatura, para as espécies: T. atropos Pinto, 1992, T. nomlaki Pinto \& Oatman, 1985 e T. stampae Vincent, 1986 em Pinto (1998); T. marandobai Brun, Moraes \& Soares, 1986, na descrição original; T. colombiensis Velásquez de Rios \& Teran, 1995 e T. guariquensis Velásquez de Rios \& Teran, 1995, na descrição original. T. castrensis não foi incluída na chave, visto que por meio da descrição original não foi possível separá-la de T. bruni. 


\section{RESULTADOS E DISCUSSÃO}

\subsection{Coleção de Trichogramma}

As espécies de Trichogramma da coleção da ESALQ foram catalogadas e incluídas em um banco de dados (Apêndice 1), reunindo as informações taxonômicas para essas espécies. Alguns dados de coletas estão incompletos, pois nem todas as informações são mencionadas nas lâminas. O banco de dados com todas as informações disponíveis da coleção será colocado à disposição para consulta em rede (Internet).

Nessa coleção encontram-se depositados os tipos de T. dissimilis Zucchi, 1988, $T$. distinctum Zucchi, 1988, T. galloi Zucchi, 1988, T. jalmirezi Zucchi, 1988, das novas espécies descritas neste trabalho e de outras duas não formalmente descritas: T. bertii e T. costaricensis (Zucchi, 1985).

\subsection{Obtenção das amostras}

As amostras de Trichogramma foram obtidas por meio de cooperação com instituições e pesquisadores de diferentes regiões do Brasil e de vários países da América do Sul . Todas as amostras recebidas foram depositadas na coleção da ESALQ.

\subsubsection{Coleta de Campo}

\subsubsection{Coleta do ovo do hospedeiro}

Durante o período de maio/1999 a agosto/2001 foram coletados ovos de 12 espécies de insetos em municípios do Estado de São Paulo (Tabela 3 e Apêndice 2 - 
Figura A). Foram encontradas T. acacioi Brun, Moraes \& Soares, 1984, T. bruni Nagaraja, 1983, T. demoraesi Nagaraja, 1983, T.pretiosum Riley, 1879 e Trichogramma sp.n.11 (Tabela 3). Todos os hospedeiros coletados pertenciam à ordem Lepidoptera, contudo, não foi possível a identificação específica de alguns hospedeiros, tanto pelo fato dos ovos estarem parasitados como pela dificuldade da criação das lagartas.

Tabela 3. Lista de espécies de Trichogramma obtidas de ovos de insetos coletados em municípios do Estado de São Paulo.

\begin{tabular}{|c|c|c|c|c|c|}
\hline Espécies & $\begin{array}{l}\text { Insetos hospedeiros } \\
\text { (Lepidoptera) }\end{array}$ & $\begin{array}{c}\text { Plantas } \\
\text { associadas }\end{array}$ & $\begin{array}{l}\text { Locais de } \\
\text { coleta }\end{array}$ & Datas & Coletores \\
\hline T. bruni & Heliconius erato phyllis & Passiflora $\mathrm{sp}$ & Piracicaba & Mai./1999 & J.A. Cerignoni \\
\hline T. bruni & Erosina hyberniata & Acnistus arborescens & Piracicaba & 02/jul./1999 & R.B. Querino \\
\hline T. demoraesi & Erinnys ello & Manihot utilissima & Piracicaba & 01/jul./1999 & R.B. Querino \\
\hline Trichogramma sp. ${ }^{1}$ & - & Eucaliptus sp. (bosque) & Anhembi & 01/set./1999 & R.B. Querino \\
\hline Trichogramma sp. ${ }^{2}$ & - & Lucaliptus sp. (bosque) & Anhembi & Set./1999 & R.B. Querino \\
\hline T. bruni & Mechanitis lysimnia & Solamum agrarium & Piracicaba & 20/set./1999 & R.B. Querino \\
\hline Trichogramma sp. ${ }^{2}$ & - & Eucaliptus sp. & Anhembi & 22/set./1999 & R.B. Querino \\
\hline T. bruni & - & Lucaliptus sp. (bosque) & Itatinga & 06/out./1999 & R.B. Querino \\
\hline Trichogramma sp.n. 11 & Eueides isabella dinasa & Passiflora sp. & Piracicaba & Out./1999 & J.A. Cerignoni \\
\hline Trichogramma sp.n. 11 & Heliconius erato phyllis & Passiflora sp. & Piracicaba & Nov./1999 & J.A. Cerignoni \\
\hline T. pretiosum & Anticarsia gemmatalis & Glycine max & Piracicaba & Jan./2000 & R.B. Querino \\
\hline T. acacioi & - & Eucaliptus sp. (bosque) & Itatinga & $09 /$ fev. $/ 2000$ & R.B. Querino \\
\hline T. acacioi & Euselasia sp. & Eucaliptussp. (bosque) & Itatinga & $01 / \mathrm{mar} / 2000$ & R.B. Querino \\
\hline T. pretiosum & - & Encaliptus sp. (bosque) & Anhembi & $13 / \operatorname{mar} . / 2000$ & R.B. Querino \\
\hline Trichogramma sp. ${ }^{2}$ & Heliconius ethilla narcaea & Passiflora sp. & Piracicaba & $17 / \mathrm{mar} . / 2000$ & J. A Cerignoni \\
\hline T. acacioi & Hamadryas feronia & Dalechampia sp. & Piracicaba & Mai./2000 & J. A Cerignoni \\
\hline T. bruni & Hamadryas feronia & Dalechampia sp. & Piracicaba & Mai./2000 & J. A Cerignoni \\
\hline T. pretiosum & Hamadryas feronia & Dalechampia sp. & Piracicaba & 1/mai./2000 & J. A Cerignoni \\
\hline T. pretiosum & Danaus plexippus erippus & Asclepias curassavica & Piracicaba & Jun./2000 & J. A Cerignoni \\
\hline Trichogramma sp. & Siproeta stelene & Ruellia sp. & Piracicaba & Mar./2001 & J. A Cerignoni \\
\hline T. pretiosum & Papillionidae & Citrus sp & Piracicaba & $27 / \mathrm{mar} . / 2001$ & J.A Cerignoni \\
\hline T. pretiosum & Papillionidae & Citrus sp. & Piracicaba & $27 / \mathrm{mar} . / 2001$ & R.B. Querino \\
\hline T. pretiosum & Trichoplusia oxygramma & Bacharis sp. & Sorocaba & 14/ago./2001 & R.B. Querino \\
\hline
\end{tabular}

amostra enviada para seqüênciamento de DNA: espécie com resultado diferente das outras já sequenciadas.

2 coletadas somente fềmeas. 


\subsubsection{Armadilha com ovos de hospedeiro alternativo}

As coletas por meio de cartelas com ovos de hospedeiro alternativo não mostraram bons resultados. Observou-se um baixo parasitismo, ocorrendo problemas com predação e chuva. Apenas T. pretiosum foi obtido de poucos ovos parasitados em algodoeiro em Rondonópolis-MS. Não houve parasitismo nos cartões enviados para o Estado do Tocantins.

\subsubsection{Armadilha de sucção}

Na armadilha de sucção (Apêndice 2, Figura B), foram coletados 551 espécimes pertencente às espécies T. bruni, Trichogramma sp, aff. pintoi e $T$. pretiosum, além de fềmeas e de outras 6 novas espécies (Tabela 4).

Tabela 4. Medidas da fauna de espécies de Trichogramma (machos e fềmeas) coletadas em armadilha de sucção, setembro de 1999 a setembro de 2000.

\begin{tabular}{|c|c|c|c|c|c|}
\hline Espécies & Total & Dominância $^{l}$ & Abundância $^{2}$ & Frequência $^{3}$ & Constância $^{4}$ \\
\hline T. pretiosum & 6 & $\mathrm{D}$ & $\mathrm{c}$ & $\mathrm{F}$ & Y \\
\hline Trichogramma sp. aff pintoi & 1 & ND & $\mathrm{r}$ & PF & Y \\
\hline T. bruni & 182 & SD & sa & SF & W \\
\hline Trichogramma sp. n. 1 & 10 & $\mathrm{D}$ & $\mathrm{ma}$ & MF & Y \\
\hline Trichogramma sp. 2 & 1 & ND & $\mathrm{r}$ & $\mathrm{PF}$ & $\mathrm{Y}$ \\
\hline Trichogramma sp. n. 3 & 2 & ND & $\mathrm{d}$ & $\mathrm{PF}$ & $\mathrm{Y}$ \\
\hline Trichogramma sp. 4 & 14 & $\mathrm{D}$ & $\mathrm{ma}$ & MF & Y \\
\hline Trichogramma sp. n. 5 & 3 & ND & $\mathrm{c}$ & $\mathrm{F}$ & Y \\
\hline Trichogramma sp. n. 6 & 9 & $\mathrm{D}$ & $\mathrm{ma}$ & MF & Y \\
\hline Trichogramma sp. n. 7 & 2 & ND & d & $\mathrm{PF}$ & $\mathrm{Y}$ \\
\hline Trichogramma sp. 8 & 1 & ND & $\mathrm{r}$ & PF & Y \\
\hline Trichogramma sp. n. 9 & 4 & ND & c & $\mathrm{F}$ & Y \\
\hline Trichogramma sp. 10 & 2 & ND & $\mathrm{d}$ & PF & Y \\
\hline Total & 237 & & & & \\
\hline \multicolumn{6}{|c|}{ Índice de diversidade de Shannon-Weaner $=1,035$} \\
\hline Fêmeas & 279 & & & & \\
\hline Trichogramma & 35 & & & & \\
\hline Total & 551 & & & & \\
\hline \multicolumn{6}{|c|}{$\begin{array}{l}{ }^{1} \mathrm{D} \text { - dominante; SD - super dominante; ND - não dominante. } \\
{ }^{2} \mathrm{c} \text { - comum ; } \mathrm{d} \text { - disperso; } \mathrm{r} \text { - raro; ma - muito abundante; as - super abundante. } \\
{ }^{3} \mathrm{~F} \text { - freqüente; PF - pouco freqüente; MF - muito freqüente; SF - super frequente. } \\
{ }^{4} \mathrm{Y} \text { - acessória; W - constante. }\end{array}$} \\
\hline
\end{tabular}


Do total de insetos capturados, destacou-se T. bruni como a espécie mais freqüente e dominante, sendo essa espécie constante durante quase todo o período de coleta (Quadro 1). Trichogramma sp.n.1, Trichogramma sp. 4 e Trichogramma sp.n. 6 foram muito abundantes.

\begin{tabular}{|c|c|c|c|c|c|c|c|c|c|c|c|c|c|}
\hline \multirow{3}{*}{ Espécies coletadas } & \multicolumn{13}{|c|}{ Épocas de ocorrência } \\
\hline & \multicolumn{4}{|c|}{1999} & \multicolumn{9}{|c|}{2000} \\
\hline & Set. & Out. & Nov. & Dez. & Jan. & Fev. & Mar. & Abr. & Mai. & Jun. & Jul. & Ago. & Set. \\
\hline \multicolumn{14}{|l|}{ T. pretiosum } \\
\hline \multicolumn{14}{|l|}{ Trichogramma sp. aff. pintoi } \\
\hline \multicolumn{14}{|l|}{ T. bruni } \\
\hline \multicolumn{14}{|l|}{ Trichogramma sp.n. 1} \\
\hline \multicolumn{14}{|l|}{ Trichogramma sp. 2} \\
\hline \multicolumn{14}{|l|}{ Trichogramma sp.n. 3} \\
\hline \multicolumn{14}{|l|}{ Trichogramma sp. 4} \\
\hline \multicolumn{14}{|l|}{ Trichogramma sp.n. 5} \\
\hline \multicolumn{14}{|l|}{ Trichogramma sp.n. 6} \\
\hline \multicolumn{14}{|l|}{ Trichogramma sp.n. 7} \\
\hline \multicolumn{14}{|l|}{ Trichogramma sp. 8} \\
\hline \multicolumn{14}{|l|}{ Trichogramma sp.n. 9} \\
\hline \multicolumn{14}{|l|}{ Trichogramma sp. 10} \\
\hline Fêmeas & & & & & & & & & & & & & \\
\hline
\end{tabular}

Quadro 1 - Época de ocorrência das espécies de Trichogramma coletadas em armadilha de sucção no Horto Florestal de Tupi, setembro de 1999 a setembro de 2000.

Com relação a $T$. bruni, notou-se grande variação morfológica entre os indivíduos coletados, provavelmente, devido à gama de hospedeiros (ver item 4.3.4, caracterização de T. bruni). Assim, houve dificuldades na identificação, pois muitos dos exemplares não se enquadravam nos padrões dessa espécie. Para auxiliar na identificação, os espécimes coletados foram comparados com $T$. bruni depositado na coleção da ESALQ (Entomologia) e com o holótipo de T. bruni (UFMG). 
As identificações das espécies foram confimadas pelo Dr. J. D. Pinto (University of Califórnia, Riverside, U.S.A). Ressalta-se a coleta de uma espécie próxima a Trichogramma aff. pintoi, ainda não registrada no Brasil.

$\mathrm{O}$ índice de diversidade (Shannon-Weaner) encontrado foi 1,03. O índice de diversidade é usado na comparação riqueza de espécies entre comunidades, no entanto, nada impede de ser usado isoladamente, como caráter informativo, já que com esse valor é possível ter uma noção da diversidade das espécies existentes no local.

Os resultados mostraram que a armadilha de sucção pode ser utilizada na coleta de Trichogramma em regiões em que o acesso e a coleta de ovos do hospedeiro são difíceis, como nas reservas florestais e matas nativas.

O método de coleta por armadilha de sucção apresenta algumas vantagens e desvantagens. A vantagem é permitir a coleta de um número considerável de indivíduos (Figura 4) e uma maior diversidade, o que provavelmente seria muito difícil utilizando outros métodos, considerando-se o tipo de ambiente. Assim, pode-se ter uma idéia das espécies presentes no local e sua época de maior ocorrência. As desvantagens estão relacionadas ao tempo gasto na triagem dos espécimes, já que um grande número de outros microinsetos é coletado. Além disso, pelo fato do equipamento ser elétrico, pode haver dificuldade em instalá-lo. Por outro lado, estando sujeito a oscilaç̃os de energia elétrica, podem ocorrer problemas mecânicos, como os observados no mês de julho (Figura 4), quando armadilha quebrou e uma das coletas foi perdida, sendo coletado um reduzido número de espécimes. Todavia, esses problemas podem ser solucionados, utilizando-se baterias em lugar de energia elétrica.

Dentre os fatores climáticos analisados, a precipitação apresentou correlação negativa $(r=-0,34)$ com a ocorrência das espécies (Figura 5). Assim, notou-se que quanto maior a precipitação, menor a coleta de Trichogramma, provavelmente, devido a menor ocorrência de hospedeiros no período de alta precipitação pluviométrica e à própria eliminação dos parasitóides pela chuva 


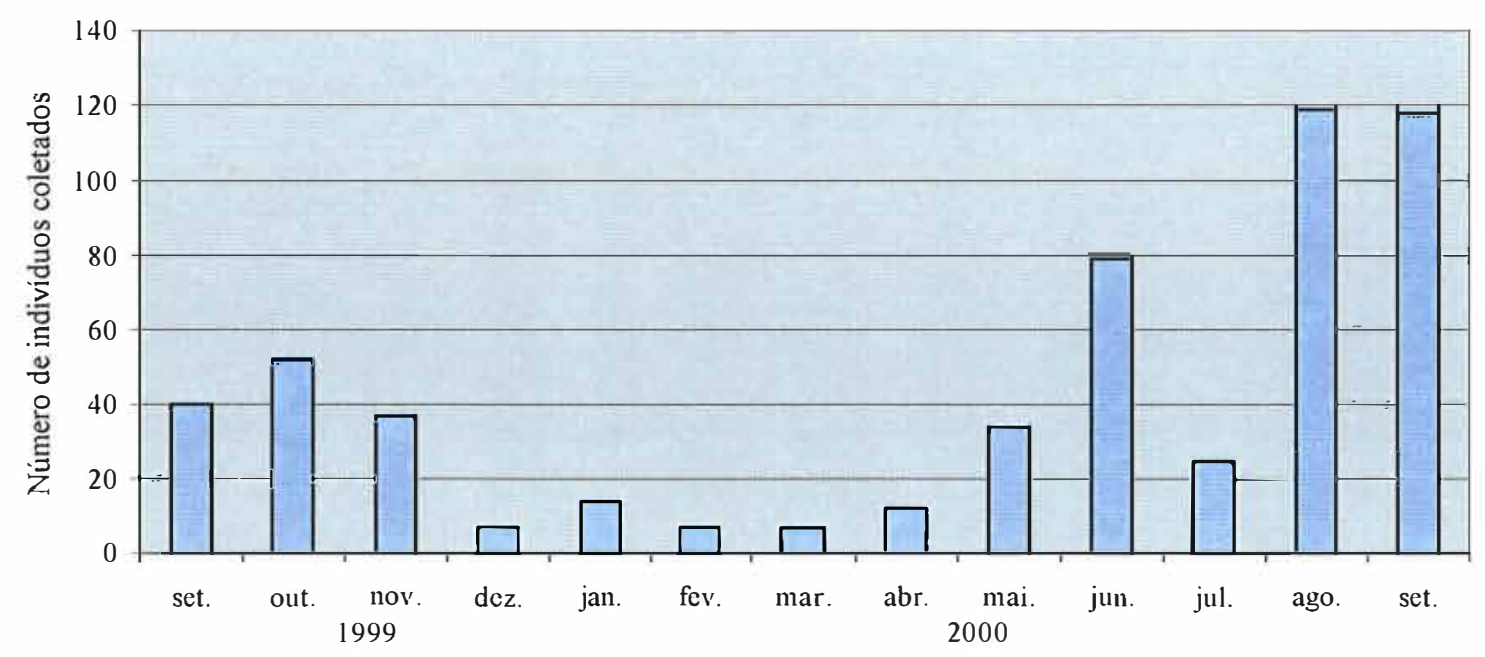

Período de coleta

Figura 4 - Número de indivíduos de Trichogramma spp. coletados em armadilha de sucção, de setembro de 1999 a setembro de 2000.

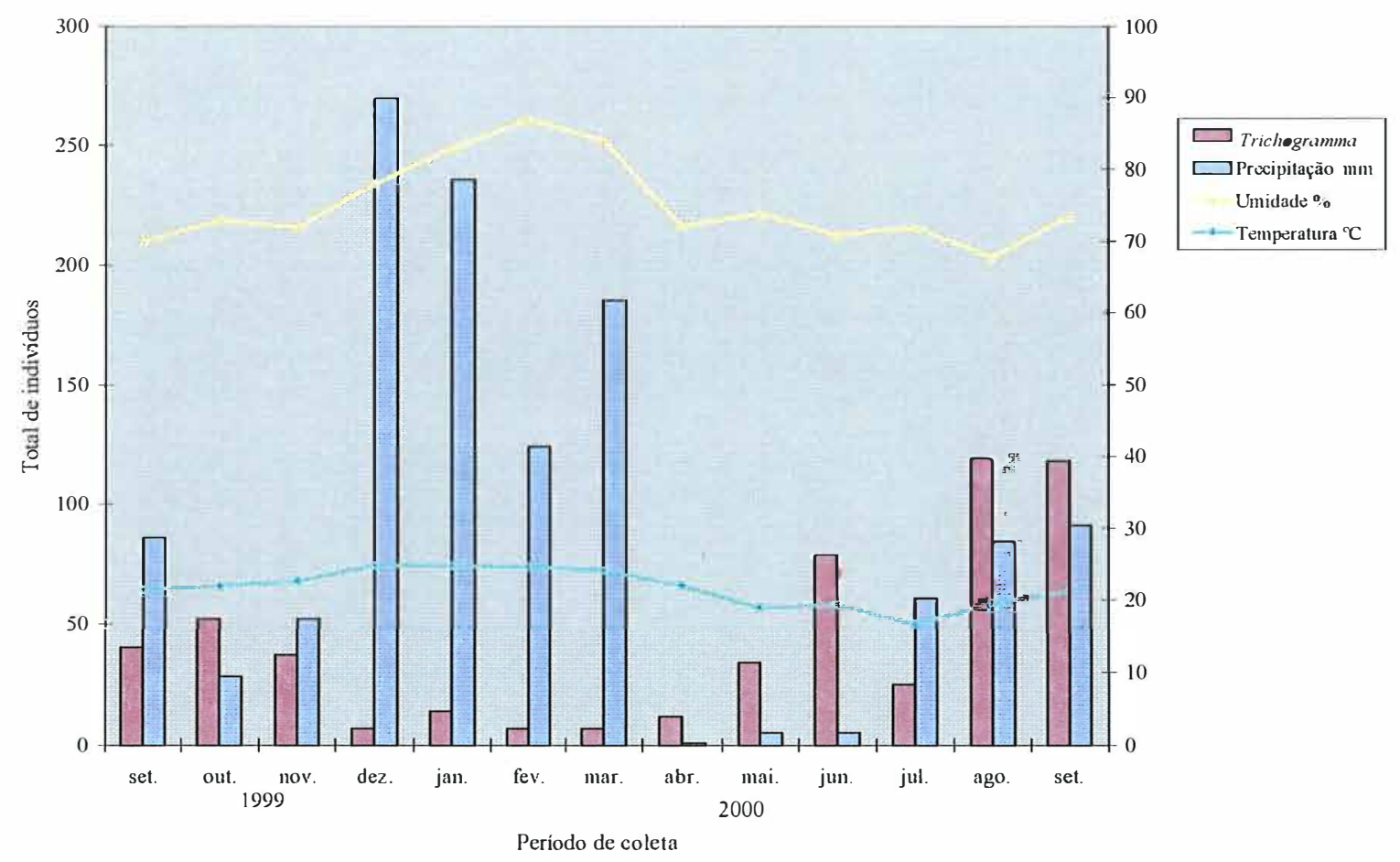

Figura 5 - Temperatura $\left({ }^{\circ} \mathrm{C}\right)$, umidade $(\%)$ e precipitação pluviométrica $(\mathrm{mm})$ no município de Piracicaba/SP, de setembro de 1999 a setembro de 2000. 


\subsection{Caracterização das espécies de Trichogramma registradas na América do Sul}

\subsubsection{Trichogramma acacioi Brun, Moraes \& Soares, 1984}

(Figura 6)

Trichogramma acacioi Brun, Moraes \& Soares, 1984: 809; Zucchi \& Monteiro, 1997:

53; Pinto, 1998: 72; Pratissoli \& Fornazier, 1999: 347; Foerster et al., 2000: 385.

\section{Caracterizacão morfológica}

Antenas: flagelo longo $(0,16 \pm 0,013)$, cerca de duas vezes o comprimento do escapo; relação entre o comprimento e a largura do flagelo $(7,47 \pm 1,30)$; comprimento do flagelo/comprimento da tíbia posterior $(1,10 \pm 0,09)$; cerdas flageliformes longas $(0,09 \pm$ 0,005), com ápice afilado uniformemente; comprimento da maior cerda do flagelo/maior largura do flagelo $(4,00 \pm 0,58)$; sensilos basicônicos ovalados, com a base levemente mais estreita, fórmula 1(2)-2-2-0-1-1; três sensilos placóideos no terço apical do flagelo, o basal com $0,05 \pm 0,003 \mathrm{~mm}$.

Asas anteriores: relação entre a largura e o comprimento da asa $(0,53 \pm 0,02)$; comprimento da maior cerda da franja da asa/comprimento da tíbia posterior $(0,24 \pm$ $0,03)$; comprimento da maior cerda da franja da asa/largura da asa anterior $(0,14 \pm 0,01)$. Número de cerdas entre a $4^{\underline{a}}$ e $5^{\underline{a}}$ fileiras da asa anterior de 8 a 14 cerdas.

Asas posteriores: fileira anterior sem cerdas e a posterior com 2 a 5 cerdas; fileira posterior não ultrapassando a metade da fileira mediana.

Escutelo: relação entre as cerdas anteriores e posteriores $(0,28 \pm 0,09)$.

Genitália masculina: cápsula genital bastante modificada em relação às demais espécies, tão longa $(0,13 \pm 0,004)$ quanto larga $(0,08 \pm 0,002)$; relação entre a largura e comprimento da cápsula genital de $0,61 \pm 0,03$; parâmeros arqueados, com dentes na margem lateral interna (observados em MEV); distância apical/comprimento da cápsula genital $(0,33 \pm 0,01)$; distância basal/comprimento da cápsula genital $(0,67 \pm 0,01)$; largura apical/largura da cápsula genital $(0,94 \pm 0,03)$; lâmina dorsal originando-se na metade da cápsula genital, não abrangendo toda a largura da cápsula genital, leve 
reentrância na região basal; relação entre o comprimento e a largura da lâmina dorsal de $0,84 \pm 0,09$; comprimento da lâmina dorsal/comprimento da cápsula genital $(0,39 \pm$ $0,03)$; extensão posterior da lâmina dorsal larga $(0,02 \pm 0,002)$ e curta, com ápice arredondado, cerca de 0,4 vezes o comprimento da lâmina dorsal, não encobrindo as volselas; abertura dorsal ampla quase duas vezes o comprimento da lâmina dorsal; carena dorsal (carena interna na vista dorsal) desenvolvida, estendendo-se por todo o comprimento da distância basal na linha mediana da cápsula genital, sendo a base mais larga e formando uma carena única até a extremidade posterior da cápsula genital; carena ventral (carena interna em vista ventral) alcançando um pouco além da metade da cápsula genital; volselas curvadas com o ápice pontiagudo e espinho apical longo e estreito; base das volselas unidas por meio de uma ponte intervolselar, sendo o processo intervolselar praticamente inexistente; processos ventrais praticamente inseridos na ponte intervolselar; edeago curto, com a base mais larga que o ápice e apódemas cerca de 1,5 vezes o comprimento do edeago; edeago/comprimento da tíbia posterior $(0,27 \pm$ $0,02)$.

Os dados quantitativos foram obtidos de 11 machos coletados de ovos de Euselasia sp. Hübner, (1819) (Lep., Riodinidae) em eucalipto, em São Simão, São Paulo, Brasil e multiplicado em Anagasta kuehniella (Zeller) (Lep., Pyralidae).

\section{Material examinado}

BRASIL. SÃO PAULO: São Simão, jan. -1990, 11 machos, ex ovos de Euselasia sp., eucalipto, multiplicados em ovos de Anagasta kuehniella, E. Bernardi col. (ESALQ); Itatinga, 01-mar.-2000, 4 machos, ex ovos de Euselasia sp., sub-bosque de eucalipto, R. B. Querino col. (ESALQ); Piracicaba, mai.-2000, 4 machos, ex ovos de Hamadryas feronia, J. A. Cerignoni col. (ESALQ); ESPÍRITO SANTO: Venda Nova do Imigrante, 7 machos, ex ovos de Euselasia sp., eucalipto, Dirceu Pratissoli col. (ESALQ). 

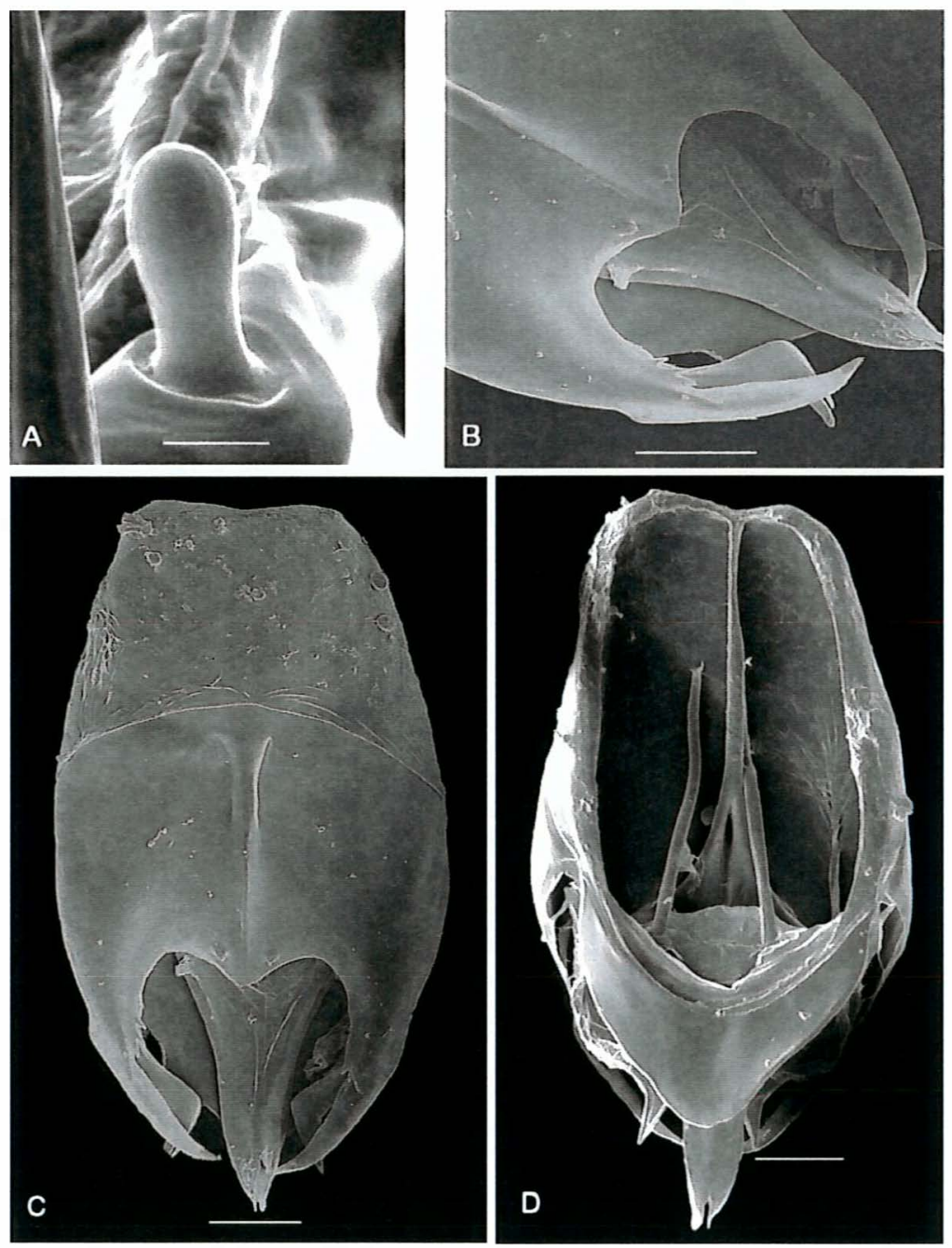

Figura 6 - Trichogramma acacioi. A - sensilo basicônico $(10000 \mathrm{x}, 1 \mu \mathrm{m})$; B - detalhe

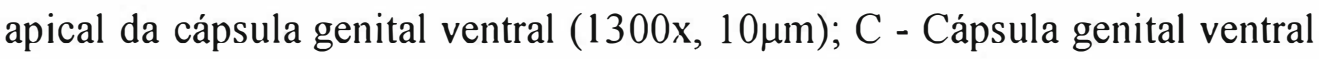

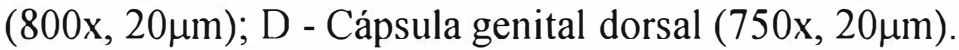

\section{$\underline{\text { Diagnose }}$}

T. acacioi pode ser distinguido principalmente pelas modificações das volselas, curvadas e interligadas pela ponte intervolselar; processo intervolselar praticamente inexistente; parâmeros arqueados e em alguns espécimes podem ser observados dentes nas margens. Outras características são: a presença de carena dorsal desenvolvida e 
lâmina dorsal abrangendo quase toda a largura da cápsula genital, sem uma distinta extensão superior.

T. acacioi é uma das espécies mais distintas dentre as que ocorrem na América do Sul, sendo mais semelhante a T. atopovirilia Oatman \& Platner, 1983 que também apresenta uma ampla cápsula genital e modificações acentuadas nas volselas e parâmeros. No entanto, T. atopovirilia pode ser distinguida pelas volselas que apresentam uma acentuada reentrância lateral, parâmeros mais dilatados e os processos ventrais tubulares situados na base do processo intervolselar.

\section{Variacões}

Os espécimes apresentaram coloração mais escura próxima ao marromamarelada. Os espécimes coletados no Espírito Santo apresentaram cerdas flageliformes da antena menores $(3,47 \pm 0,33)$, cápsula genital mais larga $(0,66 \pm 0,02)$, lâmina dorsal curta $(0,64 \pm 0,07)$ e apódemas bem menores $(1,28 \pm 0,12)$ em relação aos outros espécimes examinados.

\section{Análises multivariadas}

A projeção dos indivíduos no espaço dos dois primeiros componentes principais mostrou a presença de dois grupos, compostos pelos espécimes de São Paulo (São Simão, Itatinga e Piracicaba) e do Espírito Santo (Figura 7).

O primeiro componente explicou cerca de $44 \%$ da variação total, o segundo $21 \%$ e o terceiro $8 \%$, portanto, os dois primeiros componentes explicaram $65 \%$ da variação total presente na matriz da covariância. As variáveis comprimento do flagelo (CF) e largura da lâmina dorsal (LLD) apresentaram os maiores valores absolutos, 0,413 e 0,396, respectivamente, e foram as variáveis de maior importância no primeiro componente. No segundo componente, o comprimento dos apódemas foi que o apresentou o maior valor, 0,552. Essa variável separou os espécimes do Espírito Santo em relação aos demais. Portanto, os espécimes coletados no Espírito Santo apresentam diferenças em relação aos demais, principalmente quanto ao tamanho dos apódemas. 


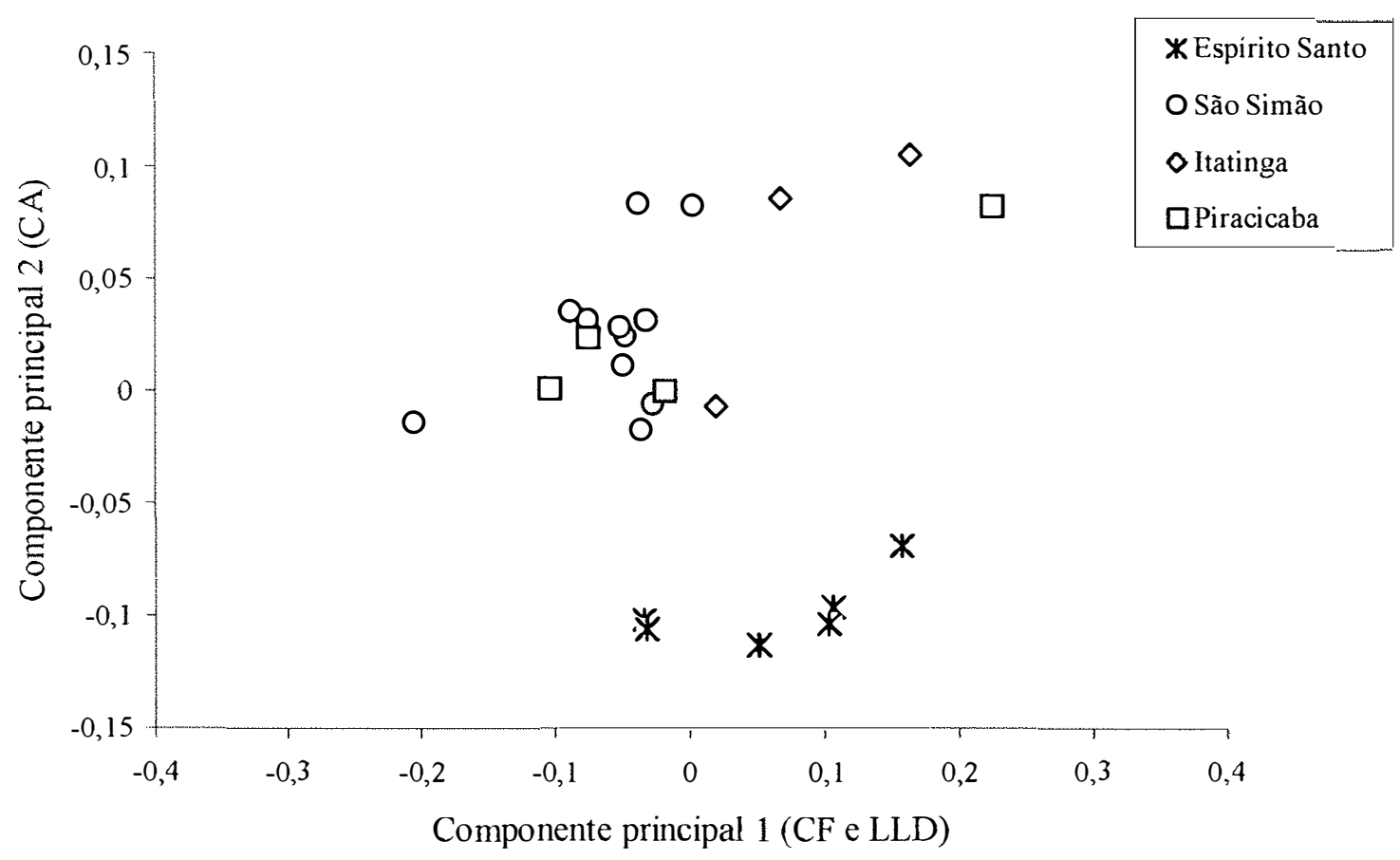

Figura 7 - Ordenação de Trichogramma acacioi nos dois primeiros componentes.

A análise das variáveis canônicas mostrou resultado similar à análise dos componentes principais. Os testes multivariados Wilks'Lambda $(\mathrm{P}<0,0024)$, Pillai's Trace $(\mathrm{P}<0,01)$, Hotelling-Lawley Trace $(\mathrm{P}<0,0005)$ e Roy's Greatest Root $(\mathrm{P}<0,0001)$ mostraram que os eixos canônicos foram estatisticamente significativos, extraídos da matriz resultante do produto da matriz de covariância entre os grupos pela matriz de covariância dentro dos grupos. A primeira variável canônica explicou $88 \%$ e a segunda $8 \%$ da variação total. Os dois primeiros eixos canônicos explicaram $96 \%$ da variação total.

A projeção dos escores dos espécimes no espaço das duas variáveis canônicas (Figura 8) mostrou que T. acacioi do Espírito Santo é discriminado dos demais ao longo do primeiro eixo canônico. As variáveis de maior contribuição foram largura da cápsula genital (LLG), largura da lâmina dorsal (LLD) e comprimento dos apódemas (CA), que apresentaram os maiores valores absolutos, $0,752,0,678$ e 0,608 , respectivamente, para o primeiro eixo canônico, permitindo separar os espécimes do Espírito Santo em relação 
aos demais. No segundo eixo canônico, a variável distância basal (DB) e comprimento da cápsula genital (CCG), com os maiores valores absolutos para a segunda variável canônicas, 0,644 e 0,678, respectivamente, foram as que mais contribuíram nesse eixo e separaram T. acacioi (Itatinga-SP) dos demais.

Os resultados das análises indicam a existência de variações intra-específicas em T. acacioi, que devem estar relacionadas ao tamanho dos espécimes, refletindo a ação de fatores ambientais, por exemplo o hospedeiro.

T. acacioi de Itatinga-SP e do Espírito Santo foram obtidos de Euselasia sp. e ficaram isolados em relação aos demais. Os espécimes de São Simão-SP e Piracicaba-SP, criados no hospedeiro alternativo (A. kuehniella), ficaram agrupados, demonstrando a influência do hospedeiro e hábitat nas variações morfológicas.

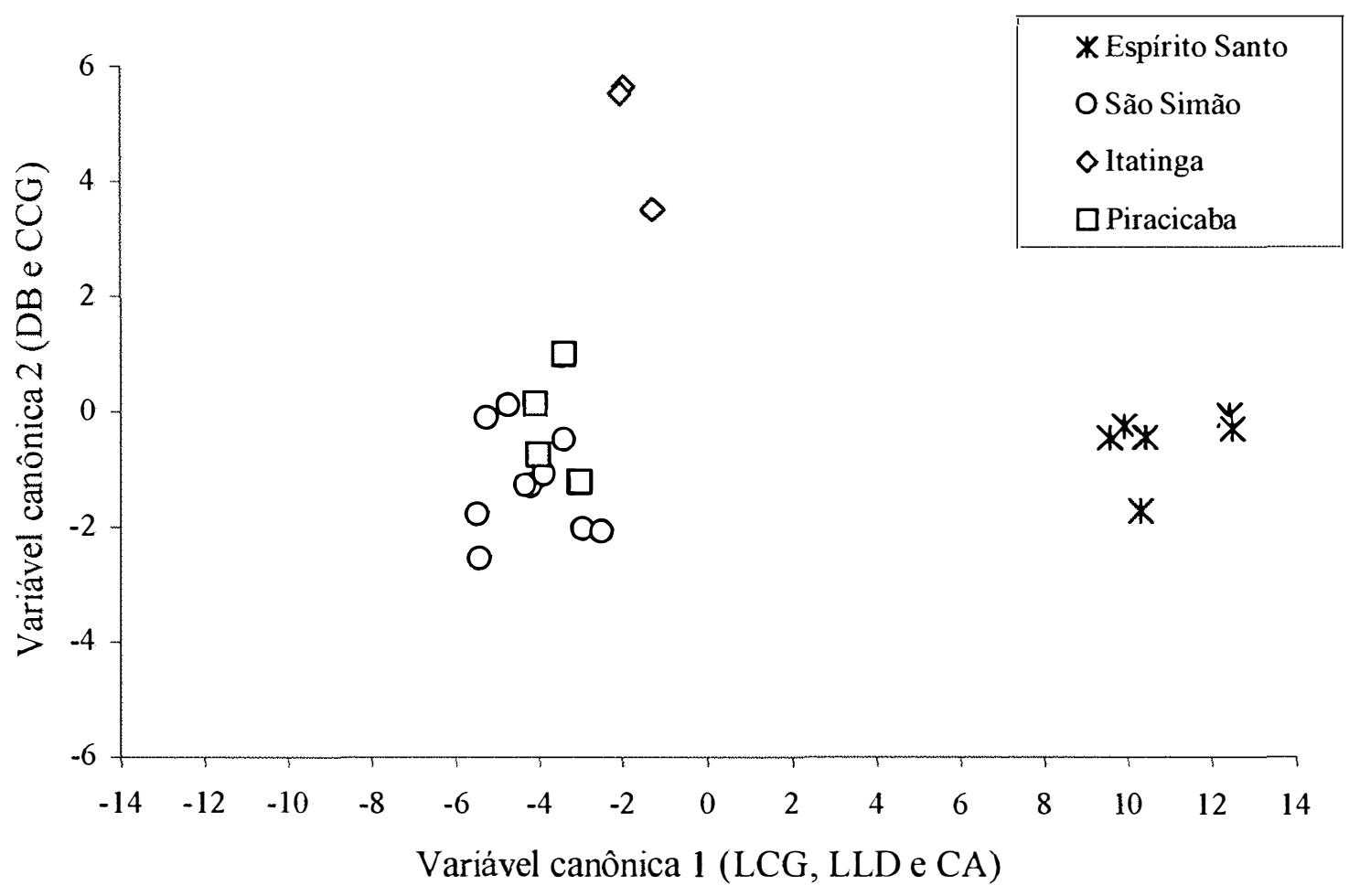

Figura 8 - Ordenação de Trichogramma acacioi nos dois primeiros eixos canônicos. 


\section{Distribuicão geográfica e hospedeiros}

T. acacioi foi originalmente coletado de ovos de Psorocampa denticulata Schaus, 1901 (Lep., Notodontidae), em eucalipto, no município de Jaboticatubas, Minas Gerais, Brasil, por Brun, Moraes \& Soares (1984). Esta espécie encontra-se distribuída nos Estados do Espírito Santo, Minas Gerais e São Paulo. T. acacioi está associado, principalmente, a lepidópteros que vivem em ambientes florestais, como Euselasia sp. (Lep., Riodinidae), comumente parasitada por esse parasitóide e, Hamadryas feronia (L., 1758) (Lep., Nymphalidae), registrada aqui como novo hospedeiro.

\subsubsection{Trichogramma atopovirilia Oatman \& Platner, 1983}

(Figura 9)

Trichogramma atopovirilia Oatman \& Platner, 1983: 710; Zucchi, 1985: 42; Zucchi \& Monteiro, 1997: 53; Pinto, 1998: 72; Foerster \& Avanci, 1999: 545; Beserra, 2000. Trichogramma caiaposi Brun, Moraes \& Soares, 1984: 808; Sorokina, 1993: 22;

Velásquez de Rios \& Teran, 1995: 44, fig. 2.2a; Zucchi \& Monteiro, 1997: 53 (sinônimo júnior).

\section{Caracterizacão morfológica}

Antenas: flagelo longo $(0,20 \pm 0,003)$; relação entre o comprimento e a largura do flagelo de 7,10 $\pm 0,97$; comprimento do flagelo/comprimento da tíbia posterior $(1,12 \pm$ $0,08)$; cerdas flageliformes longas com ápice uniformemente afilado $(0,10 \pm 0,001)$; comprimento da maior cerda do flagelo/maior largura do flagelo $(3,65 \pm 0,47)$; sensilo basicônico ovalado, fórmula 1-1-2-0-1-1; três sensilos placóideos no terço apical do flagelo, o basal com $0,05 \pm 0,00 \mathrm{~mm}$.

Asas anteriores: largura da asa anterior de $0,27 \pm 0,05 \mathrm{~mm}$; relação entre a largura e o comprimento da asa $(0,54 \pm 0,06)$; comprimento da maior cerda da franja da asa/comprimento da tíbia posterior $(0,20 \pm 0,05)$; comprimento da maior cerda da franja 
da asa anterior/largura da asa anterior $(0,13 \pm 0,04)$. Número de cerdas entre a $4^{\underline{a}}$ e $5^{\underline{a}}$ fileiras de 8 a 39 cerdas.

Asas posteriores: cerdas distintas; fileira anterior com 0 a 3 cerdas e a posterior com 9 a 13, ultrapassando a metade da fileira mediana;

Escutelo: cerdas anteriores curtas, cerca de 0,15 vezes o comprimento das posteriores $(0,28 \pm 0,09)$.

Genitália masculina: cápsula genital escurecida, modificada, longa $(0,12 \pm 0,01)$ e larga $(0,08 \pm 0,001)$; a relação entre a largura e comprimento da cápsula genital $(0,65 \pm$ 0,04); parâmeros dilatados e arqueados; distância apical/comprimento da cápsula genital $(0,28 \pm 0,01)$; distância basal/comprimento da cápsula genital $(0,70 \pm 0,04)$; largura apical/largura da cápsula genital $(0,86 \pm 0,04)$; lâmina dorsal originando-se na metade da cápsula genital e não abrangendo toda a largura da cápsula genital, com leve reentrância na região basal; comprimento da lâmina dorsal/comprimento da cápsula genital $(0,35 \pm$ $0,02)$; comprimento/largura da lâmina dorsal $(0,66 \pm 0,07)$; extensão posterior da lâmina dorsal curta $(0,02 \pm 0,00)$, cerca de 0,4 vez o comprimento da comprimento da lâmina dorsal e larga, com o ápice arredondado e ultrapassando o processo intervolselar, mas não encobrindo as volselas; abertura dorsal ampla, quase duas vezes o comprimento da lâmina dorsal; carena ventral (carena interna em vista ventral) situada na linha mediana da cápsula genital, cerca de 0,6 vezes a distância basal; carena dorsal (carena interna em vista dorsal) não muito distinta e situada na linha mediana da cápsula genital; volselas com acentuada reentrância lateral, formando um distinto lobo e o espinho apical pontiagudo; as volselas estão interligadas por meio de uma ponte intervolselar; processo intervolselar muito curto, com forma triangular e unidos às volselas; processos ventrais bastante distintos, com forma tubular e unidos ao processo intervoselar; edeago curto e cerca de 0,5 vezes o comprimento da tíbia; comprimento dos apódemas/edeago $(1,77 \pm$ $0,13)$.

Os dados quantitativos foram obtidos de 10 machos coletados de ovos de Anticarsia gemmatalis Hübner, 1818 (Lep., Noctuidae) em soja, Curitiba, Paraná, Brasil. 

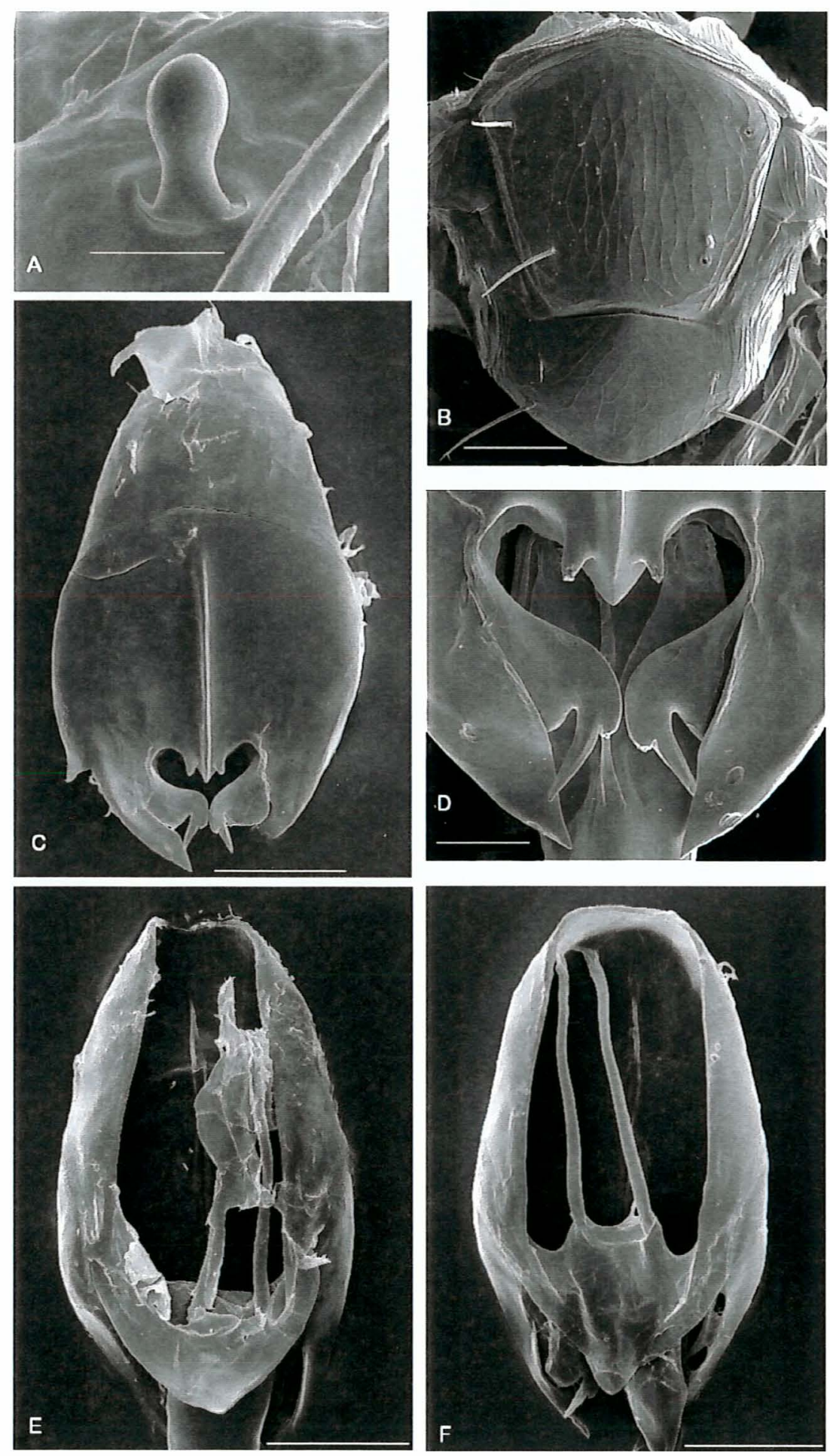

Figura 9 - Trichogramma atopovirilia. A - Sensilo basicônico (15880x, 1 $\mu \mathrm{m})$; B - Mesoescuto e escutelo $(575 x, 20 \mu \mathrm{m}) ; \mathrm{C}$ - Cápsula genital ventral $(1680 \mathrm{x}, 10 \mu \mathrm{m})$; D - Detalhe apical da cápsula genital

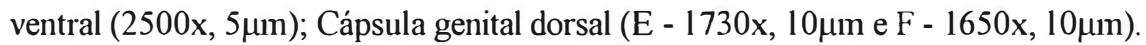




\section{Material examinado}

BRASIL. PARANÁ: Curitiba, mar.-1999, 10 machos, ex ovos de Anticarsia gemmatalis, soja, L.A. Foerster col. (ESALQ); SÃO PAULO: Piracicaba, 6 machos, ex ovos de Spodoptera frugiperda, milho, Eduardo Beserra col. (ESALQ). COLÔMBIA. 11 machos, multiplicados em ovos de Sitotroga cerealella, (ESALQ). VENEZUELA. Barina, 1 macho, ex ovos de Spodoptera frugiperda, Juan Andara col. (ESALQ).

\section{Diagnose}

T. atopovirilia é facilmente distinguido pelo aspecto geral da cápsula genital; pelas modificações nas volselas, que se apresentam dilatadas e com acentuada reentrância lateral; processo ventrais distintamente tubulares e unidos ao processo intervolselar. Essas características permitem reconhecer $T$. atopovirilia e diferenciá-la de $T$. acacioi, espécie nativa do Brasil, que apresenta o aspecto geral da cápsula genital semelhante, mas as volselas, também modificadas, são curvadas e sem reentrância lateral.

\section{Variacões}

As cerdas flageliformes são mais longas nos espécimes brasileiros do que nos espécimes colombianos. Os sensilos basicônicos dos espécimes brasileiros têm a fórmula 1-2-2-0-1-1 (um macho do Paraná apresentou 1 sensilo na posição 2). Nos espécimes colombianos, a fórmula é 1-2(1)-2-0-1-1 (um macho apresentou 2 sensilos na posição 1). Na cápsula genital, a carena dorsal é fracamente desenvolvida nos espécimes colombiano e mais difícil de ser visualizada do que nos espécimes brasileiros.

\section{Análises multivariadas}

A projeção dos indivíduos no espaço dos dois primeiros componentes principais não mostrou a presença de grupos distintos, apenas uma leve separação entre $T$. atopovirilia do Brasil (Paraná e Piracicaba) e da Colômbia (Figura 10).

O primeiro componente explicou cerca de $60 \%$ da variação total, o segundo $11 \%$ e o terceiro $7 \%$. Portanto, os dois primeiros componentes explicaram $71 \%$ da variação total presente na matriz da covariância 
As variáveis comprimento do flagelo (CF) e comprimento da tíbia posterior (CTP) apresentaram os maiores valores absolutos de 0,644 e 0,585, respectivamente. Entretanto, essas variáveis, representando o primeiro componente, não separaram nitidamente os espécimes examinados. O segundo componente, representado, principalmente, pelo comprimento da abertura dorsal (CAD) e distância basal (DB), que apresentaram os maiores valores absolutos, 0,516 e 0,470 , respectivamente, demonstram reduzidas separação entre os espécimes da Colômbia e do Brasil ao longo do segundo eixo canônico.

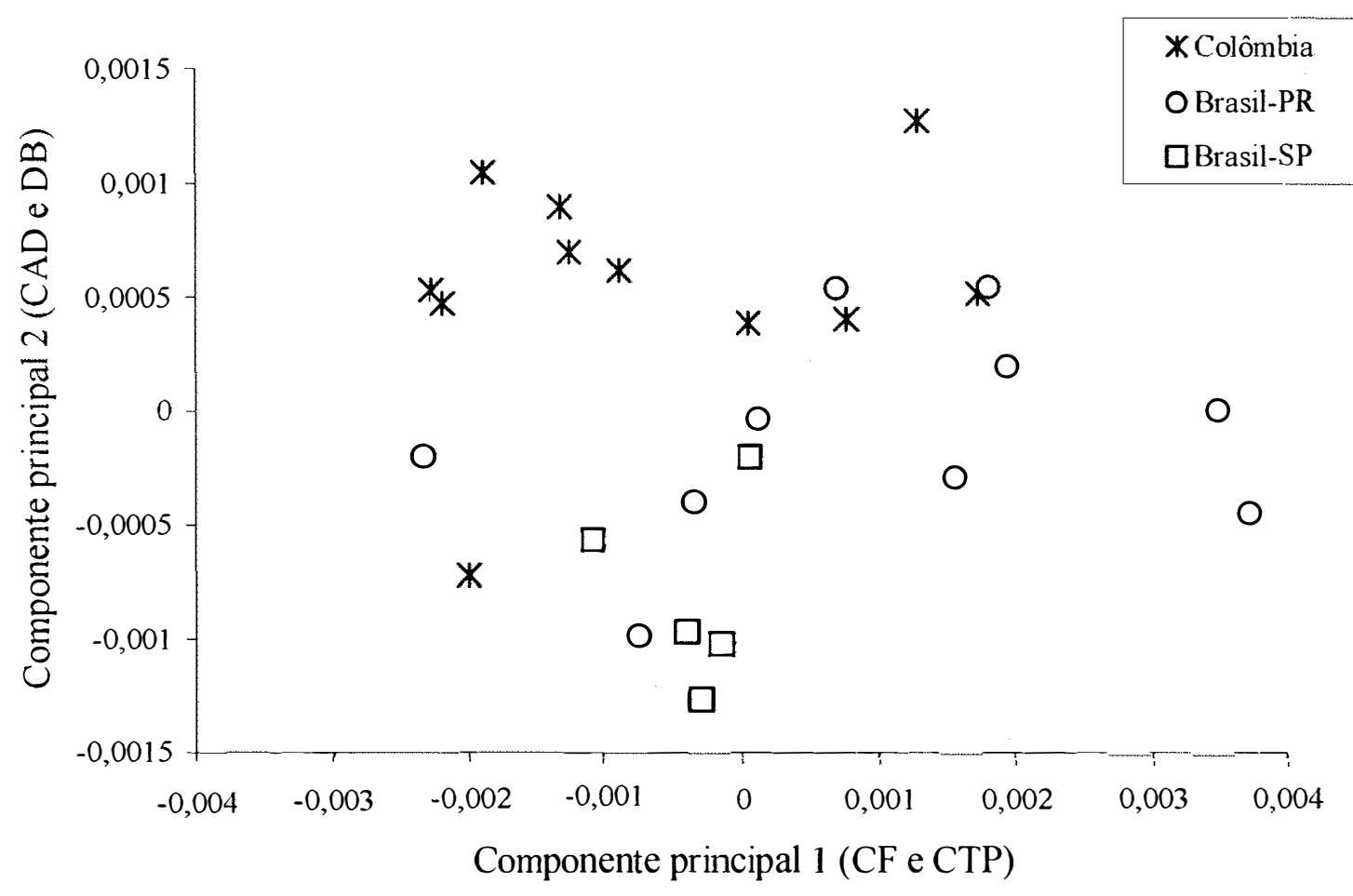

Figura 10 - Ordenação de Trichogramma atopovirilia nos dois primeiros componentes.

A análise das variáveis canônicas apresentou ordenação semelhante à análise dos componentes principais (Figura 11). Os testes multivariados Wilks'Lambda $(\mathrm{P}<0,0032)$, Pillai's Trace $(\mathrm{P}<0,0016)$, Hotelling-Lawley Trace $(\mathrm{P}<0,0065)$ e Roy's Greatest Root $(\mathrm{P}<0,0050)$ mostraram que os eixos canônicos foram estatisticamente significativos, extraídos da matriz resultante do produto da matriz de covariância entre os grupos pela matriz de covariância dentro dos grupos. A primeira variável canônica explicou $66 \%$ e a 
segunda 34 \% da variação total. Os dois primeiros eixos canônicos explicaram $100 \%$ da variação total.

A projeção dos escores dos espécimes no espaço das duas variáveis canônicas mostrou que T. atopovirilia da Colômbia é discriminado em relação aos espécimes do Brasil ao longo do primeiro eixo canônico. Nesse eixo, as variáveis de maior importância foram comprimento das cerdas da franja da asa anterior (CCFAA), comprimento da abertura dorsal (CAD) e comprimento da extensão posterior da lâmina dorsal (CEPLD), que apresentaram os maiores valores absolutos 0,656, 0,594 e 0,558, respectivamente. Essas variáveis também foram importantes para separar espécimes do Paraná dos de Piracicaba ao longo do segundo eixo canônico.

A variável largura da cápsula genital (LCG), comprimento dos apódemas (CA) e comprimento da cápsula genital (CCG), foram as de maior contribuição no eixo canônico 2, com os maiores valores absolutos dos coeficientes canônicas, 0,505, 0,502 e 0,488 , respectivamente. Essas variáveis também separaram os espécimes do Paraná em relação aos demais. Portanto, variações intra-específicas também foram observadas em T. atopovirilia.

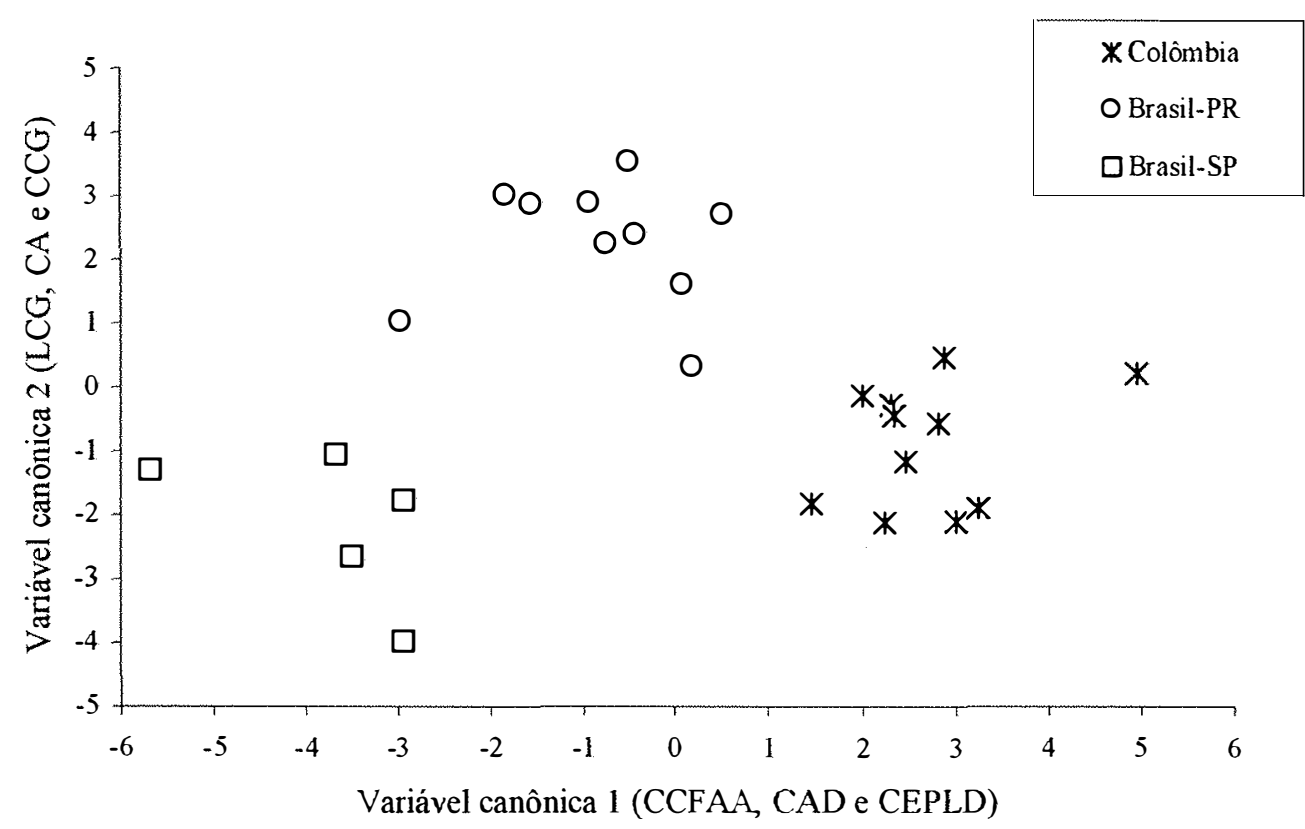

Figura 11 - Ordenação de Trichogramma atopovirilia nos dois primeiros eixos canônicos. 


\section{Distribuicão geográfica e hospedeiros}

T. atopovirilia ocorre no México, El Salvador, Guatemala, Honduras e, na América do Sul, foi registrado no Brasil, Colômbia e Venezuela (Zucchi \& Monteiro, 1997; Pinto, 1998). Foi primeiramente coletado de ovos de Vanessa sp. (Lep., Nymphalidae) em Malvaceae, na Guatemala. No Brasil, foi registrada somente em pragas de importância econômica (Zucchi \& Monteiro, 1997). Recentemente foi encontrado parasitando $A$. gemmatalis na cultura da soja no Estado do Paraná (Foerster \& Avanci, 1999) e Spodoptera frugiperda (J. E. Smith, 1797) na cultura do milho no Estado de São Paulo (Beserra, 2000).

\subsubsection{Trichogramma bertii Zucchi, n. sp.}

(Figura 12)

T. bertii é uma espécie nativa do Brasil, registrada no Estado de São Paulo, nos municípios de Altinópolis e Sorocaba. Foi coletado de ovos de Glena sp. (Zucchi, 1985) e de Melanolophia sp. (novo registro de hospedeiro), ambas da família Geometridae (Lepidoptera). Esses hospedeiros ocorrem em áreas florestais, indicando preferência da espécie por esse hábitat.

Estudos descritivos de T. bertii (não formalmente descrita) foram apresentados em uma tese (Zucchi, 1985). Apresenta caracteres distintivos como as cerdas flageliformes curtas com o ápice abruptamente afilado e processo intervolselar longo. Outras características que complementam a descrição original são: sensilos basicônicos com fórmula 1-2-2-1-1-1; presença de três sensilos placóideos situados no terço apical do flagelo da antena; número moderado de cerdas entre a $4^{\mathrm{a}}$ e $5^{\mathrm{a}}$ fileira de cerdas da asa anterior; processos ventrais situados próximos à base do processo intervolselar e carena ventral alcançando a metade da cápsula genital. Essas características auxiliam na identificação de T. bertii e separam das demais espécies de Trichogramma que ocorrem no Brasil. 
Dentre as espécies que ocorrem na América do Sul, T. bertii é mais similar a Trichogramma sp.n. 9 e a T. pretiosum, sendo separado dessas espécies, principalmente pelas cerdas flageliformes, curtas em $T$. bertii e longas em T. pretiosum e Trichogramma sp.n. 9. Como também pelas cerdas anteriores do escutelo, longas em Trichogramma sp.n. 9 e curtas em T. bertii e T. pretiosum.

\section{Material examinado}

BRASIL. SÃO PAULO: Altinópolis, 1-nov.-1984, holótipo macho, ex ovos de Glena sp., E. Berti Filho col. (ESALQ); Sorocaba, 10-jul.-1992, 2 machos, ex ovos de Melanolophia sp., C. Wilcken col. (ESALQ).
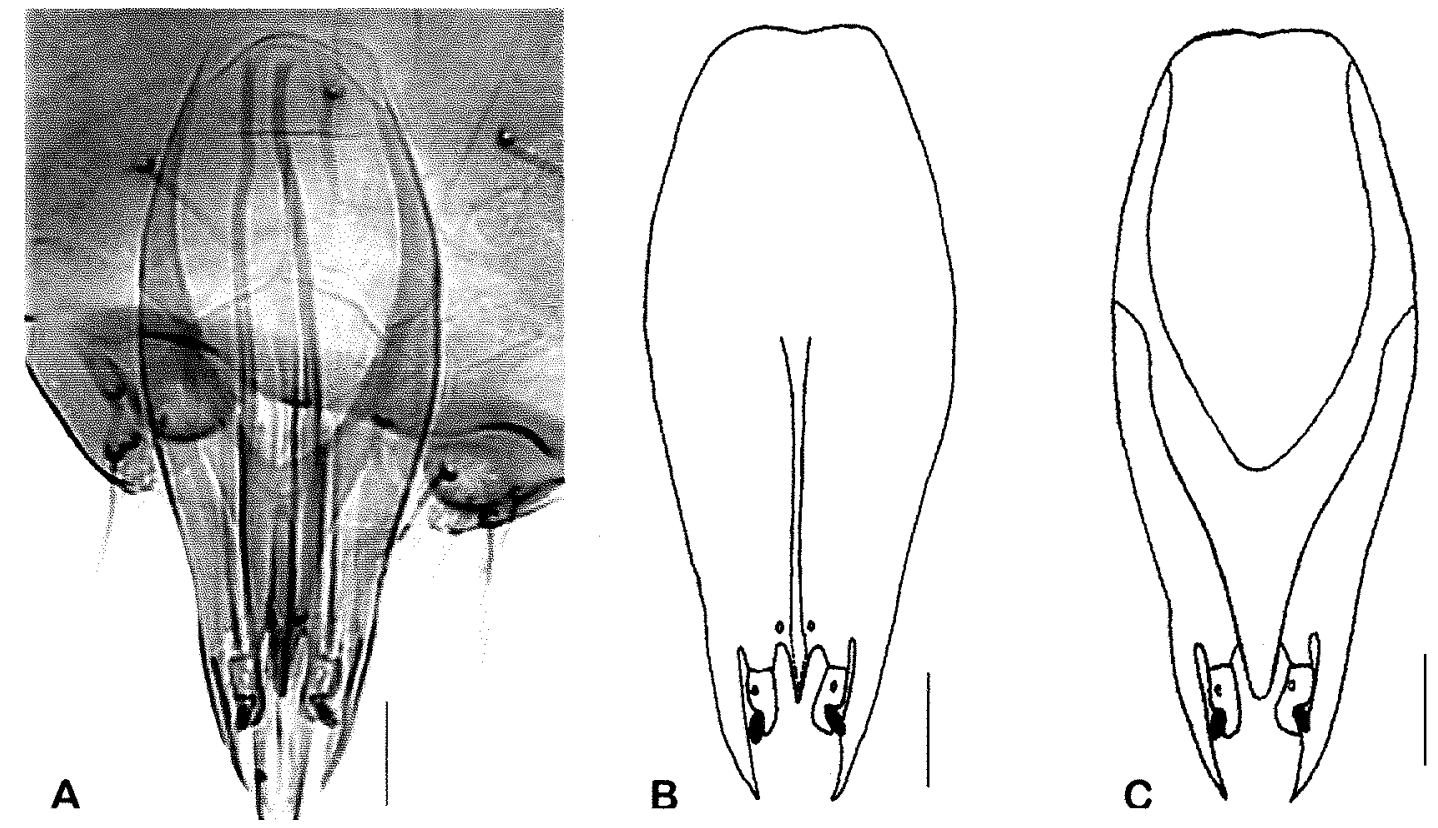

Figura 12 - Trichogramma bertii. Cápsula genital: A - ventral $(10 \mu \mathrm{m})$; B - ventral $(20 \mu \mathrm{m})$ e C - dorsal $(20 \mu \mathrm{m})$. 


\subsubsection{Trichogramma bruni Nagaraja, 1983}

(Figuras 13 e 14)

Trichogramma bruni Nagaraja, 1983: 38; Sorokina, 1993: 35; Zucchi \& Monteiro, 1997: 53; Pinto, 1998: 79 e 81 (nr. T. bruni).

\section{Caracterizacão morfológica}

Antenas: flagelo longo $(0,16 \pm 0,02)$; relação entre o comprimento e a largura do flagelo de $6,17 \pm 0,60$; cerdas flageliformes longas $(0,09 \pm 0,01)$ com o ápice uniformemente afilado; comprimento da maior cerda do flagelo/maior largura do flagelo $(3,49 \pm 0,18)$; comprimento do flagelo/comprimento da tíbia posterior $(1,24 \pm 0,08)$; sensilos basicônicos ovalado, fórmula 2(1)-2(1)-2-0(1)-1; três sensilos placóideos.

Asas anteriores: relação entre a largura e o comprimento da asa $(0,52 \pm 0,04)$; comprimento da maior cerda da franja da asa/comprimento da tíbia posterior $(0,23 \pm$ $0,05)$; comprimento da maior cerda da franja da asa anterior/largura da asa anterior $(0,13$ $\pm 0,03)$. O número de cerdas entre a $4^{\underline{a}}$ e $5^{\underline{a}}$ filleiras de $4-18$.

Asas posteriores: fileira anterior e posterior com número de cerdas variando de 0-1 e 16 , respectivamente. A fileira anterior não ultrapassando a metade da fileira mediana.

Escutelo: relação entre cerdas anterior e posterior $(0,18 \pm 0,05)$; cerdas anteriores diminutas e de difícil visualização.

Genitália masculina: cápsula genital mais longa $(0,11 \pm 0,01)$ do que larga $(0,04 \pm$ $0,00)$; relação entre a largura e o comprimento da cápsula genital $(0,38 \pm 0,02)$; relação entre a distância apical e o comprimento da cápsula genital $(0,23 \pm 0,02)$; largura apical/largura da cápsula genital $(0,72 \pm 0,04)$; comprimento da lâmina dorsal/comprimento da cápsula genital $(0,37 \pm 0,05)$; carena dorsal ausente; comprimento/largura da lâmina dorsal $(1,21 \pm 0,20)$; extensão posterior da lâmina dorsal geralmente com ápice pontiagudo; comprimento da extensão posterior da lâmina dorsal $(0,03 \pm 0,00)$; comprimento da abertura dorsal/comprimento da lâmina dorsal $(1,65 \pm$ 0,20); comprimento da extensão posterior da lâmina dorsal/comprimento da lâmina dorsal $(0,76 \pm 0,12)$; carena ventral longa $(0,06 \pm 0,00)$, ultrapassando a metade da 
cápsula genital; carena ventral/distância basal $(0,63 \pm 0,05)$; distância basal/comprimento da cápsula genital $(0,79 \pm 0,05)$; processos ventrais relativamente próximos da base do processo intervoselar $(0,01 \pm 0,002)$; processo intervolselar muito curto, não alcançando a base das volselas; comprimento do edeago/comprimento da tíbia posterior $(0,44 \pm 0,03)$; apódemas/edeago $(0,88 \pm 0,07)$.

Os dados quantitativos foram obtidos de 25 machos coletados de ovos de Heliconius erato phyllis (Fabricius, 1775) (Lep., Nymphalidae) e multiplicados em ovos de hospedeiro alternativos (A. kuehniella).

\section{Material examinado}

ARGENTINA. MISIONES: Porto Iguazu, 27-dez.-1990/06-jan.-1991, Forest roadside, 2 machos, S. \& J. Peck col. (UCR); BRASIL. MINAS GERAIS: Belo Horizonte, Holótipo, 24-fev.-1978, ex ovos de Notodontidae, G.W.G. de Moraes, P. Brun \& L.A. Soares col. (UFMG). SÃO PAULO: Piracicaba, mai.-1999, ex ovos de Heliconius erato phyllis, em Passiflora sp., 25 machos, J.A. Cerignoni col. (ESALQ); Piracicaba, 2-jul.-1999, ex ovos de Erosina hyberniata, em Acnistus arborescens, 10 machos, R.B. Querino col. (ESALQ); Piracicaba, Horto florestal de Tupi, 20-set.-1999, ex ovos de Mechanitis lysimnia, Juá bravo, 24 machos, R.B. Querino col. (ESALQ); Itatinga, 6-out.-1999, hospedeiro desconhecido, em sub-bosque de eucalipto, 24 machos, R.B. Querino col. (ESALQ); Piracicaba, 16-jun.-2000, ex ovos de Hamadryas feronia, em Dalechampia sp., 4 machos, J.A. Cerignoni col. (ESALQ); COSTA RICA. HEREDIA: Porto Viejo, jan., mar. e abr.-1994, La selva, 100m, 1 macho, (UCR); TRINIDAD \& TOBAGO. St. GEORGE: Gasparillo, 5 e 15-nov.-1987, M.T.Grass/Forest edge, 1 macho, (UCR); VENEZUELA. LARA: Sanare, 12-vii-1983, tropical plant, host unknown, 2 machos, E.R. Oatman col, (UCR); Aragua, Parque Nacional Henri Pittier, La Trilla, 200m SS, 1 macho,L. Masner col. (UCR). 


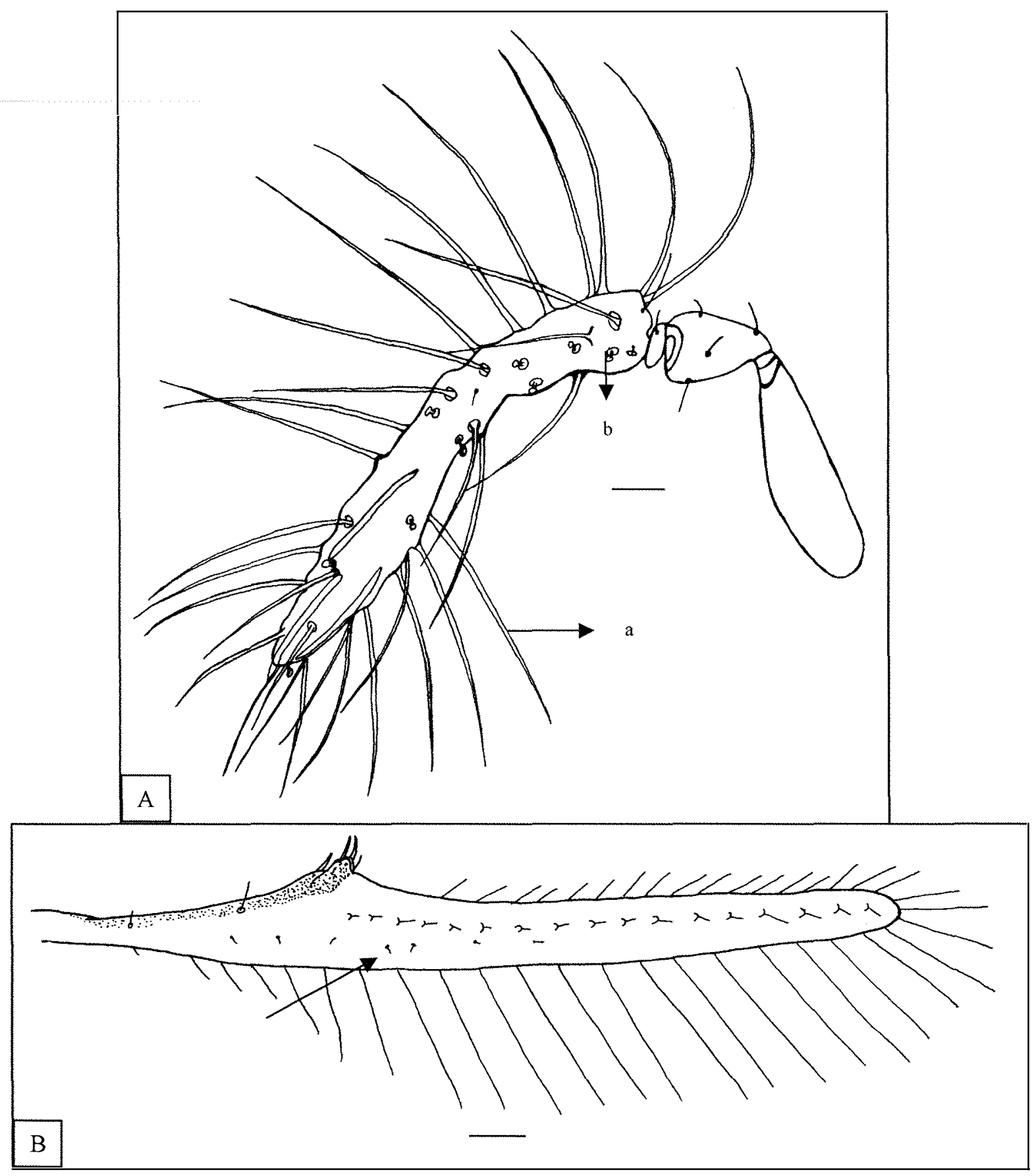

Figura 13 - A - Antena de Trichogramma bruni: a - cerda flageliforme e b - sensilo basicônico; B - Asa posterior de T. bruni: seta indica fileira posterior de cerdas. 

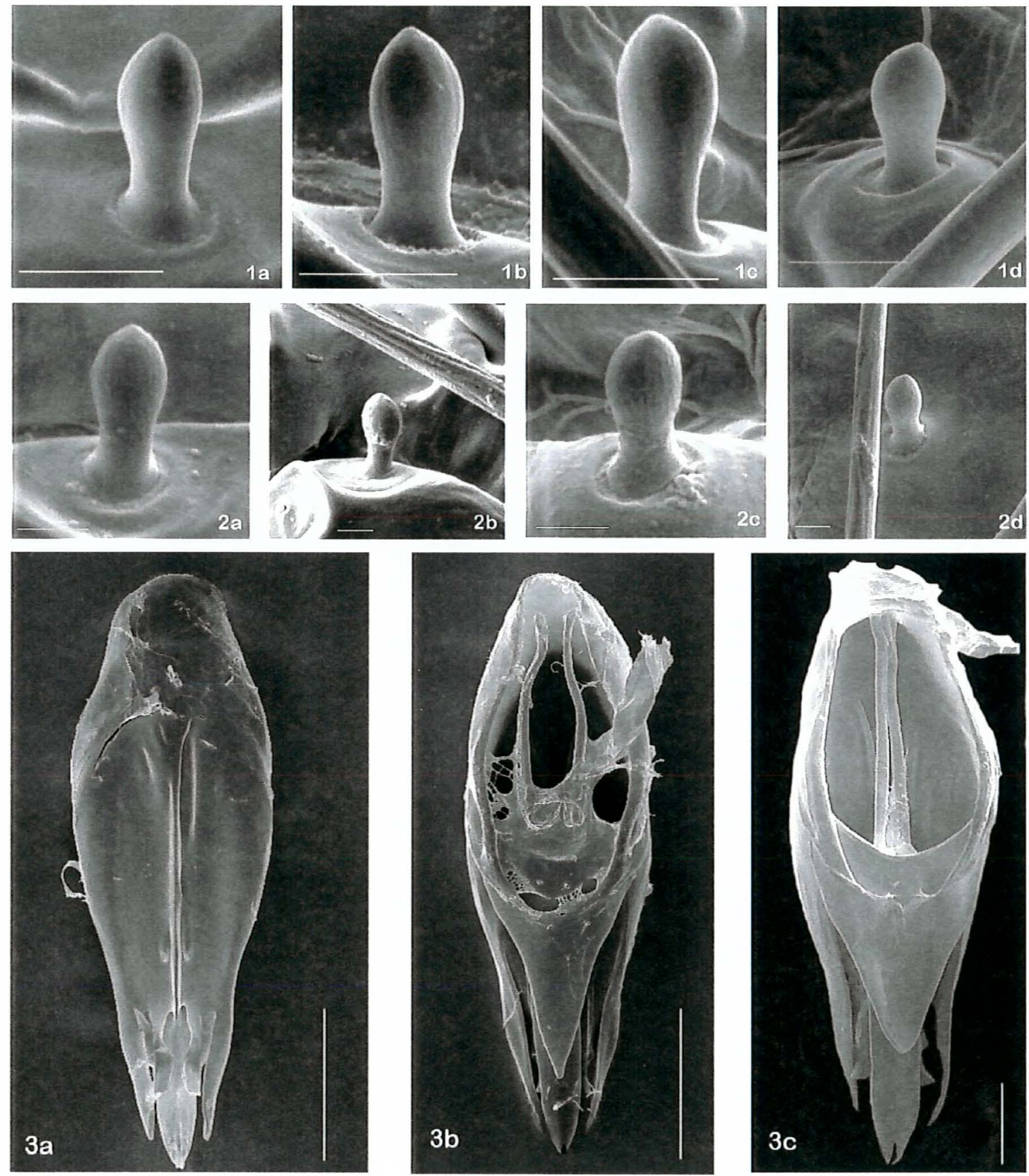

Figura 14 - Sensilos basicônicos de Trichogramma bruni. 1 - coletado de ovos de Heliconius erato phyllis: aposição 1 (16790x, $1 \mu \mathrm{m})$; b-posição $2(22300 x, 1 \mu \mathrm{m})$; c-posição 3 (23330x, $1 \mu \mathrm{m})$; d-posição 4 (15990x, $1 \mu \mathrm{m}) .2$ - coletado de ovos de hospedeiro desconhecido: a-posição 1 (10000x, $1 \mu \mathrm{m})$; bposição 2 (5000x, $11 \mu \mathrm{m})$; c-posição 3 (10000x, $1 \mu \mathrm{m})$; d-posição 4 (5000x, $1 \mu \mathrm{m}) .3$ - Cápsula genital de Trichogramma bruni: a - hospedeiro Heliconius erato phyllis, ventral (1620x, $10 \mu \mathrm{m})$ e b-dorsal (1610x, 10 $\mu \mathrm{m})$; c - hospedeiro desconhecido, dorsal $(875 \mathrm{x}, 20 \mu \mathrm{m})$. 


\section{Diagnose}

Considerando-se as variações intra-especificas, os caracteres que identificam $T$. bruni são: antenas com cerdas flageliformes longas e sensilos basicônicos ovalados; cápsula genital longa; lâmina dorsal típica com a base larga e extensão posterior estreitando-se para um ápice pontiagudo; carena ventral distinta e longa, atingindo cerca de 2/3 do comprimento da cápsula genital; processos ventrais situados próximos da base do processo intervolselar, processo intervolselar curto.

Todavia, diferenças em relação ao holótipo (Figura 15) podem ser observadas em alguns espécimes, ou seja, cápsula genital mais alongada, lâmina dorsal variando na largura da base e a extensão posterior mais curta do que o normalmente observado. A cor não deve ser usada para diagnosticar T. bruni.

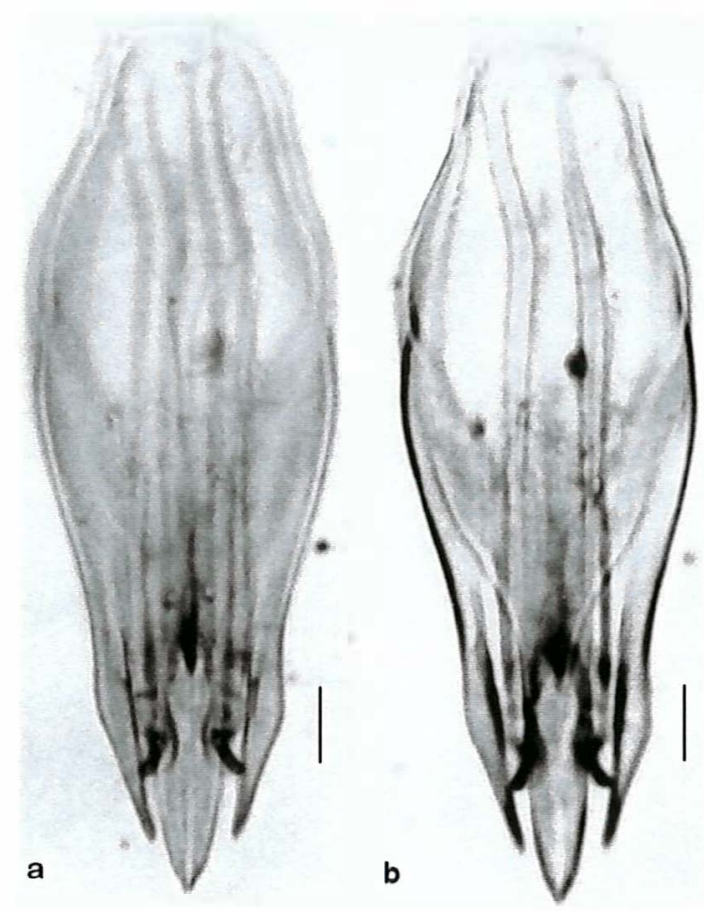

Figura 15 - Cápsula genital de Trichogramma bruni (Holótipo): a - ventral; b - dorsal (10 $\mu \mathrm{m})$.

Dentre as espécies de Trichogramma que ocorrem na região Neotropical, $T$. lasallei Pinto, 1998 e T. rojasi Nagaraja \& Nagarkatti, 1973 são mais relacionadas à $T$. bruni, além de outras espécies discutidas por Pinto (1998). Em T. bruni, pode ser 
observado, freqüentemente, um sensilo basicônico na posição 4, não sendo encontrado em T. lasallei e T. rojasi. Estas duas espécies apresentam as cerdas anteriores do escutelo maiores e escuras, diferentemente de $T$. bruni que são reduzidas e de difícil visualização. T. bruni e T. lasallei apresentam número de cerdas nas asas anteriores cerca de duas vezes menor ( 8,39 e 8,40 , respectivamente) comparadas a $T$. rojasi $(16,92)$. Nas asas posteriores de T. bruni e T. lasallei, as cerdas da fileira posterior não alcançam a metade da fileira mediana; em $T$. rojasi são maiores e alcançam o ápice da asa. A cápsula genital de $T$. lasallei e $T$. rojasi são esclerotizadas e escuras, diferentemente de T. bruni, que é mais amarelada. A carena ventral é tipicamente alongada em $T$. bruni, sendo mais curta em $T$. rojasi e em $T$. lasallei, nesta o limite anterior não é visível. Outro caráter que diferencia T. rojasi dessas duas espécies, é a presença dos processos ventrais muito próximos da base do processo intervolselar (afastados em T. bruni e $T$. lasallei). A relação entre o comprimento e a largura da lâmina dorsal, com média de $1,21 \pm 0,20,1,38 \pm 0,09$ e 1,46 $\pm 0,13$, respectivamente, para $T$. bruni, T. lasallei e T. rojasi, indica que T. bruni apresenta a base da lâmina dorsal mais larga. De modo geral, o tamanho das estruturas de T. rojasi são maiores quando comparados às outras duas espécies.

\section{$\underline{\text { Variacões }}$}

A variação individual pode ser verificada claramente na cápsula genital dos indivíduos provenientes de isofềmeas (Figura 16). A lâmina dorsal apresentou variação na largura da extensão posterior da lâmina dorsal, ocorrendo indivíduos com a base mais larga. O ápice da lâmina dorsal variou de arredondado a pontiagudo. Os processos ventrais variaram quanto a sua posição, situando-se um pouco mais afastados da base do processo intervolselar. $\mathrm{Na}$ antena, foi observada a presença de um sensilo basicônico na posição 4 . Essas mesmas variações morfológicas foram notadas nos espécimes de T. bruni coletados de ovos de H. erato phyllis, provenientes de Itatinga-SP (Figura 17).

As variações entre os indivíduos provenientes de um único hospedeiro foram semelhantes àquelas entre os diferentes hospedeiros (Figura 18). Todavia, T. bruni, coletado de ovos de Mechanitis lysimnia Fabricius, 1793 (Lep. Nymphalidae), apresentou a cápsula 
genital alongada com a lâmina dorsal mais curta, larga e de coloração escura (Figura 18, df). Características semelhantes foram observadas em um espécime coletado em Misiones na Argentina denominado "nr. bruni" por Pinto (1998). Os exemplares da Costa Rica, Trinidad (St. George) e Venezuela, também denominados "nr. bruni" por Pinto (1998), foram morfologicamente semelhantes aos demais espécimes coletados no Brasil.
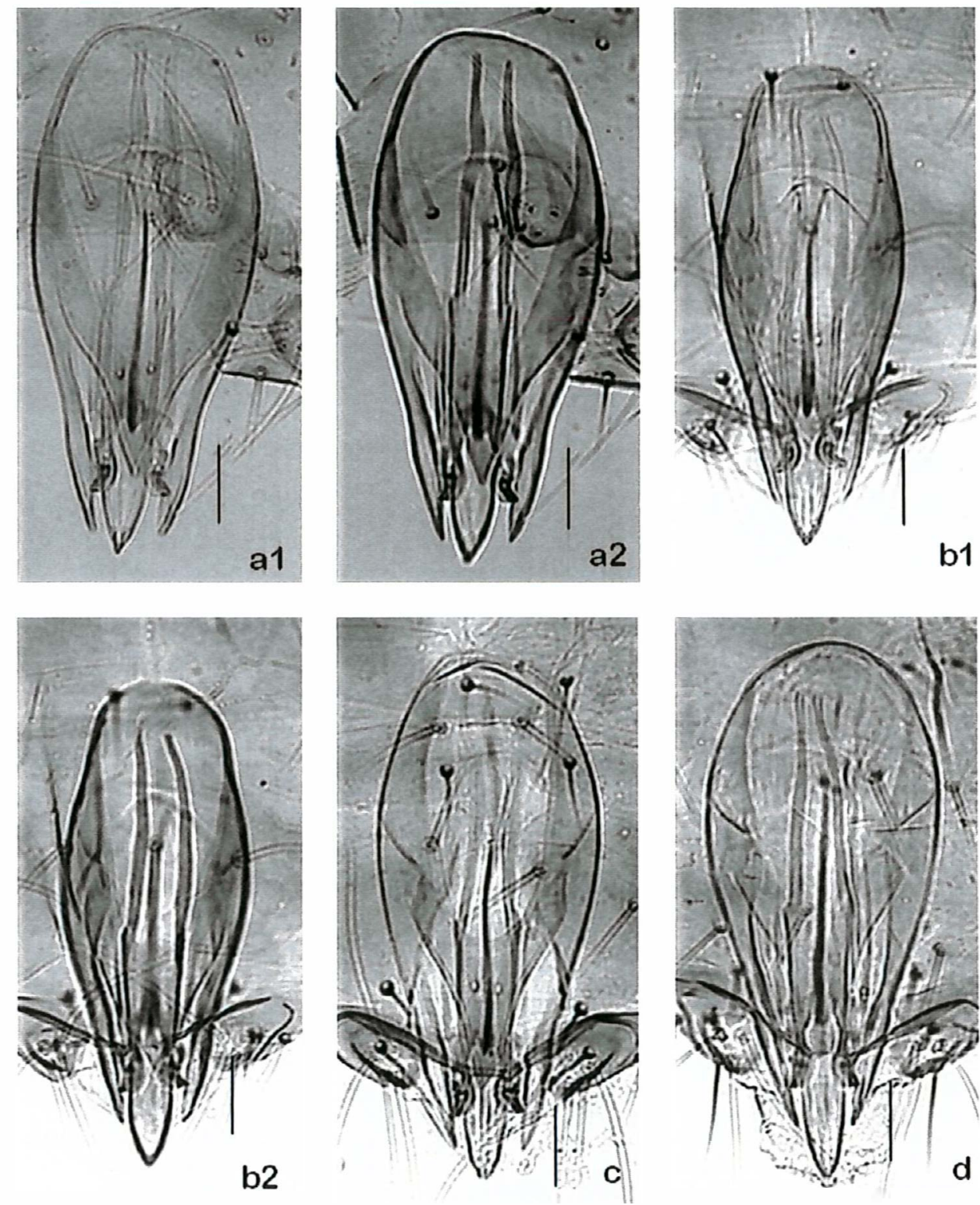

Figura 16 - Variação na cápsula genital de indivíduos de Trichogramma bruni da linhagem de Isofêmeas ( $5^{\mathrm{a}}$ geração): 1 - ventral ; 2 - dorsal $(10 \mu \mathrm{m})$. 

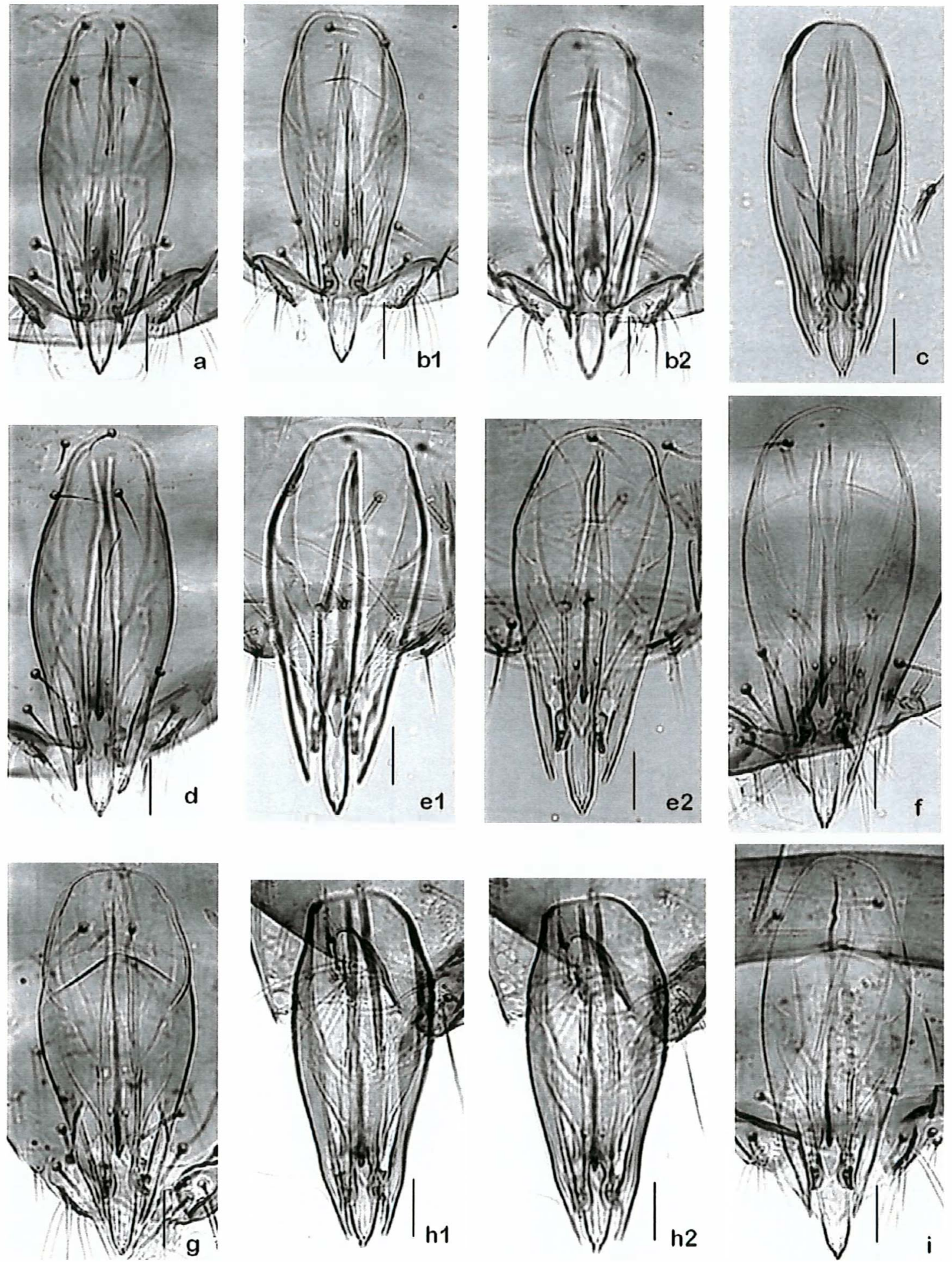

Figura 17 - Variação na cápsula genital de Trichogramma bruni: hospedeiro desconhecido, Itatinga-SP (a - c); hospedeiro Heliconius erato phyllis, Piracicaba-SP (d - i). 1 -ventral ; 2 - dorsal (escala $10 \mu \mathrm{m}$ ). 

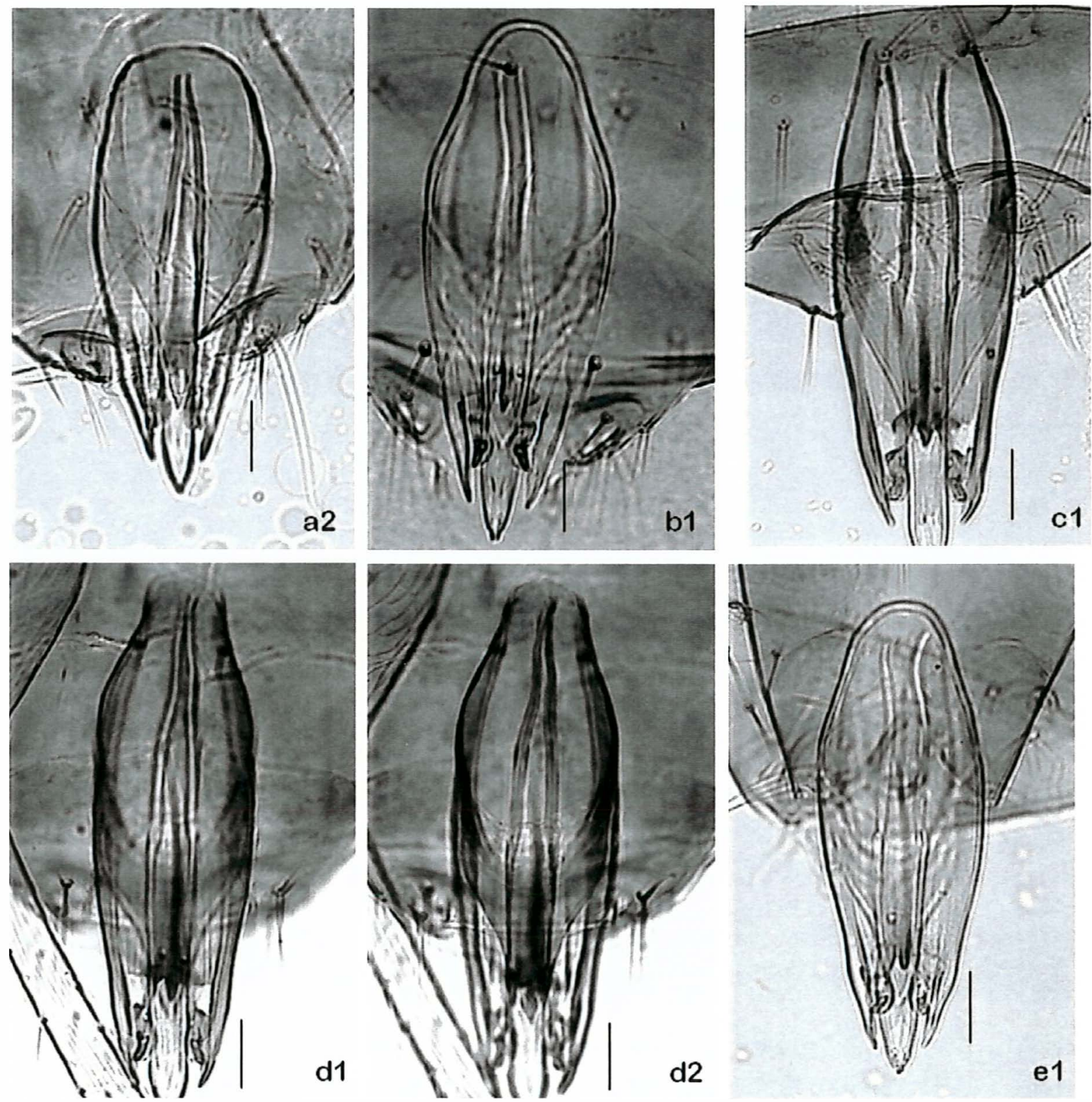

Figura 18 - Variação na cápsula genital de Trichogramma bruni coletado de ovos Erosina hyberniata (a), Hamadryas feronia (b); Mechanitis lysimnia (c-d = espécime escuro, e= espécime claro). 1 - ventral; 2 - dorsal (escala $10 \mu \mathrm{m}$ ).

A coloração dos espécimes de T. bruni variou segundo seu hospedeiro e hábitat. Assim, espécimes da Venezuela apresentaram cor clara (Estado de Aragua) e escura (Estado de Lara, Sanare). No Brasil, os espécimes provenientes de ovos M. lysimnia 
apresentaram coloração escura e clara, com diferenças morfológicas na cápsula genital (Figura 18, c-e). Os espécimes dos outros hospedeiros apresentaram coloração amareloclara. Nagaraja (1983) afirmou que T. bruni apresenta coloração amarela com manchas foscas no mesoescuto, todavia, não deixou claro se a cor foi registrada em material vivo ou após a montagem em lâmina. Pinto (1998) comentou que a coloração pode variar de marrom-claro ao escuro.

\section{Análises multivariadas}

A análise dos componentes principais demonstrou um agrupamento entre $T$. bruni obtido dos vários hospedeiros e hábitats (Figura 19). O primeiro componente principal explicou cerca de $52 \%$ da variação total, o segundo $22 \%$ e o terceiro $9 \%$. Os dois primeiros componentes explicaram $77 \%$ da variação total presente na matriz de covariância. Os coeficientes dos autovetores apresentaram valores positivos e negativos para todas as variáveis morfométricas analisadas, indicando um contraste entre as variáveis e expressando informações sobre as diferenças de forma corporal das populações.

No primeiro componente, a variável distância dos processos ventrais para a base do processo intervolselar (DPV) foi a de maior importância, pois apresentou o coeficiente com o maior valor absoluto $(0,954)$. Com relação às espécies relacionadas a T. bruni, observa-se ao longo do eixo do primeiro componente, representado principalmente pela DVP, observa-se que não há uma distinta separação entre T. bruni $\mathrm{e}$ $T$. lasalle $i$, mas nota-se claramente que $T$. lasallei está separada de $T$. rojasi. Os espécimes de $T$. bruni formam um grupos intermediário entre $T$. lasallei e $T$. rojasi.

O segundo componente foi mais influenciado pela variável comprimento da maior cerda da franja da asa anterior (CCFAA) e comprimento da extensão posterior da lâmina dorsal (CEPLD), variáveis que apresentaram os coeficientes dos autovetores com maiores valores absolutos, 0,596 e 0,400 , respectivamente. No eixo desse componente, não ocorreu distinção entre os espécimes de $T$. bruni obtidos dos vários hospedeiros, com exceção dos coletados de $M$. lysimnia, que estão em situação intermediária, entre $T$. bruni e $T$. lasallei. Além disso, as variáveis CCFAA e CEPLD, que representam o 
segundo componente, separam nitidamente $T$. bruni de $T$. lasallei e de T. rojasi, embora não tenha separado estas duas espécies.

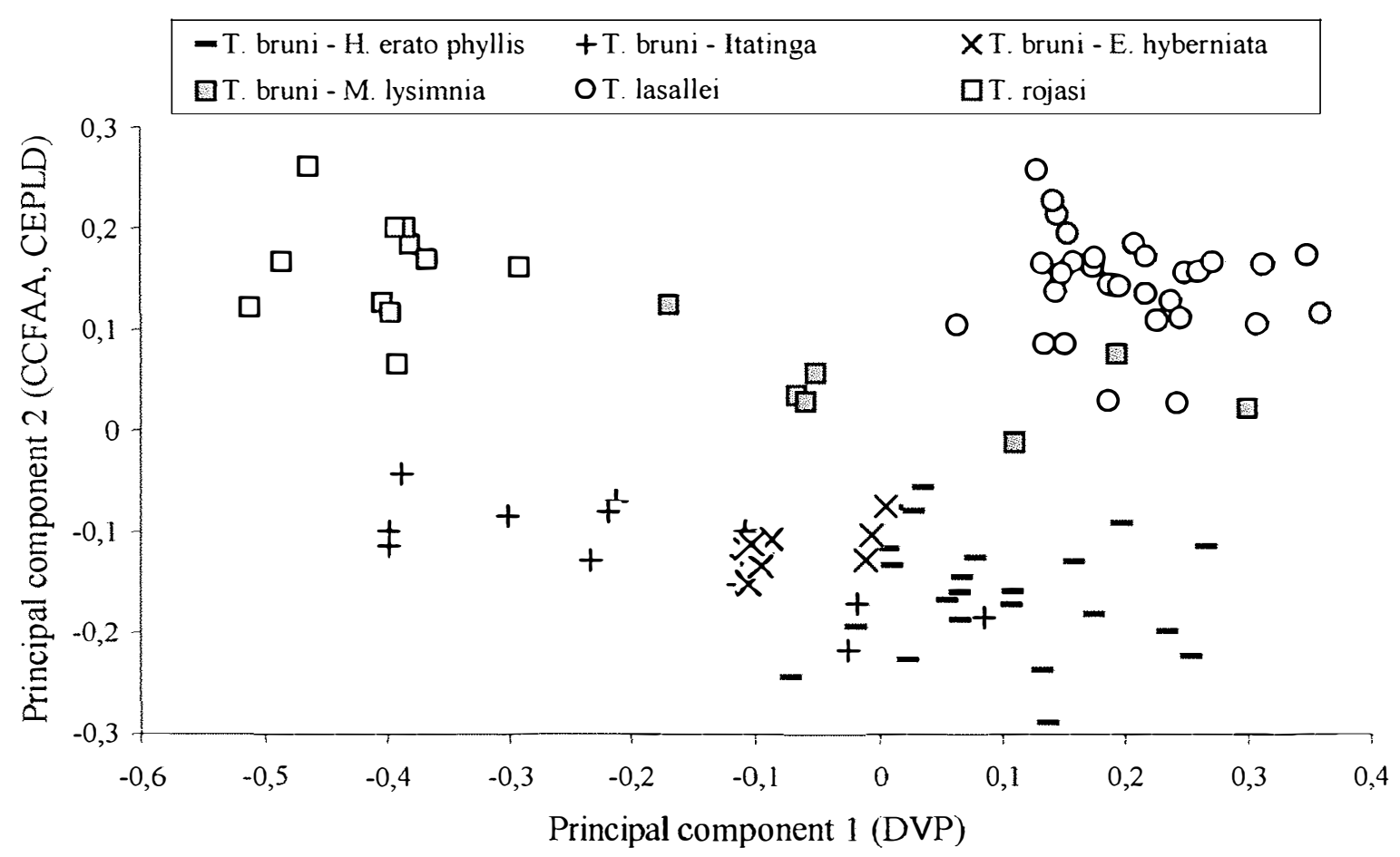

Figura 19 - Ordenação de $T$. bruni, de $T$. lasallei e de $T$. rojasi nos dois primeiros componentes.

O resultado da análise das variáveis canônicas (Figura 20) mostrou ordenação semelhante à obtida pela análise dos componentes principais. Os testes multivariados Wilks'Lambda $\quad(\mathrm{P}<0,0001)$, Pillai's Trace $(\mathrm{P}<0,0001)$, Hotelling-Lawley Trace $(\mathrm{P}<0,0001)$ e Roy's Greatest Root $(\mathrm{P}<0,0001)$ mostraram que os eixos canônicos foram estatisticamente significativos, extraídos da matriz resultante do produto da matriz de covariância entre os grupos pela matriz de covariância dentro dos grupos. A primeira variável canônica explicou $56 \%$ e a segunda $31 \%$ da variação total. Os dois primeiros eixos canônicos explicaram $87 \%$ da variação.

No primeiro eixo canônico, as variáveis de maior importância foram comprimento das cerdas da franja da asa anterior (CCFAA), comprimento da extensão posterior da lâmina dorsal (CEPLD) e comprimento da maior cerda do flagelo (CCF), 
que apresentaram os maiores valores absolutos, 0,880, 0,726 e 0,725, respectivamente. No segundo eixo canônico, a variável distância dos processos ventrais ao processo intervolselar (DVP) e comprimento da carena ventral (CCV), com os maiores valores absolutos , 0,888 e 0,703, respectivamente, foram as variáveis de maior contribuição nesse eixo.

Os resultados da análise das variáveis canônicas mostraram o agrupamento de $T$. bruni proveniente dos diferentes hospedeiros. Contudo, os espécimes obtidos de $M$. lysimnia encontram-se em situação intermediária, devido às variações morfológicas observadas na cápsula genital, principalmente analisando-se o primeiro eixo canônico (representado pela CCFAA, CEPLD e CCF); no segundo eixo (representado pela DVP e CCV) não se distingue os espécimes obtidos de $M$. lysimnia dos outros espécimes de $T$. bruni. Entretanto, observou-se a separação entre as espécies estudadas, com T. lasallei mais próximo de $T$. bruni, tanto com relação à primeira variável canônica, quanto com à segunda. A proximidade dessas duas espécies pôde ser observada também em uma análise fillogenética (Pinto,1998). T. rojasi ficou isolada e distanciada de T. bruni.

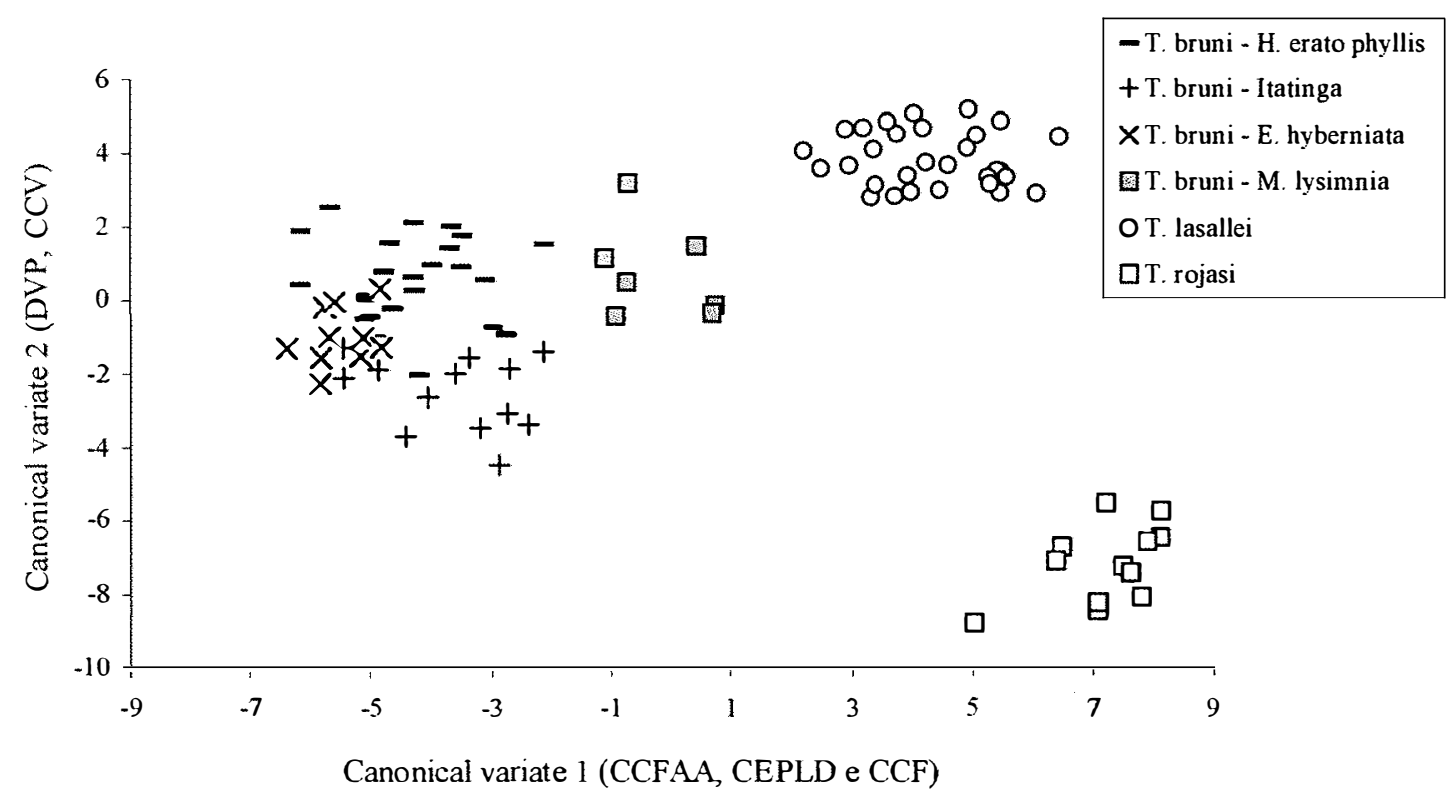

Figura 20 - Ordenação de T'. bruni, de T. lasallei e T. rojasi nos dois primeiros eixos canônicos.

\section{Cruzamentos}


Os cruzamentos realizados entre T. bruni e T. lasallei auxiliaram na separação e confirmação das espécies, principalmente com relação a $T$. bruni. Devido às acentuadas variações intra-espécificas, havia dúvidas na identificação dessa espécie. Os cruzamentos bidirecionais entre T. lasallei e T: bruni mostraram que essas espécies são incompatíveis (Tabela 5), pois foram produzidos somente machos, ou seja, as fêmeas não foram fecundadas nos cruzamentos heterogâmicos (Figura 21). Com relação ao modo de reprodução na temperatura de $25^{\circ} \mathrm{C}$, as fềmeas virgens só produziram machos, indicando, portanto, que as duas espécies são arrenótocas. A descendência de cada uma das espécies foi fértil. Não foi possível realizar cruzamentos com T. rojasi, pois não havia criação dessa espécie em laboratório.

Em algumas amostras de T. bruni, observou-se uma alta descendência de fềmeas. Procurou-se, então, avaliar se nas temperaturas de 18,25 e $30^{\circ} \mathrm{C}$ surgiriam fềmeas telítocas. Entretanto, fềmeas virgens de $T$. bruni (não-fecundadas) criadas nessas temperaturas, só produziram machos (Figura 22), indicando que a temperatura não influenciou o modo de reprodução dessa espécie.

Tabela 5. Número médio de descendentes machos e fềmeas e de ovos parasitados provenientes do cruzamento de Trichogramma lasallei (L) e Trichogramma bruni (B) na temperatura $25^{\circ} \mathrm{C}$.

\begin{tabular}{lccccc}
\hline \multicolumn{1}{c}{ Cruzamentos } & $\mathrm{n}$ & $\mathrm{N}^{\mathrm{o}}$ de Macho & $\mathrm{N}^{\mathrm{o}}$ de Fêmea & Total & Ovos parasitados \\
\hline $\begin{array}{l}\text { Heterogâmicos } \\
\text { 1 - Macho L x fêmea B }\end{array}$ & 18 & $30,17 \pm 8.40$ & 0 & $30,17 \pm 8.40$ & $31,05 \pm 8.99$ \\
2 - Macho B x fêmea L & 16 & $17,87 \pm 9.44$ & 0 & $17,87 \pm 9.44$ & $18,50 \pm 10.22$ \\
Homogâmicos & & & & & \\
3 - Macho L x Fêmea L & 09 & $14,22 \pm 4.38$ & $11.33 \pm 6.18$ & $25,55 \pm 7.52$ & $27,55 \pm 7,21$ \\
4 - Macho B Fêmea B & 10 & $15,50 \pm 7.11$ & $12.10 \pm 5.72$ & $27,60 \pm 9.14$ & $31,60 \pm 9,87$ \\
Modo de reprodução & & & & & \\
Fêmea Virgem L & 10 & 23.9 & 0 & 23.9 & 23,5 \\
Fêmea Virgem B & 11 & 35.5 & 0 & 35.5 & 36,73 \\
\hline
\end{tabular}




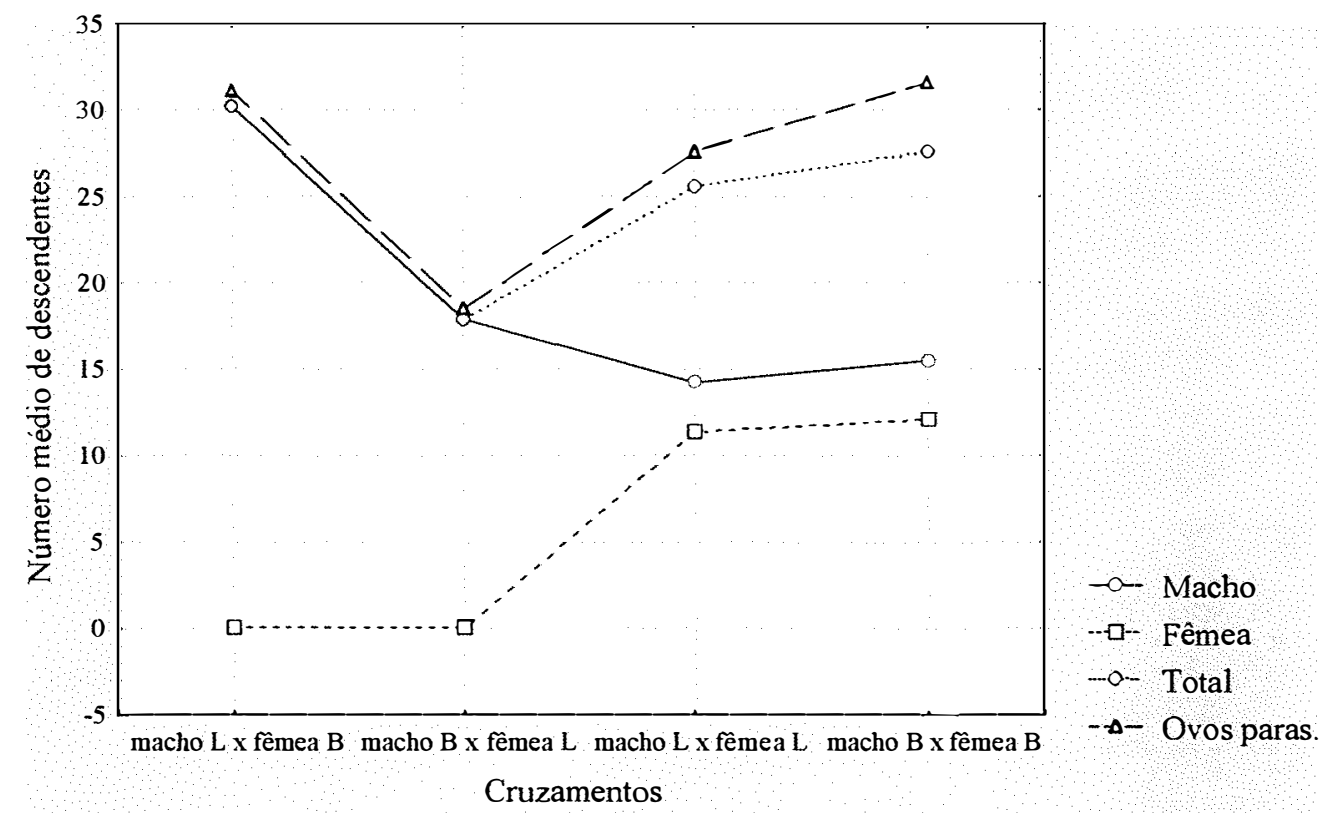

Figura 21 - Média de descendentes e número de ovos parasitados nos cruzamentos de Trichogramma bruni (B) e Trichogramma lasallei (L).

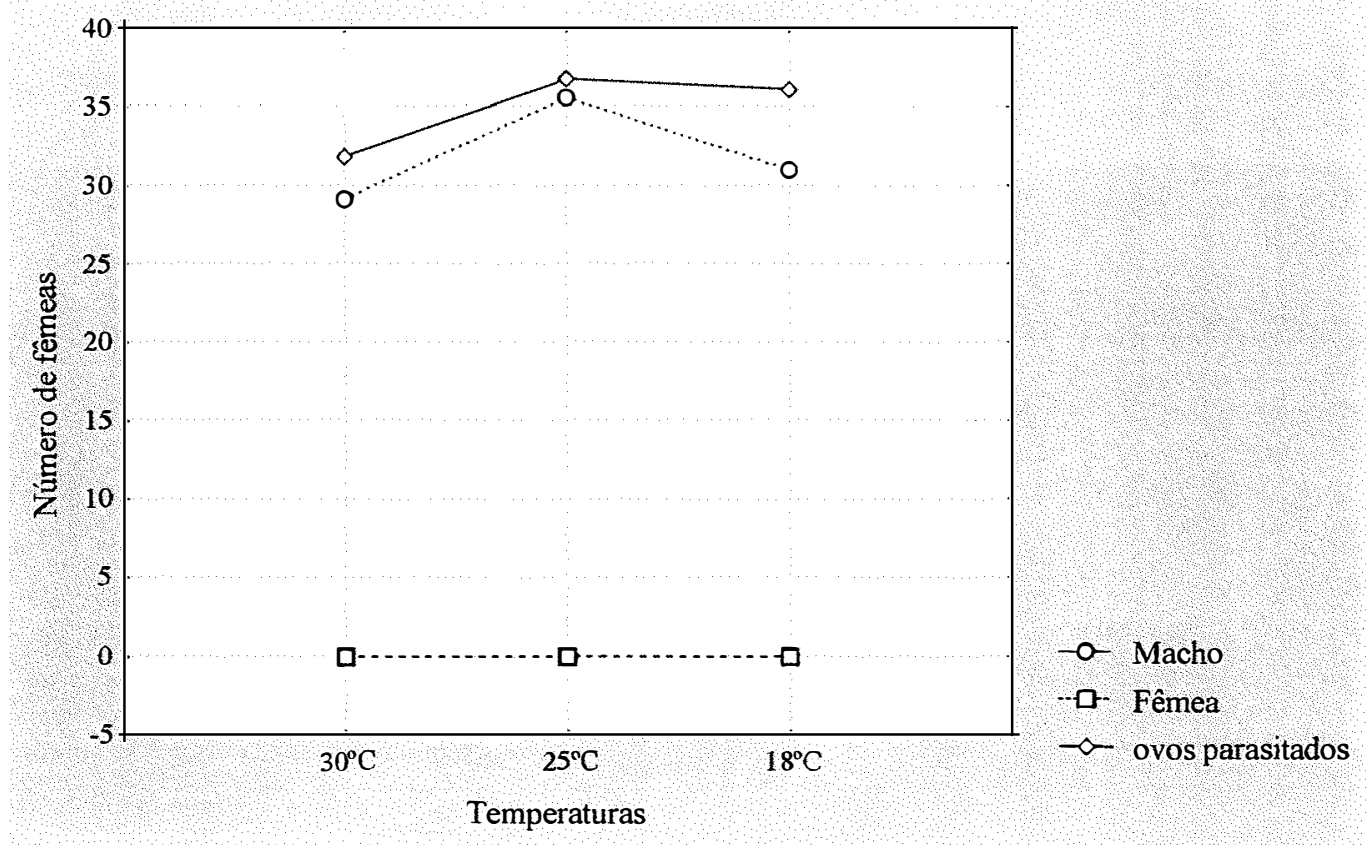

Figura 22 - Descendência de fêmeas virgens de Trichogramma bruni nas temperaturas de 18,25 e $30^{\circ} \mathrm{C}$. 


\section{Distribuição geográfica e hospedeiros}

T. bruni foi registrado apenas na região Neotropical, com distribuição na Bolívia, Brasil, Costa Rica, México, Trinidad \& Tobago e Venezuela (Figura 23). Nessa região, as espécies hospedeiras já conhecidas pertencem às famílias Notondontidae e Noctuidae (Lepidoptera). Portanto, H. erato phyllis (Lep., Nymphalidae), H. feronia (Lep., Nymphalidae), Erosina hyberniata Guenée, 1857 (Lep., Geometridae) e M. lysiminia (Lep., Nymphalidae) estão sendo registrados aqui como novos hospedeiros (Tabela 6).

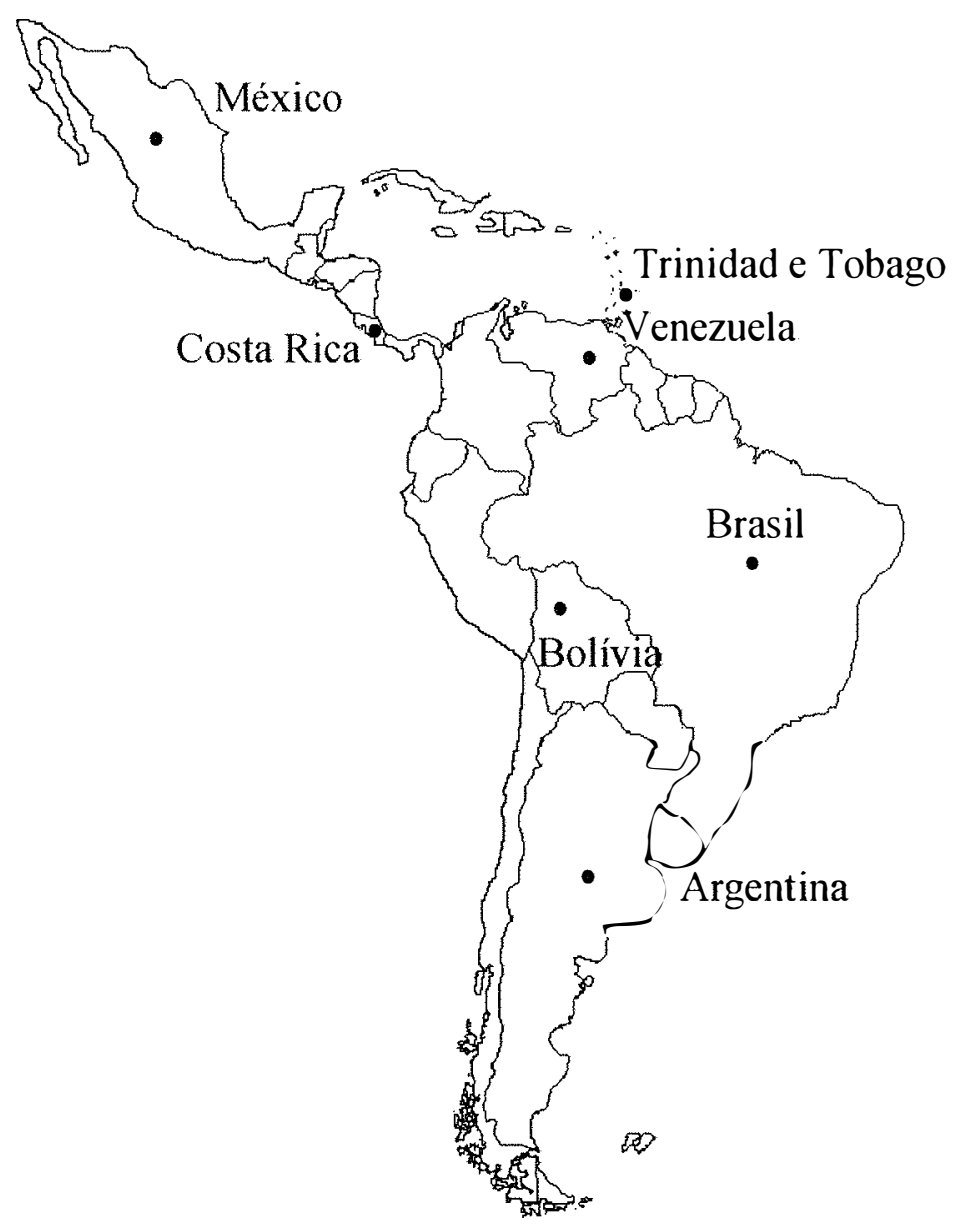

Figura 23 - Distribuição geográfica de Trichogramma bruni na região Neotropical. 
Tabela 6. Novos registros de hospedeiros e distribuição geográfica de Trichogramma bruni no Estado de São Paulo, Brasil.

\begin{tabular}{llll}
\hline \multicolumn{1}{c}{ Insetos hospedeiros } & \multicolumn{1}{c}{ Plantas associadas } & \multicolumn{1}{c}{ Coletores } & \multicolumn{1}{c}{ Locais } \\
\hline \multirow{2}{*}{ Eamadryas feronia } & Eucaliptus sp. (sub-bosque) & R.B. Querino & Itatinga (horto florestal) \\
Erosina hyberniata & Acnistus arborescens & R.B. Querino & Piracicaba (ESALQ) \\
Mechanitis lysimnia & Solanum Agrarium & R.B. Querino & Piracicaba (horto florestal de Tupi) \\
Heliconius eralo phyllis & Passiflora sp. & J.A. Cerignoni & Piracicaba (ESALQ) \\
\hline
\end{tabular}

\section{Comentários}

Os novos registros de T. bruni foram obtidos de ovos de lepidópteros silvestres, sem importância econômica, coletados em sub-bosque e na vegetação da margem de áreas florestais. Os parasitódies coletados de ovos de E. hyberniata foram encontrados na vegetação da margem de uma área florestal (Piracicaba-SP) e os coletados em $H$. erato phyllis e $H$. feronia em uma criação de borboletas em telado (Piracicaba-SP). Considerando-se ainda que em levantamentos realizados em pragas de importância econômica, como S. frugiperda e Helicoverpa zea (Boddie, 18500 (Lep., Noctuidae), em Piracicaba-SP, foram coletados apenas $T$. pretiosum e $T$. atopovirilia e nenhum espécime de T. bruni, há evidencias de uma especificidade de $T$. bruni em relação ao hábitat e aos hospedeiros silvestres. Por exemplo, em levantamento com armadilha de suç̧ão realizado no Horto Florestal de Tupi no período de um ano, T. bruni foi a espécie mais abundante e freqüente nas coletas.

A variabilidade na cápsula genital de $T$. bruni, tanto entre os indivíduos de uma mesma progênie como nos espécimes provenientes de diferentes hospedeiros, são notórias e relacionadas principalmente à lâmina dorsal, reforçando a plasticidade desse caráter, como já havia sido observado por Pinto et al. (1989). Portanto, a lâmina dorsal não deve ser usada como um caráter seguro na identificação dessa espécie. Desta forma, para a identificação de $T$. bruni, a associação de caracteres diagnósticos deve ser utilizada e as variações intra-específicas consideradas. 
As análises multivariadas demonstraram que as diferenças em T. bruni são influenciadas pelo hospedeiro e pelo hábitat. Os espécimes coletados de ovos de $M$. lysimnia apresentaram uma maior diferenciação morfológica do que os espécimes obtidos dos outros hospedeiros. Este fato indica indícios de divergência genética nessas populações simpátricas e provavelmente, a presença de uma espécie incipiente presente no Horto Florestal de Tupi, em Piracicaba, caracterizado por áreas nativas e plantadas com eucalipto.

A análise dos componentes principais e a análise das variáveis canônicas evidenciaram a distinção principalmente de $T$. bruni em relação a $T$. lasallei e T. rojasi. Essas três espécies são separadas por meio de sutis diferenças morfológicas. Assim, com base nessas análises, o comprimento das cerdas da franja da asa anterior, comprimento da extensão posterior da lâmina dorsal e a distância dos processos ventrais para a base do processo intervolselar são importantes na separação dessas espécies. Além disso, a carena ventral, a posição dos processos ventrais, o comprimento da extensão posterior da lâmina dorsal e o comprimento das cerdas da franja da asa anterior são caracteres diagnósticos para $T$. bruni, $T$. lasallei e $T$. rojasi.

Aliado à morfologia, os cruzamentos confirmaram as diferenças entre T. bruni $\mathrm{e}$ T. lasallei, demonstrando o completo isolamento reprodutivo entre essas espécies. Também, estudos moleculares (seqüênciamento da região ITS2) com amostras de $T$. bruni, T. lasallei e T. rojasi confirmaram as diferenças entre essas espécies (Ciociola Jr. et al., 2001).

A variação intra-específica apresentada por $T$. bruni é um fator que deve ser considerado no seu reconhecimento, pois a influência do ambiente (hábitat + hospedeiro) e a própria variação entre indivíduos são responsáveis pela plasticidade observada na cápsula genital. Portanto, com base nas variações morfológicas das estruturas da genitália masculina de T. bruni, tem-se que os espécimes considerados como "nr. bruni" por Pinto (1998) apresentam-se como variantes intra-específicos de $T$. bruni. Nos casos em que ocorre uma acentuada variação morfológica, como nos espécimes brasileiros coletados de ovos de M. lysimnia, há indícios de divergência genética e a presença de uma espécie incipiente. 


\subsubsection{Trichogramma demoraesi Nagaraja, 1983}

(Figura 24)

Trichogramma demoraesi Nagaraja, 1983: 37; Zucchi, 1985: 43; Zucchi et al., 1991: 131; Zucchi \& Monteiro, 1997: 53.

\section{Caracterizacão morfológica}

Antenas: flagelo longo $(0,18 \pm 0,01)$; relação entre o comprimento e a largura do flagelo de $5,26 \pm 0,41$; cerdas flageliformes curtas $(0,06 \pm 0,00)$ com ápice uniformemente afilado; comprimento da maior cerda do flagelo/maior largura do flagelo $(1,78 \pm 0,18)$; comprimento do flagelo/comprimento da tíbia posterior $(0,95 \pm 0,05)$; sensilos basicônicos com fórmula 1-2-2-0(1)-1-1; três sensilos placóideos, o basal com $0,05 \pm 0,00 \mathrm{~mm}$.

Asas anteriores: largura da asa anterior $(0,31 \pm 0,02)$ relação entre a largura e o comprimento da asa $(0,56 \pm 0,02)$; comprimento da maior cerda da franja da asa/comprimento da tíbia posterior $(0,16 \pm 0,02)$; comprimento da maior cerda da franja da asa anterior/largura da asa anterior $(0,10 \pm 0,02)$. Número de cerdas entre a $4^{\underline{a}}$ e $5^{\underline{a}}$ fileiras de 20 a 30 .

Asas posteriores: fileira anterior e posterior com número cerdas variando de 2-4 e 6-9, respectivamente. Fileira posterior não alcançando a metade da fileira mediana.

Escutelo: relação entre as cerdas anteriores e posteriores $(0,17 \pm 0,07)$.

Genitália masculina: cápsula genital mais longa $(0,15 \pm 0,01)$ do que larga $(0,06 \pm 0,0)$; relação entre a largura e o comprimento da cápsula genital $(0,38 \pm 0,02)$; distância apical/comprimento da cápsula genital $(0,21 \pm 0,01)$; largura apical/largura da cápsula genital $(0,56 \pm 0,02)$; lâmina dorsal inserida na metade da cápsula genital, com reentrância na região basal; comprimento da lâmina dorsal/comprimento da cápsula genital $(0,43 \pm 0,02)$; comprimento/largura da lâmina dorsal (1,63 $\pm 0,08)$; comprimento da abertura dorsal/ comprimento da lâmina dorsal $(1,40 \pm 0,08)$; extensão posterior da lâmina dorsal com ápice arredondado no nível do processo intervolselar e não alcançando o ápice das volselas; comprimento da extensão posterior da lâmina dorsal $(0,05 \pm 0,00)$; comprimento da extensão posterior da lâmina dorsal/comprimento da 
lâmina dorsal $(0,74 \pm 0,04)$; carena dorsal ausente; carena ventral moderadamente longa $(0,05 \pm 0,01)$, alcançando a metade da cápsula genital; carena ventral/distância basal $(0,45 \pm 0,04)$; distância basal/comprimento da cápsula genital $(0,79 \pm 0,02)$; processo intervolselar $(0,01 \pm 0,00)$, distinto e com o ápice arredondado; processos ventrais próximos da base do processo intervoselar; comprimento do edeago/comprimento da tíbia posterior $(0,39 \pm 0,02)$; apódemas/edeago $(0,90 \pm 0,07)$.

Os dados quantitativos foram obtidos de 20 machos coletados de ovos de Erinnyis ello (Linnaeus, 1758) (Lepidoptera: Sphingidae)em mandioca, em Piracicaba, São Paulo, Brasil.

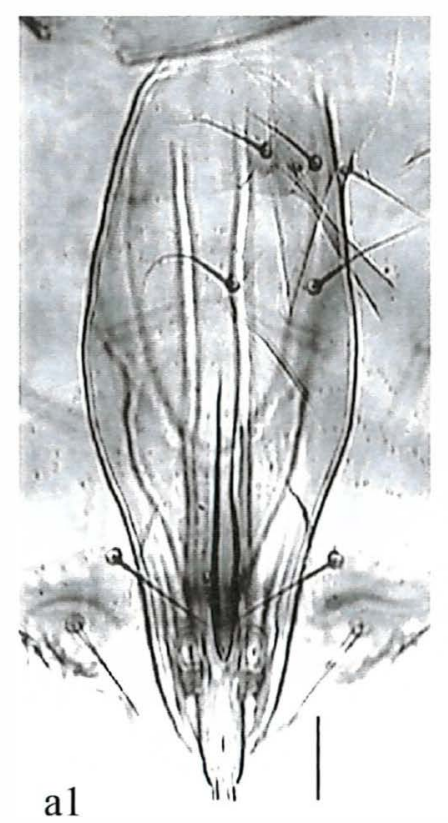

a2
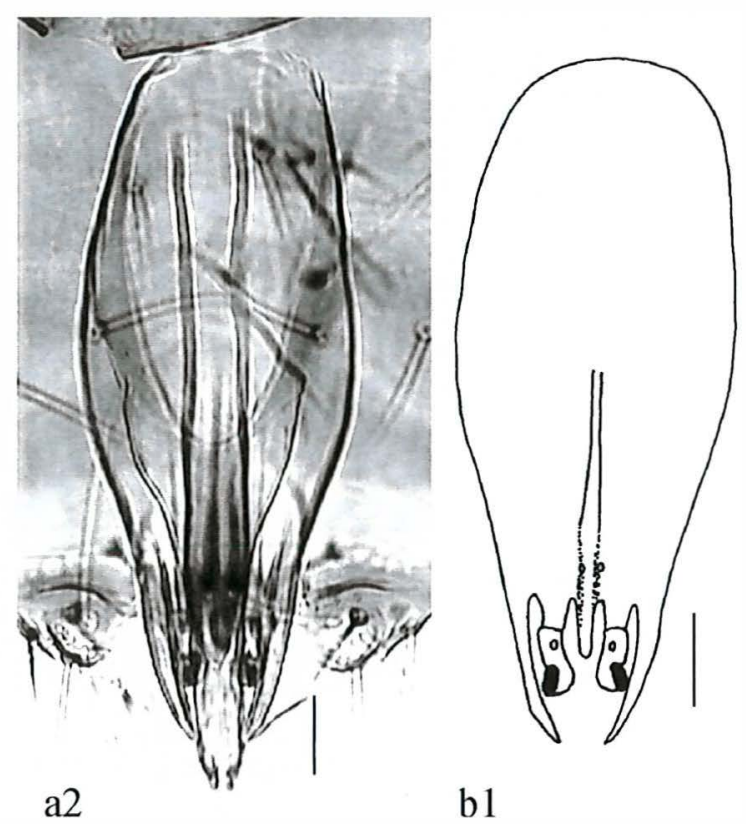

b1

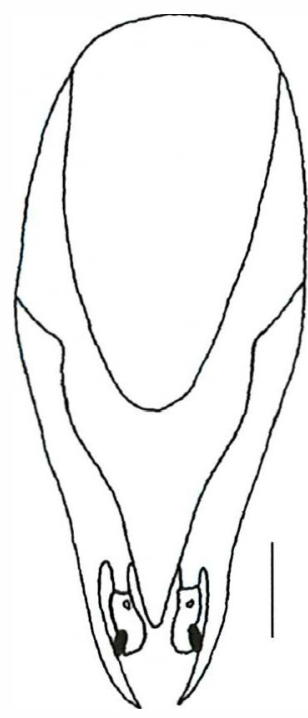

b2

Figura 24 - Cápsula genital de Trichogramma demoraesi $(\mathrm{a}-10 \mu \mathrm{m}$ e b $-20 \mu \mathrm{m}): 1$ ventral e 2 - dorsal.

\section{Material examinado}

BRASIL. SÃO PAULO: Piracicaba, 01-jul.-1999, 20 machos, ex ovos de Erinnyis ello, mandioca, R.B. Querino col. (ESALQ); Atibaia, 7 machos, ex ovos de Erinnyis ello, mandioca, (ESALQ); ESPIRITO SANTO: Itapemirim, 1 macho, ex ovos de Erinnyis ello, 
mandioca, D. Pratissoli col. (ESALQ); MINAS GERAIS: Lavras, 8 machos, ex ovos de Erinnyis ello, mandioca, Geraldo A. Carvalho col. (ESALQ). PERU. 1 macho, ex ovos de Erinniys ello, mandioca, Mary Whu col. (ESALQ).

\section{$\underline{\text { Diagnose }}$}

Os caracteres para o reconhecimento de $T$. demoraesi são as cerdas flageliformes da antena curtas com ápice uniformemente afilado e o processo intervolselar distinto, alongado e com ápice arredondado.

\section{$\underline{\text { Variacões }}$}

Nas antenas, a principal variação observada foi na fórmula dos sensilos basicônicos; quatro espécimes coletados em Piracicaba-SP apresentaram 1 sensilo na posição 4. A presença deste sensilo também foi observada nos espécimes de Atibaia-SP e do Peru. Nas asas anteriores, os espécimes de Piracicaba-SP (20-30) possuem um maior número de cerdas do que os de Lavras-MG (11-23). Na genitália, o processo intervolselar variou de arredondado a levemente pontiagudo; os processos ventrais variaram na sua posição em relação à base do processo intervolselar, próximos ou quase unidos à base do processo intervolselar.

\section{Análises multivariadas}

A análise dos componentes principais mostrou a formação de dois grupos, os espécimes coletados de Lavras-MG em relação aos de Piracicaba-SP (Figura 25). O primeiro componente explicou $99,9 \%$ da variação total presente na matriz da covariância. As variáveis comprimento das cerdas da franja das asas anteriores (CCFAA) e comprimento do flagelo (CF) apresentaram os maiores valores absolutos, 0,517 e 0,441, respectivamente. Essas variáveis separaram os espécimes de Lavras-MG e PiracicabaSP, ao longo do primeiro eixo canônico. O segundo componente apresenta pouco importância, explicou $0,001 \%$, representado pelo comprimento das cerdas da franja da asas anteriores (CCFAA) e comprimento do flagelo (CF), que apresentaram os maiores valores absolutos, 0,681 e 0,637 , respectivamente. 


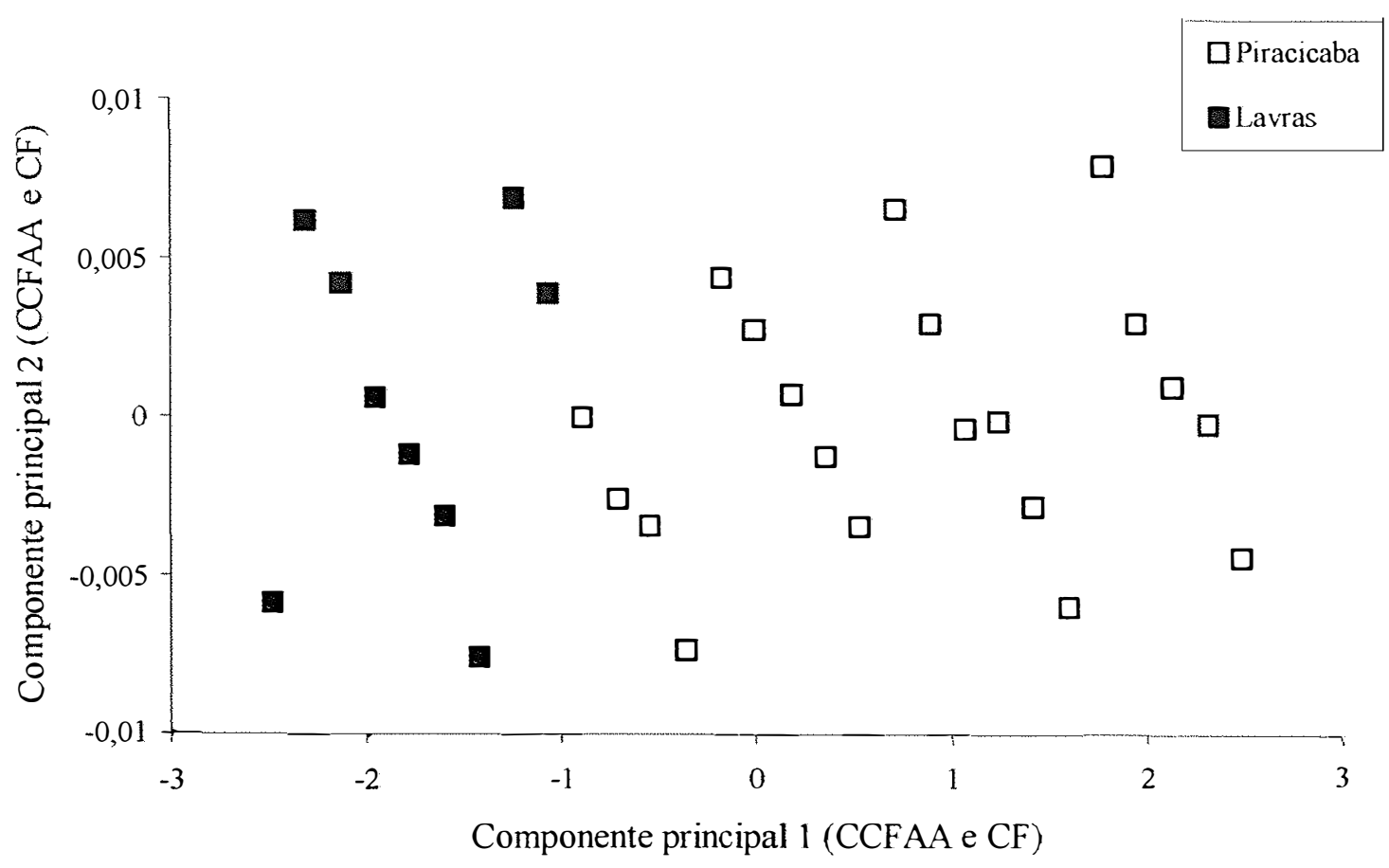

Figura 25 - Ordenação de Trichogramma demoraesi dois primeiros componentes.

A análise das variáveis canônicas (Figura 26) mostrou ordenação semelhante à obtida pela análise dos componentes principais. Os testes multivariados Wilks'Lambda $(\mathrm{P}<0,0073)$, Pillai's Trace $(\mathrm{P}<0,0073)$, Hotelling-Lawley Trace $(\mathrm{P}<0,0073)$ e Roy's Greatest Root $(\mathrm{P}<0,0073)$ mostraram que os eixos canônicos foram estatisticamente significativos, extraídos da matriz resultante do produto da matriz de covariância entre os grupos pela matriz de covariância dentro dos grupos. A primeira variável canônica já explicou $100 \%$ da variação total.

No primeiro eixo canônico, as variáveis de maior importância foram comprimento da abertura dorsal (CAD), distância basal (DB) e comprimento da cápsula genital (CCG), que apresentaram os maiores valores absolutos, 0,927, 0,879 e 0,808, respectivamente. Essas variáveis contribuíram para separar os espécimes provenientes de Lavras-MG e de Piracicaba-SP. O segundo eixo canônico não foi importante, representado pelo cápsula genital (CCG), com o maior valor absoluto de 0,178 . Essa variável não separou $T$. demoraesi desses dois locais. 


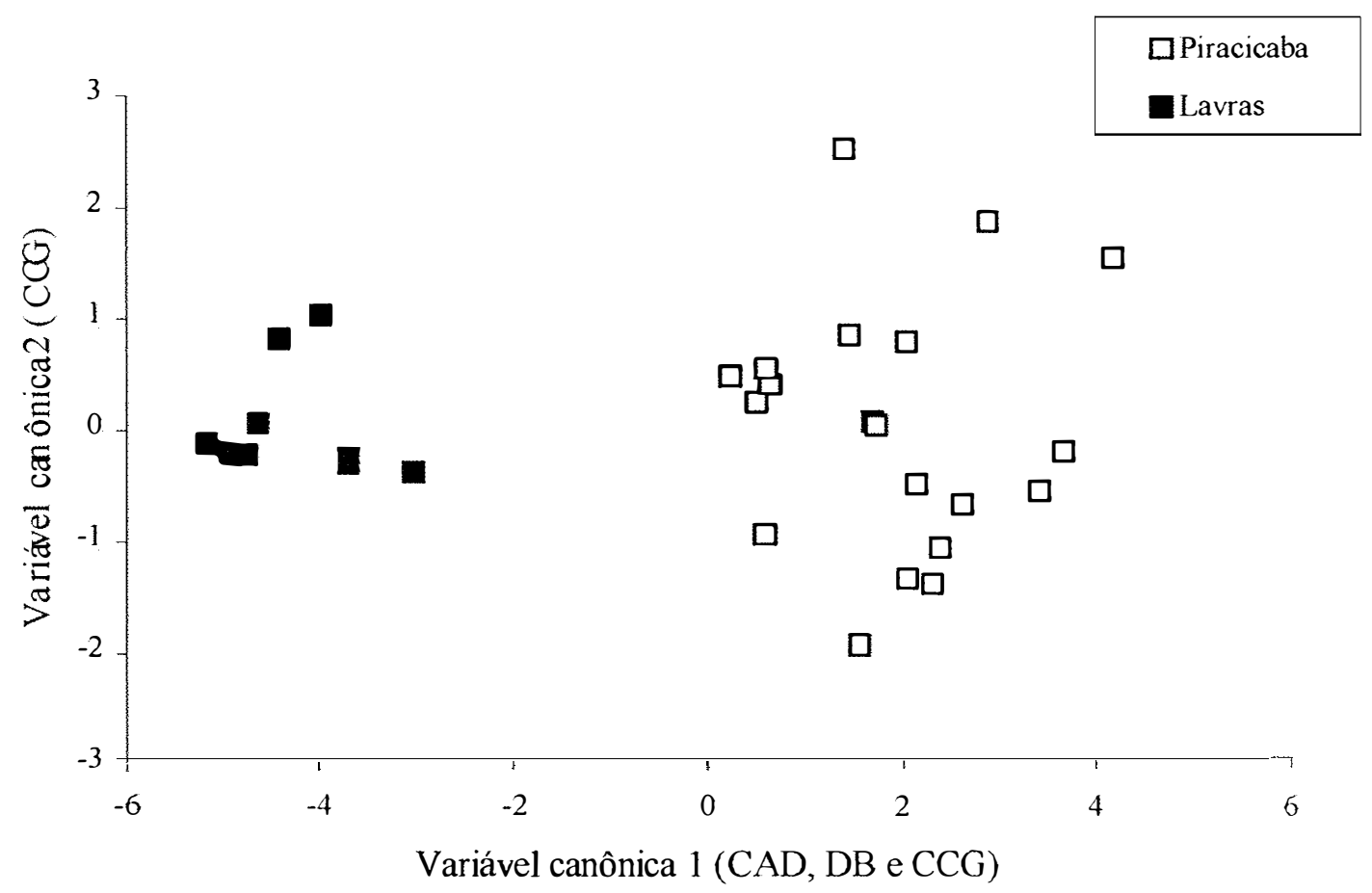

Figura 26 - Ordenação de Trichogramma demoraesi nos dois primeiros eixos canônicos.

\section{Distribuição geográfica e hospedeiros}

T. demoraesi foi coletado pela primeira vez em ovos de Glena bipennaria Guenée, 1857 (Lepidoptera: Geometridae), em Eucalyptus grandis, em Minas Gerais, Brasil, por G.W.G. de Moraes, P. Brun \& L.A. Soares.

Essa espécie é freqüentemente associada a E. ello, em mandioca, no Brasil, tendo sido registrada nos Estados do Espírito Santo, Minas Gerais e São Paulo. No Peru, foi recentemente coletada de ovos de E. ello, em 1999, por M. Whu P. (inf. pes.). Os registros de hospedeiros dessa espécie na América do Sul foram relacionados por Zucchi \& Monteiro (1997). 


\subsubsection{Trichogramma dissimilis Zucchi, 1988}

(Figura 27)

Trichogramma dissimilis Zucchi, 1988: 133; Zucchi, 1995: 30; Zucchi et al., 1991: 131; Zucchi \& Monteiro, 1997: 53.

\section{Caracterização morfológica}

Antenas: flagelo relativamente longo $(0,14 \pm 0,01)$; relação entre o comprimento e a largura do flagelo de $4,27 \pm 0,33$; cerdas flageliformes curtas $(0,06 \pm 0,01)$, com o ápice abruptamente afilado; comprimento da maior cerda do flagelo/maior largura do flagelo $(1,94 \pm 0,14)$; comprimento do flagelo/comprimento da tíbia posterior $(0,95 \pm 0,06)$; número reduzido de sensilos basicônicos, fórmula 1-1-1-0-1-1; três sensilos placóideos, o basal medindo $0,04 \pm 0,00 \mathrm{~mm}$.

Asas anteriores: largura da asa anterior $(0,23 \pm 0,02)$; relação entre a largura e o comprimento da asa $(0,52 \pm 0,02)$; comprimento da maior cerda da franja da asa/comprimento da tíbia posterior $(0,24 \pm 0,08)$; comprimento da maior cerda da franja da asa/largura da asa $(0,15 \pm 0,05)$. Número reduzido de cerdas entre a $4^{\underline{a}}$ e $5^{\underline{a}}$ fileiras de 7 a 12 cerdas.

Asas posteriores: fileira anterior e posterior com número cerdas variando de 0-2 e 3-6, respectivamente.

Escutelo: relação entre as cerdas anteriores e posteriores $(0,17 \pm 0,01)$.

Genitália masculina: cápsula genital pequena $(0,12 \pm 0,00)$; relação entre a largura e o comprimento da cápsula genital $(0,53 \pm 0,02)$; distância apical/comprimento da cápsula genital $(0,24 \pm 0,01)$; largura apical/largura da cápsula genital $(0,58 \pm 0,02)$; lâmina dorsal inserida na metade da cápsula genital, com reentrância na região basal; comprimento da lâmina dorsal/comprimento da cápsula genital $(0,35 \pm 0,02)$; carena dorsal ausente; comprimento/largura da lâmina dorsal (1,08 $\pm 0,08)$; comprimento da extensão posterior da lâmina dorsal $(0,04 \pm 0,00)$; comprimento da abertura dorsal/comprimento da lâmina dorsal $(1,56 \pm 0,16)$; extensão posterior da lâmina dorsal com a base larga e o ápice estreito, afilado posteriormente, no nível do processo intervolselar; comprimento da extensão posterior da lâmina dorsal/comprimento da lâmina 
dorsal $(0,87 \pm 0,09)$; carena ventral ultrapassando a metade da cápsula genital $(0,03 \pm 0,00)$; carena ventral/distância basal $(0,37 \pm 0,03)$; distância basal/comprimento da cápsula genital $(0,75 \pm 0,01)$; processo intervolselar robusto, com o ápice no nível das volselas; processos ventrais próximos da base do processo intervoselar $(0,01 \pm 0,00)$; comprimento do edeago/comprimento da tíbia posterior $(0,41 \pm 0,02)$; apódemas/edeago $(0,96 \pm 0,07)$.

Os dados quantitativos foram obtidos de cinco machos coletados de ovos de Diatraea saccharalis (Fabricius) (Lepidoptera: Crambidae) em cana-de-açúcar, em Valparaíso, São Paulo, Brasil.
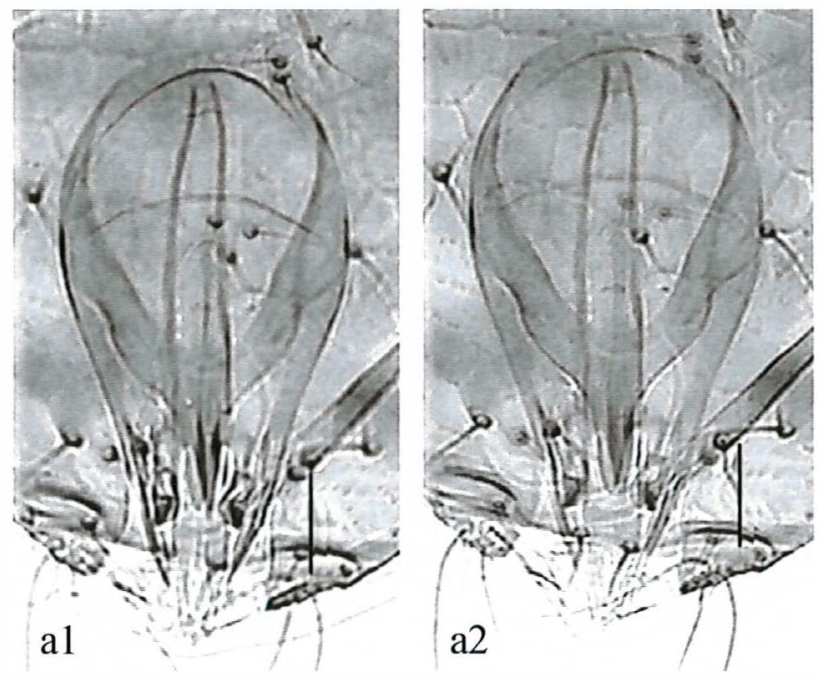

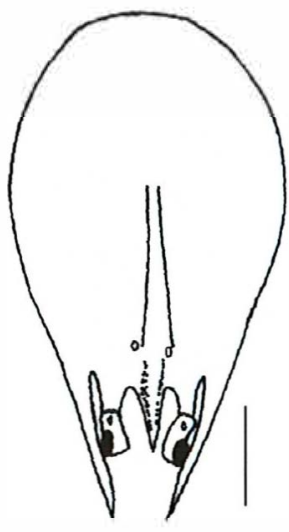

b1

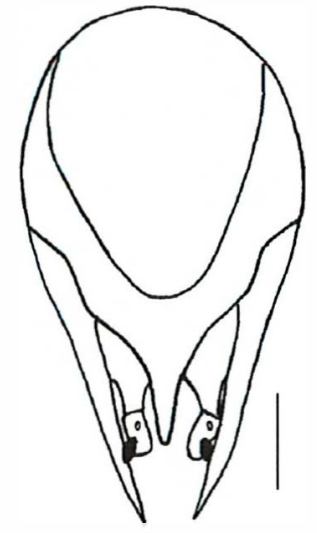

b2

Figura 27 - Cápsula genital de Trichogramma dissimilis $(\mathrm{a}-10 \mu \mathrm{m}$ e b - 20 $\mu \mathrm{m}): 1$ ventral e 2 - dorsal.

\section{Material examinado}

BOLÍVIA. SANTA CRUZ: 23-mai.-1985, 1 macho, ex ovos de Diatraea saccharalis, em cana-de-açúcar, E. Coloque col. (ESALQ). BRASIL. SÃO PAULO: Araras, Holótipo, 11-nov.-1982, ex ovos de Diatraea saccharalis, em cana-de-açúcar, J.R. de Araújo col. (ESALQ); Macatuba, 25-set.-1986, 6 machos, ex ovos de Diatraea saccharalis, em cana-de-açúcar (ESALQ); Pirassununga, 1-set.-1986, 4 machos, ex ovos de Diatraea saccharalis, em cana-de-açúcar (ESALQ); Pradópolis, 1-mar.-1983, 4 
machos, ex ovos de Diatraea saccharalis, em cana-de-açúcar (ESALQ); Valparaíso, 19set.-1996, 5 machos, ex ovos de Diatraea saccharalis, em cana-de-açúcar, J.R. Barros col. (ESALQ); MATO GROSSO DO SUL: Rio Brilhante, 21-jan.-1988, 3 machos, ex ovos de Diatraea saccharalis, em cana-de-açúcar (ESALQ).

\section{$\underline{\text { Diagnose }}$}

T. dissimilis é distinguido pela cápsula genital pequena e larga; processo intervolselar robusto e lâmina dorsal curta, com a extensão posterior afilada e estreita. Antenas, com cerdas flageliforme curtas com o ápice abruptamente afilado e número reduzido de sensilos basicônico, com fórmula 1-1-1-0-1-1. Essas características, separam essa espécie das outras associadas a $D$. saccharalis, tais como $T$. distinctum, $T$. galloi e T.jalmirezi, (Zucchi, 1985).

\section{$\underline{\text { Variacões }}$}

Foram observadas variações no tamanho das estruturas, principalmente no comprimento do flagelo, no comprimento da cápsula genital, na distância basal, no comprimento da abertura dorsal, no comprimento da tíbia posterior e no comprimento do escapo da antena, entre os espécimes examinados. Entre esses espécimes, a fileira posterior da asa posterior variou também quanto ao comprimento, com 7 a 12 cerdas, alcançando ou ultrapassando a metade da fileira mediana.

Os espécimes provenientes do Brasil e da Bolívia foram menores do que o holótipo para vários caracteres morfológicos, como por exemplo para o flagelo, indicando as variações intra-específica em $T$. dissimilis (Figura 28).

\section{Distribuição geográfica e hospedeiros}

$T$. dissimilis foi primeiramente coletado de ovos de D. saccharalis, em cana-deaçúcar, em Araras no Estado de São Paulo, Brasil. Na América do Sul, foi registrado na Bolívia e no Brasil. No Brasil, encontra-se distribuído no Estado de São Paulo (Araras, Macatuba, Pirassununga, Pradrópolis e Valparaíso) e no Mato Grosso do Sul (Rio 
Brilhante), parasitando ovos de D. saccharalis em cana-de-açúcar. Na Bolívia (Santa Cruz) foi encontrado também em ovos de $D$. saccharalis em cana-de-açúcar.

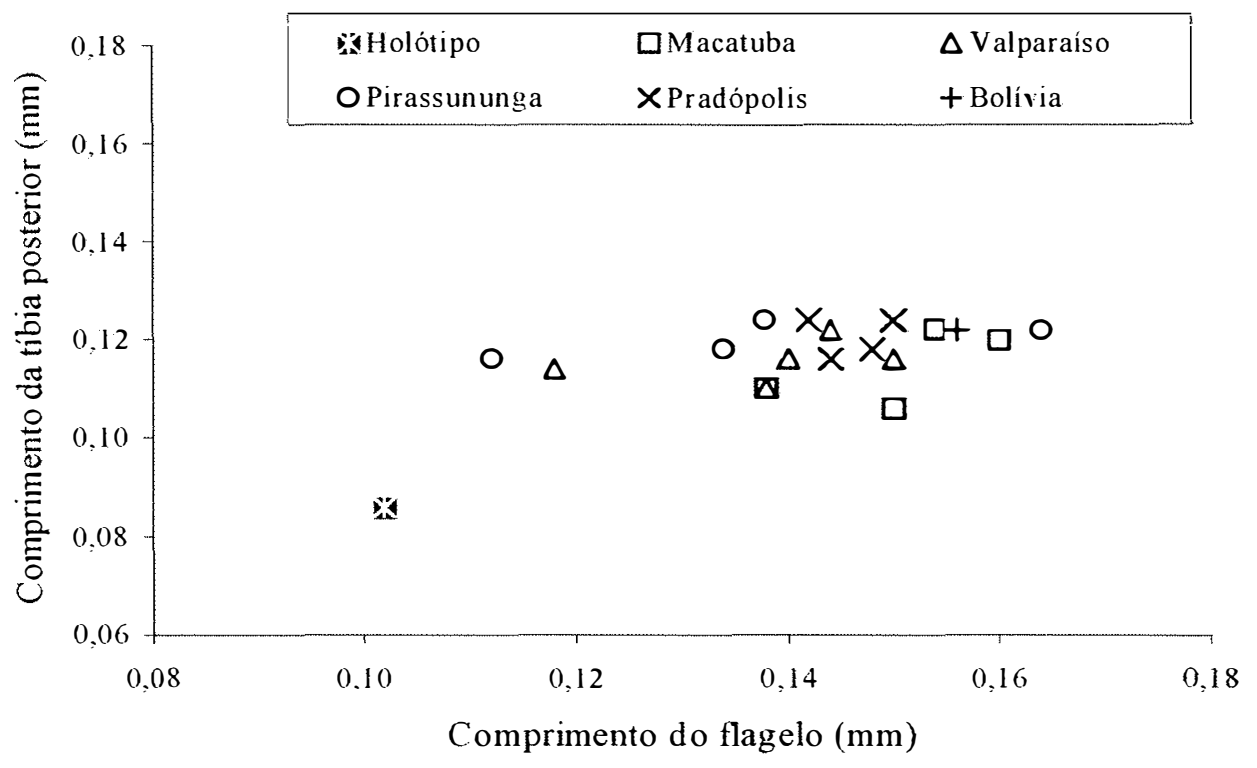

Figura 28 - Comprimento do flagelo versus comprimento da tíbia posterior em espécimes de Trichogramma dissimilis.

\subsubsection{Trichogramma distinctum Zucchi, 1988}

(Figura 29)

Trichogramma distinctum Zucchi, 1988: 135; Zucchi, 1995: 32; Zucchi et al., 1991: 81; Zucchi \& Monteiro, 1997: 54.

\section{Caracterizacão morfológica}

Antenas: flagelo longo $(0,15 \pm 0,02)$; relação entre o comprimento e a largura do flagelo de 4,57 $\pm 0,55$; cerdas flageliforme moderadamente curtas $(0,06 \pm 0,01)$, com o ápice abruptamente afilado; comprimento da maior cerda do flagelo/maior largura do flagelo $(1,94 \pm 0,21)$; comprimento do flagelo/comprimento da tíbia posterior $(0,97 \pm 0,07)$; 
número reduzido de sensilos basicônicos, fórmula 1-1-1-0(1)-1-1; três sensilos placóideos, o basal medindo $0,05 \pm 0,00 \mathrm{~mm}$.

Asas anteriores: largura da asa anterior $(0,24 \pm 0,02)$; relação entre a largura e o comprimento da asa $(0,51 \pm 0,02)$; comprimento da maior cerda da asa anterior $(0,03 \pm$ 0,004); comprimento da maior cerda da franja da asa/comprimento da tíbia posterior $(0,22 \pm 0,06)$; comprimento da maior cerda da franja da asa anterior/largura da asa anterior $(0,14 \pm 0,04)$. Número de cerdas entre a $4^{\mathrm{a}}$ e $5^{\mathrm{a}}$ fileiras foi de 8 a 18 .

Asas posteriores: fileira anterior e posterior com número de cerdas variando de 1-2 e 710 , respectivamente; fileira posterior ultrapassando a metade do comprimento da fileira mediana.

Escutelo: relação entre as cerdas anteriores e posteriores $(0,26 \pm 0,09)$.

Genitália masculina: cápsula genital mais longa $(0,12 \pm 0,01)$ do que larga $(0,05 \pm$ $0,00)$; relação entre a largura e o comprimento da cápsula genital $(0,46 \pm 0,03)$; distância apical/comprimento da cápsula genital $(0,27 \pm 0,01)$; largura apical/largura da cápsula genital $(0,62 \pm 0,03)$; lâmina dorsal com reentrância basal; comprimento da lâmina dorsal/comprimento da cápsula genital $(0,36 \pm 0,02)$; comprimento/largura da lâmina dorsal $(1,27 \pm 0,14)$; comprimento da abertura dorsal/comprimento da lâmina dorsal $(1,62 \pm 0,14)$; extensão posterior da lâmina dorsal estreitando-se em direção ao ápice e ultrapassando as volselas $(0,04 \pm 0,00)$; comprimento da extensão posterior da lâmina dorsal/comprimento da lâmina dorsal $(0,83 \pm 0,07)$; carena ventral alcançando metade da cápsula genital $(0,03 \pm 0,002)$, com engrossamento na base do processo intervolselar; carena ventral/distância basal $(0,32 \pm 0,22)$; distância basal/comprimento da cápsula genital $(0,72 \pm$ $0,02)$; processos ventrais próximos da base do processo intervoselar; processo intervolselar distinto $(0,01 \pm 0,001)$ e não alcançando o ápice das volselas; comprimento do edeago/comprimento da tíbia posterior $(0,42 \pm 0,03)$; apódemas/edeago $(0,87 \pm 0,08)$.

Os dados quantitativos foram obtidos de 10 machos coletados de ovos de $D$. saccharalis, em cana-de-açúcar, em Pernambuco, Brasil. 


\section{$\underline{\text { Material examinado }}$}

BRASIL. Pernambuco: Carpina, Holótipo, macho, ex ovos de Diatraea saccharalis, criação laboratório de Trichogramma (ESALQ); Parátipos, 10 machos, mesmos dados do holótipo (ESALQ).
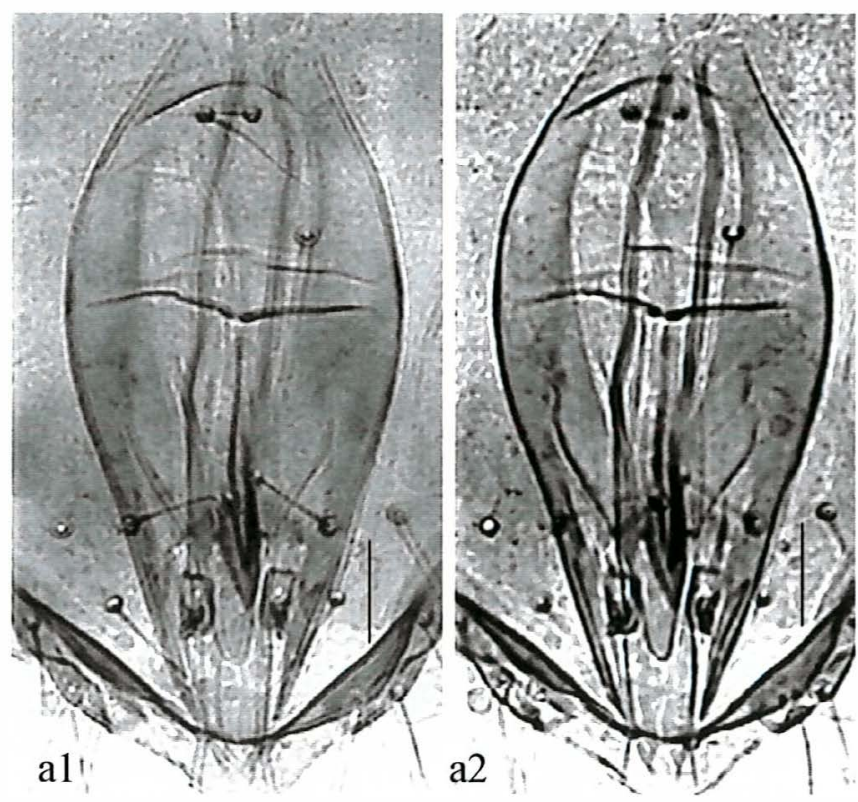

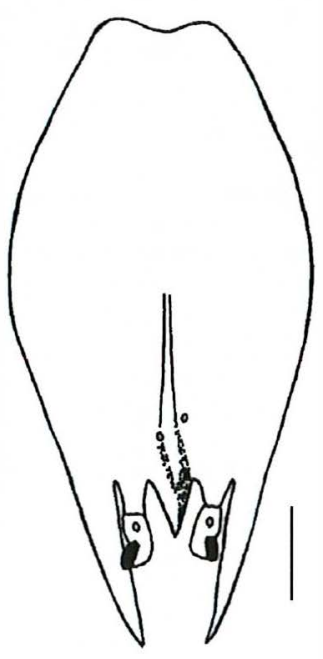

b1

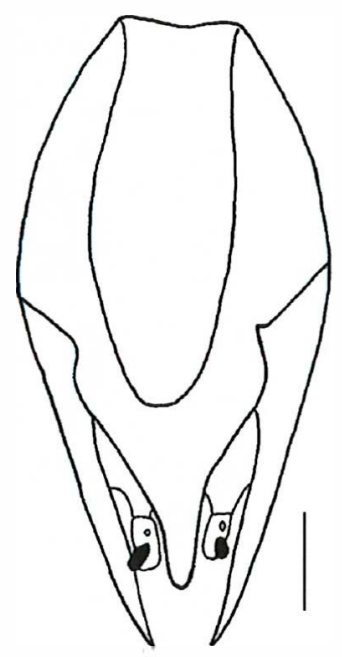

b2

Figura 29 - Cápsula genital de Trichogramma distinctum (a -10 $\mu \mathrm{m}$ e b - $20 \mu \mathrm{m}): 1$ ventral e 2 - dorsal.

\section{Diagnose}

Dentre as espécies associadas a $D$. saccharalis, $T$. distinctum pode ser confundido com T. galloi e T. jalmirezi. T. distinctum diferencia-se de T. galloi, principalmente pelo processo intervolselar distinto e não alcançando o ápice das volselas. Enquanto, distingue-se de $T$. jalmirezi, por apresentar a lâmina dorsal com a reentrância basal mais suave .

\section{$\underline{\text { Variacões }}$}

Foi observada variação nos sensilos basicônicos, onde um espécime apresentou dois sensilos na posição 3 e outro espécime, nenhum sensilo na posição 2. Observou-se 
que quando o espécime é de tamanho reduzido, ocorre também uma redução no número de sensilos e das cerdas presente na asa anterior.

Análise Multivariada

A análise dos componentes principais demonstrou não haver uma nítida formação de grupos. Portanto, as diferenças são mínimas entre T. distinctum e T. galloi (espécie relacionada) (Figura 30). O primeiro componente explicou cerca de $47 \%$ da variação total, o segundo $23 \%$ e o terceiro $11 \%$, portanto, os dois primeiros componentes explicaram $70 \%$ da variação total presente na matriz da covariância.

No primeiro componente, a variável distância dos processos ventrais à base do processo intervolselar (DVP) foi a que apresentou o coeficiente com o maior valor absoluto $(0,966)$, não separando $T$. distinctum de $T$. galloi. O segundo componente foi mais influenciado pelo comprimento das cerdas da franja da asa anterior (CCFAA) e comprimento da extensão posterior da lâmina dorsal (CEPLD), que apresentou os maiores valores absolutos, 0,491 e 0,456 , respectivamente.

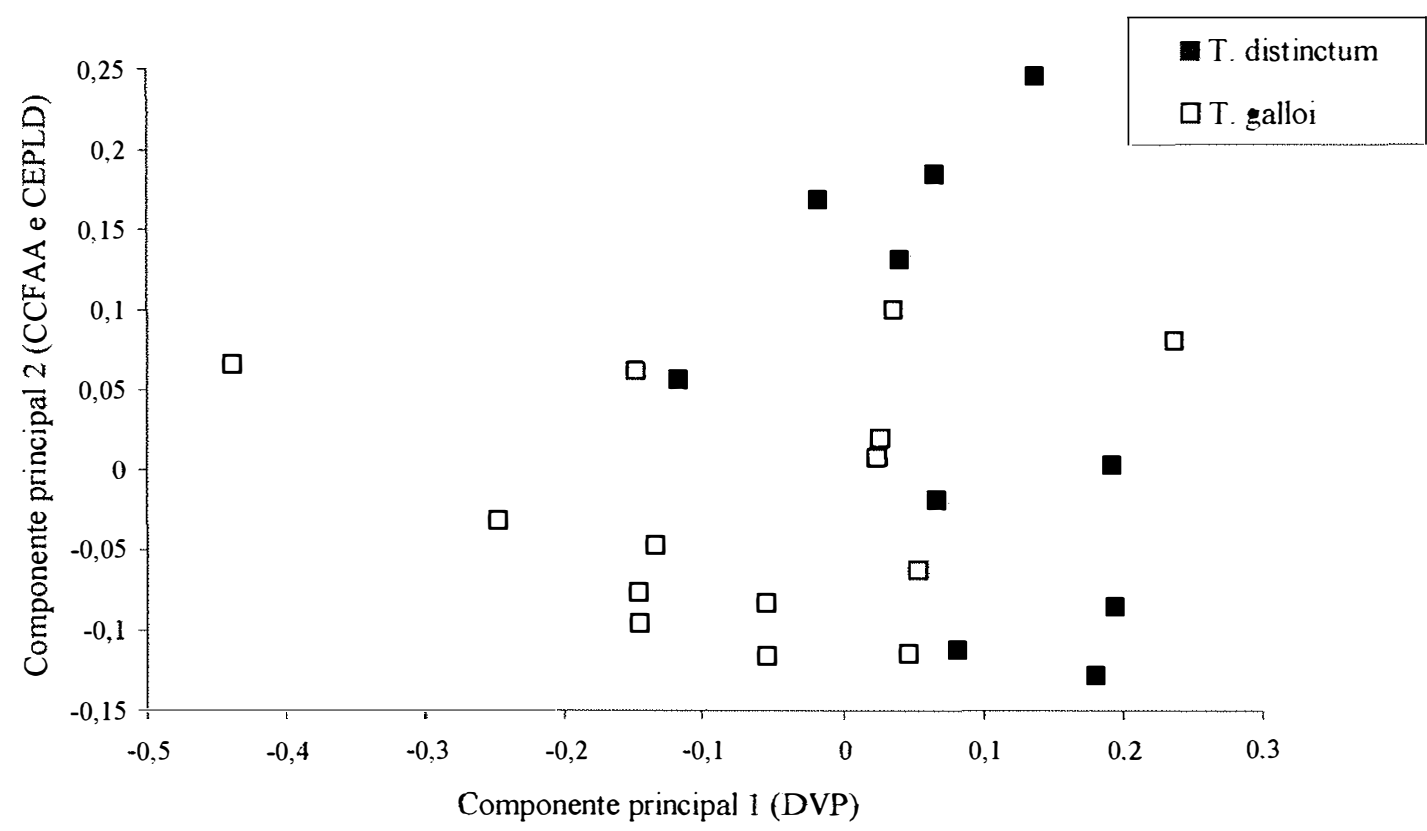

Figura 30 - Ordenação de Trichogramma distinctum e Trichogramma galloi nos dois primeiros componentes. 
$\mathrm{Na}$ análise das variáveis canônicas, os testes multivariados Wilks'Lambda $(\mathrm{P}<0,0236)$, Pillai's Trace $(\mathrm{P}<0,0236)$, Hotelling-Lawley Trace $(\mathrm{P}<0,00236)$ e Roy's Greatest Root $(\mathrm{P}<0,0236)$ mostraram que os eixos canônicos foram estatisticamente significativos, extraídos da matriz resultante do produto da matriz de covariância entre os grupos pela matriz de covariância dentro dos grupos. A primeira variável canônica explicou $100 \%$ da variação total.

No primeiro eixo canônico, as variáveis de maior contribuição foram comprimento da abertura dorsal (CAD) e comprimento da extensão posterior da lâmina dorsal (CEPLD), que apresentaram os maiores valores absolutos, 0,787 e 0,767, respectivamente (Figura 31) e mostram a ordenação de $T$. galloi e $T$. distinctum ao longo desse eixo. O segundo eixo canônico não foi importante, representado pelas variáveis largura da lâmina dorsal (LLD) e largura apical (LA) .

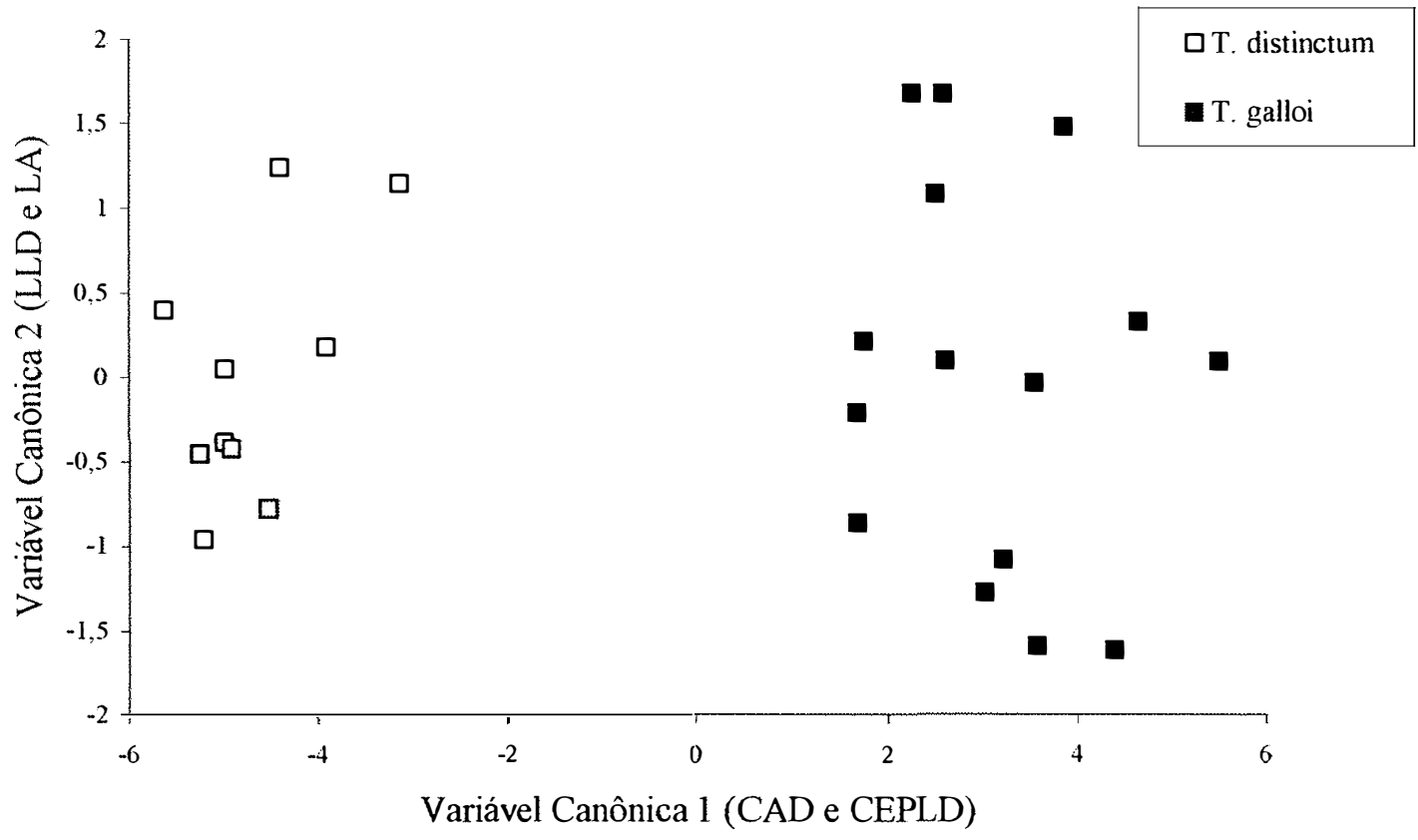

Figura 31 - Ordenação de Trichogramma distinctum e Trichogramma galloi nos dois primeiros eixos canônicos. 
Os resultados das análises demonstram que $T$. distinctum é bastante semelhante a T. galloi e que as variações intra-específicas, dificultam a separação morfológica entre essas duas espécies. A extensão posterior da lâmina dorsal é um caráter importante para separar de $T$. distinctum de $T$. galloi, como também a distância dos processos ventrais a base do processo intervolselar.

\section{Distribuição geográfica e hospedeiros}

T. distinctum foi pela primeira vez coletado de ovos de D. saccharalis, em canade-açúcar, no Estado de Pernambuco, Brasil. Na América do Sul, ocorre somente no Brasil e no Uruguai.

\section{Comentários}

Estudos biológicos demonstraram requerimentos térmicos diferenciados entre $T$. distinctum e T. galloi (Parra et al., 1991). Todavia, T. distinctum é morfologicamente muito semelhante a $T$. galloi e o caráter usado para separá-los em muitas espécies é plástico. Por isso, há necessidade de mais levantamentos para se coletar novamente essa espécie, permitindo o estudo das variações intra-específicas, a realização de cruzamentos e análises moleculares.

\subsubsection{Trichogramma exiguum Pinto \& Platner, 1983}

(Figura 32)

Trichogramma exiguum Pinto \& Platner, 1983: 591; Pinto et al., 1978: 177; Zucchi \& Monteiro, 1997: 54; Pinto, 1998: 137; Whu \& Valdivieso,1999: 61; Basso et al., 1999: 374

Trichogramma perkinsi Girault: Nagarkatti \& Nagaraja, 1971:23, 1977: 160-169; Nagaraja \& Nagarkatti, 1973: 289; Ruiz \& Korytkoswski, 1979:10. 


\section{Caracterização morfológica}

Antenas: flagelo longo $(0,17 \pm 0,01)$; relação entre o comprimento e a largura do flagelo de $6,10 \pm 0,61$; cerdas flageliformes curtas $(0,05 \pm 0,01)$, com o ápice abruptamente afilado; comprimento da maior cerda do flagelo/maior largura do flagelo (1,95 $\pm 0,22)$; comprimento do flagelo/comprimento da tíbia posterior $(1,17 \pm 0,04)$; sensilos basicônicos proeminentes, subgloboso, fórmula 1-2-2-1-1-1; três sensilos placóideos, o basal medindo $0,05 \pm 0,00 \mathrm{~mm}$.

Asas anteriores: largura das asas anteriores $(0,24 \pm 0,017)$; relação entre a largura e 0 comprimento da asa $(0,55 \pm 0,02)$; comprimento da maior cerda da franja da asa $(0,02 \pm$ $0,002)$, cerca de 0,17 o comprimento da tíbia posterior e 0,10 a largura da asa anterior. Número de cerdas entre a $4^{\mathrm{a}}$ e $5^{\mathrm{a}}$ fileiras de 5 a 17.

Asas posteriores: fileira anterior e posterior com número cerdas variando de 1 a 2 e 3 a 5 , respectivamente; fileira posterior ultrapassa a metade da fileira mediana.

Escutelo: relação entre as cerdas anteriores e posteriores $(0,15 \pm 0,03)$.

Genitália masculina: cápsula genital mais longa $(0,12 \pm 0,007)$ do que larga $(0,05 \pm 0,004)$; relação entre a largura e o comprimento da cápsula genital $(0,42 \pm 0,02)$; distância apical/ comprimento da cápsula genital $(0,21 \pm 0,01)$; largura apical/largura da cápsula genital $(0,58 \pm$ 0,04); lâmina dorsal origina-se no meio da cápsula genital, com leve reentrância na região basal, os lados estreitam-se em direção ao ápice; comprimento da lâmina dorsal/comprimento da cápsula genital $(0,42 \pm 0,02)$; comprimento/largura da lâmina dorsal $(1,23 \pm 0,11)$; comprimento da abertura dorsal/comprimento da lâmina dorsal $(1,31 \pm 0,09)$; comprimento da extensão posterior da lâmina dorsal $(0,04 \pm 0,003)$, com a base mais larga que o ápice, sendo este pontiagudo e no mesmo nível do processo intervolselar, geralmente com a forma de um triângulo; comprimento da extensão posterior da lâmina dorsal/comprimento da lâmina dorsal $(0,73 \pm 0,05)$; carena dorsal ausente; carena ventral longa $(0,05 \pm 0,005)$, além da metade da cápsula genital; carena ventral/distância basal $(0,54 \pm 0,04)$; distância basal/comprimento da cápsula genital $(0,77 \pm 0,01)$; processo intervolselar longo $(0,01 \pm 0,001)$, com o ápice pontiagudo ou truncado, não alcançando o nível das volselas; processos ventrais próximos ou unidos a base do processo intervoselar; comprimento do edeago/comprimento da tíbia posterior $(0,47 \pm 0,03)$; apódemas/edeago $(0,85 \pm 0,08)$. 
Os dados quantitativos foram obtidos de 20 machos coletados na Colômbia.

\section{Material examinado}

COLÔMBIA. 09-jul.-1999, 20 machos, multiplicado em Sitotroga cerealella, (ESALQ); 20-jul.-1987, 1 macho, ex ovos de Erinnyis ello, mandioca (ESALQ); PERU. vários hospedeiros (Argyrotaenia sphaleropa em citros e algodoeiro, Diatraea saccharalis em cana-de-açúcar, Heliothis zea em milho, Dione juno em maracujazeiro, Palpita persimilis em olivieira e Heliothis virescens em algodoeiro), 14 machos, M. Whu P. col. (ESALQ). URUGUAI. Montevidéu, 27-jun.-1995, 15 machos, ex ovos de Argyrotaenia sphaleropa, videira, C. Basso col. (ESALQ).

\section{Diagnose}

T. exiguum é distinguido pelas cerdas flageliformes curtas e robustas, abruptamente afiladas; sensilos basicônicos proeminentes e a presença de um sensilo na posição 4 . $\mathrm{Na}$ cápsula genital, a carena ventral é longa e o processo intervolselar é pontiagudo ou truncado no ápice, como em T. marthae Goodpasture, 1986 (espécie norte-americana) e não alcança o nível das volselas. Essa característica do processo intervolselar, vista no microscópio óptico, apresenta-se pontiagudo e, em alguns casos, levemente arredondado.

Dentre as espécies sul-americanas, $T$. exiguum pode ser confundido com $T$. fuentesi Torre, 1980 e T. mimutum Riley, 1871. Neste, as cerdas do flagelo são longas e afiladas e em T. exiguum, são curtas com ápice abruptamente afilado. Em T. fuentesi, a fileira posterior de cerdas da asa posterior alcança o ápice e a carena ventral não é tão longa, diferentemente de $T$. exiguum. 

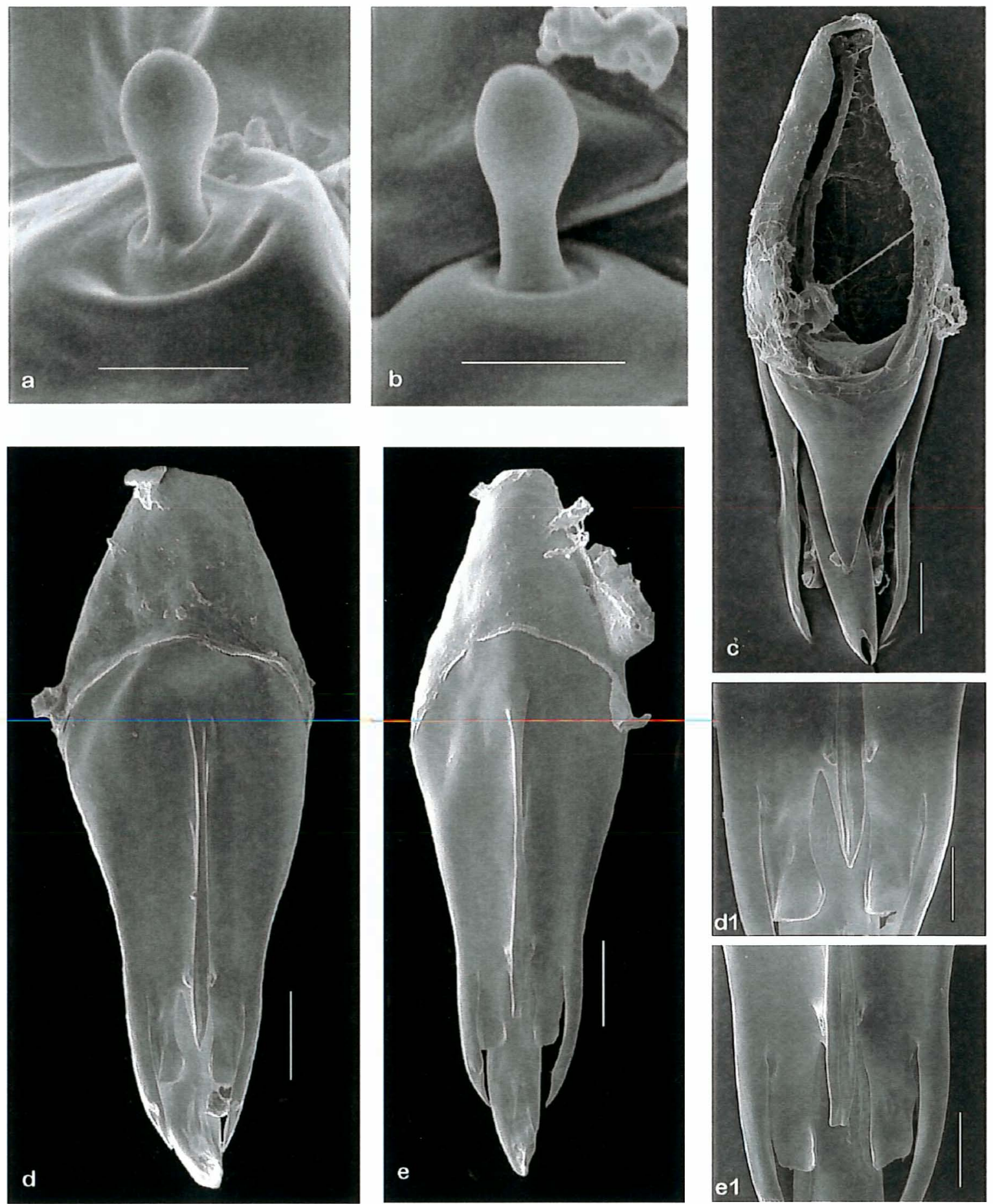

Figura 32 - Trichogramma exiguum. Sensilo basicônico: a - posição $2(17870 x, 1 \mu \mathrm{m})$ e b - posição 3 $(18370 \mathrm{x}, 1 \mu \mathrm{m})$. Cápsula genital: c - dorsal $(2180 \mathrm{x}, 10 \mu \mathrm{m}) ; \mathrm{d}$ - ventral (processo intervolselar pontiagudo, $825 \mathrm{x}, 20 \mu \mathrm{m}), \mathrm{dl}-$ detalhe $(3000 \mathrm{x}, 5 \mu \mathrm{m})$; e - ventral (processo intervolselar truncado, $850 \mathrm{x}, 20 \mu \mathrm{m})$, el - detalhe $(3000 \mathrm{x}, 5 \mu \mathrm{m})$. 


\section{$\underline{\text { Variacões }}$}

Nas antenas, foi observada variação no número de sensilos basicônicos, isto é, um espécime do Peru e um da Colômbia apresentaram dois sensilos basicônicos na posição 1; um outro da Colômbia apresentou somente um sensilo na posição 2 . Na cápsula genital, a extensão posterior da lâmina dorsal variou quanto a largura da base e do ápice; processo intervolselar apresentou o ápice ponituagudo ou truncado com uma pequena reentrância apical. Essas variações ocorreram tanto entre os espécimes do mesmo local como os de locais diferentes.

\section{$\underline{\text { Análise multivariada }}$}

A análise dos componentes principais indicou a formação de dois grupos de $T$. exiguum da Colômbia e do Peru (Figura 33). O primeiro componente explicou cerca de $41,6 \%$ da variação total, o segundo $13,4 \%$ e o terceiro $9,8 \%$, portanto, os dois primeiros componentes explicaram $55 \%$ da variação total presente na matriz da covariância. Ao longo do eixo do primeiro componente, os espécimes da Colômbia separam-se dos espécimes do Peru. As variáveis comprimento da abertura dorsal (CAD), distância basal (DB) e comprimento da carena ventral (CCV), apresentaram os maiores valores absolutos de 0,358,0,305 e 0,294, respectivamente, foram as que mais contribuíram nesse eixo. O segundo componente foi mais influenciado pelo comprimento da lâmina dorsal (CLD) e comprimento da extensão posterior da lâmina dorsal (CEPLD), que apresentaram os maiores valores absolutos, 0,503 e 0,454, respectivamente.

A análise das variáveis canônicas (Figura 34) mostrou resultado semelhantes a análise dos componentes principais. Os testes multivariados Wilks'Lambda ( $\mathrm{P}<0,0009)$, Pillai's Trace $(\mathrm{P}<0,0073)$, Hotelling-Lawley Trace $(\mathrm{P}<0,0009)$ e Roy's Greatest Root $(\mathrm{P}<0,0009)$ mostraram que os eixos canônicos foram estatisticamente significativos, extraídos da matriz resultante do produto da matriz de covariância entre os grupos pela matriz de covariância dentro dos grupos. A primeira variável canônica explicou 100\% da variação total.

No primeiro eixo canônico, as variáveis de maior importância foram comprimento da lâmina dorsal (CLD) e comprimento da abertura dorsal (CAD), com os maiores valores absolutos, 0,715 e 0,610, respectivamente. Essas variáveis foram 
responsáveis pelas principais diferenças entre de T. exiguum da Colômbia e do Peru. O segundo eixo canônico não foi importante, representado pelo comprimento das cerdas da franja da asa anterior (CCFAA) e o comprimento da cápsula genital (CCG), com os maiores valores absolutos de 0,175 e 0,170 , respectivamente.

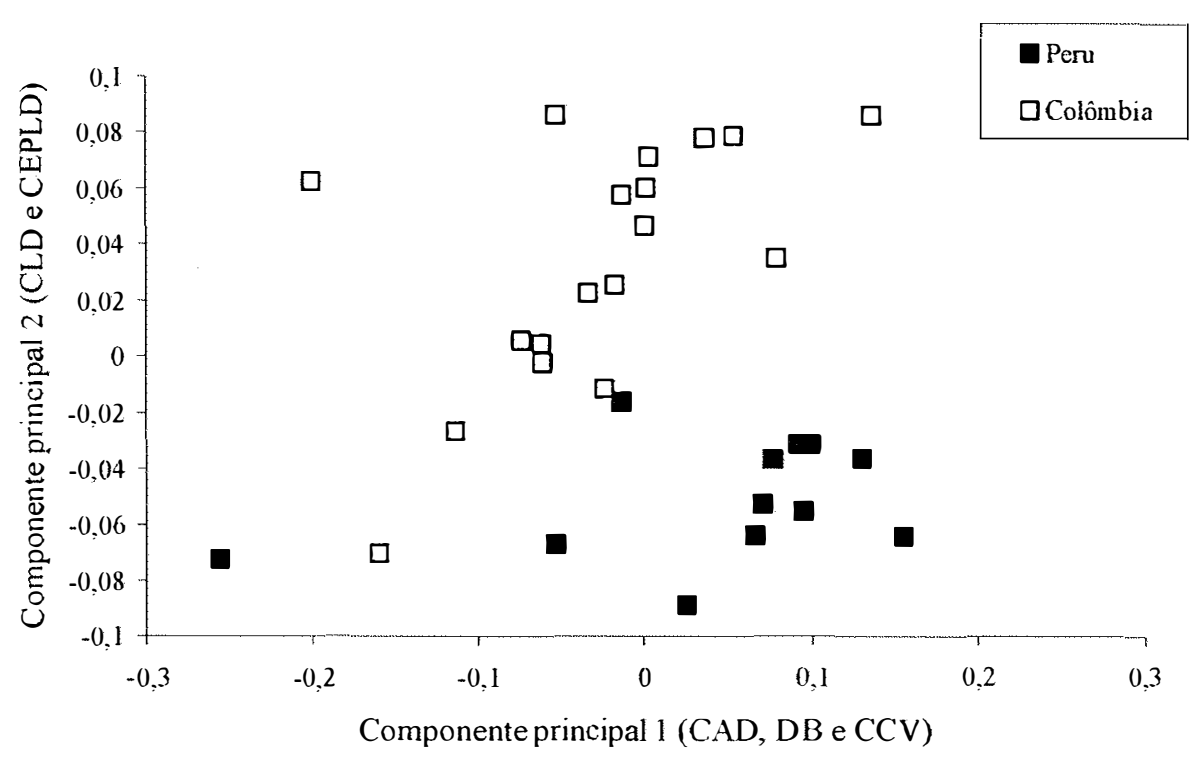

Figura 33 - Ordenação de Trichogramma exiguum nos dois primeiros componentes.

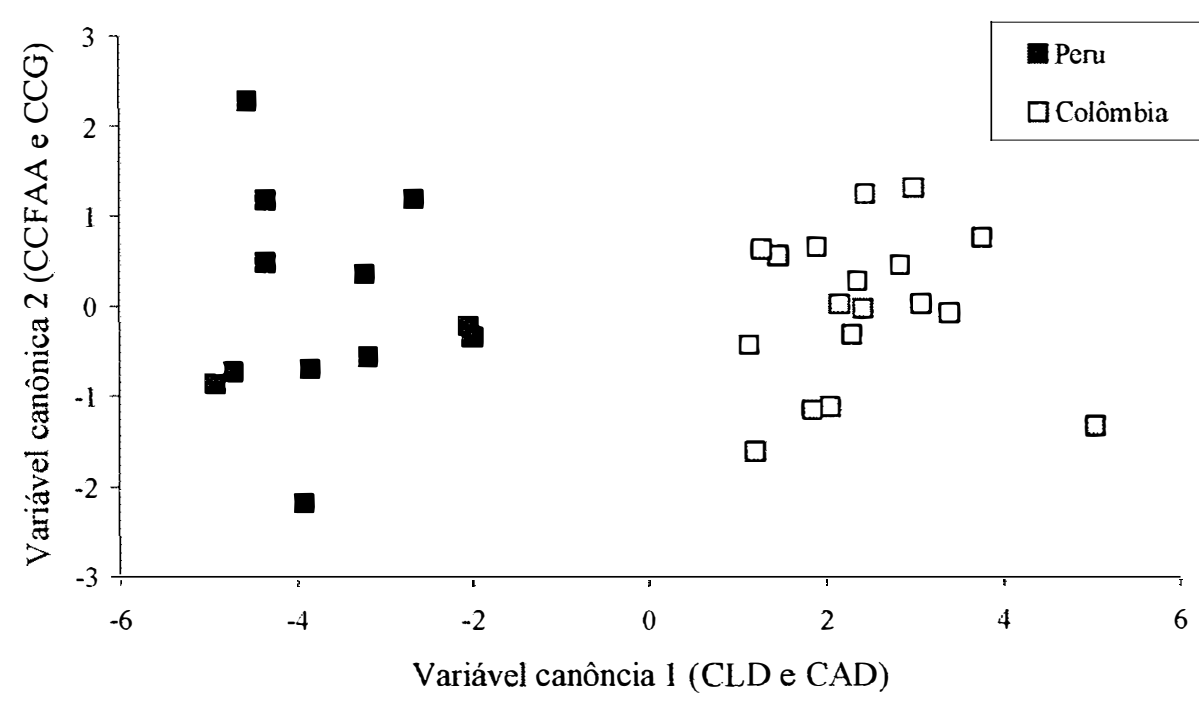

Figura 34 - Ordenação de Trichogramma exiguum nos dois primeiros eixos canônicos. 
As análises mostraram que existem variações entre os espécimes provenientes da Colômbia e do Peru e que estas diferenças estão relacionadas ao tamanho das estruturas analisadas, principalmente, do comprimento da abertura dorsal e lâmina dorsal.

\section{Distribuicão geográfica e hospedeiros}

T. exiguum é uma espécie distribuída na região Neotropical, ocorre no oeste da América do Norte, do sul de Quebec a Flórida nos EUA; no México em Tamaulipas e Nuevo Leon e também no sudeste deste país; na América Central e do Sul (Pinto, 1998). $\mathrm{Na}$ América do Sul, foi assinalado no Chile, Colômbia, Peru e Uruguai. Recentemente, Basso et al. (1999) publicou o primeiro registro T. exiguum no Uruguai, tendo como hospedeiros Bonagota cranaodes (Meyrick) e Argyrotaenia sphaleropa (Meyrick) (Lepidoptera: Tortricidae). Os hospedeiros de $T$. exiguum estão relacionados principalmente às pragas agrícolas. Pinto (1998) relatou que essa espécie é freqüentemente associada a Heliothis (Lep., Noctuidae) em algodoeiro e milho, mas parasita 29 espécies de insetos. Atualmente, na América do sul, T. exiguum pode ser encontrado parasitando 13 espécies de hospedeiros (Zucchi \& Monteiro, 1997; Basso et al., 1999).

\section{Comentários}

Há muita controvérsia na literatura com $T$. exiguum e espécies relacionadas, como T. fasciatum (Perkins, 1912) e T. fuentesi. Erros de identificação podem ser encontrados em muitos trabalhos anteriores ao publicado por Pinto et al. (1993), no qual redescreveram $T$. exiguum e discutiram os caracteres que claramente o diferenciam de $T$. fasciatum e de $T$. fuentesi e verificaram que exemplares de $T$. exiguum haviam sido erroneamente identificados como $T$. perkinsi.

Neste trabalho, examinando-se espécimes de $T$. fasciatum do Peru, verificou-se que se tratavam de T. exiguum. Esse material foi coletado em 1974 e 1976 de ovos de Heliothis sp., nas cidades de Pampa Callana e Túman, no Peru. O exame dos espécimes de $T$. perkinsi, discutidos por Ruiz \& korytkowski (1979), demonstraram que são na realidade $T$. exiguum. Esse material foi coletado de ovos de Heliothis virescens 
(Fabricius, 1777) (Lep., Noctuidae) em algodoeiro e milho e de H. zea em milho, nas cidades de Lambayeque e Paramonga, no Peru.

Amostras de T. exiguum utilizadas na caracterização morfológica neste trabalho, foram enviadas para o sequiênciamento da região ITS2 do r-DNA e os resultados confirmaram a identificação específica (Raul P. Almeida, inf. pes.).

\subsubsection{Trichogramma fasciatum (Perkins, 1912)}

(Figura 35)

Pentarthron fasciatum Perkins, 1912: 19.

Trichogramma beckeri Nagarkatti, 1973: 233.

Trichogramma fasciatum: Pinto et al., 1978: 176; Pinto 1998: 84.

\section{Caracterizacão morfológica}

Antenas: flagelo longo $(0,20 \pm 0,04)$, cerca de duas vezes o comprimento do escapo; comprimento/largura do flagelo $(6,73 \pm 0,81)$; comprimento do flagelo/comprimento da tíbia posterior $(1,18 \pm 0,11)$; cerdas flageliformes longas $(0,10 \pm 0,01)$, com o ápice uniformemente afilado; comprimento da maior cerda do flagelo/maior largura do flagelo de 3,33 $\pm 0,61$; sensilo placóideo basal com $0,04 \mathrm{~mm}(\mathrm{n}=1)$.

Asas anteriores: largura da asa $(0,31 \pm 0,04)$; relação entre a largura e o comprimento da asa $(0,63 \pm 0,11)$; comprimento da maior cerda da franja da asa/comprimento da tíbia posterior $(0,23 \pm 0,04)$; comprimento da maior cerda da franja da asa anterior/largura da asa anterior $(0,12 \pm 0,03)$. O número de cerdas entre a $4^{\underline{a}}$ e $5^{\mathrm{a}}$ fileiras de 9 a 17 cerdas.

Escutelo: cerdas anteriores do escutelo relativamente grandes; relação entre as cerdas anteriores/posterior $(0,31 \pm 0,24)$.

Genitália masculina: cápsula genital pequena $(0,10 \pm 0,01)$ e larga $(0,06 \pm 0,00)$, com forma ovalada; relação entre a largura e comprimento da cápsula genital de $0,59 \pm 0,02$; distância apical/comprimento da cápsula genital $(0,23 \pm 0,01)$; distância basal/comprimento da cápsula genital $(0,77 \pm 0,01)$; largura apical/largura da cápsula genital $(0,42 \pm 0,02)$; 
lâmina dorsal originando-se na metade da cápsula genital, com $0,04 \mathrm{~mm}$ de largura; comprimento/largura da lâmina dorsal $(0,66 \pm 0,04)$; comprimento da lâmina dorsal/comprimento da cápsula genital $(0,28 \pm 0,01)$; extensão posterior da lâmina dorsal curta $(0,02 \pm 0,00)$, com ápice arredondado, além do processo intervolselar e encobrindo as volselas; comprimento da extensão posterior da lâmina dorsal/comprimento da lâmina dorsal $(0,85 \pm 0,07)$; abertura dorsal ampla cerca de duas vezes o comprimento da lâmina dorsal; carena ventral alcançando a metade da cápsula genital $(0,02 \pm 0,02)$; processo intervolselar distinto, muito curto, com forma triangular e unidos as volselas; processos ventrais situados na base do processo intervoselar; comprimento dos apódemas/comprimento do edeago $(0,70 \pm 0,07)$; edeago/comprimento da tíbia posterior $(0,32 \pm 0,02)$.

Os dados quantitativos foram obtidos de quatro machos coletados de ovos de Peridroma saucia (Hübner, 1808) (Lep., Noctuidae), em Agave sisalana, em Chimborazo, Equador.

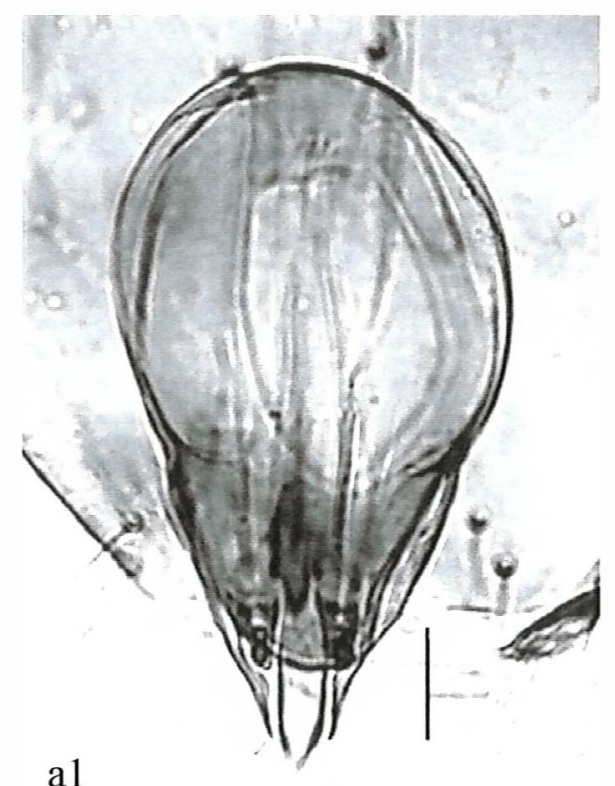

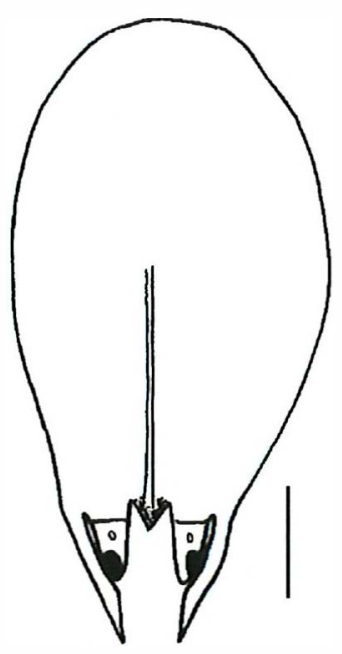

b 1

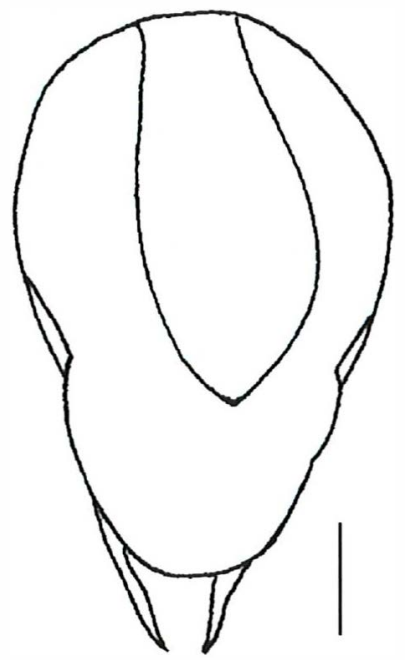

b2

Figura 35 - Cápsula genital de Trichogramma fasciatum (a - $10 \mu \mathrm{m}$ e b - $20 \mu \mathrm{m}): 1$ ventral e 2 - dorsal. 


\section{Material examinado}

EQUADOR. Chimborazo, 14-jan.-1997, 4 machos, ex ovos de Peridroma saucia, em Agave sisalana, J. C. Monje col. (ESALQ).

\section{Diagnose}

T. fasciatum é facilmente distinguido por apresentar uma pequena cápsula genital com forma ovalada e uma lâmina dorsal, encobrindo as volselas e o processo intervolselar.

\section{$\underline{\text { Variacões }}$}

T. fasciatum apresenta consideráveis variações morfológicas, ocorrendo formas intermediárias (detalhes dessas variações encontram-se em Pinto,1998). Os espécimes coletados no Equador apresentam uma cápsula genital semelhante ao material de Cerro de la Muerte, Costa Rica, discutido por Pinto (1998), principalmente, pelo aspecto geral da cápsula genital. Entretanto, o sensilo placóideo não é nitidamente curvado e a carena dorsal não é distinta, como mencionado por Pinto (1998).

\section{Distribuicão geográfica e hospedeiros}

Em razão dos erros de identificação existentes na literatura com relação à $T$. fasciatum, serão considerados neste trabalho apenas os registros publicados após os trabalhos de Pinto et al. $(1978,1983)$ e que tiveram a participação de um taxonomista. Assim, na América do Sul, T. fasciatum encontra-se assinalado no Equador, parasitando ovos de P. saucia, em Agave sisalana (novo registro) e ovos de uma espécie de Noctuidae (Lepidoptera) em milho (Benzing, 1998). Foi também registrado na Venezuela (Pinto, 1998).

\section{Comentários}

Segundo Pinto et al. (1978) a espécie referida por Nagarkatti \& Nagaraja (1971) como T. fasciatum, na verdade é T. fuentesi. Esses autores redescreveram T. fasciatum designando o lectótipo. Determinaram ainda que T. fasciatum é sinônimo sênior de $T$. beckeri Nagarkatti, 1973 e que populações designadas como T. fasciatum por Quednau 
(1960), Nagarkatti \& Nagaraja $(1971,1977)$ são erros de identificação. Além disso, Pinto et al. (1983) esclareceram a confusão existente com essas espécies. Consideraram T. fasciatum discutido por Quednau (1960), Flanders (1968), Nagarkatti \& Nagaraja (1971, 1977), Nagaraja \& Nagarkatti (1973), Nagarkatti \& Fazaluddin (1973) como $T$. fuentesi e não T. exiguum como mencionado por Pinto et al. (1978).

Portanto, as informações da literatura sobre $T$. fasciatum antes dos trabalhos de Pinto et al. $(1978,1983)$ não devem ser consideradas. Assim, examinando o trabalho de Ruiz \& Korytkowski (1979) e pelas características das ilustrações de T. fasciatum, constatou-se que na verdade se trata de T. fuentesi, segundo aqueles autores uma espécie nativa do Peru. Espécimes de T. fasciatum coletado no Peru foram examinados e correspondem a T. exiguum. De Santis (1981) incluiu T. fasciatum em seu catálogo dos himenópteros calcidóideos, como presente na Venezuela e tendo como hospedeiros $D$. saccharalis e $H$. virescens. Entretanto, pela falta de informações taxonômicas precisas, o registro para Venezuela deve ser confirmado.

\subsubsection{Trichogramma fuentesi Torre, 1980}

(Figura 36)

Trichogramma fasciatum Quednau, 1960: 32; Flanders, 1968: 1122; Nagarkatti \& Nagaraja, 1971: 20, 1977: 159-168; Nagaraja \& Nagarkatti, 1973: 289; Nagarkatti \& Fazaluddin, 1973:103.

Trichogramma fuentesi Torre, 1980: 12; Pinto et al., 1983: 589; Zucchi \& Monteiro, 1997: 54; Pinto, 1998: 142; Whu \& Valdivieso, 1999: 61.

\section{Caracterizaç̃̃o morfológica}

Antenas: flagelo longo $(0,15 \pm 0,004)$; relação entre o comprimento e a largura do flagelo de $5,98 \pm 0,35$; cerdas flageliformes curtas $(0,05 \pm 0,003)$, com o ápice abruptamente afilado; comprimento da maior cerda do flagelo/maior largura do flagelo $(1,98 \pm 0,13)$; comprimento do flagelo/comprimento da tíbia posterior $(0,98 \pm 0,03)$; 
sensilos basicônicos globosos, fórmula 1-1(2)-2-0-1-1; três sensilos placóideos, o basal medindo $0,04 \pm 0,003 \mathrm{~mm}$.

Asas anteriores: largura da asa anterior $(0,23 \pm 0,005)$; relação entre a largura e o comprimento da asa $(0,54 \pm 0,01)$; comprimento da maior cerda da franja da asa anterior/largura da asa anterior $(0,11 \pm 0,01)$. O número de cerdas entre a $4^{\underline{a}}$ e $5^{\underline{a}}$ fileiras foi de 7 a 12 .

Asas posteriores: fileira anterior e posterior com número de cerdas variando de 0-3 e 79 , respectivamente; fileira posterior ultrapassando a metade da fileira mediana e quase atingindo o ápice.

Escutelo: relação entre as cerdas anteriores e posteriores $(0,18 \pm 0,04)$.

Genitália masculina: cápsula genital mais longa $(0,14 \pm 0,003)$ do que larga $(0,06 \pm$ $0,004)$, relação entre a largura e o comprimento da cápsula genital $(0,42 \pm 0,03)$; distância apical/comprimento da cápsula genital $(0,25 \pm 0,01)$; largura apical/largura da cápsula genital $(0,64 \pm 0,06)$; lâmina dorsal origina-se no meio da cápsula genital, com leve reentrância basal; comprimento da lâmina dorsal/comprimento da cápsula genital $(0,36 \pm 0,02)$; comprimento/largura da lâmina dorsal $(1,14 \pm 0,07)$; comprimento da extensão posterior da lâmina dorsal $(0,04 \pm 0,003)$; extensão posterior com a base mais larga que o ápice, este pontiagudo ou levemente arredondado, no nível do processo intervolselar; comprimento da abertura dorsal/comprimento da lâmina dorsal (1,54 \pm 0,09); comprimento da extensão posterior da lâmina dorsal/comprimento da lâmina dorsal $(0,84 \pm 0,04)$; carena dorsal ausente; carena ventral alcançando a metade da cápsula genital $(0,04 \pm 0,004)$; carena ventral/distância basal $(0,36 \pm 0,04)$; distância basal/comprimento da cápsula genital $(0,75 \pm 0,01)$; processo intervolselar longo, robusto e com o ápice pontiagudo ou bífido, no nível das volselas; os processos ventrais próximos da base do processo intervoselar; comprimento do edeago/comprimento da tíbia posterior $(0,48 \pm 0,03)$; apódemas/edeago $(0,95 \pm 0,06)$.

Os dados quantitativos foram obtidos de 20 machos coletados no Peru. 

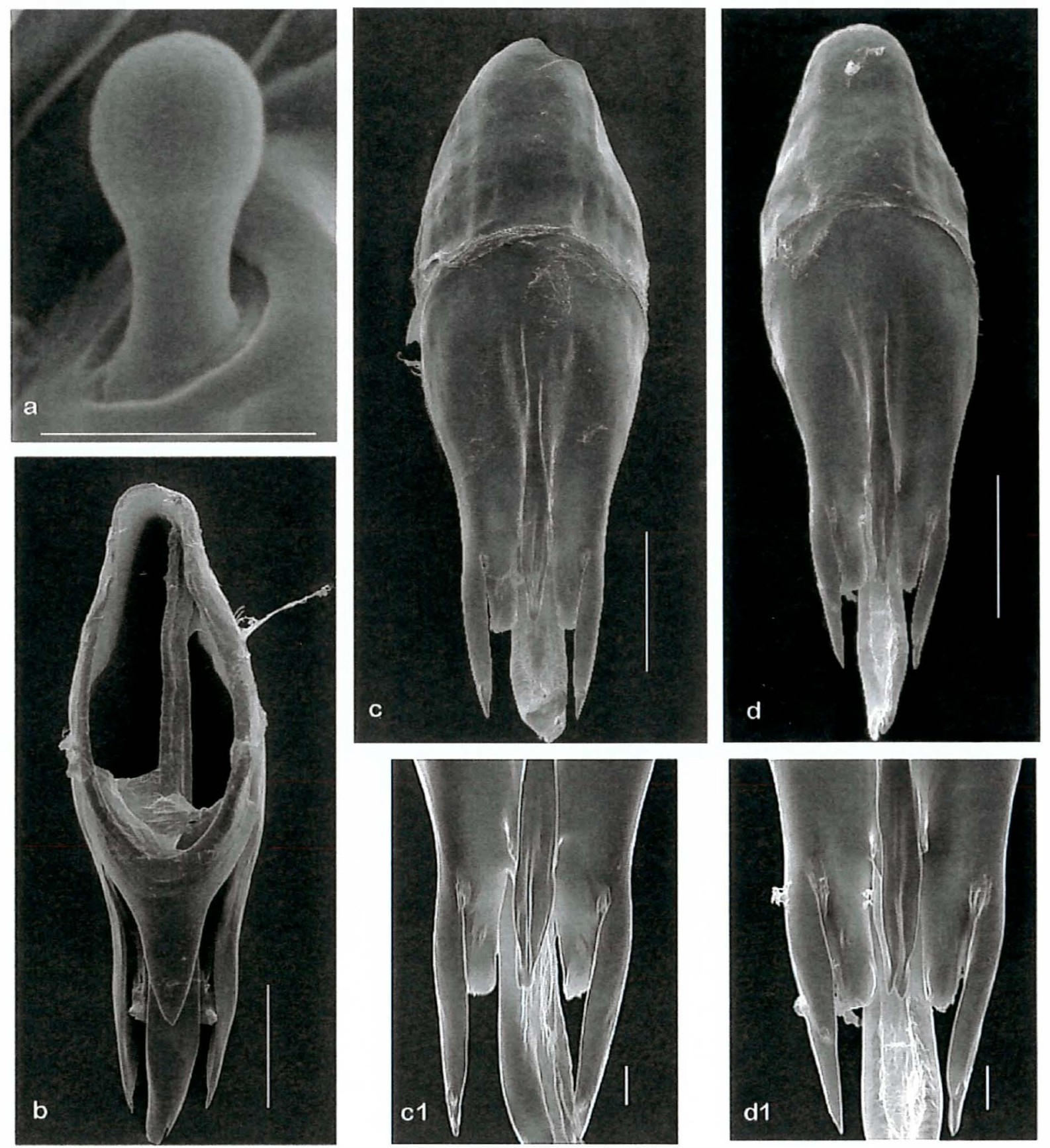

Figura 36 - Trichogramma fuentesi a - Sensilo basicônico (43240x, 300ๆm); b - Cápsula genital dorsal (1240x, $20 \mu \mathrm{m}$ ); c - Cápsula genital ventral (processo intervolselar pontiagudo, 1310x, 10 $\mu \mathrm{m})$, c l- detalhe (4000x, $3 \mu \mathrm{m})$; d - Cápsula genital ventral (processo intervolselar bífido, $1310 \mathrm{x}, 10 \mu \mathrm{m}), \mathrm{dl}-$ detalhe $(4510 \mathrm{x}, 5 \mu \mathrm{m})$. 


\section{Material examinado}

PERU. 20 machos, vários hospedeiros (Diatraea saccharalis em milho e canade-açúcar, Helicoverpa zea em milho, Heliothis virescens em algodoeiro e Anomis texana em algodoeiro), Mary Whu P. col. (ESALQ).

\section{$\underline{\text { Diagnose }}$}

T. fuentesi é distinguido pelas cerdas flageliformes curtas com o ápice abruptamente afilado, sensilos basicônicos com forma globosa e ausente na posição 4 . Asa posterior com a fileira posterior com cerdas distintas, alcançando ou além da metade da fileira mediana e quase alcançando o ápice. Os caracteres distintivos na cápsula genital são o processo intevolselar robusto, com o ápice quase no nível das volselas e a carena ventral não ultrapassando a metade da cápsula genital. Essas características separam T. fuentesi de T. exiguum (espécie comumente confundida com T. fuentesi), principalmente pelas cerdas da fileira posterior que é curta em $T$. fuentesi, não alcançando a metade da fileira mediana e pela carena ventral bem mais longa em $T$. exiguum.

\section{$\underline{\text { Variacões }}$}

As variações foram encontradas na fórmula do sensilo basicônico; alguns indivíduos apresentaram dois sensilos na posição 2 , concordando com a descrição de Pinto (1998), entretanto, a maioria apresentou apenas um sensilo nesta posição e nenhum na posição 4, diferentemente do descrito por Pinto (1998). Outra variação observada foi com relação ao ápice do processo intervolselar, isto é, bífido em alguns indivíduos.

\section{Análises multivariadas}

A análise dos componentes principais com $T$ : fuentesi (Peru), T. exiguum (Uruguai, línea 183) e T. exiguum (Peru), demonstrou a formação de três grupos e a projeção dos escores permitiu visualizar as diferenças entre $T$. exiguum do Peru e do Uruguai, e principalmente dos espécimes do Uruguai (línea 183) em relação a $T$ : exiguum do Peru (Figura 37). 
O primeiro componente explicou cerca de $46,5 \%$ da variação total, o segundo $28,8 \%$ e o terceiro $6,2 \%$, portanto, os dois primeiros componentes explicaram $75,3 \%$ da variação total presente na matriz da covariância. As variáveis comprimento da carena ventral (CCV) e comprimento do processo intervolselar (PIV) apresentaram os maiores valores absolutos de 0,629 e 0,521, respectivamente. Essas variáveis separaram distintamente $T$. fuentesi (Peru) de $T$. exigumm (Peru), entretanto, não mostraram diferenças entre T. fuentesi (Peru) e T. exiguum (Uruguai), ao longo do eixo do primeiro componente. O segundo componente foi mais influenciado pelo comprimento das cerdas da franja da asa anterior (CCFAA), comprimento da carena ventral (CCV) e processo intervolselar (PIV), que apresentaram os maiores valores absolutos de 0,363, 0,325 e 0,316 , respectivamente. No eixo do segundo componente, representado por essas variáveis, não separaram-se $T$. fuentesi e $T$. exiguum do Peru, mas mostram diferenças entre T. fuentesi (Peru) e T. exiguum (Uruguai)

$\mathrm{Na}$ análise das variáveis canônicas, os testes multivariados Wilks'Lambda ( $P<0,0001)$, Pillai's Trace $(\mathrm{P}<0,0001)$, Hotelling-Lawley Trace $(\mathrm{P}<0,0001)$ e Roy's Greatest Root $(\mathrm{P}<0,0001)$ mostraram que os eixos canônicos foram estatisticamente significativos, extraídos da matriz resultante do produto da matriz de covariância entre os grupos pela matriz de covariância dentro dos grupos. A primeira variável canônica explicou 78,6\% e a segunda $21,4 \%$ da variação total.

O resultado da análise das variáveis canônicas mostrou ordenação semelhante à obtida pela análise dos componentes principais (Figura 38). No primeiro eixo canônico, as variáveis de maior importância foram comprimento do processo intervolselar (PIV) e comprimento da carena ventral (CCV) que apresentaram os maiores valores absolutos, 0,869 e 0,784 , respectivamente. No segundo eixo canônico, o comprimento da cápsula genital (CCG) e a distância basal (DB) foram as variáveis de maior importância, com os maiores valores absoluto, 0,746 e 0,735 , respectivamente. 


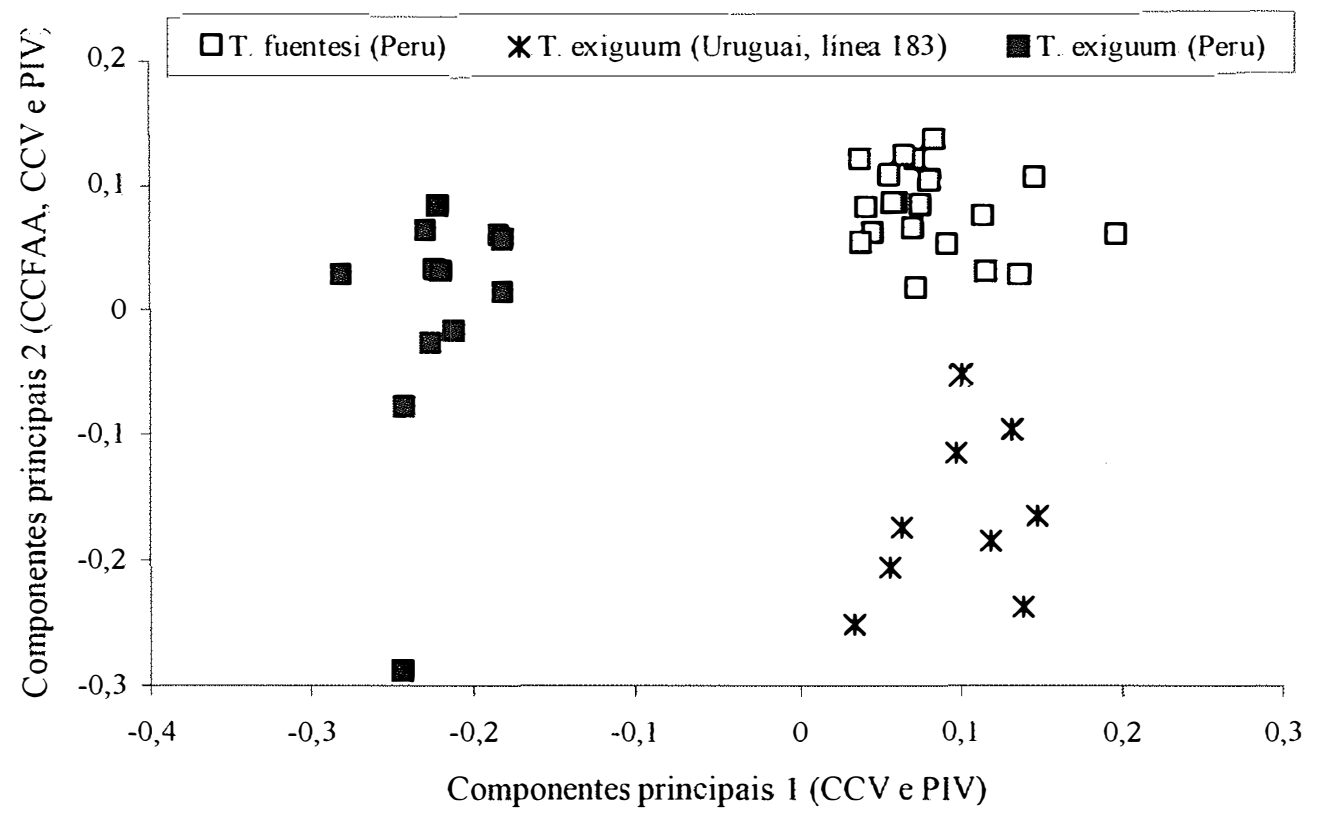

Figura 37 - Ordenação de Trichogramma fuentesi e T. exiguum nos dois primeiros componentes.

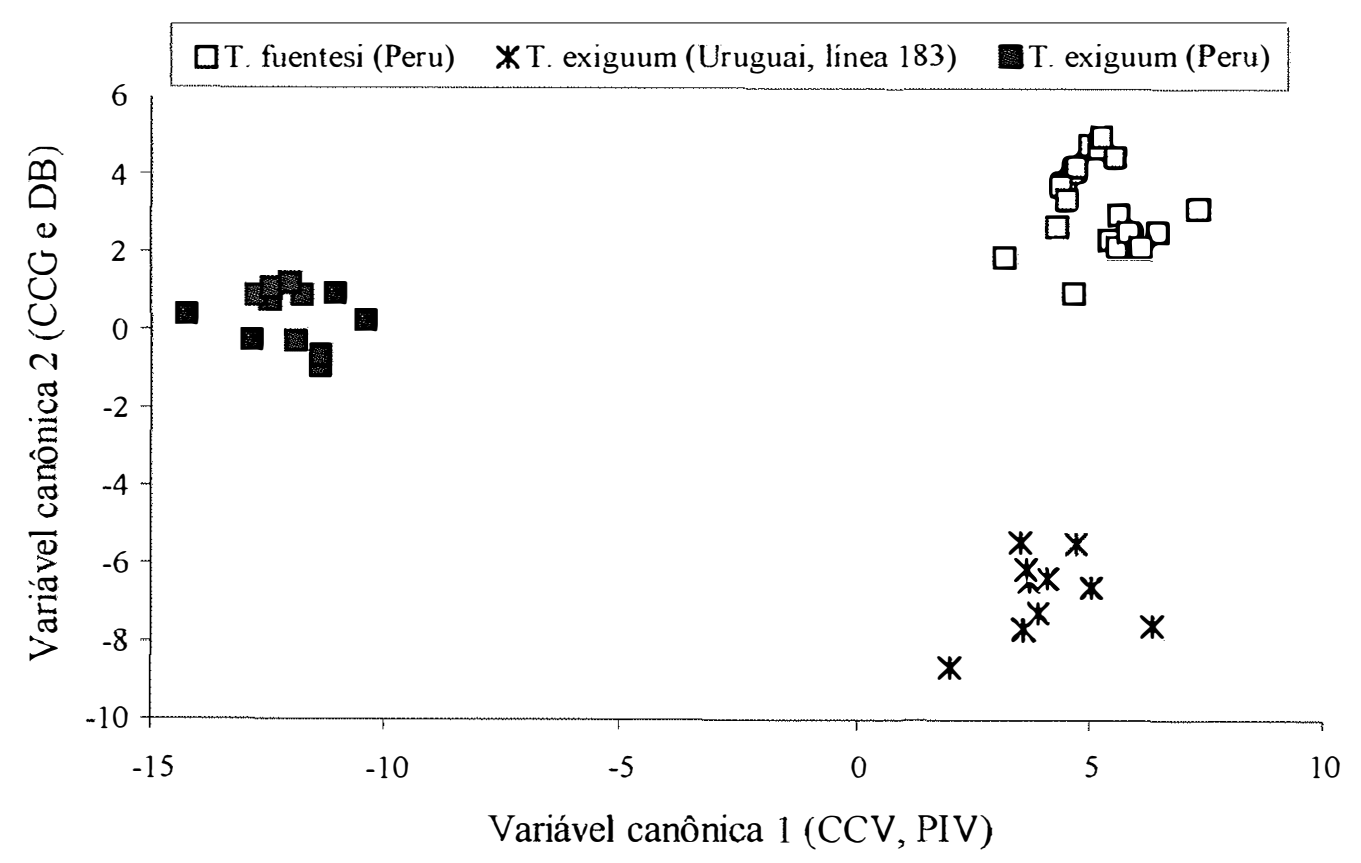

Figura 38 - Ordenação de Trichogramma fuentesi e T'. exiguum nos dois primeiros eixos canônicos. 
Pelas análises, separa-se claramente T. fuentesi (Peru) de T. exiguum (Peru), entretanto, não há uma distinta separação entre $T$. fuentesi (Peru) de $T$. exiguum (Uruguai, línea 183). Essas análises evidenciam uma situação intermediária dos espécimes de $T$. exiguum proveniente do Uruguai, concordando os estudos de Basso et al. (1999) que consideraram a línea 183 como uma forma intermediária entre $T \cdot$ exiguum e $T$. fuentesi. Todavia, observando os caracteres taxonômicos (morfológicos) que permitem a separação das espécies T. exiguum e $T$. fuentesi, indicam que os espécimes da línea 183 são muito semelhantes a $T$. fuentesi.

\section{Distribuicãogeográfica e hospedeiros}

Na América do Sul T. fuentesi foi encontrado na Argentina e Peru (Zucchi \& Monterio, 1997). Essa espécie ocorre também no sudoeste dos EUA e nas West Indian (Pinto, 1998). Nagarkatti \& Nagaraja (1971) examinaram material proveniente da Argentina coletado por De Santis, em 1970 (localidade e hospedeiros desconhecidos) e também do Peru, das cidades de Pucala-Chiclayo, coletados de ovos de D. saccharalis por S.H. Risco, em 1969.

Há poucos registros de hospedeiros de $T$. fuentesi na América do Sul, o mais conhecido é D. saccharalis. Whu \& Valdivieso (1999) afirmaram que T. fuentesi parasita, em diferentes cultivos, diversos hospedeiros, principalmente, os noctuídeos Helicoverpa zea, Heliothis virescens, Anomis texana Riley, 1885 (Noctuidae) e D. saccharalis (Crambidae).

\section{Comentários}

T. fuentesi foi erroneamente identificada por vários autores, que a confundiram com T. fasciatum (Nagarkatti \& Nagaraja, 1971 e Ruiz \& Korytkowski, 1979). Pinto et al. (1983) esclareceram os erros de identificação e discutiram os caracteres para separar T. fuentesi e T. exiguum. Estas espécies apresentam semelhanças nas estruturas e por isso são facilmente confundidas, sendo que para separá-las são utilizadas diferenças na fileira posterior de cerdas da asa posterior e genitália do macho. 
Amostra de T. fuentesi, utilizado na caracterização morfológica, foi analisado por meio do seqüênciamento da região ITS2 do r-DNA na Wageningen University (Holanda) e os resultados confirmaram a identificação específica (Raul P. Almeida, inf. pes.).

\subsubsection{Trichogramma galloi Zucchi, 1988}

(Figura 39 e 40)

Trichogramma galloi Zucchi, 1988: 133; Zucchi et al., 1991: 131; Zucchi \& Monteiro, 1997: 54.

\section{Caracterizacão morfológica}

Antenas: flagelo longo $(0,16 \pm 0,013)$; relação entre o comprimento e a largura do flagelo de $5,43 \pm 1,12$; cerdas flageliforme curtas $(0,06 \pm 0,004)$, com o ápice abruptamente afilado; comprimento da maior cerda do flagelo/maior largura do flagelo $(2,23 \pm 0,55)$; comprimento do flagelo/comprimento da tíbia posterior $(0,98 \pm 0,06)$; número reduzido de sensilos basicônicos e de difícil visualização, fórmula 1-1-1-0-1-1; três sensilos placóideos, o basal medindo $0,04 \pm 0,002 \mathrm{~mm}$.

Asas anteriores: largura da asa anterior $(0,24 \pm 0,019)$; relação entre a largura e o comprimento da asa $(0,49 \pm 0,04)$; comprimento da maior cerda da asa anterior $(0,03 \pm$ 0,004); comprimento da maior cerda da franja da asa/comprimento da tíbia posterior $(0,22 \pm 0,04)$; comprimento da maior cerda da franja da asa anterior/largura da asa anterior $(0,15 \pm 0,02)$. Número de cerdas entre a $4^{\underline{a}}$ e $5^{\underline{a}}$ fileiras foi de 7 a 16 .

Asas posteriores: fileira anterior e posterior com número de cerdas variando de 0-4 e 610 , respectivamente.

Escutelo: relação entre as cerdas anteriores e posteriores $(0,21 \pm 0,05)$.

Genitália masculina: cápsula genital mais longa $(0,12 \pm 0,006)$ do que larga $(0,05 \pm$ $0,003)$, relação entre a largura e o comprimento da cápsula genital $(0,43 \pm 0,03)$; distância apical/comprimento da cápsula genital $(0,27 \pm 0,01)$; largura apical/largura da cápsula genital $(0,59 \pm 0,05)$; comprimento da lâmina dorsal/comprimento da cápsula 
genital $(0,35 \pm 0,02)$; comprimento/largura da lâmina dorsal $(1,10 \pm 0,05)$; comprimento da abertura dorsal/comprimento da lâmina dorsal $(1,88 \pm 0,12)$; extensão posterior da lâmina dorsal com o ápice muito estreito em relação à base, no nível do processo intervolselar e ultrapassando ou não as volselas; comprimento da extensão posterior da lâmina dorsal $(0,03 \pm 0,003)$; comprimento da extensão posterior da lâmina dorsal/comprimento da lâmina dorsal $(0,67 \pm 0,05)$; carena ventral $(0,03 \pm 0,002)$; carena ventral/distância basal $(0,38 \pm 0,03)$; distância basal/comprimento da cápsula genital $(0,74 \pm 0,02)$; processos ventrais próximos da base do processo intervoselar; processo intervolselar distinto e delgado $(0,01 \pm 0,001)$; comprimento do edeago/comprimento da tíbia posterior $(0,42 \pm 0,03)$; apódemas/edeago $(0,85 \pm 0,07)$.

Os dados quantitativos foram obtidos de 15 machos coletados de ovos de $D$. saccharalis, em cana-de-açúcar, em Piracicaba, São Paulo, Brasil.

\section{$\underline{\text { Material examinado }}$}

BOLÍVIA. SANTA CRUZ: 23-mai.-1985, 1 macho, ex ovos de Diatraea saccharalis, em cana-de-açúcar, E. Coloque col. (ESALQ); SANTA CRUZ: 28-abr.1989, 1 macho, ex ovos de Diatraea saccharalis, em cana-de-açúcar, J.C. Monje col. (ESALQ); SANTA CRUZ. 28-abr.-1989, 5 machos, ex ovos de Diatraea rufescens, em cana-de-açúcar, J.C. Monje col. (ESALQ); BRASIL. SÃO PAULO: Araras, $\underline{\text { Holótipo }}$ macho, ex ovos de Anagasta kuehniella, criação laboratório de Trichogramma (ESALQ); Piracicaba, 4 machos, ex ovos de Diatraea saccharalis, em cana-de-açúcar (ESALQ). RIO DE JANEIRO: Conceição do Macabu, Usina Victor Sence, Fazenda São Luiz, 13-jul.-1983, 1 macho, ex ovos de Diatraea saccharalis, em cana-de-açúcar (ESALQ). PERU. 16 machos, ex ovos de Diatraea saccharalis, em cana-de-açúcar, J. Salazar Torres col. (ESALQ); URUGUAI. ARTIGAS: Bella Union, 16-abr.-1988, 35 machos, ex ovos de Diatraea saccharalis, em cana-de-açúcar, C. Basso col. (ESALQ). 

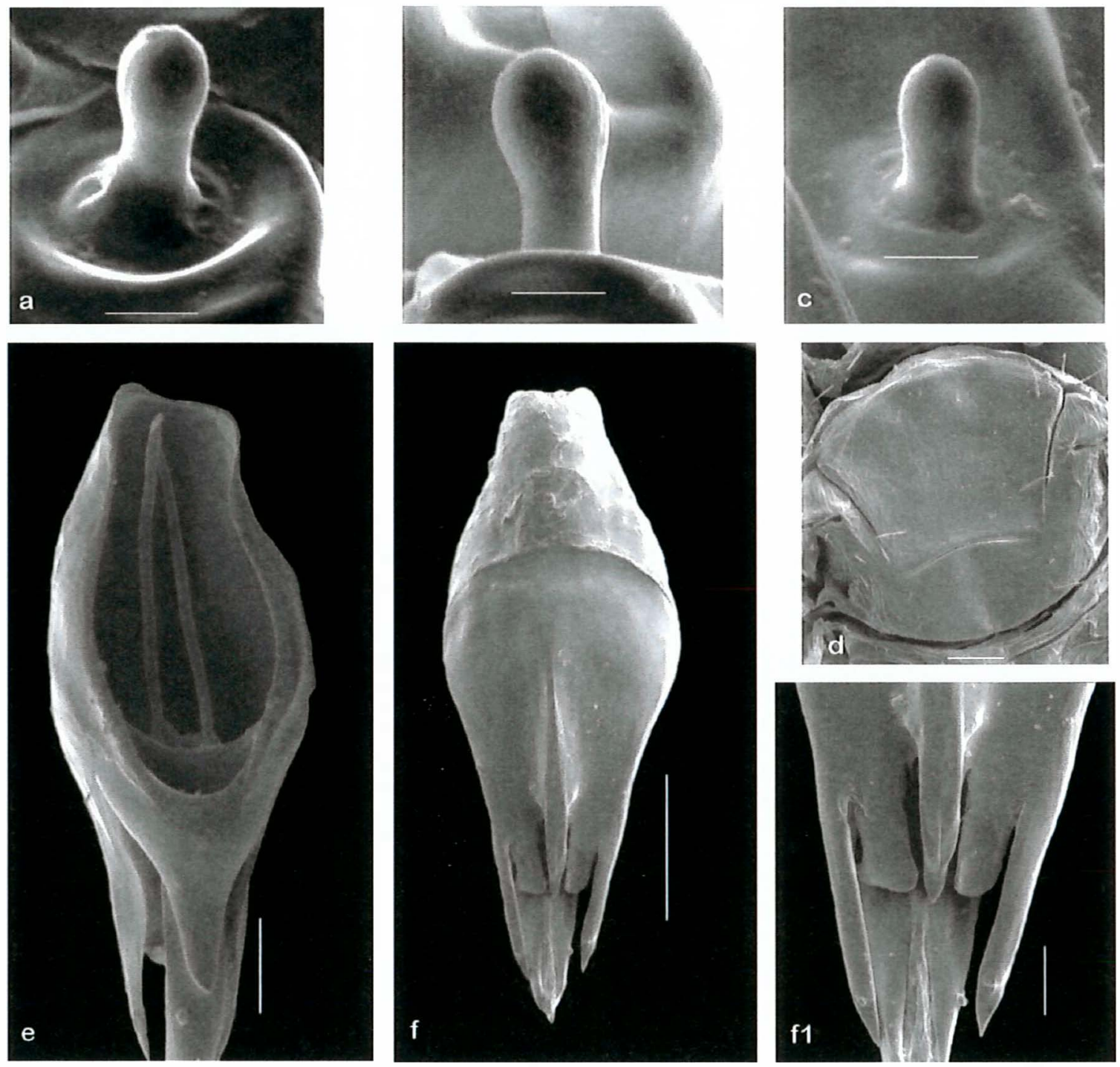

Figura 39 - Trichogramma galloi coletado no Brasil. Sensilo basicônico: a - posição 2 (10000x, $1 \mu \mathrm{m}) ; \mathrm{b}$ - posição $3(10000 \mathrm{x}, 1 \mu \mathrm{m})$; c - posição $5(1000 \mathrm{x}, 1 \mu \mathrm{m})$. Mesoescuto e escutelo: d (490x, $20 \mu \mathrm{m})$; Cápsula genital: e - dorsal (850x, $20 \mu \mathrm{m})$; f - ventral (750x, $20 \mu \mathrm{m})$ e fl- detalhe apical $(2100 x, 5 \mu \mathrm{m})$;

\section{Diagnose}

T. galloi é distinguido pelas cerdas flageliformes curtas, com ápice abruptamente afilado; número reduzido de sensilos basicônico; lâmina dorsal com a extensão posterior estreita e, geralmente, ultrapassando as volselas; processo intervolselar distinto, delgado, 
com o ápice no nível das volselas. Essas características separam T. galloi de outras espécies associadas a D. saccharalis, como T. dissimilis, T. distinctum e T'. jalmirezi.

\section{Variações}

Os espécimes coletados no Brasil apresentaram pequenas variações no comprimento das cerdas flageliformes e no CLD/LLD, no CAD/CLD, no CEPLS/CLD e no CA/CE em relação aos espécimes coletados no Uruguai, Bolívia e Peru. Comparando os espécimes do Peru com os do Brasil, os sensilos basicônicos são semelhantes para os espécimes dos dois países, entretanto, na cápsula genital, o processo intervolselar é mais robusto nos espécimes brasileiros do que nos espécimes peruanos (Figura 40).
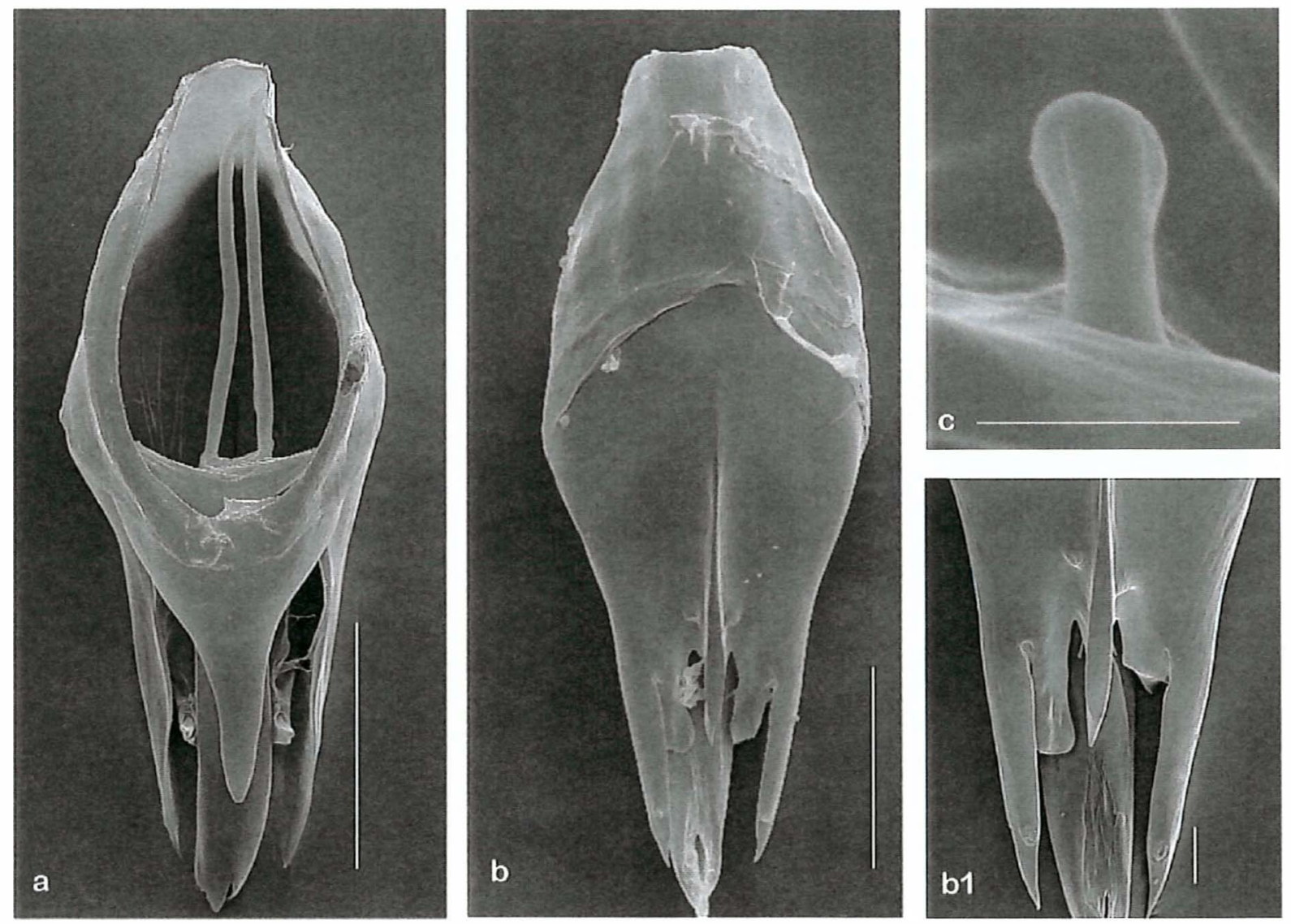

Figura 40 - Trichogramma galloi coletado no Peru. Cápsula genital: a - dorsal (1840x, $10 \mu \mathrm{m}) ; \mathrm{b}$ - ventral (1500x, $10 \mu \mathrm{m})$ e bl-detalhe apical (5060x, $3 \mu \mathrm{m})$. Sensilo basicônico: c - $(23990,1 \mu \mathrm{m})$. 
Análise Multivariada

A análise dos componentes principais demonstrou não haver uma nítida formação de grupos, sendo mínimas as diferenças entre os espécimes do Uruguai, Bolívia e Brasil (Figura 41). O primeiro componente explicou cerca de $41,4 \%$ da variação total, o segundo $26,5 \%$ e o terceiro $14,4 \%$, portanto, os dois primeiros componentes explicaram $67,9 \%$ da variação total presente na matriz da covariância. No primeiro componente, a variável distância dos processos ventrais à base do processo intervolselar (DVP) foi a que apresentou o maior valor absoluto $(0,894)$, sendo responsável pelas reduzidas diferença entre os espécimes de $T$. galloi do Brasil, Bolívia e Uruguai. O segundo componente foi mais influenciado pelo comprimento do processo intrvolselar (PIV), com maior valor absoluto $(0,456)$.

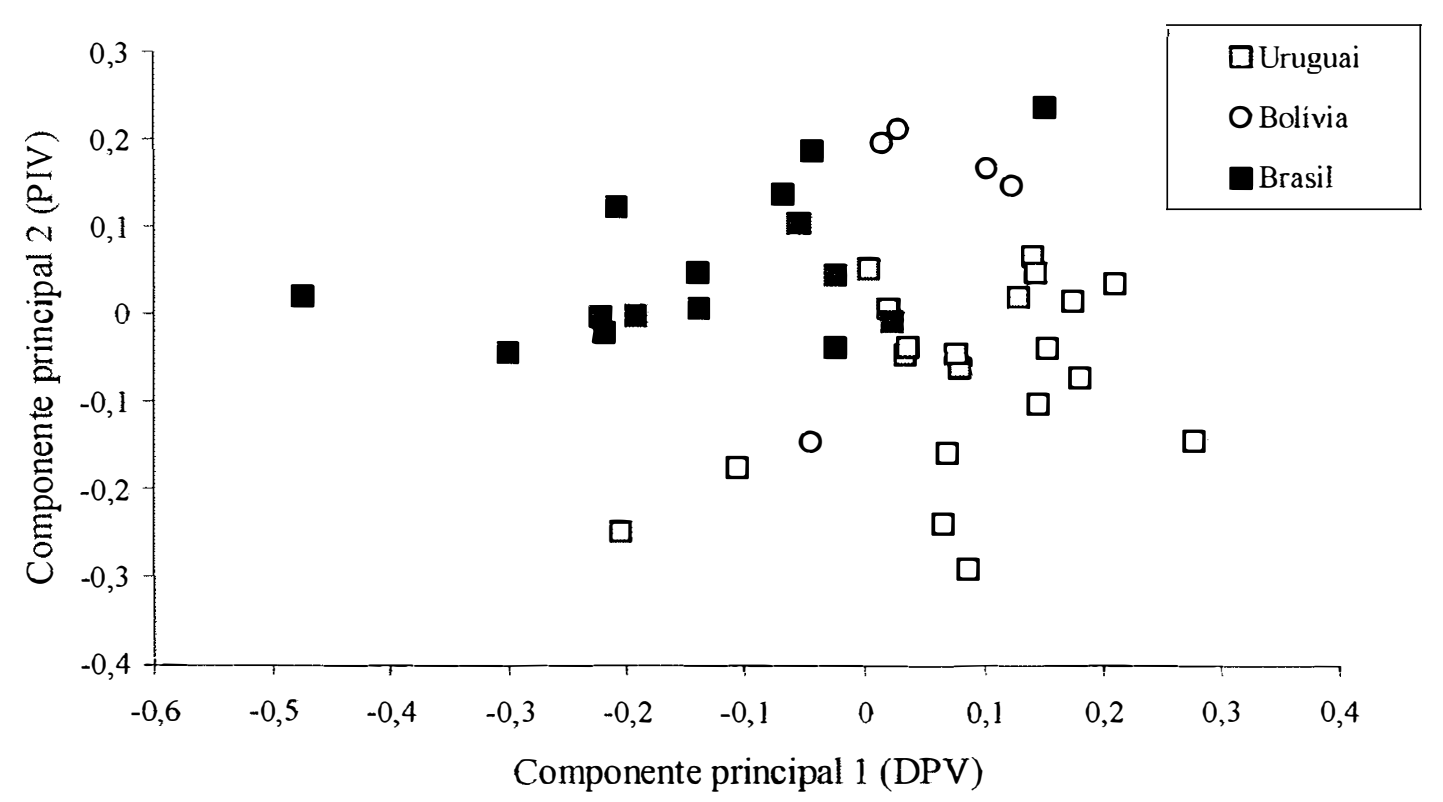

Figura 41 - Ordenação de Trichogramma galloi nos dois primeiros componentes.

$\mathrm{Na}$ análise das variáveis canônicas, os testes multivariados Wilks'Lambda $(\mathrm{P}<0,0001)$, Pillai's Trace $(\mathrm{P}<0,0001)$, Hotelling-Lawley Trace $(\mathrm{P}<0,0001)$ e Roy's Greatest Root $(\mathrm{P}<0,0001)$, mostraram que os eixos canônicos foram estatisticamente significativos, extraídos da matriz resultante do produto da matriz de covariância entre 
os grupos pela matriz de covariância dentro dos grupos foram estatisticamente significativos. A primeira variável canônica explicou $84 \%$ e a segunda $16 \%$ da variação total.

No primeiro eixo canônico, as variáveis de maior importância foram comprimento da abertura dorsal (CAD), largura da lâmina dorsal (LLD), comprimento da extensão posterior da lâmina dorsal (CEPLD) e comprimento do processo intervolselar (PIV), que apresentaram os maiores valores absolutos, $0,865,0,788,0,708$ e 0,702 , respectivamente. Ao longo do segundo eixo canônico, os espécimes do Brasil são completamente discriminados dos do Uruguai, ao contrário, os espécimes da Bolívia separam-se do Uruguai. Ao longo do segundo eixo canônico, os espécimes da Bolívia e Uruguai estão separados, no entanto, não há uma distinta separação entre os espécimes do Brasil e Bolívia (Figura 42). As variáveis de maior importância foram o comprimento da lâmina dorsal (CLD), distância basal (DB) e largura apical (LA) com valores absolutos de $0,615,0,584,0,535$ e 0,506 ,

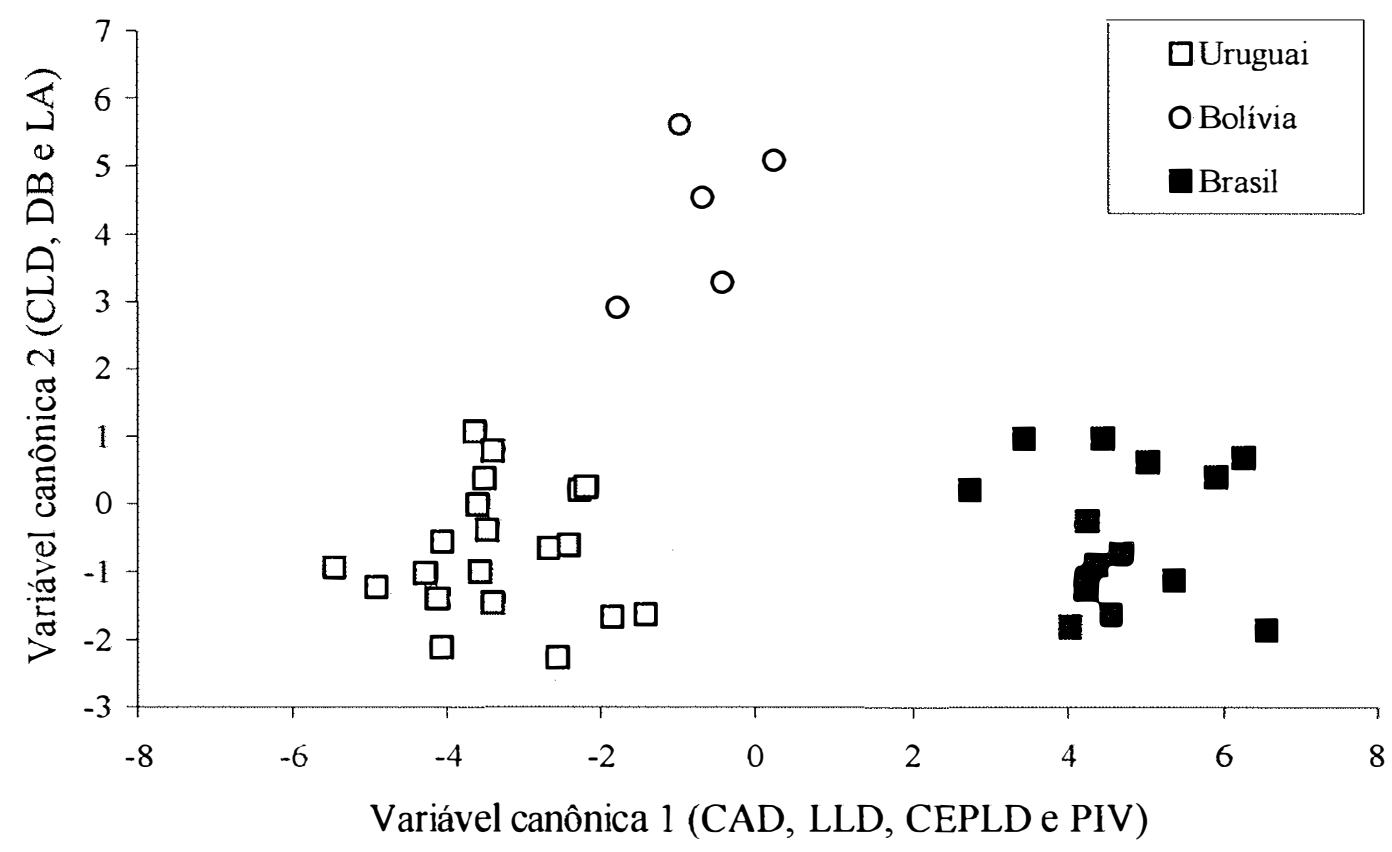

Figura 42 - Ordenação de Trichogramma galloi nos dois primeiro eixos canônicos. 


\section{Distribuiç̃o geográfica e hospedeiros}

T. galloi foi pela primeira vez coletado de ovos de Diatraea sp., em cana-deaçúcar, no Estado de São Paulo, Brasil. Na América do Sul, T. galloi ocorre na Bolívia, Brasil, Paraguai, Peru e Uruguai. No Brasil, essa espécie encontra-se distribuída nos Estados de São Paulo (Araras e Piracicaba) e no Rio de Janeiro (Conceição de Macabu). Essa espécie está associada às espécies de Diatraea em cana-de-açúcar em todos os países em que foi registrada.

\subsubsection{Trichogramma jalmirezi Zucchi, 1988}

(Figura 43)

Trichogramma jalmirezi Zucchi, 1988: 137; Zucchi, 1985: 40; Zucchi \& Monteiro, 1997: 54.

T. jalmirezi foi coletada de ovos de Diatraea sp., no Estado do Rio de Janeiro, no município de Macaé (Zucchi, 1988). Os caracteres para o reconhecimento dessa espécie são as cerdas flageliformes curtas com o ápice abruptamente afilado; lâmina dorsal com acentuada reentrância basal; extensão posterior da lâmina dorsal ultrapassando o ápice das volselas e processo intervolselar longo, conspícuo não alcançando as volselas.

Outras características que auxiliam a identificação dessa espécie são o número reduzido de sensilos basicônicos, com fórmula 1-1-1-0-1-1; presença de três sensilos placóideos situados no terço apical do flagelo; número moderado de cerdas (13) entre a $4^{\underline{a}}$ e $5^{\underline{a}}$ fileiras de cerdas da asa anterior; processos ventrais situados próximos da base do processo intervolselar e carena ventral alcançando a metade da cápsula genital.

T. jalmirezi é uma das espécies associadas a D. saccharalis em cana-de-açúcar no Brasil, apresentando características morfológicas muito semelhantes a T. distinctum e a $T$. galloi. Essa espécie diferencia-se de $T$. distinctum por apresentar a lâmina dorsal com reentrância mais suave e de $T$. galloi pela extensão posterior da lâmina dorsal afilando-se mais gradualmente e o processo intervolselar não alcançando o nível das volselas. 
Os caracteres que separam essas espécies (por exemplo, características da lâmina dorsal) estão muito sujeitas a variações intra-específicas. Além disso, a lâmina dorsal é um dos caracteres mais plástico em Trichogramma. É necessário realizar levantamentos para redescobrir a espécie, para que estudos biológicos e moleculares possam ser realizados para definir seus limites e permitir uma melhor caracterização.

\section{Material examinado}

BRASIL. RIO DE JANEIRO: Macaé , 2-ago.-1983, holótipo, macho, ex ovos de Diatraea sp., José Luiz col. (ESALQ).

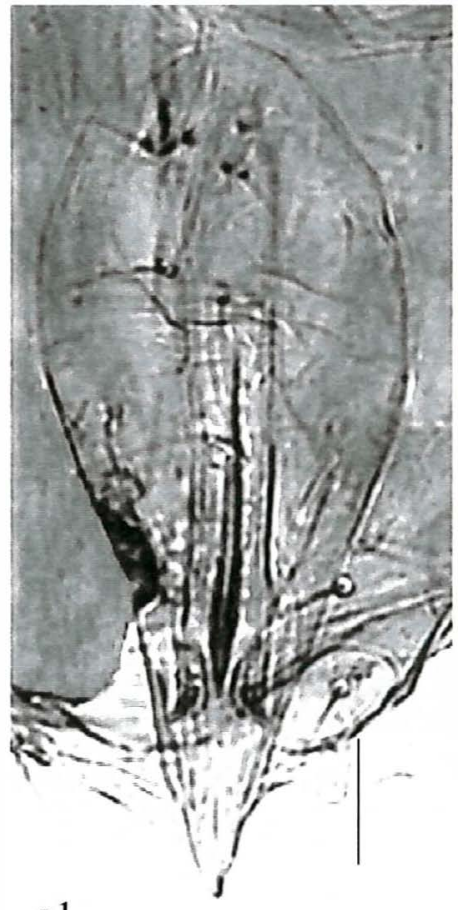

al
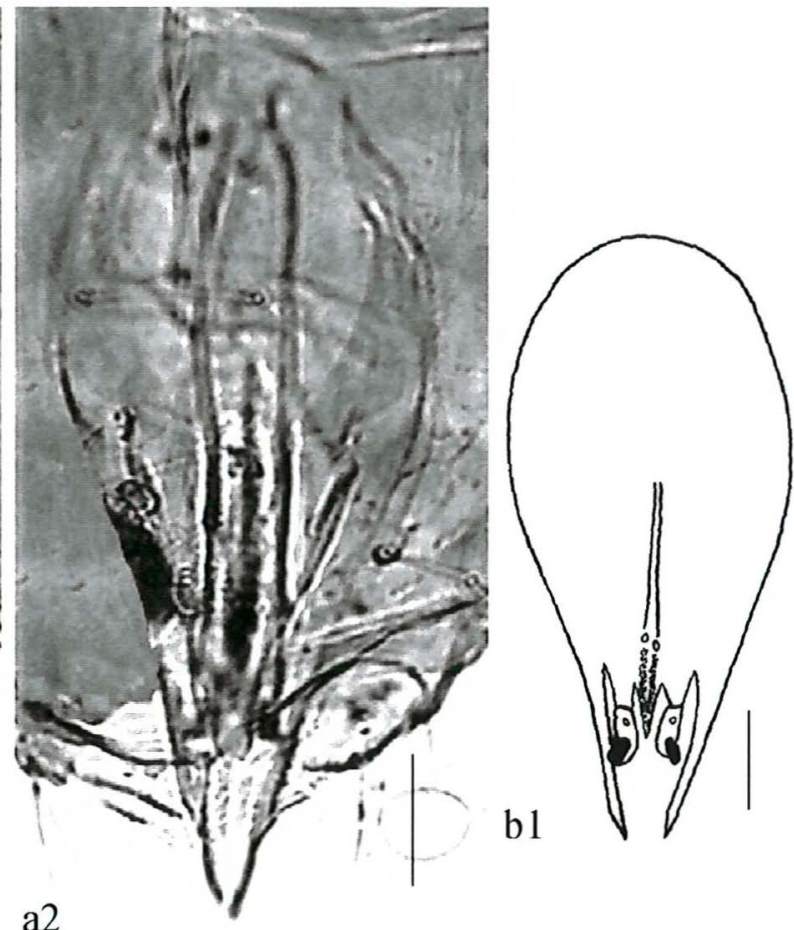

b2

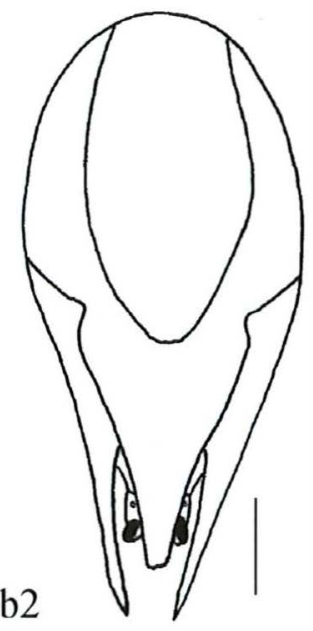

Figura 43 - Cápsula genital de Trichogramma jalmirezi (a -10 $\mu \mathrm{m}$ e b-20 $\mu \mathrm{m})$ : 1 - ventral e 2-dorsal. 


\subsubsection{Trichogramma lasallei Pinto, 1998}

(Figura 44)

Trichogramma lasallei Pinto, 1998: 187; Foerster et al., 2000: 385; Querino et al., 2000:

411; Zucchi \& Querino, 2000: 201; Ciociola Jr. et al., 2001: 259.

Trichogramma rojasi Galán \& Rodríguez, 1991: 177.

\section{Caracterizacão morfológica}

Antenas: flagelo longo $(0,17 \pm 0,010)$; relação entre o comprimento e a largura do flagelo $(6,04 \pm 0,50)$; cerdas flageliformes longas $(0,09 \pm 0,010)$, com o ápice uniformemente afilado; comprimento da maior cerda do flagelo/maior largura do flagelo $(3,13 \pm 0,31)$; comprimento do flagelo/comprimento da tíbia posterior $(1,16 \pm 0,06)$; sensilo basicônico subgloboso, fórmula 1-2-2-0-1-1; três sensilos placóideos.

Asas anteriores: largura da asa anterior $(0,23 \pm 0,010)$; comprimento da maior cerda da franja da asa/comprimento da tíbia posterior $(0,33 \pm 0,03)$; relação entre a largura e o comprimento da asa $(0,49 \pm 0,02)$; comprimento da maior cerda da franja da asa/largura da asa anterior $(0,20 \pm 0,01)$; número de cerdas entre a $4^{\underline{a}}$ e $5^{\underline{a}}$ fíleiras de 6 a 13.

Asas posteriores: fileira anterior com 0 ou 1 cerda e a posterior com 3 a 7 cerdas; fileira posterior alcançando a metade do comprimento da fileira mediana.

Escutelo: relação entre as cerdas anteriores e posteriores $(0,27 \pm 0,08)$.

Genitália masculina: cápsula genital escurecida; largura/comprimento da cápsula genital $(0,34 \pm 0,02)$; distância apical/comprimento da cápsula genital $(0,23 \pm 0,03)$; largura apical/largura da cápsula genital $(0,79 \pm 0,05)$; lâmina dorsal com reentrância na região basal; comprimento da lâmina dorsal/comprimento da cápsula genital $(0,39 \pm$ 0,03); carena dorsal ausente; comprimento/largura da lâmina dorsal (1,38 $\pm 0,09)$; comprimento da extensão posterior da lâmina dorsal $(0,04 \pm 0,010)$; comprimento da abertura dorsal/comprimento da lâmina dorsal $(1,46 \pm 0,10)$; comprimento da extensão posterior da lâmina dorsal/comprimento da lâmina dorsal $(0,87 \pm 0,03)$; carena ventral/distância basal $(0,44 \pm 0,06)$; distância basal/comprimento da cápsula genital $(0,78 \pm 0,05)$; processos ventrais afastados do processo intervolselar $(0,01 \pm 0,010)$; 
processo intervolselar curto, não alcançando as volselas; comprimento do edeago/comprimento da tíbia posterior $(0,44 \pm 0,05)$; apódema/edeago $(0,96 \pm 0,12)$.

Dados quantitativos obtidos de 30 machos coletados de ovos de $A$. gemmatalis em soja.

\section{Material examinado}

BOLÍVIA. 8 machos, Líbia Gárzon col. (ESALQ). BRASIL. PARANÁ: Curitiba, 02-fev.-1999, 30 machos, ex ovos de Anticarsia gemmatalis, em soja, L.A. Foerster col. (ESALQ). PERU. 13 machos, ex ovos de Quinta cannae, em Achira, Mary Whu col. (ESALQ). URUGUAI. ARTIGAS: Bella Union, 16-abr.-1988, 6 machos, ex ovos de Diatraea saccharalis, em cana-de-açúcar, César Basso col. (ESALQ).

\section{$\underline{\text { Diagnose }}$}

T. lasallei é distinguido pelas cerdas flageliformes longas, com ápice uniformemente afilado; sensilo basicônico subgloboso, fórmula 1-2-2-0-1-1; cerdas anteriores do escutelo distintas e escuras; cerdas da fileira posterior das asas posteriores distintas e alcançando a metade da fileira mediana; cápsula genital escurecida; carena ventral curta, com limite anterior pouco definido e de difícil visualização; processos ventrais afastados da base do processo intervolselar; processo intervolselar curto; lâmina dorsal com aspecto triangular, com os lados retos e a extensão posterior levemente pontiaguda. Essas características permitem separar T. lasallei de T. bruni e de T. rojasi.

\section{Variacões}

Os espécimes de $T$. lasallei coletados no Uruguai são levemente menores que os do Brasil, isto é, possuem o flagelo, as cerdas flageliformes e a tíbia posterior menores (Figura 45). Não foram observadas variações no número de sensilos basicônicos Os caracteres observados nos espécimes brasileiros correspondem aos da descrição original (Pinto, 1998). 

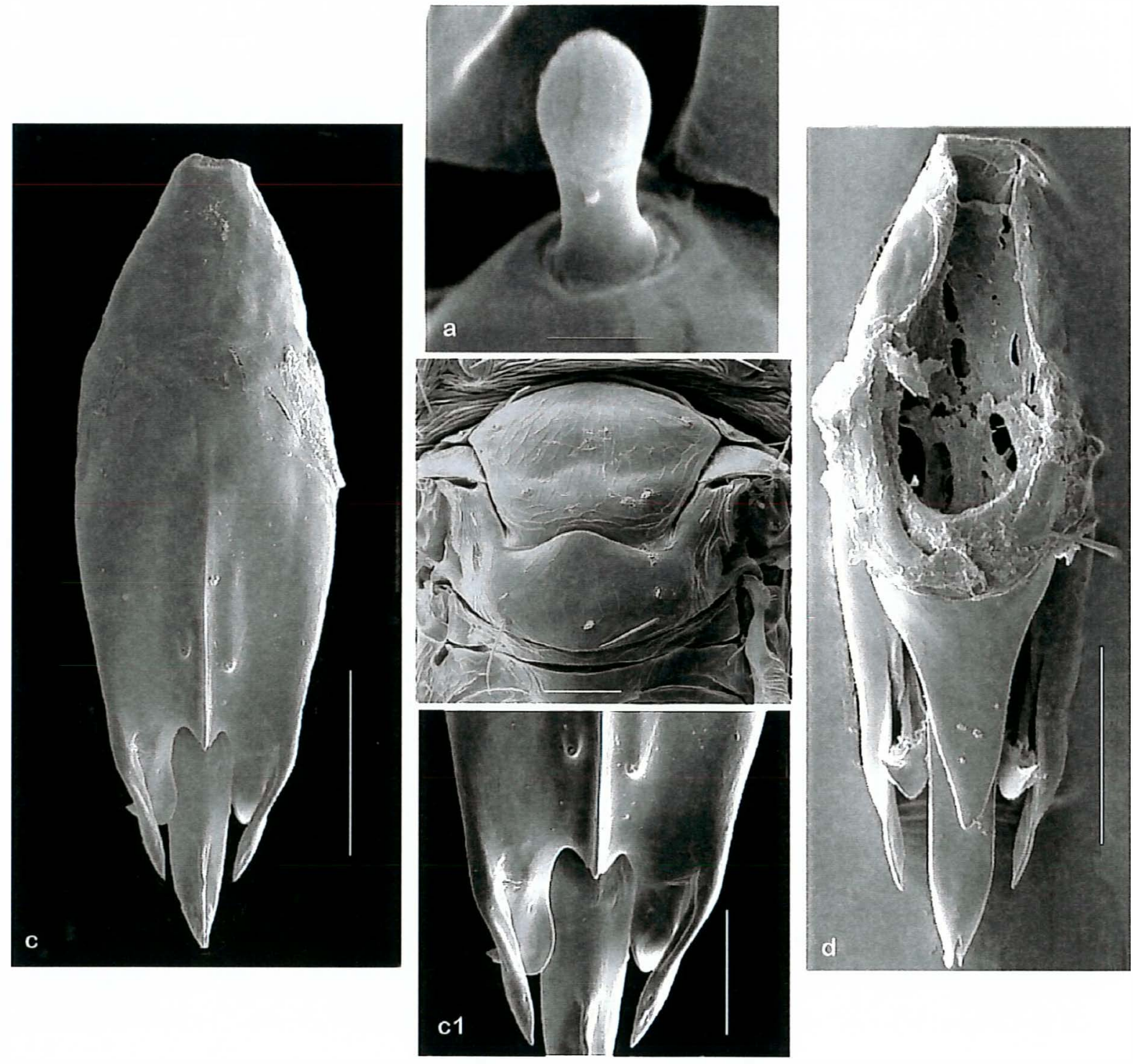

Figura 44 - Trichogramma lasallei: a - sensilo basicônico (10000x, 1 $\mu \mathrm{m})$; b - mesoescuto e escutelo $(550 \mathrm{x}, 20 \mu \mathrm{m})$; c - cápsula genital vental $(775 \mathrm{x}, 20 \mu \mathrm{m})$, cl - detalhe apical $(1750 \mathrm{x}, 10 \mu \mathrm{m}) ; \mathrm{d}$ - cáspula genital dorsal $(775 \mathrm{x}, 20 \mu \mathrm{m})$. 


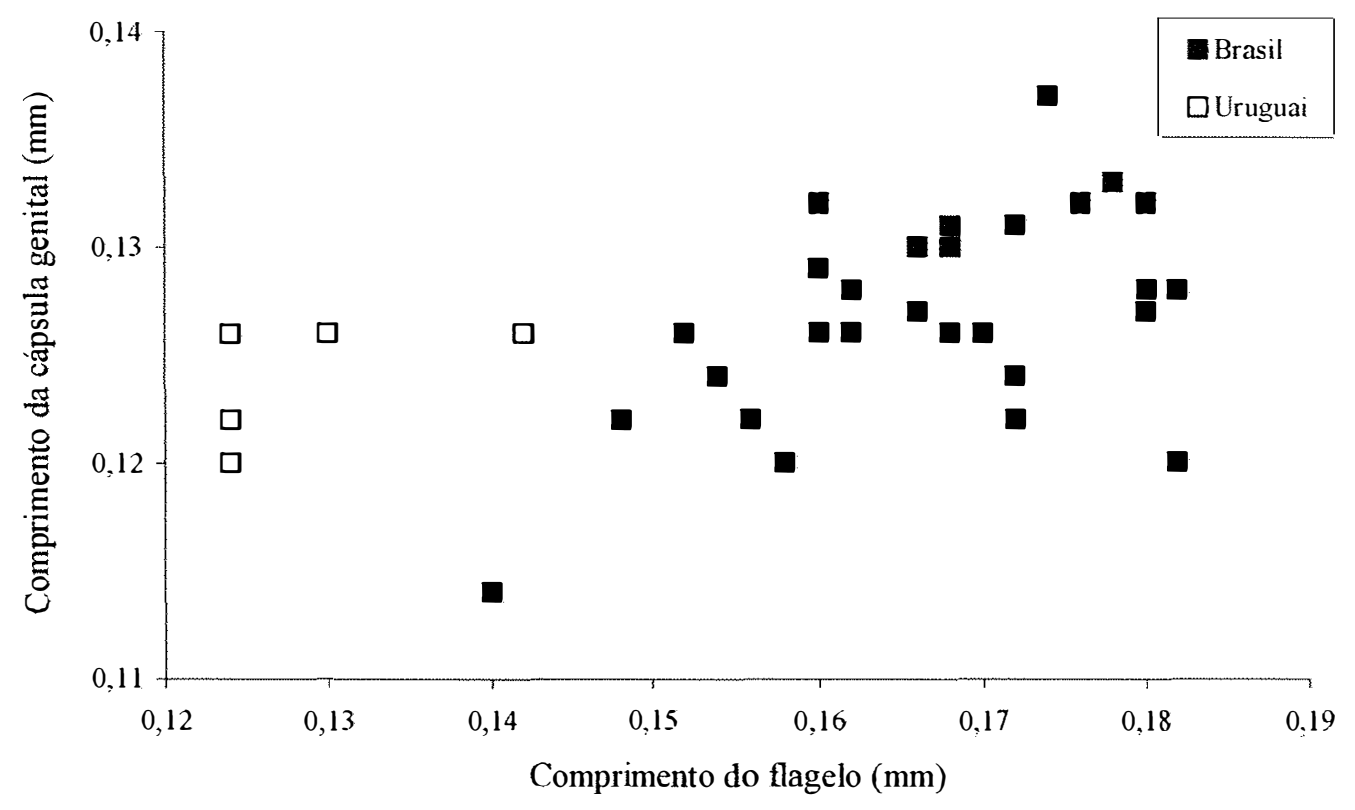

Figura 45 - Comprimento do flagelo versus comprimento da cápsula genital dos espécimes de Trichogramma lasallei coletados no Brasil e no Uruguai.

\section{Distribuicão geográfica e hospedeiros}

T. lasallei foi originalmente coletado nas ilhas Virgens Britânicas, ocorrendo também em Cuba, Costa Rica, México e Estados Unidos, em vegetação rasteira ao nível do mar e hábitat florestais (Pinto, 1998). Na América do Sul, foi registrado no Brasil, parasitando ovos de A. gemmatalis, em soja, em Curitiba, no Estado do Paraná (Foerster et al., 2000); na Colômbia, coletado de ovos de Diatraea spp., em arroz (L.J. Garzon, n.publ.); no Peru, de ovos de Quinta cannae (Herrich-Schäffer, 1869) (Lepidoptera: Hesperiidae) em Achira (Canna indica) (M.Whu, n. publ.) e no Uruguai, de ovos de $D$. saccharalis em cana-de-açúcar.

Não há referência de distribuição em outras regiões e de outros hospedeiros, à exceção do registro dessa espécie em Cuba (como T. rojasi) coletada de ovos de Mocis latipes (Guenée, 1852) (Lepidoptera: Noctuidae) em Panicum maximum por Galán \& Rodrigues (1991). 


\section{Comentários}

T. lasallei foi descrita recentemente por Pinto (1998). Apresenta características gerais semelhantes a $T$. rojasi. Assim, muitos espécimes considerados $T$. rojasi antes de 1998, podem tratar-se de T. lasallei, como observado por Pinto (1998) no material identificado por Galán \& Rodrigues (1991). Um caso semelhante foi observado no Brasil com o material proveniente de Curitiba, Paraná, que havia sido identificado como $T$. rojasi. O exame dessa amostra, revelou que tratava-se de $T$. lasalle $i$. Outro caso foi com uma amostra recebida do Peru, que havia sido identificada como T. rojasi por S. Nagarkatti (M. Whu P., inf. pes.), entretanto, o exame desse material constatou-se que se tratava de T. rojasi.

Ciociola Jr. et al (2001) realizou o seqüenciamento de r-DNA (região ITS-2) das amostras de $T$. rojasi e $T$. lasallei utilizadas neste trabalho, que foram coletadas de ovos de A. gemmatalis em soja, em Curitiba, Paraná, e confirmou que se tratava de duas espécies distintas, apesar das sutis diferenças morfológicas entre elas.

\subsubsection{Trichogramma lopezandinensis Sarmiento, 1983}

(Figura 46)

Trichogramma lopezandinensis Sarmiento, 1993: 3; Zucchi \& Monteiro, 1997: 54; Pinto, 1998: 80.

\section{Caracterizacão morfológica}

Antenas: flagelo longo $(0,15 \pm 0,011)$; relação entre o comprimento e a largura do flagelo $(7,34 \pm 0,60)$; cerdas flageliformes longas $(0,09 \pm 0,005)$, com ápice uniformemente afilado; comprimento da maior cerda do fl agelo/maior largura do flagelo $(4,06 \pm 0,39)$; comprimento do flagelo/comprimento da tíbia posterior $(1,05 \pm 0,05)$; sensilos basicônicos ovalado e fórmula 1-0-0-1(0)-1-1; três sensilos placóideos, o basal medindo $0,01 \pm$ 0,001 . 
Asas anteriores: relação entre a largura e o comprimento da asa $(0,46 \pm 0,02)$; comprimento da maior cerda da franja da asa/comprimento da tíbia posterior $(0,59 \pm$ $0,04)$; comprimento da maior cerda da franja da asa anterior/largura da asa anterior $(0,44$ $\pm 0,04)$. Número de cerdas entre a $4^{\underline{a}}$ e $5^{\underline{a}}$ fileiras de 3-14.

Asas posteriores: fileira anterior ausente e a posterior com número de cerdas variando de 4-9.

Escutelo: relação entre as cerdas anteriores e posteriores $(0,34 \pm 0,10)$.

Genitália masculina: cápsula genital mais longa $(0,11 \pm 0,003)$ do que larga $(0,04 \pm$ $0,002)$; relação entre a largura e o comprimento da cápsula genital $(0,40 \pm 0,02)$; distância apical/comprimento da cápsula genital $(0,24 \pm 0,02)$; largura apical/largura da cápsula genital $(0,60 \pm 0,04)$; lâmina dorsal inserida na metade da cápsula genital, com leve reentrância na região basal; comprimento da lâmina dorsal/comprimento da cápsula genital $(0,41 \pm 0,003)$; comprimento/largura da lâmina dorsal $(1,66 \pm 0,15)$; comprimento da abertura dorsal/comprimento da lâmina dorsal $(1,31 \pm 0,10)$; extensão posterior da lâmina dorsal com ápice pontiagudo e longa $(0,04 \pm 0,002)$; comprimento da extensão posterior da lâmina dorsal/comprimento da lâmina dorsal $(0,80 \pm 0,03)$; carena dorsal ausente; carena ventral longa $(0,05 \pm 0,005)$ ultrapassando a metade da cápsula genital; carena ventral/distância basal $(0,59 \pm 0,06)$; distância basal/comprimento da cápsula genital $(0,76 \pm 0,02)$; processos ventrais próximos da base do processo intervoselar $(0,01 \pm 0,001)$; comprimento do edeago/comprimento da tíbia posterior $(0,40 \pm 0,03)$; apódemas/edeago $(0,88 \pm 0,05)$.

Dados quantitativos obtidos de 11 machos criados em S. cerealella (hospedeiro alternativo).

\section{Material examinado}

COLÔMBIA. 09-set.-1999, 11 machos, criados em ovos de Sitotroga cerealella (ESALQ). 

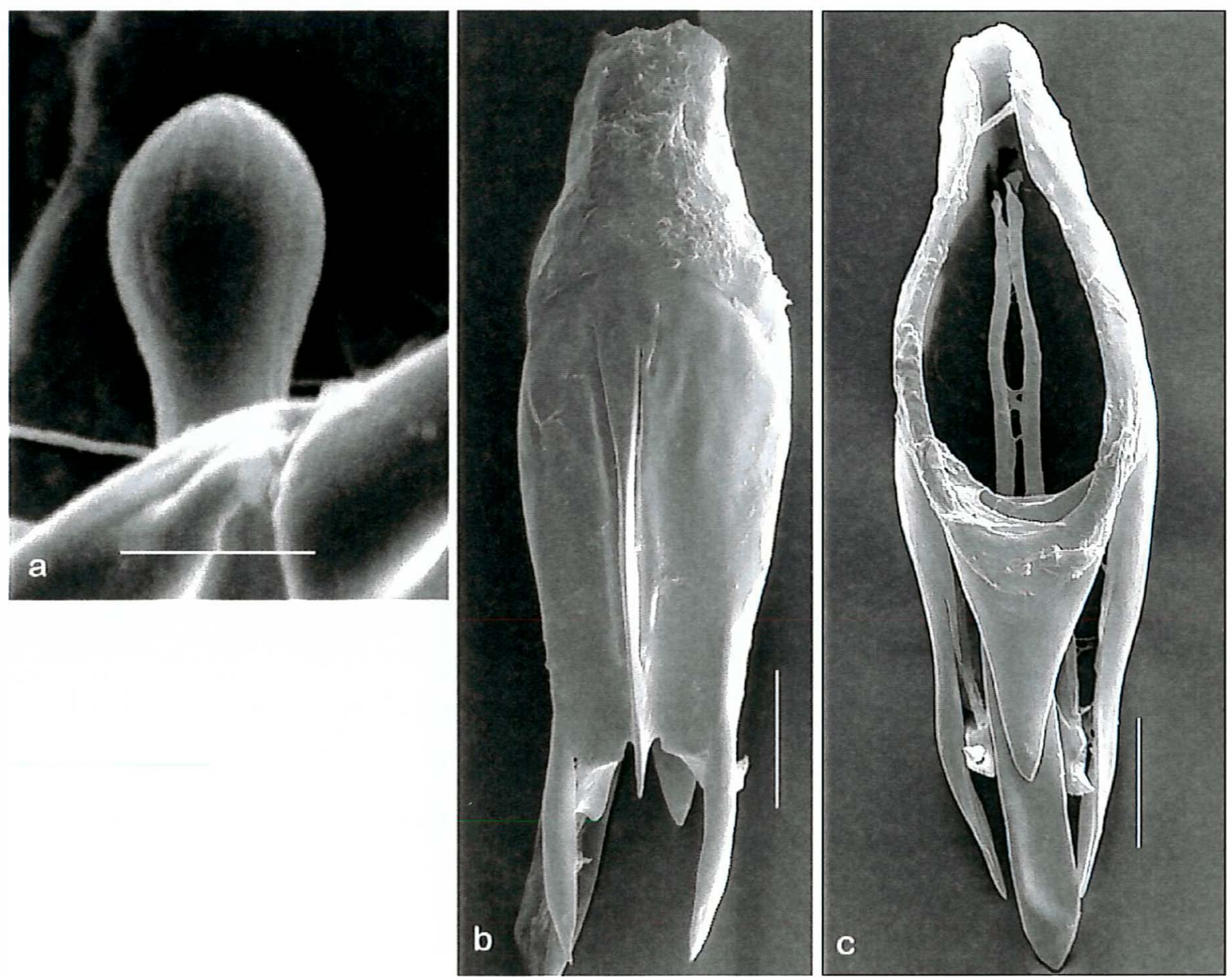

Figura 46 - Trichogramma lopezandinensis: a - sensilo basicônico (15000x, 1 $\mu \mathrm{m})$; b cápsula genital ventral $(925 \mathrm{x}, 20 \mu \mathrm{m})$; d - cápsula genital dorsal $(925 \mathrm{x}$, $20 \mu \mathrm{m})$.

\section{$\underline{\text { Diagnose }}$}

T. lopezandinensis é distinguido de outras espécies da América do Sul, principalmente, pelas cerdas longas da asa anterior (Figura 47) e reduzido número de sensilos basicônico na antena, fórmula 1-0-0-1(0)-1-1. Dentre as espécies que ocorrem na região Neotropical, T. lopezandinensis pode ser confundida com T. bruni. T. lopezandinensis apresenta características semelhantes a T. bruni, entretanto, é separada por estruturas das asas (Sarmiento, 1983 e Pinto, 1998). Em T. lopezandinensis, a asa 
anterior é mais estreita e o comprimento das cerdas da franja da asa anterior consideravelmente maior do que em T. bruni. Na asa posterior, a fileira posterior de cerdas é mais longa em $T$. lopezandinensis do que em $T$. bruni. As estruturas da cápsula genital de T. lopezandinensis são semelhantes à T. bruni.

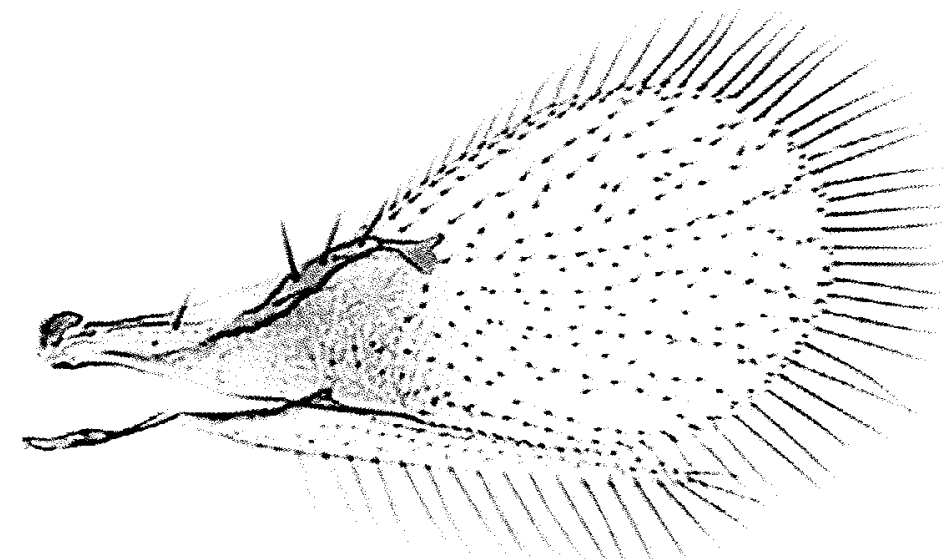

Figura 47 - Asa anterior e posterior de Trichogramma lopezandinensis $(50 \mu \mathrm{m})$.

\section{$\underline{\text { Variações }}$}

A principal variação ocorreu no comprimento da carena ventral $(0,04$ a $0,06 \mathrm{~mm})$.

\section{Análises multivariadas}

A análise dos componentes principais separou distintamente $T$. lopezandinensis de T. bruni (Figura 48). O primeiro componente explicou cerca de $65,24 \%$ da variação total, o segundo $13,01 \%$ e o terceiro $5,89 \%$, portanto, os dois primeiros componentes explicaram 78,25\% da variação total presente na matriz da covariância.

O comprimento das cerdas da franja da asa anterior (CCFAA) apresentou o maior autovetor, com valor absoluto de 0,742 , sendo a variável de maior importância no primeiro componente; ao longo desse eixo $T$. lopesandinensis é completamente discriminada de $T$. bruni $\mathrm{O}$ segundo componente foi mais influenciado pelo 
comprimento das cerdas anteriores do escutelo, que apresentou o maior valor absoluto de 0,597 , entretanto, esse eixo não foi importante para separar as duas espécies.

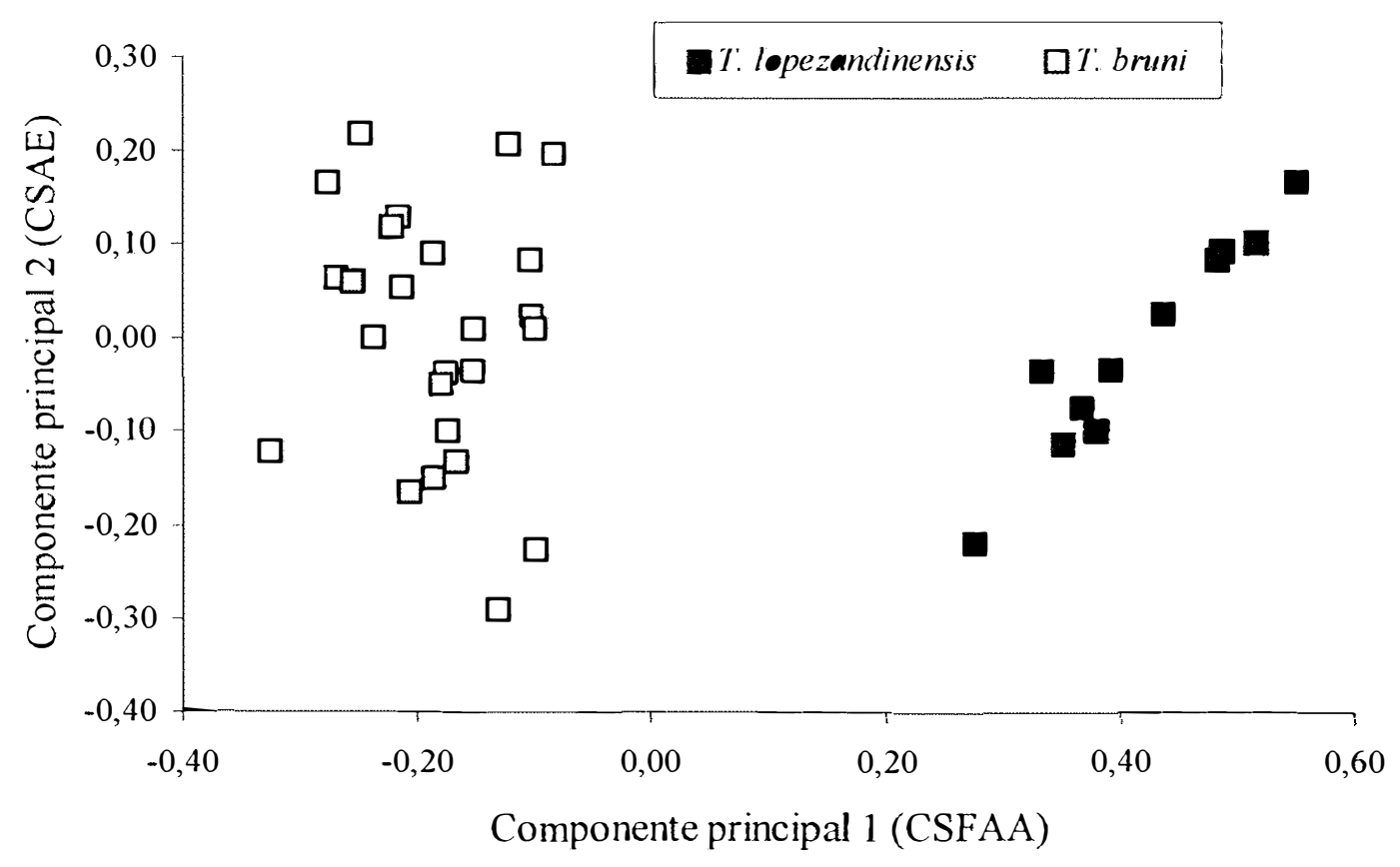

Figura 48 - Ordenação de Trichogramma lopezandinensis e Trichogramma bruni, nos dois primeiros componentes.

A análise das variáveis canônicas (Figura 49) demonstrou ordenação semelhante à obtida pela análise dos componentes principais. Os testes multivariados Wilks'Lambda $(\mathrm{P}<0,0001)$, Pillai's Trace $(\mathrm{P}<0,0001)$, Hotelling-Lawley Trace $(\mathrm{P}<0,0001)$ e Roy's Greatest Root $(\mathrm{P}<0,0001)$ mostraram que os eixos canônicos foram estatisticamente significativos, extraídos da matriz resultante do produto da matriz de covariância entre os grupos pela matriz de covariância dentro dos grupos. A primeira variável canônica explicou $100 \%$ da variação total.

No primeiro eixo canônico, a variável comprimento das cerdas da franja da asa anterior (CCFAA) foi a variável mais importante com valor absoluto de 0,980. A projeção dos escores dos espécimes no espaço das duas variáveis canônicas, mostra que T. lopezandinensis é completamente discriminado de T. bruni ao longo do primeiro eixo 
canônico. O segundo eixo canônico não foi importante para a separação das espécies, representado pelo comprimento da extensão posterior da lâmina dorsal (CEPLD) e o comprimento da lâmina dorsal (CLD), com os maiores valores absolutos de 0,109 e 0,182 , respectivamente.

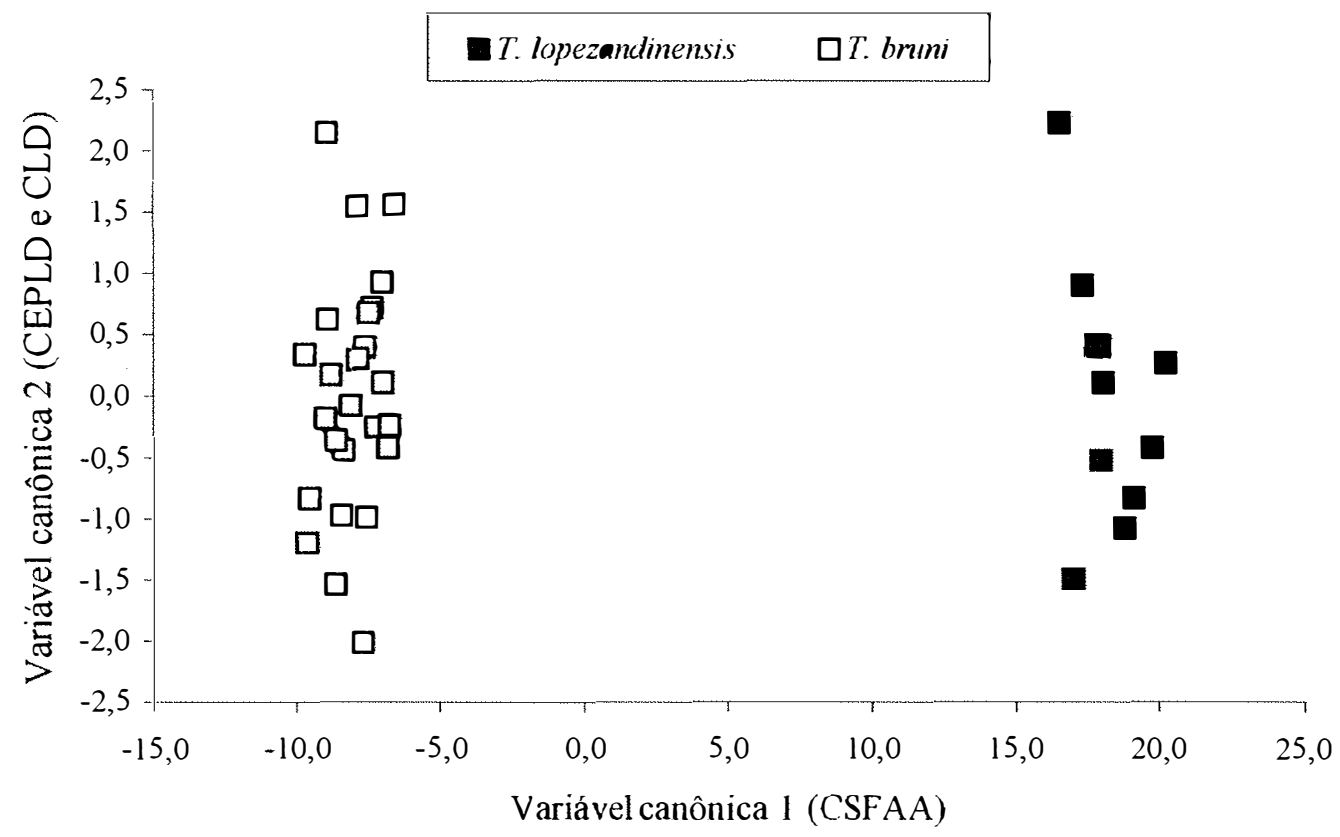

Figura 49 - Ordenação de Trichogramma lopezandinensis e Trichogramma bruni nos primeiros eixos canônicos

As análises mostraram que o comprimento das cerdas da franja da asa anterior, é o caráter mais importante para a separação das duas espécies.

\section{Distribuicão geográfica e hospedeiros}

T. lopezandinensis é uma espécie dos Andes colombiano. Foi registrada pela primeira vez de ovos de Colias dimera Doubleday, 1847 (Lepidoptera: Pieridae) em Trifolium repens (trevo) em Chipaque, Cundinamarca, Colômbia, (Sarmiento, 1983). Esta espécie também foi coletada de ovos de Copitarsia consueta (Walker) (Lepidoptera: Noctuidae) em batata (Zucchi \& Monteiro, 1997). Não há informações da ocorrência dessa espécie em outros países da América do Sul. 


\subsubsection{Trichogramma maxacalii Vogelé \& Pointel, 1980}

(Figura 50)

Trichogramma maxacalii Vogelé \& Pointel, 1980: 599; Zucchi, 1985: 49; Zucchi \& Monteiro, 1997: 54.

Trichogramma soaresi Nagaraja, 1983: 38; Zucchi \& Monteiro, 1997: 46 (sinônimo júnior).

T. maxacalii foi originalmente coletado de ovos de Euselasia euploes eucerus Hewitson (Lepidoptera: Rhiodinidae) em Eucalyptus peniculata, em Minas Gerais, Brasil, por G.W.G de Moraes, P. Brun e L.A. Soares (Voegelé \& Pointel, 1980). Essa espécie foi encontrada somente no Brasil e tem como único registro de hospedeiro, espécies de Euselasia, em Eucalipto, nos Estados do Espírito Santo, Minas Gerais e São Paulo (Zucchi \& Monteiro, 1997).

Estudos descritivos dessa espécie estão detalhados em Voegelé \& Pointel (1980), Nagaraja (1983) e Zucchi \& Monteiro (1997). Nos espécimes examinados, os sensilos basicônicos são distintos, fórmula 1-2-2-0(1)-1-1 e apresentam três sensilos placóideos, diferentemente dos quatro observados no holótipo por Voegelé \& Pointel (1980). O número de cerdas entre a $4^{\underline{a}}$ e $5^{\mathrm{a}}$ fileiras da asa anterior variou de 6 a 12. Na cápsula genital, os parâmeros são retos e pontiagudos; volselas muito próximas do ápice dos parâmeros; lâmina dorsal com leve reentrância basal; extensão posterior da lâmina dorsal com lados retos e ápice levemente arredondado, não alcançando o ápice das volselas; processos ventrais afastados da base do processo intervolselar; carena ventral ultrapassando a metade da cápsula genital; processo intervolselar relativamente curto, alcançando a metade do comprimento das volselas.

Voegelé \& Pointel (1980) indicaram as "protuberâncias ventrais" da genitália do macho como característica principal de $T$. maxacalii. Esse caráter, provavelmente, corresponde atualmente aos processos ventrais, que são semelhantes às várias espécies de Trichogramma, não sendo, portanto, um caráter distintivo.

Dentre os espécimes examinados, variações foram observadas no comprimento processo intervolselar, mais alongado em T. maxacalii do Rio Grande do Sul. 


\section{Material examinado}

BRASIL. RIO GRANDE DO SUL: Guaíba, 1-nov.-1984, 3 machos, ex ovos de Euselasia sp., Eucalipto, Dirceu Bressan col. (ESALQ). SÃO PAULO: Mogi Guaçu, s.d., 1 macho, ex ovos de Euselasia sp., Eucalipto, E. Berti fillho col. (ESALQ).
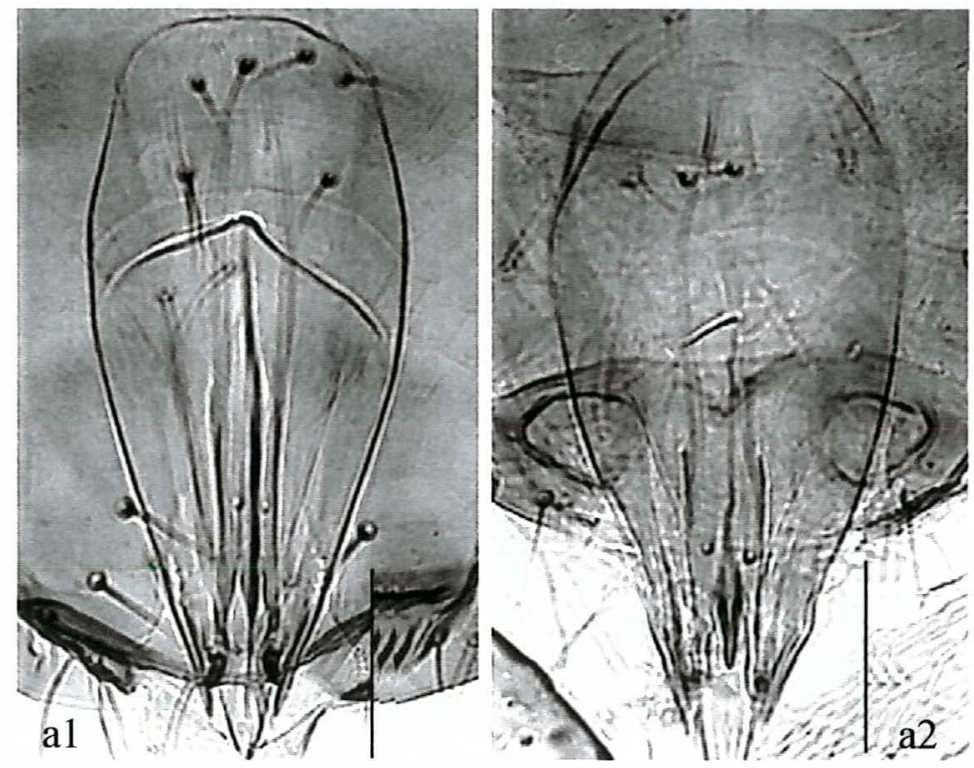

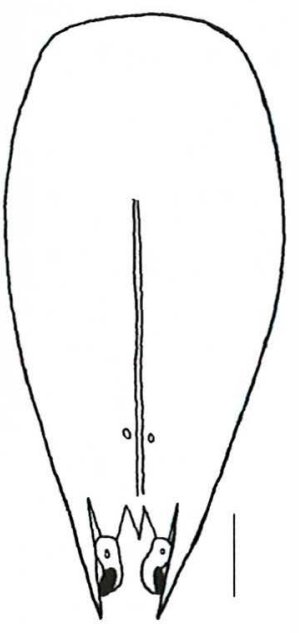

b1

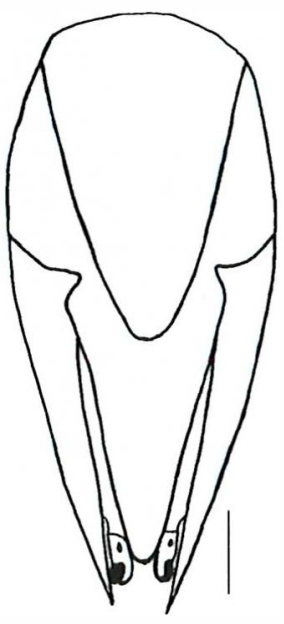

b2

Figura 50 - Cápsula genital de Trichogramma maxacalii (a -10 $\mu \mathrm{m}$ e b - $20 \mu \mathrm{m}): 1$ ventral e 2 - dorsal.

\subsubsection{Trichogramma nerudai Pintureau \& Gerding, 1999}

(Figura 51)

Trichogramma nerudai Pintureau \& Gerding, 1999: 56.

\section{Caracterizacão morfológica}

Antenas: Comprimento do flagelo $(0,13 \pm 0,012)$; relação entre o comprimento e a largura do flagelo $(4,76 \pm 0,47)$; cerdas flageliforme longas $(0,07 \pm 0,006)$, com ápice abruptamente afilado; comprimento da maior cerda do flagelo/maior largura do flagelo $(2,66 \pm 0,26)$; comprimento do flagelo/comprimento da tíbia posterior $(0,92 \pm 0,05)$; 
número reduzido de sensilos basicônicos, forma ovalado e fórmula 1-1-0-0-1-1; três sensilos placóideos, o basal medindo 0,04 $\pm 0,005$.

Asas anteriores: relação entre a largura e o comprimento da asa $(0,53 \pm 0,01)$; comprimento da maior cerda da franja da asa/comprimento da tíbia posterior $(0,21 \pm$ $0,05)$; comprimento da maior cerda da franja da asa anterior/largura da asa anterior $(0,13$ $\pm 0,03$ ); número de cerdas entre a $4^{\underline{a}}$ e $5^{\mathrm{a}}$ filleiras de 23-35.

Asas posteriores: fileira anterior com 6-12 cerdas e a posterior com número de cerdas variando de 8-13, alcançando o ápice da asa.

Escutelo: relação das cerdas anteriores e posteriores $(0,22 \pm 0,004)$.

Genitália masculina: cápsula genital escurecida; os lados da cápsula genital apresentam uma acentuada constrição ao nível do processo intervolselar; cápsula genital mais longa $(0,12 \pm 0,004)$ do que larga $(0,04 \pm 0,002)$; relação entre a largura e o comprimento da cápsula genital $(0,31 \pm 0,01)$; distância apical/comprimento da cápsula genital $(0,20 \pm$ $0,01)$; largura apical/largura da cápsula genital $(0,54 \pm 0,12)$; lâmina dorsal estreita inserida um pouco acima da metade da cápsula genital; comprimento da lâmina dorsal/comprimento da cápsula genital $(0,45 \pm 0,002)$; comprimento/largura da lâmina dorsal $(2,34 \pm 0,19)$; comprimento da abertura dorsal/comprimento da lâmina dorsal $(1,16 \pm 0,07)$; extensão posterior da lâmina dorsal estreita, com os lados retos e o ápice geralmente pontiagudo, ao nível do processo intervolselar e alcançando a base das volselas; comprimento da extensão posterior da lâmina dorsal $(0,04 \pm 0,003)$; comprimento da extensão posterior da lâmina dorsal/comprimento da lâmina dorsal $(0,79 \pm 0,04)$; carena dorsal ausente; carena ventral longa $(0,05 \pm 0,004)$, além da metade da cápsula genital; carena ventral/distância basal $(0,51 \pm 0,03)$; distância basal/comprimento da cápsula genital $(0,80 \pm 0,01)$; processos ventrais próximos da base do processo intervoselar; processo intervolselar curto, alcançando a base das volselas; parâmeros retos em direção ao ápice da cápsula genital; volselas próximas ao ápice dos parâmeros; comprimento do edeago/comprimento da tíbia posterior $(0,50 \pm 0,03)$; apódemas/edeago $(0,79 \pm 0,07)$.

Os dados quantitativos foram obtidos de 18 machos proveniente da Argentina (material oriundo do Chile), multiplicado em laboratório (E. Botto, Argentina). 


\section{$\underline{\text { Material examinado }}$}

ARGENTINA. 18 machos (material proveniente do Chile), criação de laboratório por E. Botto (ESALQ). CHILE. Malloa, 11-mar.-1993, 1 macho, ex ovos de Tuta absoluta, tomate, R. Trincado col. (ESALQ).
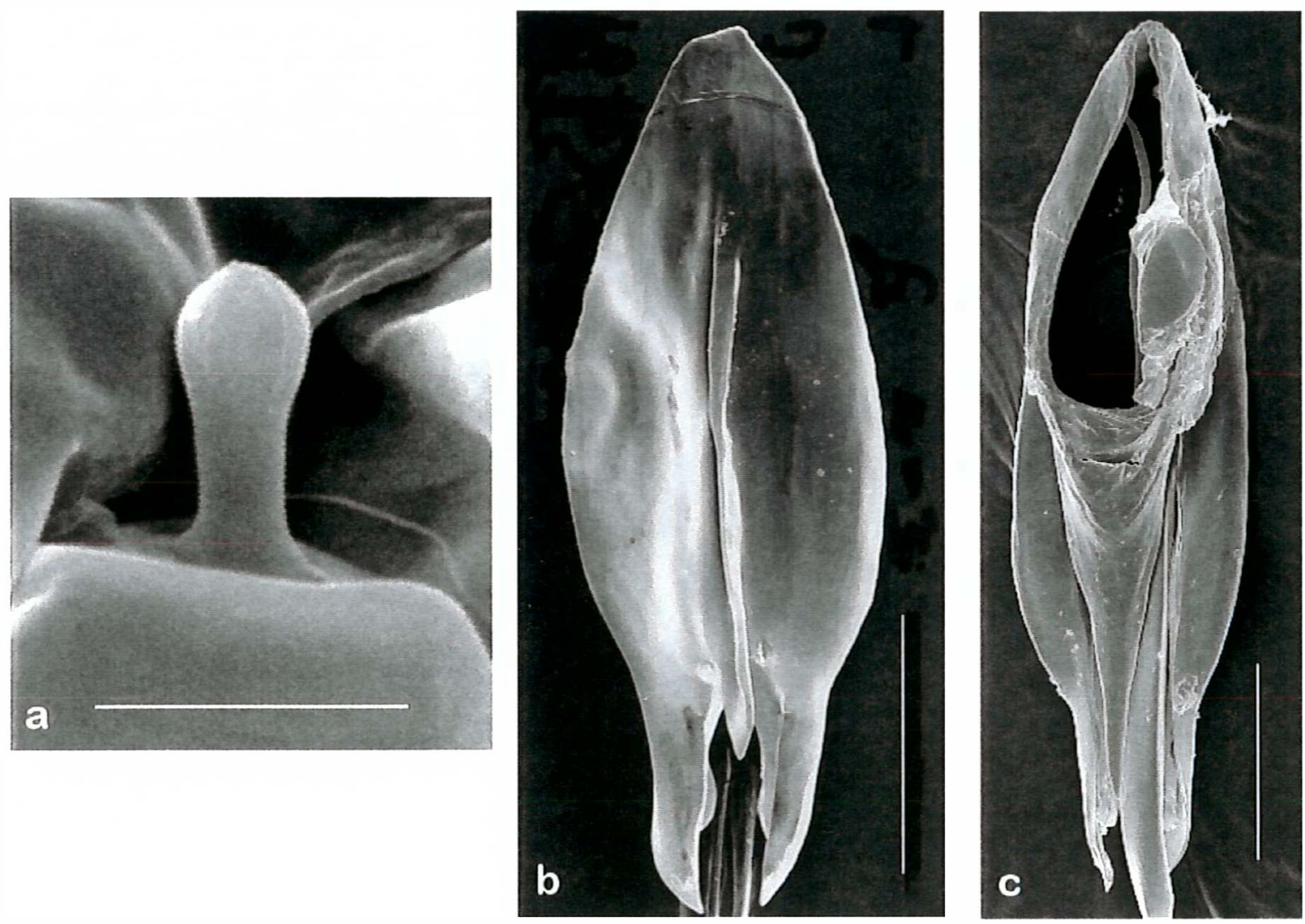

Figura 51 - Trichogramma nerudai: a - sensilo basicônico $(21690 x, 1 \mu \mathrm{m})$; b - cápsula genital ventral (1930x, $20 \mu \mathrm{m})$; c - cápsula genital dorsal $(1400 x, 10 \mu \mathrm{m})$.

\section{Diagnose}

T. nerudai é reconhecido pelo aspecto geral da cápsula genital, ou seja, estreita e com forte constrição ao nível do processo intervolselar. Esse caráter T. nerudai separa de T. pintoi Voegelé, 1992. Em T. nerudai, os lados da cápsula genital estreitam-se abruptamente ao nível do processo intervolselar e os parâmeros são retos em direção ao ápice. Em T. pintoi, os lados da cápsula são mais gradualmente estreitos e os parâmeros são arqueados. Outras espécies que 
podem ser confundidas com T. nerudai, foram discutidas por Pintureau et al. (1999) e, segundo J. D. Pinto (inf. pes.), é difícil separar morfologicamente $T$. nerudai de T. principium Sugonjaev \& Sorokina, 1976.

\section{$\underline{\text { Variacões }}$}

Asas posteriores com variação na fileira posterior de cerdas, atingindo ou não o ápice da asa. Em dois espécimes não foram observados sensilos basicônicos na posição 2 .

\section{Distribuicão geográfica e hospedeiros}

T. nerudai foi descrita originalmente do Chile (região de Angol) e está registrado somente nesse país. Essa espécie foi encontrada parasitando ovos de Rhyacionia buoliana (Denis and Schiffermuller, 1775) (Lepidoptera: Tortricidae), em Pinus radiata, em 1994 por E. Cisternas e, em 1996, por E. Gerding (Pintureau et al., 1999). T. nerudai também foi coletado de ovos de Tuta absoluta Meyrick, 1917, (Lep., Gelechiidae) em tomate (Lycopersicon esculentum), por R. Trincado, em 1993, neste mesmo país (novo registro).

\subsubsection{Trichogramma pintoi Voegelé, 1982}

(Figuras 49)

Trichogramma pintoi Voegelé, 1982: 165; Sorokina 1993:26.

Trichogramma euproctidis: Nagarkatti \& Nagaraja, 1971: 18; Nagarkatti, 1975: 248; Torre, 1980: 28.

T. pintoi é uma espécie originária da região Holoártica, mas há registros em várias áreas da região Paleártica. Essa espécie também tem sido introduzida em vários países em diferentes regiões do mundo (Pinto, 1998). Na América do Sul, foi introduzida na Argentina (Pinto, n. publ.) e no Peru, em 1972. Dentre as espécies introduzidas no Peru, T. pintoi é uma das que têm sido recuperada e está adaptada a três zonas agroecológicas peruanas, parasitando ovos de pragas agrícolas (Whu \& Valdivieso, 1999). São conhecidos cinco 
hospedeiros de T. pintoi (Pinto, 1998). Uma espécie coletada em armadilha de sucção no Horto Florestal de Tupi, em Piracicaba-SP, é muito semelhante a T. pintoi. Entretanto, a cápsula genital parece ser mais ampla e a lâmina dorsal não é tão estreita com em $T$. pintoi . Por essa razão, esta sendo tratada aqui como Trichogramma sp. aff. Pintoi (Figura 53).

As principais características de T. pintoi são cerdas das antenas relativamente longas com ápice abruptamente afilado; número reduzido de sensilos basicônico, fórmula 1-1-1-0-1-1 (ou 1-1(2)-1-(0)-0-1-1, Pinto, 1998); moderado número de cerdas entre a $4^{\underline{a}}$ e $5^{\underline{a}}$ fileiras da asa anterior, variando de 18 a 24; asa posterior também com um elevado número de cerda na fileira anterior (9-10) e fileira posterior (18-24); cápsula genital, com os lados apresentando acentuada constrição ao nível do processo intervolselar; parâmeros nitidamente arqueados; lâmina dorsal com a base estreita e a extensão posterior com o ápice pontiagudo. As características dessa espécie e sua discussão com outras espécies relacionadas estão detalhadas em Pinto (1998).
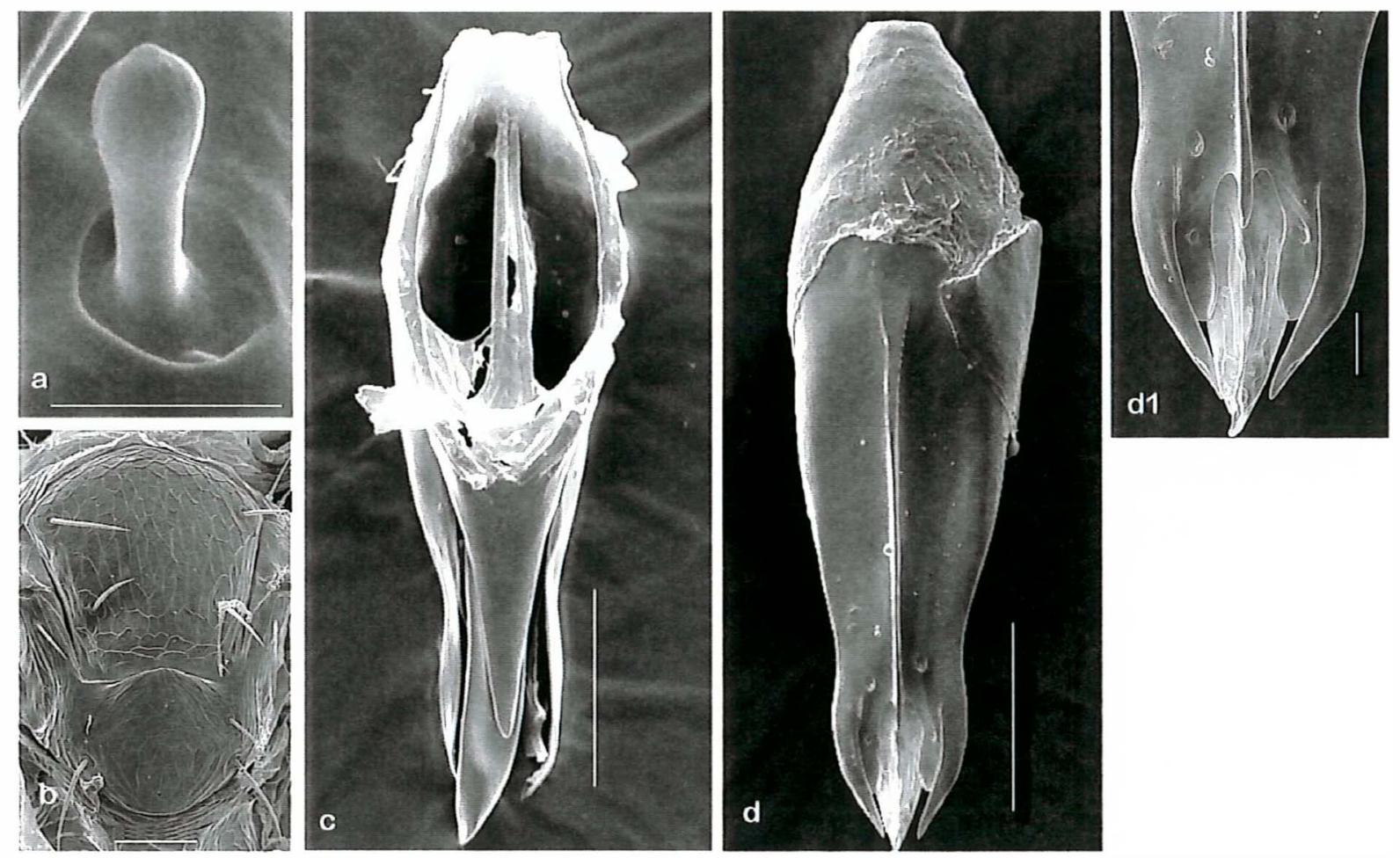

Figura 52 - Trichogramma pintoi: a - sensilo basicônico posição 3 (28040x, l $\mu \mathrm{m})$; b - mesoescuto e escutelo

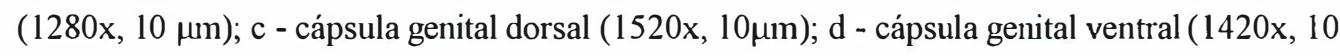

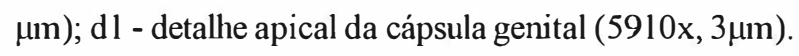




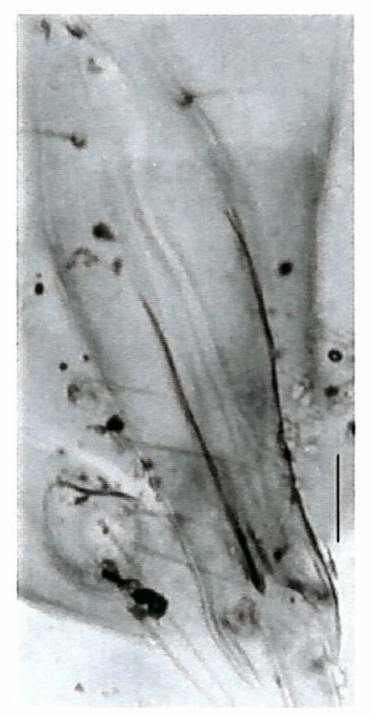

Figura 53 - Cápsula genital de Trichogramma sp. aff. pintoi (ventral -10 $\mu \mathrm{m}$ ).

\subsubsection{Trichogramma pretiosum Riley, 1879}

T. pretiosum é uma espécie bastante estudada e, conseqüentemente, há muitas informações disponiveis na literatura (e.g. Pinto, 1998). Por isso, neste item não é seguida a seqüência usada nos demais. É dada ênfase à aplicação de uma nova metodologia para os estudos morfométrico, que auxilia na caracterização de espécies.

Essa espécie apresenta baixa variabilidade genética e aparente uniformidade morfológica. Entretanto, há populações reprodutivamente incompativeis, sugerindo a presença de espécies cripticas (Pinto, 1998). Variações morfológicas tem sido observadas principalmente na genitália do macho, mesmo sendo esta particularmente resistente à variação ecofenotipica (Pinto et al., 1989).

Os estudos sobre a influência do hospedeiro na morfologia desse parasitóide são escassos. Sabe-se que o tamanho do ovo do hospedeiro influencia no tamanho da espécie de Trichogramma (Marston \& Ertle, 1973; Bai et al, 1992; Kazmer \& Luck, 1991). A maioria dos estudos morfométricos com Trichogramma tem sido baseado em medidas lineares, que certamente são influenciadas pelo tamanho dos indivíduos amostrados. Contudo, não há informações sobre a variação na forma de estruturas morfológicas em 
Trichogramma, mas os hospedeiros podem ser um dos fatores que influencia a variação na forma da cápsula genital de T. pretiosum.

Foram realizados estudos morfométricos para comprovar a variação na forma da cápsula genital de $T$. pretiosum, proveniente de diferentes hospedeiros, usando-se a morfometria geométrica por meio das análises das deformações relativas. Pode-se demonstrar que houve uma variação de forma devido às diferenças nas cápsulas genitais amostradas, observada pela ordenação dos espécimes provenientes dos 10 hospedeiros (círculos claros) em relação à forma média (círculos pretos). A maior variação na forma ocorreu na região anterior da cápsula genital (Figura 54).

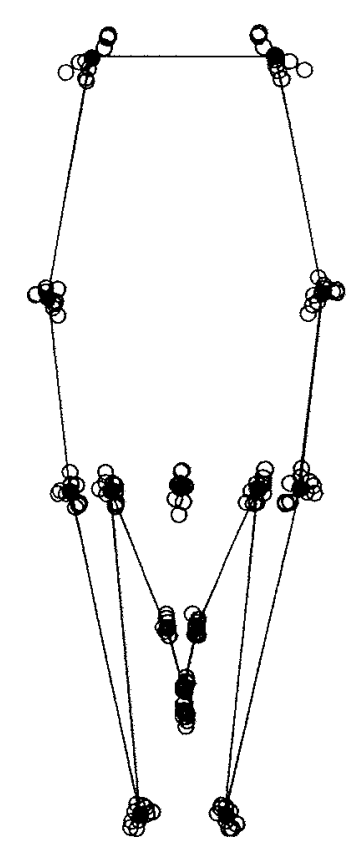

Figura 54 - Configuração dos marcos anatômicos das populações de Trichogramma pretiosum superpostas por quadrados mínimos. As linhas ligam marcos da configuração média (círculos pretos) e a variação de forma pode ser observada ao redor de cada marco (círculo claro).

Os 15 marcos anatômicos geraram 24 escores de deformações para cada amostra de T. pretiosum. A análise das deformações relativas, usando os componentes de forma, ordenou grupos de $T$. pretiosum (Figura 55). Os dois primeiros eixos das deformações relativas explicaram $64,28 \%$ e $18,75 \%$, ou seja, $83,03 \%$ da variação total da forma dos espécimes, não necessitando a utilização de outros eixos. 
T. pretiosum foi ordenado em relação às diferenças totais (globais e localizadas) na forma da cápsula genital (Figura 55). As grades com deformações hipotéticas indicam que os parasitóides provenientes dos hospedeiros localizados em determinada posição nos eixos podem apresentar deformações semelhantes à grade hipotética mais próxima (Figura $55 \mathrm{~A}$ - D).

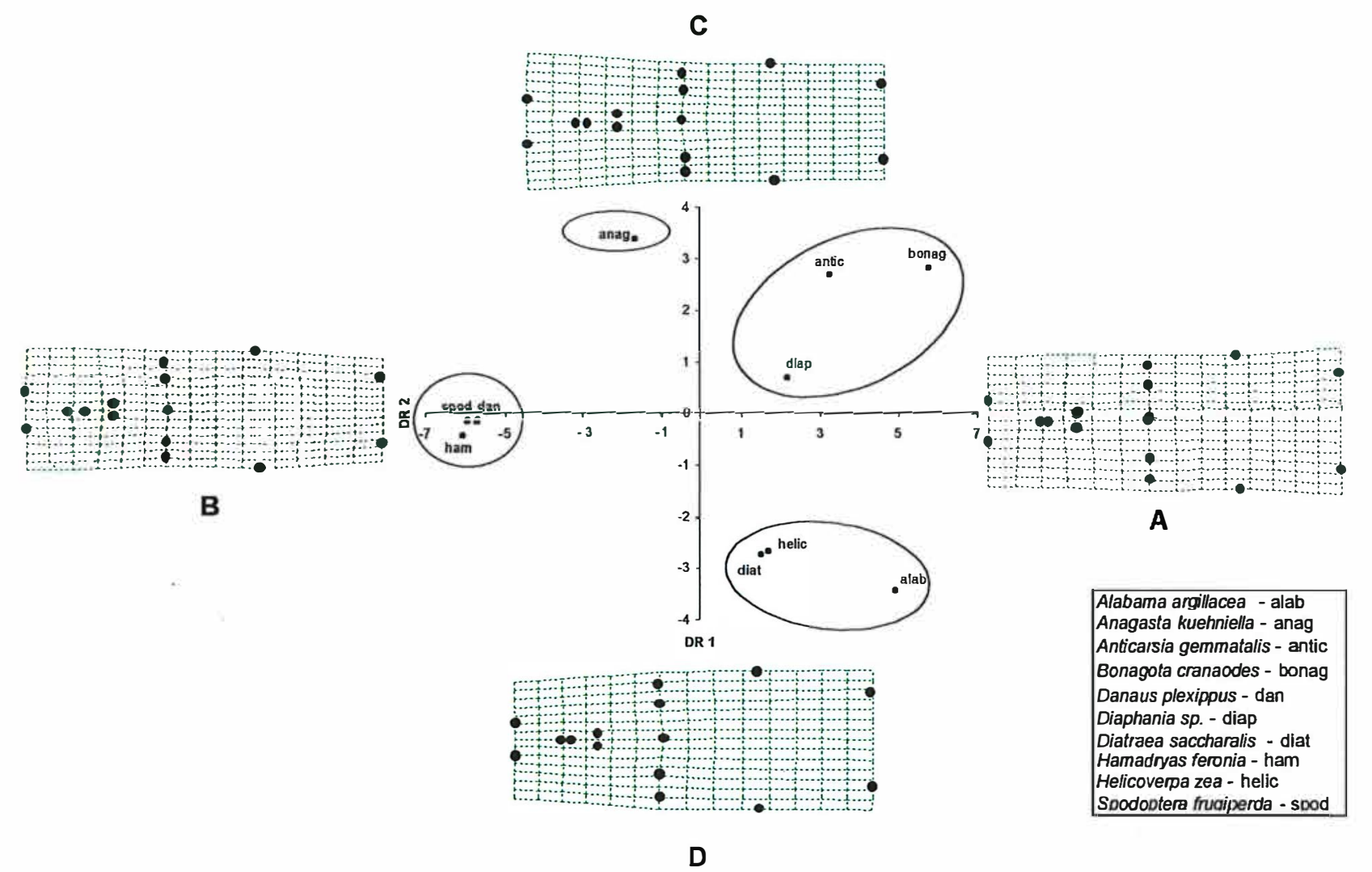

Figura 55 - Deformações relativas (DR) para valores de $\alpha=0$ de Trichogramma pretiosum provenientes de 10 hospedeiros (legenda). A. Variação na forma da cápsula genital prevista como desvios positivos da média no eixo das defonnações relativas 1 . B. Variação na forma da cápsula genital prevista como desvios negativos da média no eixo das defonnações relativas 1 . C. Variação na fonna da cápsula genital prevista como desvios positivos da média no eixo das deformações relativas 2. D. Variação na forma da cápsula genital prevista como desvios negativos da média no eixo das deformações relativas 2 .

Foram estabelecidos 4 agrupamentos de $T$. pretiosum (Figura 56): (1) espécimes proveniente de Alabama argillacea, Helicoverpa zea e Diatraea saccharalis que apresentaram grades de deformações relativas mais dilatadas na extensão posterior da lâmina dorsal (Figura 57, marcos 2 e 7) e na região anterior da cápsula genital (Figura 57, marcos 3 a 6), indicando 
que os espécimes desse grupo possuem cápsulas genitais relativamente mais largas; (2) espécimes de T. pretiosum oriundos de Danaus plexippus, Hamadryas feronia e Spodoptera frugiperda, com grades mais estreitas, indicando que estes espécimes apresentam cápsula genital mais estreita; (3) espécimes de T. pretiosum obtidos de Anticarsia gemmatalis, Bonagota cranaodes e Diaphania sp. formaram um agrupamento com grades pouco deformadas e com poucas diferenças entre si, indicando que estes espécimes apresentam cápsula genital em situação intermediária em relação às demais e (4) espécimes de $T$. pretiosum multiplicados em de Anagasta kuehniella (hospedeiro alternativo) ficaram isolados, pois apresentaram grade da deformação relativa com um estreitamento da região anterior (Figura 57, marcos 2 a 7) e dilatação na região posterior (Figura 57, marcos 1 e 8). Dos hospedeiros estudados, apenas A. kuehniella não é um hospedeiro natural, pois é utilizado na criação do parasitóide em laboratório (hospedeiro alternativo).

Com base nas grades das deformações relativas de T. pretiosum verificou-se que a diferença na forma foi principalmente em relação à região anterior da extensão posterior da lâmina dorsal, à inserção da lâmina dorsal e à região anterior da cápsula genital.

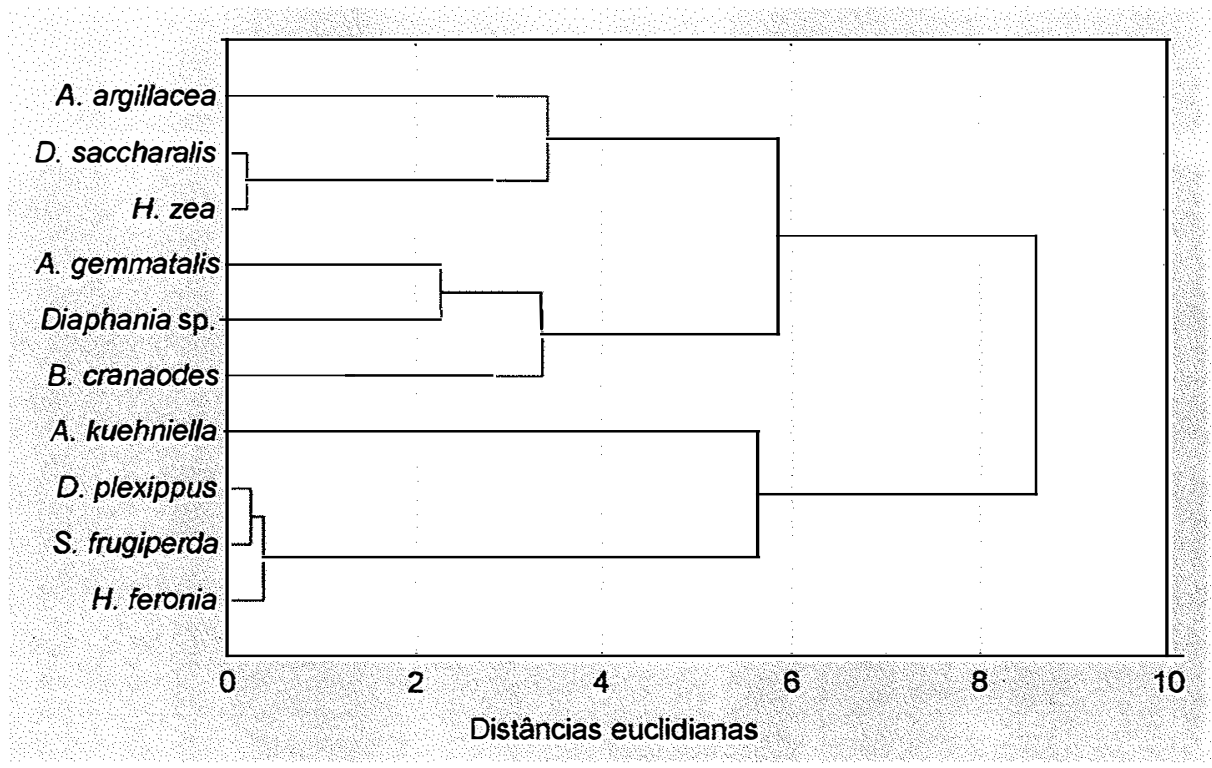

Figura 56 - Dendograma das populações de Trichogramma pretiosum provenientes de diferentes hospedeiros com base em distâncias euclidianas calculadas a partir dos escores de deformações relativas $(\alpha=0)$. 


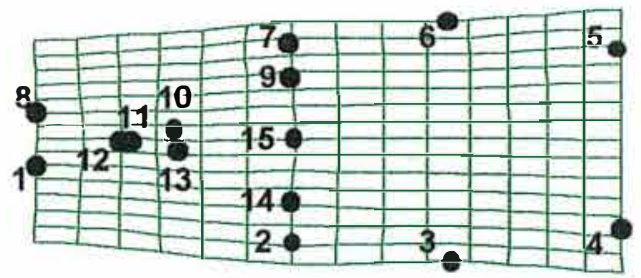

Alabama argillacea

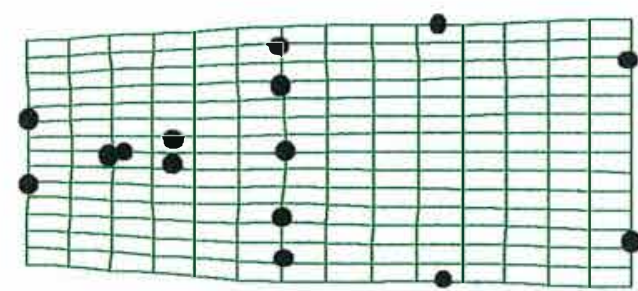

Helicoverpa zea

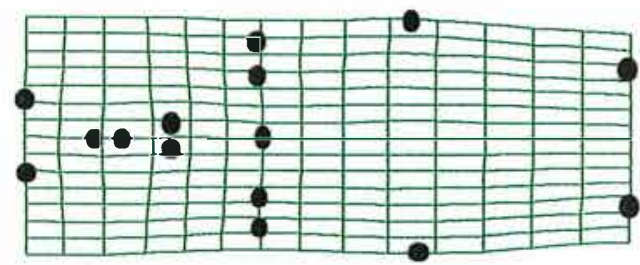

Hamadryas feronia

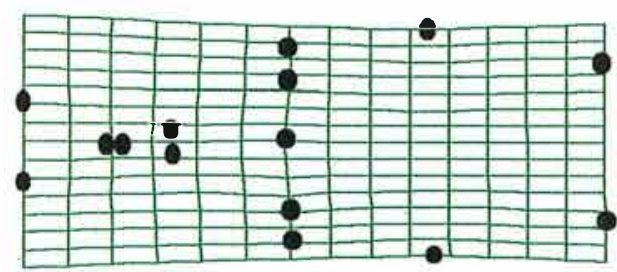

Anticarsia gemmatalis

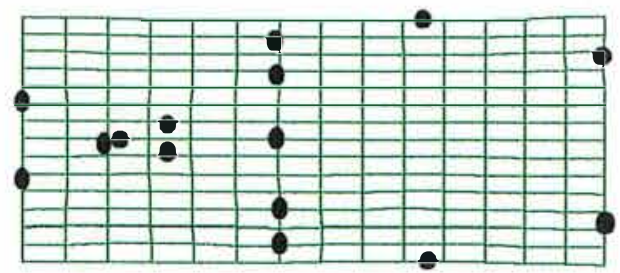

Diaphania sp.

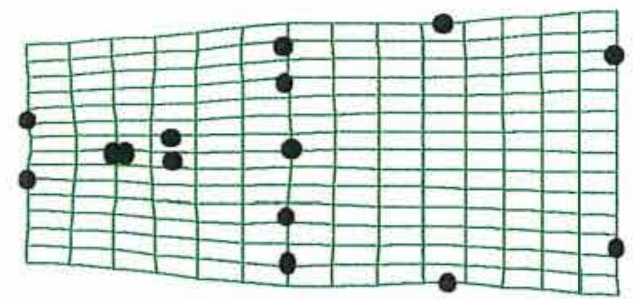

Diatraea saccharalis

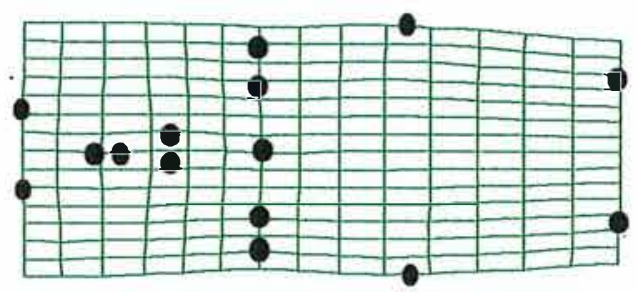

Danaus plexippus

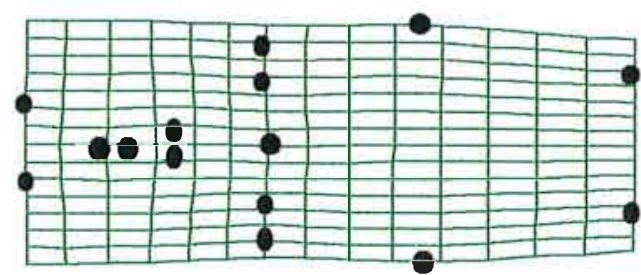

Spodoptera frugiperda

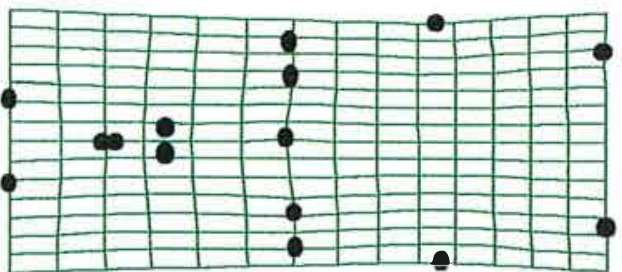

Bonagota cranaodes

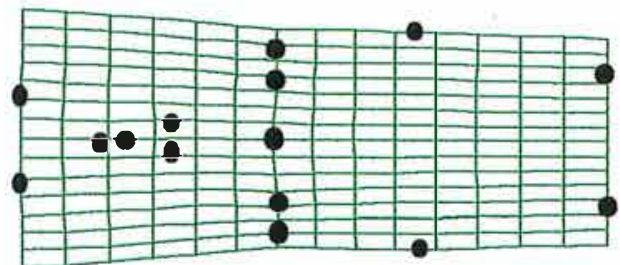

Anagasta kuehniella

Figura 57 - Grades das deformações relativas $(\alpha=0)$ com a forma média das cápsulas genitais de Trichogramma pretiosum proveniente dos diferentes hospedeiros (ápice da genitália à esquerda; marcos anatômicos: 1 a 15, ver Figura 1-grade de Alabama argillacea). 
A associação entre os espécimes de $T$. pretiosum provenientes de diferentes hospedeiros com relação a forma da cápsula genital, foi detectada pelas deformações relativas. A influência dos hospedeiros na biologia desse parasitóide é amplamente discutida na literatura (Marston \& Ertle, 1973; Kazmer \& Luck, 1990), entretanto, alterações morfológicas causadas pelos hospedeiros não têm sido relatadas. A maioria dos trabalhos discute a influência do tamanho do ovo do hospedeiro no tamanho do parasitóide (e. g. Grenier, 2001).

Os resultados obtidos neste trabalho não permitem inferências sobre a influência do tamanho do ovo do hospedeiro na variação da forma da cápsula genital. Entretanto, informações obtidas na literatura dão indícios de que essas alterações podem ocorrer, uma vez que $T$. pretiosum proveniente de ovos de maior tamanho e volume, por exemplo, D. saccharalis $(1136,0 \mu \mathrm{mx} 826,9 \mu \mathrm{m})$ (Cônsoli, 1997), apresentaram cápsula genital relativamente mais larga e quando oriundos de hospedeiros com ovos menores, como os de $A$. kuehniella $\left(520,7 \mu \mathrm{m} \times 289,8 \mu \mathrm{m}\right.$, volume: $\left.0,023 \mathrm{~mm}^{3}\right)$, de $S$. frugiperda $\left(454,9 \mu \mathrm{mx} 390,2 \mu \mathrm{m}\right.$, volume: $\left.0,036 \mathrm{~mm}^{3}\right)$ e de A. gemmatalis $(628,2 \mu \mathrm{mx} 428,0 \mu \mathrm{m}$, volume; 0,089 $\mathrm{mm}^{3}$ ) (Cônsoli, 1997), apresentaram relativamente menor largura na cápsula genital. Esses dados são concordantes com os obtidos neste trabalho.

T'. pretiosum apresenta ainda variação intra-específica, isto é, muitos caracteres morfológicos são plásticos e sujeitos à variação ecofenotípica (Pinto et al., 1989 e Pinto \& Stouthamer, 1994). Neste trabalho, o número reduzido de espécimes provenientes de cada hospedeiro, impossibilitou a realização de uma análise multivariada correlacionando as variações intra e interpopulacionais. Ciociola Jr. et al. (2001) comparou espécimes de $T$. pretiosum provenientes de diferentes hospedeiros oriundos de diversas regiões do Brasil, por meio do seqüenciamento da região ITS2 do rDNA, mostrando que há pequenas diferenças genéticas entre as populações, mas é mantido o padrão do seqüenciamento da espécie.

Dessa forma, vários fatores podem interagir para causar diferenças na forma, tanto genéticos quanto os possíveis efeitos do hospedeiro (tamanho ou valor nutricional do ovo). Para identificar as causas das diferenças na forma da cápsula genital de espécimes de T'. pretiosum são necessários estudos mais específicos. Para tanto, novos 
trabalhos devem ser realizados com a finalidade de identificar estas causas e relacionálas às variáveis ambientais e genéticas. Os resultados obtidos são iniciais e exploratórios, demonstrando que a morfometria geométrica, por meio das análises das deformações relativas, pode ser de grande utilidade no estudo taxonômico do gênero Trichogramma.

\subsubsection{Trichogramma rojasi Nagaraja \& Nagarkatti, 1973}

(Figura 58)

Trichogramma rojasi Nagaraja \& Nagarkatti, 1973: 296; Galán \& Rodríguez, 1991: 177; Zucchi \& Monteiro, 1997: 53; Pinto 1998, 79.

\section{Caracterizacão morfológica}

Antenas: flagelo relativamente longo $(0,19 \pm 0,015)$; comprimento/largura do flagelo $(6,68 \pm 1,26)$; cerdas flageliformes relativamente longas $(0,07 \pm 0,004)$, com o ápice uniformemente afilado; comprimento da maior cerda do flagelo/maior largura do flagelo $(2,47 \pm 0,37)$; comprimento do flagelo/comprimento das tíbias posteriores $(1,16 \pm 0,13)$; sensilos basicônicos subglobosos, fórmula 1-2(1)-2-0-1-1; três sensilos placóideos, o apical estendendo-se $0,01 \pm 0,003 \mathrm{~mm}$ além do flagelo.

Asas anteriores: largura da asa anterior $(0,23 \pm 0,019)$; comprimento da maior cerda da franja da asa/comprimento da tíbia posterior $(0,27 \pm 0,03)$; largura/comprimento da asa $(0,49 \pm 0,02)$; comprimento da maior cerda da franja da asa/largura da asa anterior $(0,18$ $\pm 0,02$ ); com 10 a 29 cerdas entre a $4^{\underline{a}}$ e $5^{\underline{a}}$ fileiras de cerdas.

Asas posteriores: ausência de cerdas na fileira anterior e 12 a 15 cerdas na posterior; a fileira posterior alcançando o ápice da asa posterior.

Escutelo: relação entre as cerdas anteriores e posteriores $(0,48 \pm 0,08)$.

Genitália masculina: cápsula genital escurecida; largura/comprimento da cápsula genital $(0,38 \pm 0,03)$; distância apical/comprimento da cápsula genital $(0,23 \pm 0,02)$; largura apical/largura da cápsula genital $(0,75 \pm 0,05)$; lâmina dorsal inserida na metade da cápsula genital, com leve reentrância basal; comprimento da lâmina dorsal/comprimento 
da cápsula genital $(0,37 \pm 0,03)$; carena dorsal ausente; comprimento/largura da lâmina dorsal $(1,46 \pm 0,13)$; comprimento extensão posterior da lâmina dorsal $(0,04 \pm 0,003)$; extensão posterior da lâmina dorsal com a base mais larga que o ápice e este pontiagudo; comprimento da abertura dorsal/comprimento da lâmina dorsal $(1,54 \pm 0,14)$; comprimento da extensão posterior da lâmina dorsal/comprimento da lâmina dorsal $(0,89 \pm 0,05)$; carena ventral curta, próxima da metade da cápsula genital; carena ventral/distância basal $(0,67 \pm$ $0,13)$; distância basal/comprimento da cápsula genital $(0,80 \pm 0,07)$; processos ventrais muito próximos da base do processo intervolselar $(0,004 \pm 0,001)$; comprimento do edeago/comprimento da tíbia posterior $(0,37 \pm 0,04)$; apódemas/edeago $(1,03 \pm 0,11)$.

\section{Material examinado}

BRASIL. PARANÁ: Curitiba, Fazenda Rio Grande, 12 machos, ex ovos de Anticarsia gemmatalis, em soja, L. A. Foerster col. (ESALQ).

\section{Diagnose}

$T \cdot$ rojasi pode ser confundido com $T$. lasallei, espécie relacionada e recentemente descrita por Pinto (1998). Muitas das referências à $T$ rojasi, antes da descrição original de T: lasallei, podem estar equivocadas (e.g. Galán \& Rodríguez, 1991). O material examinado do Peru, identificado como T. rojasi, apesar de mal preservado, foi possível observar que se tratava de $T$. lasallei.

De modo geral, o tamanho das estruturas de $T$. rojasi são maiores que às de $T$. lasalle $i$, apesar de apresentarem as cerdas flageliformes menores do que T. lasallei. Três características importantes e de fácil observação distinguem T. rojasi de T. lasallei: (1) fileira posterior de cerdas alcança o ápice das asas posteriores em $T$. rojasi e apenas a metade da fileira mediana em $T$. lasallei; (2) a carena ventral é mais nítida e pode alcança a metade da cápsula genital em T'. rojasi; em $T$. lasallei é menor e o limite anterior é difícil de ser visualizado; (3) processos ventrais situados muito próximo da base do processo intervolselar em T. rojasi, diferentemente do observado em T. lasallei, que é bastante afastado. 

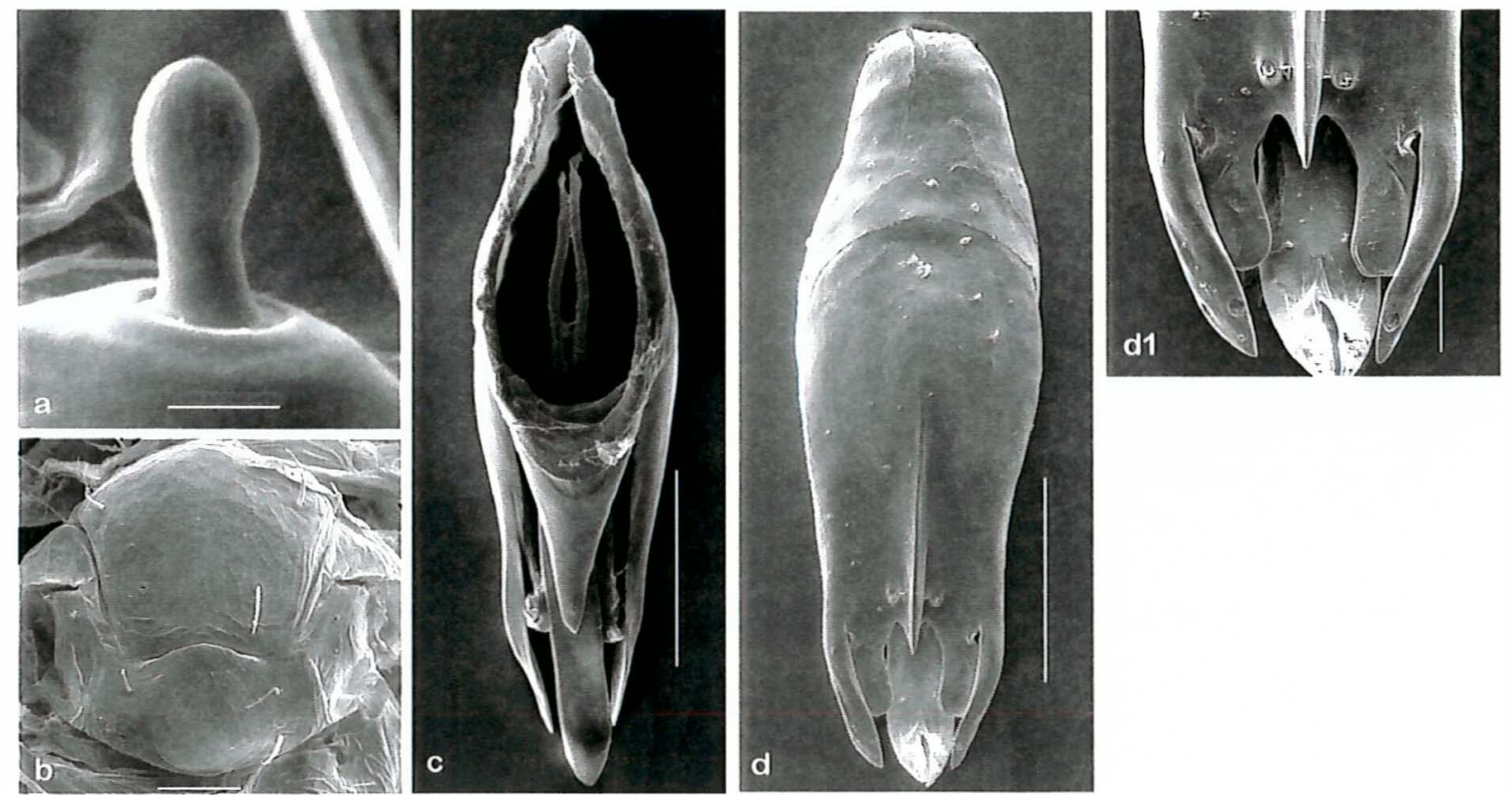

Figura 58 - Trichogramma rojasi: a - sensilo basicônico (10000x, $1 \mu \mathrm{m})$; b - mesoescuto e escutelo (600x, $20 \mu \mathrm{m})$; c - cápsula genital dorsal $(900 \mathrm{x}, 20 \mu \mathrm{m})$; d - cápsula genital ventral $(800 \mathrm{x}$, $20 \mu \mathrm{m})$ e d $\mathrm{l}$ - detalhe apical da cápsula genital $(2400 \mathrm{x}, 5 \mu \mathrm{m})$.

\section{$\underline{\text { Variacões }}$}

Os espécimes examinados apresentaram coloração escura, diferentemente do observado por Nagaraja e Nagarkatti (1973), que descreveram uma coloração amareloclara, com o tórax e abdome escurecido.

\section{Distribuicão geográfica e hospedeiros}

T. rojasi foi originalmente descrita com base em exemplares coletados no Chile (La Cruz), em ovos de Tatochila sp. Butler, 1870 (Lepidoptera: Pieridae) em Trifolium sp. (Nagaraja e Nagarkatti, 1973). Galán e Rodrígues (1991) registraram T. rojasi em Cuba, mas segundo Pinto (1998), tratava-se de T. lasallei. De acordo com Zucchi \& Monteiro (1997), esta espécie está distribuída na Argentina, Brasil e Chile, com os seguintes hospedeiros e plantas associadas: Colias lesbia Fabricius, 1775 (Lepidoptera: Pieridae) (em soja), A. gemmatalis (em soja) e Tatochila sp. (em trevo), respectivamente. 


\subsection{Descrição das novas espécies}

A descrição das novas espécies será incluída neste trabalho, porém, ainda não será atribuído nenhum nome específico, pois de acordo com o Capítulo 3, Artigo 9, item 9.7 do INTERNATIONAL CODE OF ZOLOGICAL NOMENCLATURE (2000) a tese não é considerada publicação apropriada para a atribuição de novos nomes.

\subsubsection{Trichogramma sp. $\mathrm{n} .1$}

(Figura 59)

\section{Descrição}

Antenas: flagelo longo $(0,18 \pm 0,02)$; relação entre o comprimento e a largura do flagelo $(7,71 \pm 0,84)$; cerdas flageliformes longas $(0,08 \pm 0,01)$, com o ápice uniformemente afilado; comprimento da maior cerda do flagelo/maior largura do flagelo $(3,55 \pm 0,28)$; comprimento do flagelo/comprimento da tíbia posterior $(1,12 \pm 0,08)$; cerdas com base indistinta nas seções 2 e 3 do flagelo; sensilos basicônicos com fórmula 2-2-2-0-1-1; três sensilos placóideos, o basal com $0,04 \pm 0,00 \mathrm{~mm}$.

Asas anteriores: relação entre a largura e o comprimento da asa $(0,51 \pm 0,02)$; comprimento da maior cerda da franja da asa/comprimento da tíbia posterior $(0,26 \pm$ $0,03)$; comprimento da maior cerda da franja da asa/largura da asa anterior $(0,16 \pm 0,02)$. Número de cerdas entre a $4^{\underline{a}}$ e $5^{\text {a }}$ fileiras de 6 a 13 .

Asas posteriores: fileira anterior ausente e a posterior com número reduzido de cerdas, variando de 2 a 4; fileira posterior não ultrapassa a metade da fileira mediana.

Escutelo: cerdas anteriores moderadamente longas; relação entre o par de cerdas anterior e posterior $(0,19 \pm 0,04)$.

Genitália masculina: cápsula genital mais longa $(0,12 \pm 0,01)$ do que larga $(0,04 \pm$ $0,00)$; relação entre a largura e o comprimento da cápsula genital $(0,33 \pm 0,02)$; distância apical/comprimento da cápsula genital $(0,24 \pm 0,01)$; largura apical/largura da cápsula genital $(0,71 \pm 0,02)$; comprimento/largura da lâmina dorsal $(1,52 \pm 0,18)$; comprimento 
da lâmina dorsal/comprimento da cápsula genital $(0,41 \pm 0,04)$; base da extensão posterior da lâmina dorsal mais larga que o ápice; extensão posterior da lâmina dorsal longa $(0,04 \pm$ 0,00 ) alcançando as volselas e com o ápice pontiagudo; comprimento da extensão posterior da lâmina dorsal/comprimento da lâmina dorsal $(0,72 \pm 0,03)$; comprimento da abertura dorsal/comprimento da lâmina dorsal $(1,39 \pm 0,19)$; carena dorsal ausente; carena ventral indistinta, limite anterior difícil de visualizar; distância basal/comprimento da cápsula genital $(0,76 \pm 0,01)$; processos ventrais distintos e na base do processo intervoselar; parâmeros robustos; processo intervolselar alcançando a base das volselas; comprimento do edeago/comprimento da tíbia posterior $(0,41 \pm 0,03)$; apódemas/edeago $(0,88 \pm 0,06)$.

Os dados quantitativos foram obtidos de oito machos coletados de armadilha de sucção.
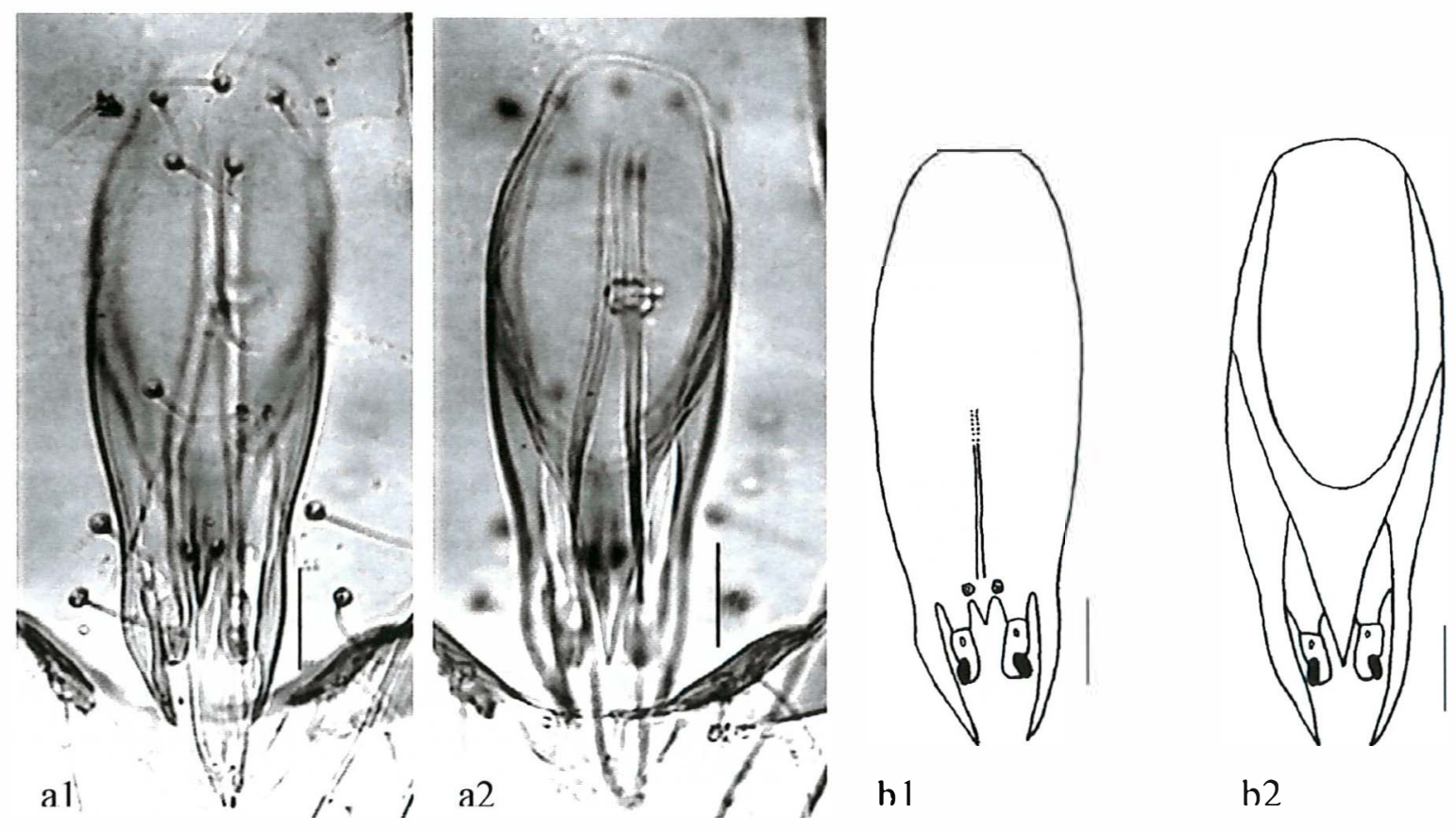

Figura 59 - Cápsula genital de Trichogramma sp. n. 1 (a -10 $\mu \mathrm{m}$ e b - $20 \mu \mathrm{m})$ : 1 - ventral e 2 - dorsal.

\section{Material-tipo}

Holótipo macho. BRASIL. SÃO PAULO: Piracicaba, coletado de armadilha de sucção, Horto Florestal de Tupi, R.B. Querino col. (ESALQ). Parátipos três machos com os mesmos dados do holótipo (ESALQ). 


\section{$\underline{\text { Diagnose }}$}

Trichogramma sp. n. 1 é reconhecido principalmente pelos processos ventrais distintos, situados na base do processo intervolselar e a lâmina dorsal sem distinta reentrância basal.

Dentre as espécies sul-americanas, Trichogramma sp. n. 1 é uma espécie relacionada a $T$. bruni e a Trichogramma sp. n. 11. Entretanto, Trichogramma sp.n. 1 difere de $T$. bruni principalmente pelo processo intervolselar mais alongado e pelo processo ventral mais distinto, situado na base do processo intervolselar. Em T. bruni, os processos ventrais estão numa posição mais anterior e próximos ao processo intervolselar. Em Trichogramma sp. n. 11, diferentemente dessas duas espécies, as cerdas anteriores do escutelo são mais longas, cápsula genital mais alongada, lâmina dorsal curta, extensão posterior da lâmina dorsal com ápice arredondado e os processos ventrais próximos da base do processo intervolselar.

Jonh D. Pinto (inf. pes.) considerou Trichogramma sp. n. 1, próxima a T. bruni e semelhante aos espécimes que tem coletado na América Central.

\section{Variaç̃es}

Em um dos espécimes examinados, foi observada a ausência de cerdas com base indistinta nas três primeiras seções do flagelo.

\section{Distribuicão geográfica e hospedeiros}

Trichogramma sp. $\mathrm{n}$. 1 foi coletado em uma armadilha de sucção no Horto Florestal de Tupi, Piracicaba, São Paulo, Brasil. O Horto Florestal é uma área de reserva, constituída predominantemente por eucalipto e por árvores nativas. A armadilha de suç̧ão foi instalada em sub-bosque composto principalmente de eucalipto. Durante o período de coleta, borboletas da família Nymphalidae (Itomiinae e Danainae) foram observadas em grande quantidade. 


\subsubsection{Trichogramma sp. $\mathrm{n} .3$}

(Figura 60)

\section{$\underline{\text { Descrição }}$}

Antenas: flagelo longo $(0,17 \pm 0,00)$; relação entre o comprimento e a largura do flagelo $7,31 \pm 0,33$; comprimento do flagelo/comprimento da tíbia posterior $(1,11 \pm 0,02)$; cerdas flageliformes longas $(0,06 \pm 0,002)$, com o ápice unifomemente afilado; comprimento da maior cerda do flagelo/maior largura do flagelo $(2,81 \pm 0,27)$; cerdas com base indistinta nas seções 2, 3 e 4 do flagelo; sensilos basicônicos com fórmula 2-22-1-1-1; três sensilos placóideos, o basal com $0,05 \pm 0,00 \mathrm{~mm}$.

Asas anteriores: relação entre a largura e o comprimento da asa $(0,55 \pm 0,00)$; comprimento da maior cerda da franja da asa/comprimento da tíbia posterior $(0,17 \pm$ $0,00)$; comprimento da maior cerda da franja da asa/largura da asa anterior $(0,10 \pm 0,00)$. Número de cerdas entre a $4^{\underline{a}}$ e $5^{\underline{a}}$ fileiras de 7 a 8 cerdas.

Asas posteriores: fileira anterior ausente e a posterior com 4 cerdas, alcançando a metade da fileira mediana.

Escutelo: cerdas anteriores curtas; relação entre as cerdas anteriores e posteriores $(0,06 \pm$ $0,00)$.

Genitália masculina: cápsula genital pequena $(0,10 \pm 0,02)$ e larga $(0,05 \pm 0,01)$; relação entre a largura e o comprimento da cápsula genital $(0,49 \pm 0,03)$; distância apical/comprimento da cápsula genital $(0,32 \pm 0,04)$; largura apical/largura da cápsula genital $(0,65 \pm 0,05)$; comprimento/largura da lâmina dorsal $(1,20 \pm 0,05)$; comprimento da lâmina dorsal/comprimento da cápsula genital $(0,43 \pm 0,08)$; extensão posterior da lâmina dorsal larga, com o ápice arredondado ao nível das volselas; comprimento da extensão posterior da lâmina dorsal $(0,03 \pm 0,00)$; comprimento da extensão posterior da lâmina dorsal/comprimento da lâmina dorsal $(0,71 \pm 0,07)$; comprimento da abertura dorsal/comprimento da lâmina dorsal $(1,55 \pm 0,03)$; carena dorsal presente; carena ventral de difícil visualização; distância basal/comprimento da cápsula genital $(0,80 \pm$ 0,12 ); processos ventrais próximos à base do processo intervolselar; processo intervolselar 
diminuto, praticamente inexistente; comprimento do edeago/comprimento da tíbia posterior $(0,33 \pm 0,00) ;$ apódemas/edeago $(1,08 \pm 0,11)$.

Os dados quantitativos foram obtidos de dois machos coletados de uma armadilha de sucção.
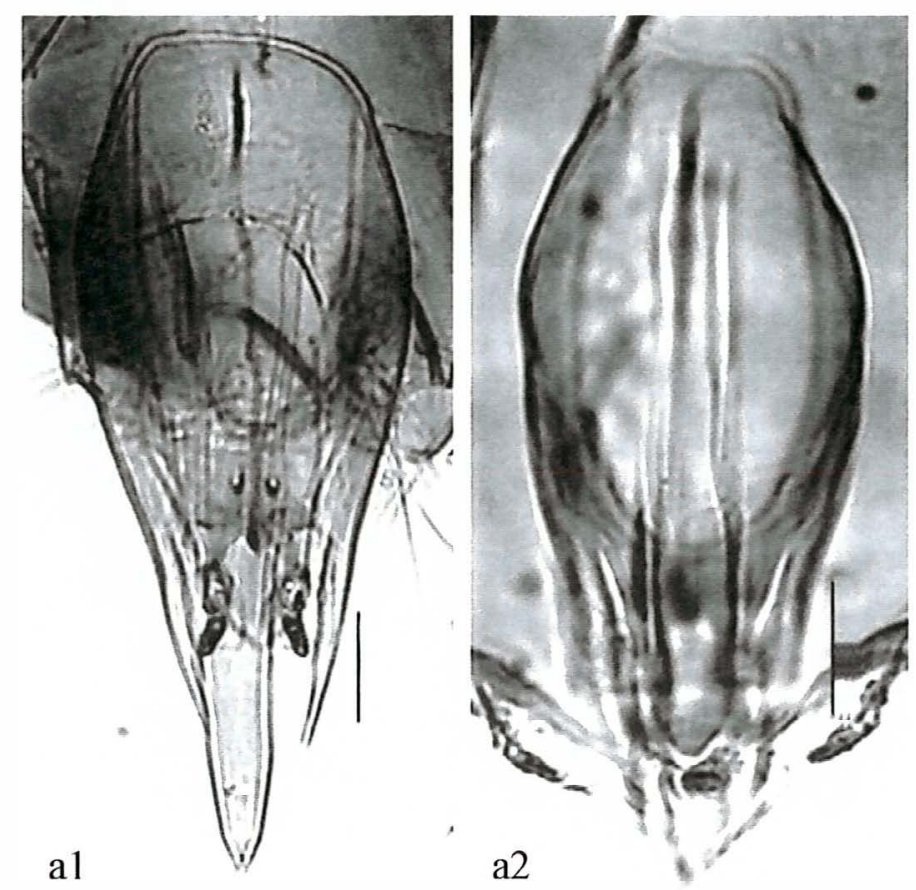

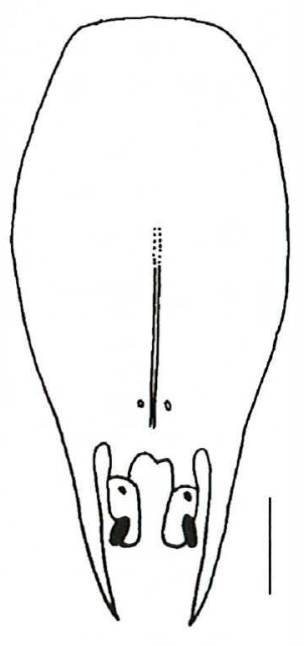

b1

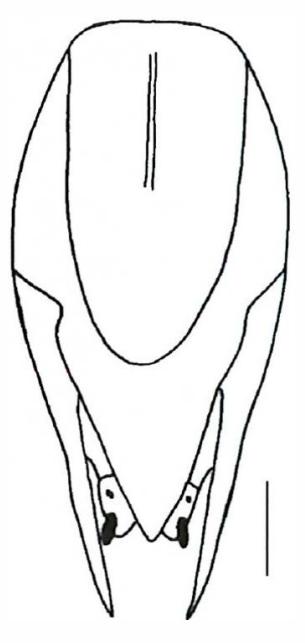

b2

Figura 60 - Cápsula genital de Trichogramma sp. n. 3 (a -10 $\mu \mathrm{m}$ e b - $20 \mu \mathrm{m}): 1$ ventral e 2 - dorsal.

\section{$\underline{\text { Material-tipo }}$}

Holótipo macho. BRASIL. SÃO PAULO: Piracicaba, coletado de armadilha de sucção, Horto Florestal de Tupi, R.B. Querino col. (ESALQ). Um parátipo macho com os mesmos dados do holótipo (ESALQ).

\section{Diagnose}

Trichogramma sp. n. 3 distingui-se principalmente pela pequena cápsula genital; lâmina dorsal distinta com a extensão posterior larga e ápice arredondado e processo intervolselar muito diminuto. 
Segundo Jonh D. Pinto (inf. pes.), Trichogramma sp. n. 3 é semelhante a $T$. benetti, uma espécie que ocorre em Trinidad \& Tobago e na Colômbia. Diferenciando-se de T. Benetti pelo processo intervolselar mais curto, cerdas flageliformes mais curtas, volselas não modificadas, cápsula genital não muito ampla e uma curta carena ventral com a extremidade anterior indistinta. Essas duas espécies são facilmente separadas pelas volselas, que em $T$. bennetti são modificadas (aparentemente lobadas).

\section{Distribuição geográfica e hospedeiros}

As informações são as mesmas comentadas para Trichogramma sp. n. 1.

\subsubsection{Trichogramma sp. n. 5}

(Figura 61)

\section{$\underline{\text { Descrição }}$}

Antenas: flagelo longo $(0,21 \pm 0,004)$; relação entre o comprimento e a largura do flagelo $(9,02 \pm 0,52)$; comprimento do flagelo/comprimento da tíbia posterior $(1,01 \pm$ $0,01)$; cerdas flageliformes longas $(0,10 \pm 0,005)$, com o ápice uniformemente afilado; comprimento da maior cerda do flagelo/maior largura do flagelo $(4,45 \pm 0,37)$; várias cerdas com base indistinta na $1^{\underline{a}}$ e $2^{\underline{a}}$ seção do flagelo; sensilos basicônicos com fórmula 2-2-2-0-1-1; três sensilos placóideos, o basal longo com 0,06 $\pm 0,002 \mathrm{~mm}$.

Asas anteriores: relação entre a largura e o comprimento da asa $(0,71 \pm 0,16)$; cerdas da franja da asa anterior curta $(0,02 \pm 0,004)$; comprimento da maior cerda da franja da asa/comprimento da tíbia posterior $(0,12 \pm 0,02)$; comprimento da maior cerda da franja da asa/largura da asa anterior $(0,07 \pm 0,01)$. Número de cerdas entre a $4^{\underline{a}}$ e $5^{\underline{a}}$ fileiras de 11 a 14 . Asas posteriores: fileira anterior sem cerdas e fileira posterior com 4 cerdas.

Escutelo: cerdas anteriores relativamente longas, escuras e distintas.

Genitália masculina: cápsula genital escurecida, longa $(0,15 \pm 0,002)$ e larga $(0,06 \pm$ $0,001)$; relação entre a largura e o comprimento da cápsula genital $(0,41 \pm 0,00)$; distância apical/comprimento da cápsula genital $(0,27 \pm 0,01)$; largura apical/largura da 
cápsula genital $(0,60 \pm 0,01)$; lâmina dorsal com acentuada reentrância basal e aspecto linguiforme; comprimento/largura da lâmina dorsal (2,34 $\pm 0,20)$; comprimento da lâmina dorsal/comprimento da cápsula genital $(0,42 \pm 0,01)$; extensão posterior da lâmina dorsal longa $(0,04 \pm 0,002)$, estreita, com o ápice arredondado e ultrapassando as volselas; comprimento da extensão posterior da lâmina dorsal/comprimento da lâmina dorsal $(0,60 \pm 0,01)$; abertura dorsal alongada, afilando-se posteriormente; comprimento da abertura dorsal/comprimento da lâmina dorsal $(1,60 \pm 0,06)$; carena dorsal ausente; carena ventral ultrapassando a metade da cápsula genital $(0,06 \pm 0,002)$; comprimento da carena ventral/distância basal $(0,53 \pm 0,01)$; distância basal/comprimento da cápsula genital $(0,73 \pm 0,01)$; processos ventrais próximos da base do processo intervoselar $(0,01 \pm$ 0,001 ); processo intervolselar relativamente longo, alcançando a base das volselas, com pequeno engrossamento na base do processo intervolselar; parâmeros longos; comprimento do edeago/comprimento da tíbia posterior $(0,42 \pm 0,04)$; apódemas/edeago $(0,94 \pm 0,04)$.

Os dados quantitativos foram obtidos de três machos coletados de armadilha de sucção.

\section{Material-tipo}

Holótipo macho. BRASIL. SÃO PAULO: Piracicaba, coletado de armadilha de sucção, Horto Florestal de Tupi, R.B. Querino col. (ESALQ). Parátipos dois machos com os mesmos dados do holótipo (ESALQ).

\section{$\underline{\text { Diagnose }}$}

Dentre as novas espécies estabelecidas neste trabalho, Trichogramma sp. n. 5 é uma das espécies mais facilmente reconhecida. $\mathrm{O}$ aspecto linguiforme da lâmina dorsal, ultrapassando as volselas e as várias cerdas com base indistinta nas primeiras seções do flagelo, permitem separá-la das demais espécies que ocorrem na região Neotropical. Segundo John D. Pinto (inf. pes.), é uma das mais distintivas entre as novas espécies, que parece não ser tão distante de Trichogramma sp. n. 3 e possivelmente do mesmo grupo de $T$. bennett $i$ 

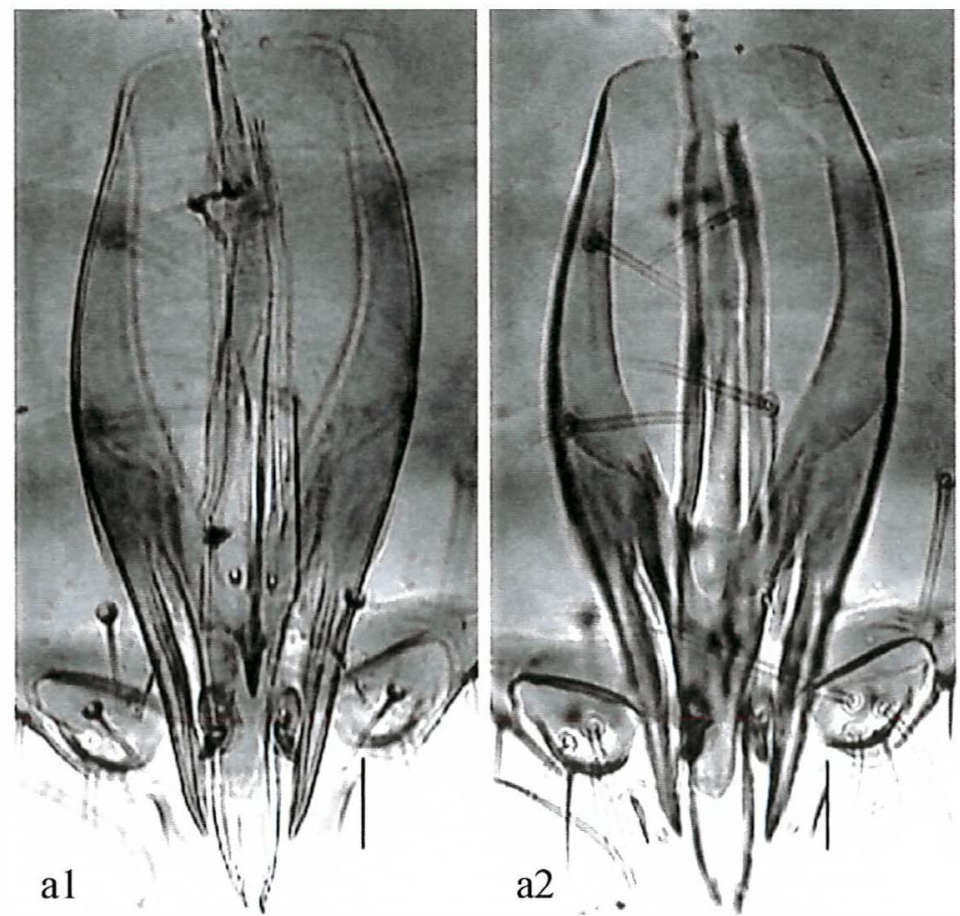

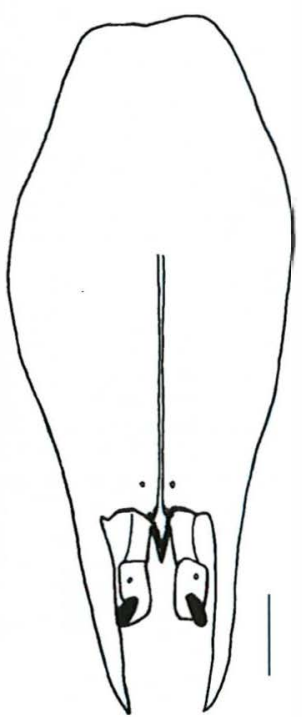

b1

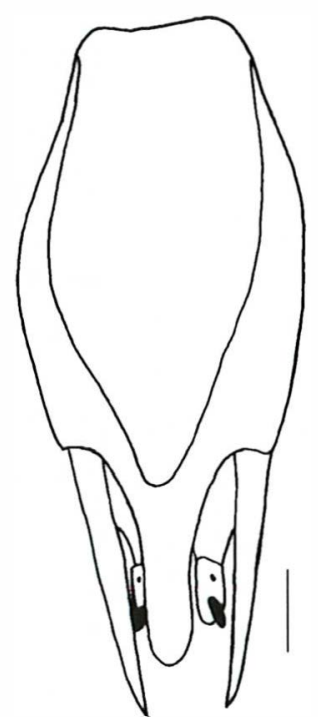

b2

Figura 61 - Cápsula genital de Trichogramma sp. n. $5(\mathrm{a}-10 \mu \mathrm{m}$ e b - $20 \mu \mathrm{m}): 1$ ventral e 2 - dorsal.

\section{Distribuicão geográfica e hospedeiros}

As informações são as mesmas comentadas para Trichogramma sp. n. 1 .

\subsubsection{Trichogramma sp. n. 6}

(Figura 58)

\section{Descricão}

Antenas: flagelo relativamente longo $(0,15 \pm 0,024)$; relação entre o comprimento e a largura do flagelo $(6,20 \pm 0,69)$; comprimento do flagelo/comprimento da tíbia posterior $(1,03 \pm 0,08)$; cerdas flageliformes longas $(0,08 \pm 0,006)$, com o ápice uniformemente afilado; comprimento da maior cerda do flagelo/maior largura do flagelo $(3,32 \pm 0,18)$; 
sensilos basicônicos com fórmula 2-2-2-0-1-1; três sensilos placóideo, o basal com 0,04 $\pm 0,004 \mathrm{~mm}$.

Asas anteriores: relação entre a largura e o comprimento da asa $(0,59 \pm 0,09)$; cerdas da franja da asa anterior curtas $(0,04 \pm 0,006)$; comprimento da maior cerda da franja da asa/comprimento da tíbia posterior $(0,20 \pm 0,12)$; comprimento da maior cerda da franja da asa/largura da asa anterior $(0,13 \pm 0,04)$. Número de cerdas entre a $4^{\underline{a}}$ e $5^{\underline{a}}$ fileiras de 8 a 9 cerdas.

Asas posteriores: fileira anterior sem cerdas e a posterior com 3 a 5 cerdas, alcançando a metade da fileira mediana.

Escutelo: cerdas anteriores escuras e relativamente longas; relação entre as cerdas anteriores e posteriores $(0,23 \pm 0,00)$.

Genitália masculina: cápsula genital escurecida, pequena $(0,12 \pm 0,005)$ e larga $(0,04 \pm$ 0,004); relação entre a largura e o comprimento da cápsula genital $(0,37 \pm 0,03)$; distância apical/comprimento da cápsula genital $(0,25 \pm 0,02)$; largura apical/largura da cápsula genital $(0,69 \pm 0,04)$; lâmina dorsal inserida na metade da cápsula genital, sem uma distinta reentrância lateral; comprimento/largura da lâmina dorsal $(1,58 \pm 0,17)$; comprimento da lâmina dorsal/comprimento da cápsula genital $(0,43 \pm 0,01)$; comprimento da abertura dorsal/comprimento da lâmina dorsal $(1,30 \pm 0,05)$; comprimento da extensão posterior da lâmina dorsal $(0,04 \pm 0,002)$, afilando-se em direção ao ápice e no nível das volselas; comprimento da extensão posterior da lâmina dorsal/comprimento da lâmina dorsal $(0,76 \pm 0,04)$; carena dorsal ausente; carena ventral alcançando a metade da cápsula genital $(0,04 \pm 0,002)$; comprimento da carena ventral/distância basal $(0,50 \pm 0,01)$; distância basal/comprimento da cápsula genital $(0,75 \pm 0,02)$; processos ventrais fortemente dilatados e na base do processo intervolselar; processo intervolselar curto; parâmeros dilatados com margem interna esclerotizada; comprimento do edeago/comprimento da tíbia posterior $(0,42 \pm 0,03)$; apódemas/edeago $(0,86 \pm 0,11)$.

Os dados quantitativos foram baseados em cinco machos coletados de armadilha de sucção. 


\section{Material-tipo}

Holótipo macho. BRASIL. SÃO PAULO: Piracicaba, coletado em armadilha de sucção, Horto Florestal de Tupi, R.B. Querino col. (ESALQ). Parátipos quatro machos com os mesmos dados do holótipo (ESALQ).
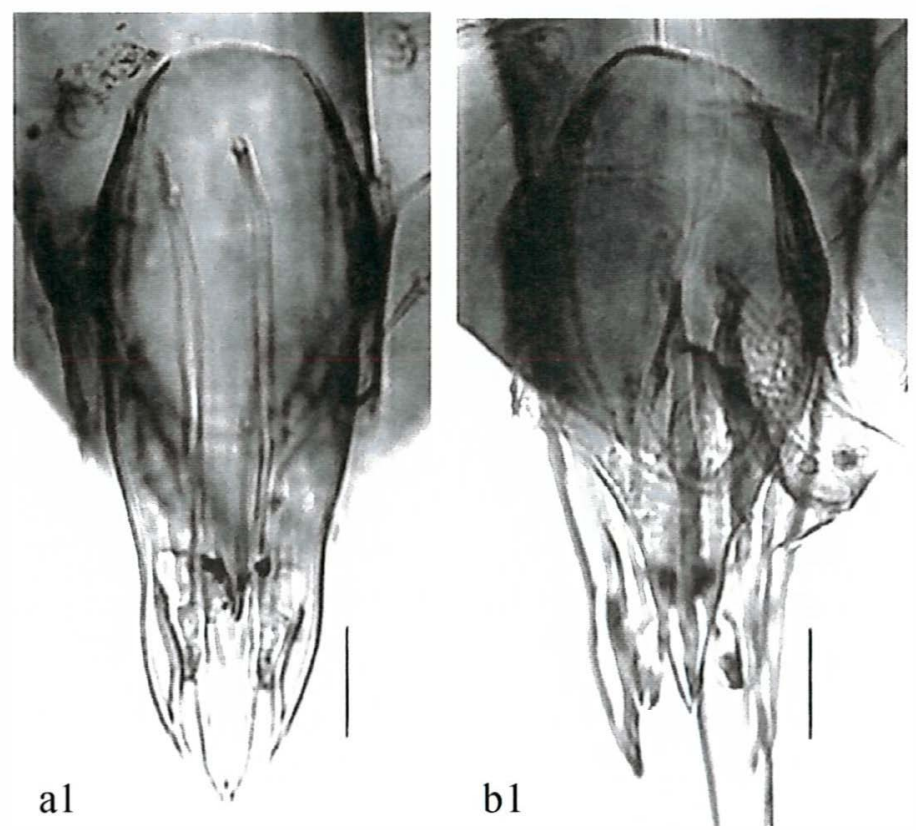

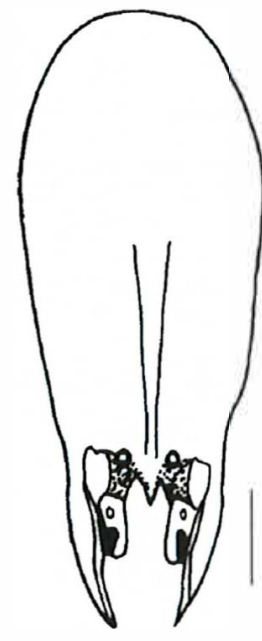

al

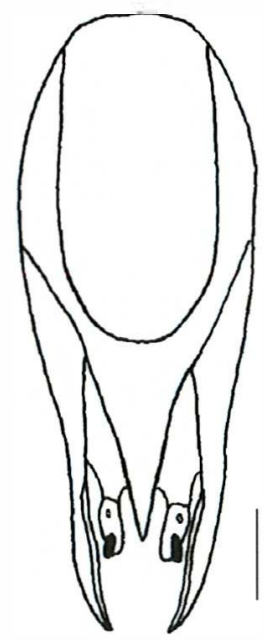

b2

Figura 62 - Cápsula genital de Trichogramma sp.n. 6 (a -10 $\mu \mathrm{m}$ e b - 20 $\mu \mathrm{m}): 1$ - ventral e 2 - dorsal.

\section{Diagnose}

Trichogramma sp. n. 6 é reconhecido pelos processos ventrais bastante dilatados; lâmina dorsal sem distinta reentrância basal e com a extensão posterior afilando-se para um ápice estreito, alcançando o ápice das volselas.

Esta espécie talvez seja próxima à norte-americana T. browningi Pinto \& Oatman, 1985, pois nesta espécie os processos ventrais também são dilatados na base do processo intervolselar. Entretanto, como observado também por John D. Pinto (inf. pes.), difere de T. browningi, principalmente, pela forma da lâmina dorsal, sem reentrância basal e afilando-se para um ápice estreito. 


\section{$\underline{\text { Variação }}$}

Um dos exemplares apresentou redução no número de sensilos, com fórmula 1-12-0-1-1; observou-se que quando o adulto é de tamanho reduzido, ocorre também uma diminuição no tamanho das estruturas e conseqüentemente diminui o número de sensilos basicônicos e de cerdas.

\section{Distribuicão geográfica e hospedeiros}

As informações são as mesmas comentadas para Trichogramma sp. n. 1 .

\subsubsection{Trichogramma sp. $\mathrm{n} .7$}

(Figura 63)

\section{Descriç̃̃o}

Antenas: flagelo longo $(0,16 \pm 0,013)$; relação entre o comprimento e a largura do flagelo $(7,51 \pm 1,11)$; comprimento do flagelo/comprimento da tíbia posterior $(1,10 \pm$ $0,06)$; cerdas flageliformes longas $(0,08 \pm 0,003)$, com o ápice uniformemente afilado; comprimento da maior cerda do flagelo/maior largura do flagelo $(3,91 \pm 0,13)$; sensilos basicônicos ovalado, fórmula 2-2-2-0-1-1; três sensilos placóideo, o basal com $0,04 \pm$ $0,00 \mathrm{~mm}$.

Asas anteriores: relação entre a largura e o comprimento da asa $(0,52 \pm 0,01)$; comprimento das cerdas da franja da asa $(0,04 \pm 0,003)$; comprimento da maior cerda da franja da asa/comprimento da tíbia posterior $(0,27 \pm 0,03)$; comprimento da maior cerda da franja da asa/largura da asa anterior $(0,15 \pm 0,00)$. Número de cerdas entre a $4^{\underline{a}}$ e $5^{\underline{a}}$ fileiras de 8 a 10 cerdas.

Asas posteriores: fileira anterior ausente e fileira posterior com 6 cerdas, alcançando a metade da fileira mediana.

Escutelo: cerdas anteriores curtas e finas; relação entre as cerdas anteriores e posteriores $(0,12 \pm 0,02)$. 
Genitália masculina: cápsula genital escurecida, mais longa $(0,12 \pm 0,001)$ do que larga $(0,04 \pm 0,001)$; relação entre a largura e o comprimento da cápsula genital $(0,33 \pm 0,02)$; distância apical/comprimento da cápsula genital $(0,25 \pm 0,01)$; largura apical/largura da cápsula genital $(0,74 \pm 0,06)$; lâmina dorsal inserida na metade da cápsula genital, sem reentrância basal; lâmina dorsal com a base mais larga que o ápice; comprimento da extensão posterior da lâmina dorsal $(0,04 \pm 0,001)$; extensão posterior da lâmina dorsal estreitando-se gradualmente para um ápice pontiagudo; comprimento/largura da lâmina dorsal $(1,47 \pm 0,17)$; comprimento da lâmina dorsal/comprimento da cápsula genital $(0,43 \pm$ $0,05)$; comprimento da abertura dorsal/comprimento da lâmina dorsal $(1,29 \pm 0,20)$; comprimento da extensão posterior da lâmina dorsal/comprimento da lâmina dorsal $(0,70 \pm 0,05)$; carena dorsal ausente; carena ventral não muito distinta, alcançando a metade da cápsula genital $(0,03 \pm 0,006)$; comprimento da carena ventral/distância basal $(0,39 \pm 0,06)$; distância basal/comprimento da cápsula genital $(0,75 \pm 0,01)$; processos ventrais dilatados e próximos da base do processo intervoselar; processo intervolselar curto $(0,008 \pm 0,00)$, alcançando a metade do comprimento das volselas; comprimento do edeago/comprimento da tíbia posterior $(0,43 \pm 0,00)$; apódemas/edeago $(0,80 \pm$ $0,04)$.

Os dados quantitativos foram obtidos de dois machos coletados de armadilha de sucção.

\section{Material-tipo}

Holótipo macho. BRASIL. SÃO PAULO. Piracicaba, coletado em armadilha de sucção, Horto Florestal de Tupi, R.B. Querino col. (ESALQ). Parátipo um macho com os mesmos dados do holótipo (ESALQ).

\section{Diagnose}

Trichogramma sp. n. 7 é reconhecido principalmente pelo aspecto triangular da lâmina dorsal e sem reentrância basal, com a base mais larga que o ápice e a extensão posterior estreitando-se para um ápice pontiagudo. Além disso, o processo intervolselar 
é curto, mas alcança a base das volselas. Essas características separam-na das demais espécies sul-americanas.

Trichogramma sp. n. 7 pertence presumivelmente à seção Arcanum (John D. Pinto, inf. pes.). Essa seção inclui atualmente três espécies norte-americanas, caracterizadas primariamente pelo aspecto da lâmina dorsal, que se estreita consideravelmente na região posterior, falta de distinta reentrância basal e processo intervolselar relativamente curto, menos que a metade do comprimento das volselas.

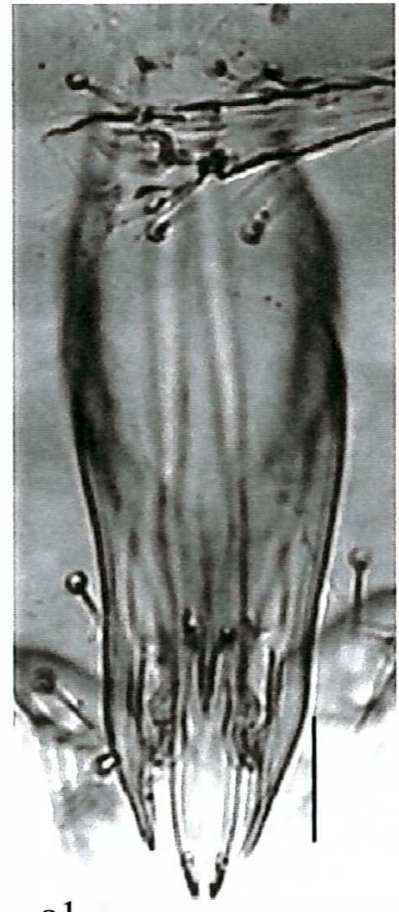

a1

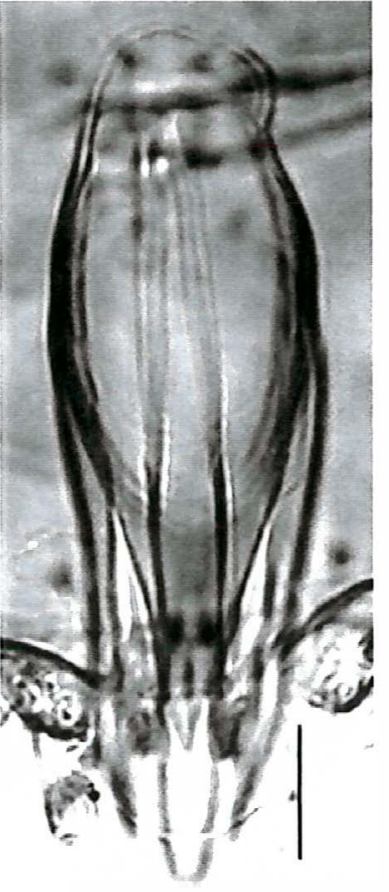

a2
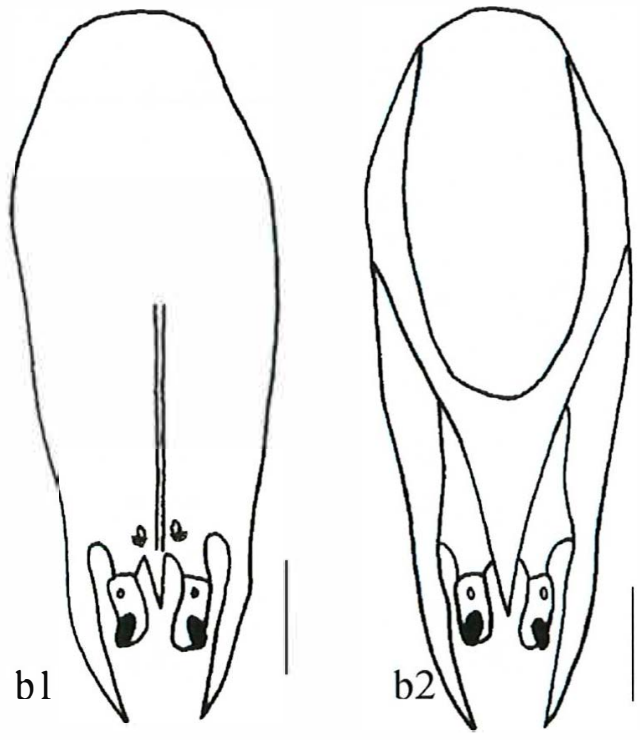

Figura 62 - Cápsula genital de Trichogramma sp. n. 7 (a -10 $\mu \mathrm{m}$ e b - $20 \mu \mathrm{m}): 1$ ventral e 2 - dorsal.

\section{Distribuiç̃ao geográfica e hospedeiros}

As informações são as mesmas comentadas para Trichogramma sp. n. 1 . 


\subsubsection{Trichogramma sp. n.9}

(Figura 64)

\section{Descricão}

Antenas: flagelo longo $(0,18 \pm 0,010)$; relação entre o comprimento e a largura do flagelo de 7,87 $\pm 0,72$; comprimento do flagelo/comprimento da tíbia posterior $(1,09 \pm 0,04)$; cerdas flageliformes longas $(0,08 \pm 0,006)$, com o ápice uniformemente afilado; comprimento da maior cerda do flagelo/maior largura do flagelo $(3,59 \pm 0,36)$; várias cerdas com base indistinta em todo o flagelo; sensilos basicônicos proeminentes e globosos, fórmula 2-2-2-0-1-1; três sensilos placóideo, o basal medindo 0,05 $\pm 0,004 \mathrm{~mm}$.

Asas anteriores: relação entre a largura e o comprimento da asa $(0,57 \pm 0,02)$; cerdas da franja da asa anterior curtas $(0,03 \pm 0,003)$; comprimento da maior cerda da franja da asa/comprimento da tíbia posterior $(0,17 \pm 0,02)$; comprimento da maior cerda da franja da asa/largura da asa anterior $(0,09 \pm 0,01)$. Número de cerdas entre a $4^{\underline{a}}$ e $5^{\text {a }}$ fileiras de 4 a 13 . Asas posteriores: número reduzido de cerdas; fileira anterior sem cerdas e a posterior com 3 a 5 cerdas, não alcançando a metade da fileira mediana.

Escutelo: cerdas anteriores relativamente longas; relação entre as cerdas anteriores e posteriores $(0,29 \pm 0,14)$.

Genitália masculina: cápsula genital levemente escurecida, mais longa $(0,15 \pm 0,006)$ do que larga $(0,05 \pm 0,003)$; relação entre a largura e o comprimento da cápsula genital $(0,35 \pm$ $0,02)$; distância apical/comprimento da cápsula genital $(0,26 \pm 0,02)$; largura apical/largura da cápsula genital $(0,73 \pm 0,06)$; lâmina dorsal com leve reentrância basal; comprimento/largura da lâmina dorsal $(1,93 \pm 0,19)$; comprimento da lâmina dorsal/comprimento da cápsula genital $(0,44 \pm 0,03)$; comprimento da abertura dorsal/comprimento da lâmina dorsal $(1,32 \pm 0,10)$; extensão posterior da lâmina dorsal longa $(0,05 \pm 0,007)$, ultrapassando as volselas; comprimento da extensão posterior da lâmina dorsal/comprimento da lâmina dorsal $(0,78 \pm$ 0,07); carena dorsal ausente; carena ventral longa, ultrapassando a metade da cápsula genital $(0,07 \pm 0,03)$; comprimento da carena ventral/distância basal $(0,64 \pm 0,01)$; distância basal/comprimento da cápsula genital $(0,74 \pm 0,02)$; processos ventrais afastados entre si e 
próximos da base do processo intervolselar; processo intervolselar longo $(0,02 \pm 0,002)$, pontiagudo ou levemente arredondado; comprimento do edeago/comprimento da tíbia posterior $(0,48 \pm 0,03)$; apódemas/edeago $(0,90 \pm 0,11)$.

Os dados quantitativos foram obtidos de cinco machos coletados de armadilha de sucção.
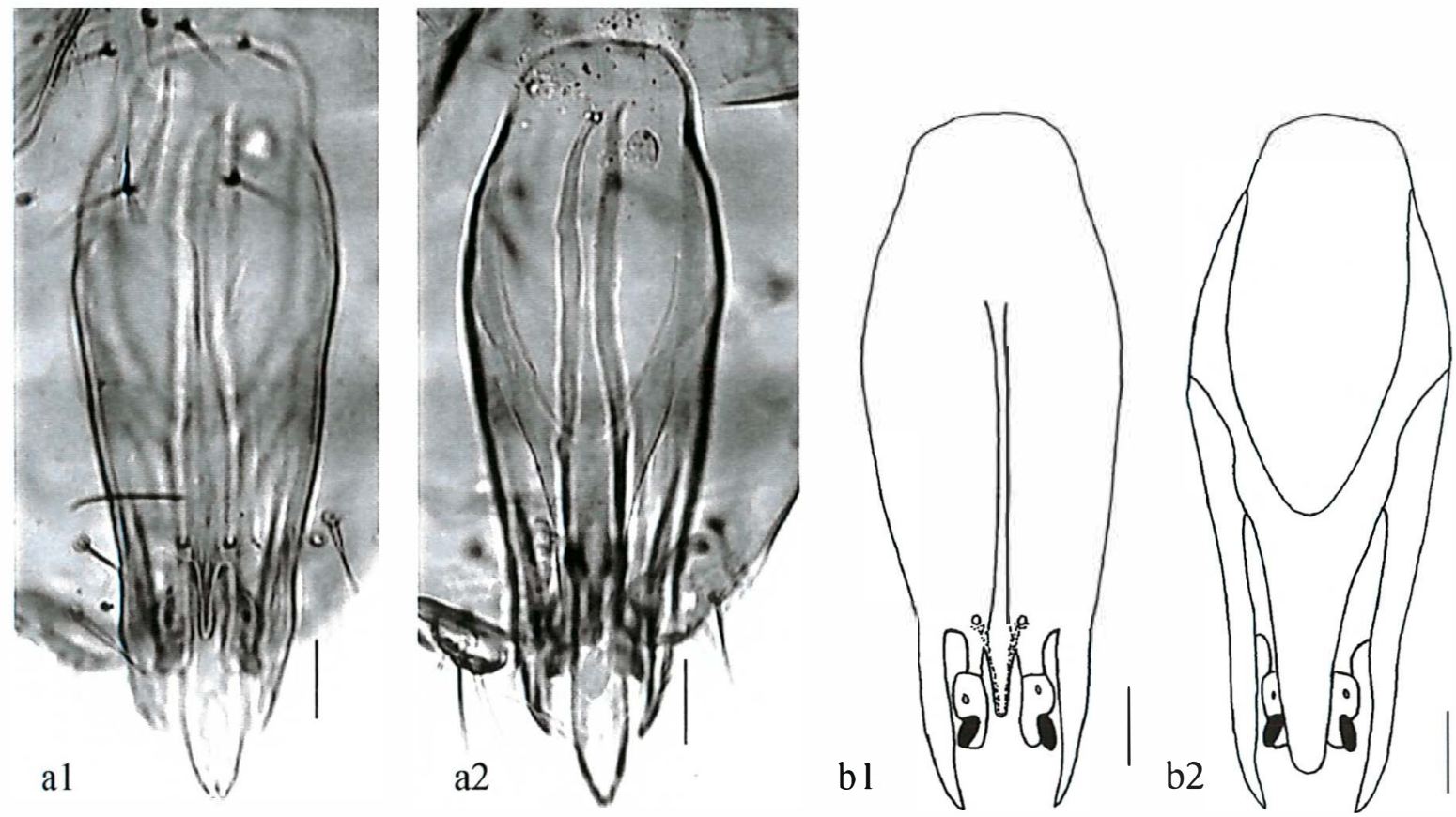

Figura 64 - Cápsula genital de Trichogramma sp. n. $9(\mathrm{a}-10 \mu \mathrm{m}$ e b $-20 \mu \mathrm{m}): 1$ ventral e 2 - dorsal.

\section{Material-tipo}

Holótipo macho. BRASIL. SÃO PAULO: Piracicaba, coletado em armadilha de sucção, Horto Florestal de Tupi, R.B. Querino col. (ESALQ). Parátipos três machos com os mesmos dados do holótipo (ESALQ).

\section{Diagnose}

Trichogramma sp. n. 9 é caracterizado pelos sensilos basicônicos proeminentes e globosos, pela presença de cerdas de base indistinta no flagelo da antena, pela lâmina dorsal com leve reentrância basal e extensão posterior longa, estreita, ultrapassando as 
volselas. Trichogramma sp. n. 9 é remotamente relacionado a T. stampae Vincent, 1986 e a T. nemesis Pinto, 1998. Entretanto, essas duas espécies são facilmente separadas de Trichogramma sp.n. 9, por caracteres da antena e genitália (John D. Pinto, inf. pes.).

\section{$\underline{\text { Variacões }}$}

O processo intervolselar às vezes não é distintamente pontiagudo.

\section{Distribuição geográfica e hospedeiros}

As informações são as mesmas comentadas para Trichogramma sp. n. 1 .

\subsubsection{Trichogramma sp. $n .11$}

(Figura 65)

\section{Descriç̃o}

Antenas: flagelo longo $(0,15 \pm 0,009)$; relação entre o comprimento e a largura do flagelo de $6,25 \pm 1,00$; comprimento do flagelo/comprimento da tíbia posterior $(1,02 \pm$ $0,05)$; cerdas flageliformes longas $(0,09 \pm 0,006)$, com o ápice uniformemente afilado; comprimento da maior cerda do flagelo/maior largura do flagelo $(3,61 \pm 0,40)$; presença de cerdas curtas com base indistinta, nas três primeiras secções do flagelo; sensilos basicônicos delgados, com a base mais comprida que o ápice, fórmula 2-2-2-0-1-1; três sensilos placóideo, o basal medindo $0,04 \pm 0,003 \mathrm{~mm}$.

Asas anteriores: largura da asa anterior $(0,25 \pm 0,012)$; relação entre a largura e o comprimento da asa $(0,55 \pm 0,01)$; comprimento da maior cerda da franja da asa $(0,03 \pm$ 0,002 ), cerca de 0,22 o comprimento da tíbia posterior; número reduzido de cerdas entre a $4^{\mathrm{a}}$ e $5^{\mathrm{a}}$ fileiras de 4 a 7 .

Asas posteriores: fileira anterior ausente e a posterior não ultrapassando a metade da fileira mediana, com 2 a 4 cerdas.

Escutelo: cerdas anteriores longas; relação entre as cerdas anteriores e posteriores $(0,53$ $\pm \bullet, 01)$. 
Genitália masculina: cápsula genital escurecida, mais longa $(0,13 \pm 0,006)$ do que larga $(0,05 \pm 0,004)$; relação entre a largura e o comprimento da cápsula genital $(0,37 \pm 0,02)$; distância apical/comprimento da cápsula genital $(0,23 \pm 0,01)$; largura apical/largura da cápsula genital $(0,74 \pm 0,05)$; lâmina dorsal originando-se no meio da cápsula genital, com reentrância na região basal; comprimento da lâmina dorsal/comprimento da cápsula genital $(0,37 \pm 0,03)$; comprimento/largura da lâmina dorsal $(1,46 \pm 0,11)$; comprimento da abertura dorsal/comprimento da lâmina dorsal $(1,44 \pm 0,13)$; extensão posterior da lâmina dorsal curta $(0,04 \pm 0,003)$ e com o ápice, sendo este arredondado e no nível do processo intervolselar, próximo das volselas; comprimento da extensão posterior da lâmina dorsal/comprimento da lâmina dorsal $(0,78 \pm 0,06)$; carena dorsal ausente; carena ventral longa $(0,06 \pm 0,004)$, além da metade da cápsula genital; carena ventral/distância basal $(0,63 \pm 0,05)$; distância basal/comprimento da cápsula genital $(0,77 \pm 0,01)$; processo intervolselar curto $(0,01 \pm 0,002)$ com o ápice pontiagudo; processos ventrais próximos da base do processo intervoselar; volselas próximas do ápice dos parâmeros; comprimento do edeago/comprimento da tíbia posterior $(0,52 \pm 0,02)$; apódemas/edeago $(0,77 \pm 0,05)$.

Os dados quantitativos foram obtidos de 20 machos coletados de ovos de Heliconius erato phyllis, em Passiflora sp., no Brasil.

\section{$\underline{\text { Material-tipo }}$}

Holótipo macho. BRASIL. SÃO PAULO: Piracicaba, out./1999, ex ovos de Heliconius erato phyllis, em Passiflora sp., J. A. Cerignoni col. (ESALQ). Parátipos cinco machos com os mesmos dados do holótipo (ESALQ).

\section{Material examinado}

BRASIL. SÃO PAULO: Piracicaba, out-1999, 20 machos, ex ovos de Heliconius erato phyllis, em Passiflora sp., J. A. Cerignoni col. (ESALQ); out.-1999, 10 machos, ex ovos de Mechanitis lysimnia, J. A. Cerignoni col. (ESALQ). 

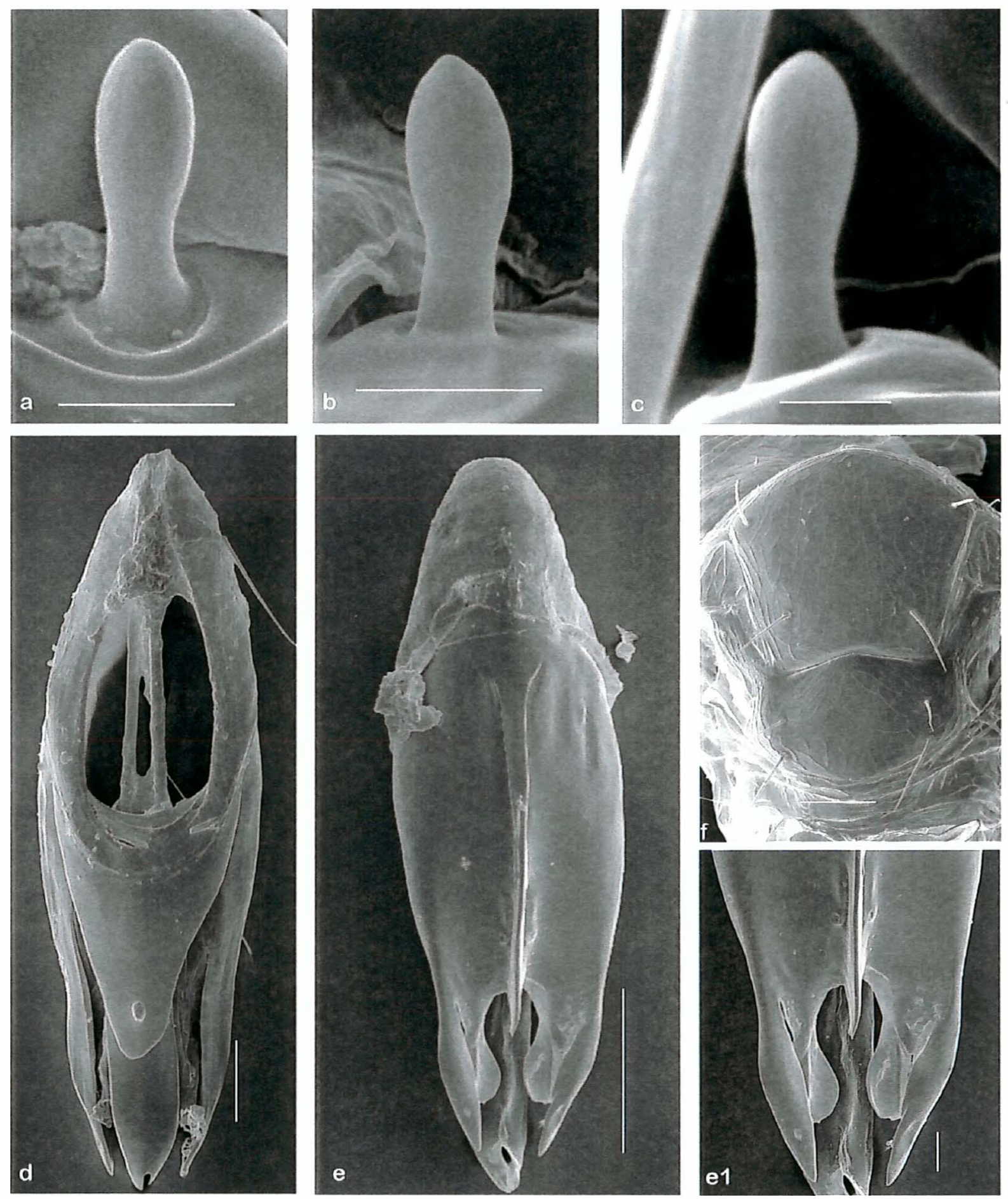

Figura 65 - Trichogramma sp. n. 11. Sensilo basicônico: a - posição 1 (21470x, $1 \mu \mathrm{m})$; b - posição 2 (22000x, 1 $\mu \mathrm{m})$; c - posição $3(10000 \mathrm{x}, 1 \mu \mathrm{m})$. Cápsula genital: d - vista dorsal $(2380 \mathrm{x}, 10 \mu \mathrm{m})$; e - vista ventral (1440x, $10 \mu \mathrm{m})$; el-detalhe apical $(4440 \mathrm{x}, 3 \mu \mathrm{m}) ; \mathrm{f}$ - mesoescuto e escutelo ( $1210 \mathrm{x}, 10 \mu \mathrm{m})$; 


\section{Diagnose}

Trichogramma sp. n. 11 é reconhecido principalmente pelas cerdas flageliformes longas; presença de cerdas com base indistinta nas três primeiras seç̧ões do flagelo; sensilo basicônico alongado; cerdas anteriores do escutelo longas e escurecidas; cápsula genital longa e escurecida; lâmina dorsal curta e a extensão posterior da lâmina dorsal com ápice arredondado próximo da base das volselas. Dentre as espécies da região Neotropical, Trichogramma sp. n. 11 é uma espécie relacionada à T. bruni, que difere de Trichogramma sp. n. 11 pelos caracteres da antena, como forma e fórmula dos sensilos basicônico, ausência de cerdas de base indistinta na primeira seção do flagelo e pelas cerdas anteriores do escutelo curtas, além do aspecto geral da cápsula genital.

Amostras de Trichogramma sp. n. 11 utilizadas na caracterização morfológica neste trabalho, foram enviadas para o sequêenciamento da região ITS2 do r-DNA e os resultados não foram similares a nenhuma espécie em que já é conhecido o seqüênciamento (Raul P. Almeida, inf. pes.).

\section{$\underline{\text { Variacões }}$}

$\mathrm{Na}$ antena, as cerdas de base indistintas variaram quanto ao número, na primeira seção do flagelo variou de 0 a 3 cerdas; na segunda, 1 cerda e na terceira, 1 a 2 cerdas. $\mathrm{Na}$ genitália, a extensão posterior da lâmina dorsal variou quanto ao comprimento, podendo alcançar ou não a base das volselas, alguns indivíduos apresentaram o ápice da extensão posterior com uma pequena reentrância; o processo intervolselar variou quanto ao comprimento, mais alongado, alcançando ou não a base das volselas. No ápice do processo intervolselar também foi observado uma pequena reentrância, principalmente em fotografias de microscopia eletrônica de varredura.

\section{Distribuicão geográfica e hospedeiros}

Trichogramma sp. n. 11 foi coletada em Piracicaba, São Paulo, de ovos de Heliconius erato phyllis (Lepidoptera: Nymphalidae) em passiflora sp. e de ovos de Mechanitis lysimnia (Lepidoptera: Nymphalidae). Foi também coletada em uma armadilha de sucção instalada no Horto Florestal de Tupi, em Piracicaba, SP. 
4.4.8 Trichogramma sp. n. 12

(Figura 66)

\section{$\underline{\text { Descriç̃̃o }}$}

Antenas: flagelo longo $(0,15 \pm 0,014)$; relação entre o comprimento e a largura do flagelo de $6,75 \pm 0,74$; comprimento do flagelo/comprimento da tíbia posterior $(0,92 \pm$ $0,05)$; cerdas flageliformes longas $(0,08 \pm 0,006)$, com o ápice uniformemente afilado; comprimento da maior cerda do flagelo/maior largura do flagelo $(3,41 \pm 0,41)$; presença de cerdas curtas com base indistinta; sensilos basicônicos com fórmula 1-2(1)-2-0-1-1; três sensilos placóideo, o basal medindo $0,04 \pm 0,011 \mathrm{~mm}$.

Asas anteriores: largura da asa anterior $(0,18 \pm 0,112)$; relação entre a largura e o comprimento da asa $(0,49 \pm 0,02)$; comprimento da maior cerda da franja da asa $(0,03 \pm$ $0,015)$; comprimento da maior cerda da franja da asa/comprimento da tíbia posterior $(0,24 \pm 0,03)$; comprimento da maior cerda da franja da asa/largura da asa anterior $(0,17$ $\pm 0,02)$; número reduzido de cerdas entre a $4^{\mathrm{a}}$ e $5^{\mathrm{a}}$ fileira de 7 a 15 .

Asas posteriores: fileira anterior com 0 a 1 cerda e a posterior com 5 a 8 cerdas, não ultrapassando a metade da fileira mediana.

Escutelo: cerdas anteriores curtas; relação entre as cerdas anteriores e posteriores $(0,18 \pm 0,08)$.

Genitália masculina: cápsula genital longa $(0,16 \pm 0,006)$ e larga $(0,06 \pm 0,005)$; relação entre a largura e o comprimento da cápsula genital $(0,39 \pm 0,02)$; distância apical/comprimento da cápsula genital $(0,21 \pm 0,01)$; largura apical/largura da cápsula genital $(0,70 \pm 0,08)$; lâmina dorsal com reentrância na região basal, originando-se no meio da cápsula genital; comprimento da lâmina dorsal/comprimento da cápsula genital $(0,44 \pm 0,03)$; comprimento/largura da lâmina dorsal $(1,39 \pm 0,09)$; comprimento da abertura dorsal/comprimento da lâmina dorsal $(1,28 \pm 0,10)$; extensão posterior da lâmina dorsal curta $(0,05 \pm 0,002)$, com o ápice e alcançando a base das volselas; comprimento da extensão posterior da lâmina dorsal/comprimento da lâmina dorsal $(0,69$ $\pm 0,05)$; carena dorsal ausente; carena ventral longa $(0,07 \pm 0,004)$, além da metade da cápsula genital; carena ventral/distância basal $(0,52 \pm 0,04)$; distância basal/comprimento da 
cápsula genital $(0,79 \pm 0,01)$; processo intervolselar muito curto $(0,004 \pm 0,002)$, bífido ou com o ápice pontiagudo; processos ventrais afastados entre si e próximos $(0,01 \pm 0,002)$ da base do processo intervoselar; volselas muito próximas do ápice dos parâmeros; comprimento do edeago/comprimento da tíbia posterior $(0,51 \pm 0,04)$; apódemas/edeago $(0,96 \pm 0,08)$.

Os dados quantitativos foram obtidos de 19 machos coletados de ovos de Calpodes ethlius (Stoll, 1781) (Lepidoptera: Hesperiidae), em Canna spp. (Cannaceae).

\section{Material-Tipo}

Holótipo macho. BRASIL. ALAGOAS: Maceió, abr.-2000, ex ovos de Calpodes ethlius, em Canna spp, I.M.M. Lima col. (ESALQ). Cinco parátipos machos com os mesmos dados do holótipo (ESALQ).

\section{Diagnose}

Trichogramma sp. n.12 distingui-se pelos processos ventrais afastados entre si e o processo intervolselar geralmente bífido. Este caráter também é observado em $T$. marthae Goodpasture, 1986, entretanto, o processo intervolselar é diferente. Outra característica importante em Trichogramma sp. n. 12 é a cápsula genital ampla, com a extensão posterior da lâmina dorsal curta, com o ápice arredondado.

\section{Variacões}

Foram observados indivíduos com cerdas de base indistinta nas três primeiras seções do flagelo; sensilos basicônicos variando em número na posição 2; cerdas da fileira posterior alcançando o ápice da asa; processo intervolselar bífido, em 12 dos 19 indivíduos analisados.

\section{Distribuição geográfica e hospedeiros}

Trichogramma sp.n. 12 foi coletado de ovos de Calpodes ethlius (Stoll, 1781) (Lepidoptera: Hesperiidae) em Canna spp. (Cannaceae), em Maceió, Alagoas, Brasil (I.M.M. Lima, n. publ.). 

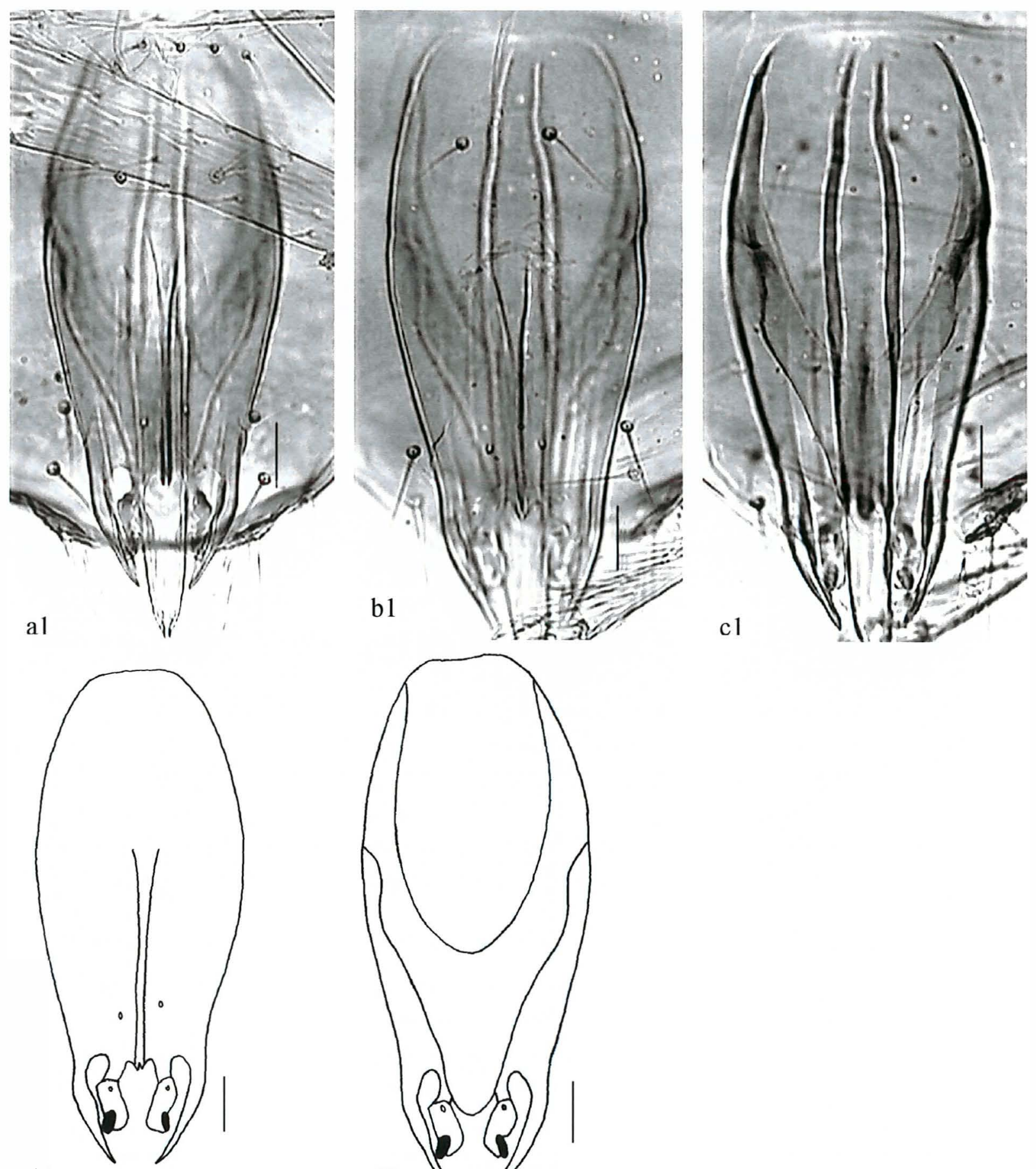

dl

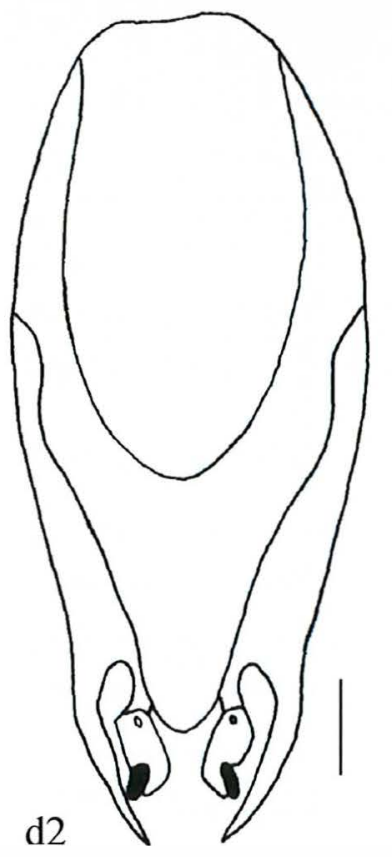

Figura 66 - Cápsula genital de Trichogramma sp.n. 9: a - ventral, processo intervolselar pontiagudo $(10 \mu \mathrm{m}) ; \mathrm{b}$ - ventral, processo intervolselar bífido $(10 \mu \mathrm{m}) ; \mathrm{c}-$ dorsal $(20 \mu \mathrm{m}) ; \mathrm{d}$ - $(10 \mu \mathrm{m}) .1$ - ventral e 2 - dorsal. 


\subsection{Chave ilustrada para as espécies de Trichogramma da América do Sul}

1. Flagelo da antena constituído de dois distintos segmentos no funículo e três na clava (a); nervura marginal da asa anterior com uma cerda próxima do bordo posterior (b); asa posterior sem a fileira posterior de cerdas (subgênero Vanlisus) (c); segundo segmento do funículo subquadrado, levemente mais longo do que largo (d); genitália do macho com a extensão posterior da lâmina dorsal com o ápice arredondado (e)..

T.atropos

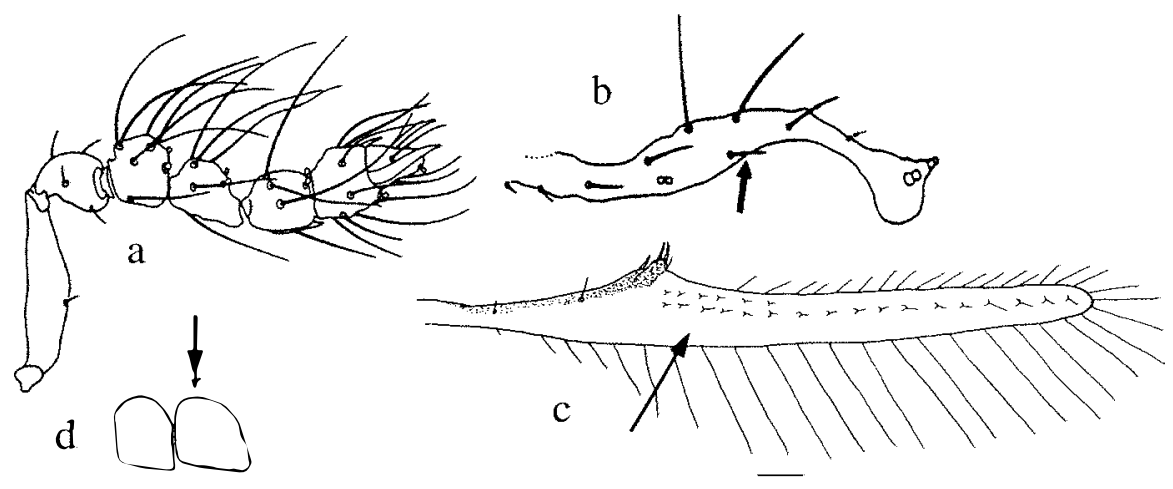

Figuras de Pinto $(1992,1998)$

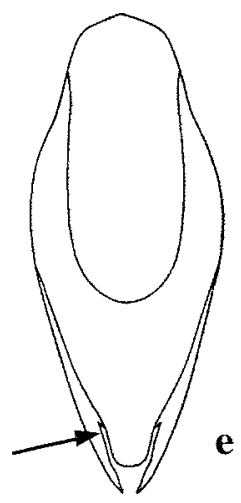

1'. Flagelo da antena com os segmento unidos para formar uma estrutura única (a); nervura marginal com rês robustas e longas cerdas na superfície dorsal (b); asa posterior sempre com no mínimo duas fileiras de cerdas (c) (subgênero Trichogramma) 2
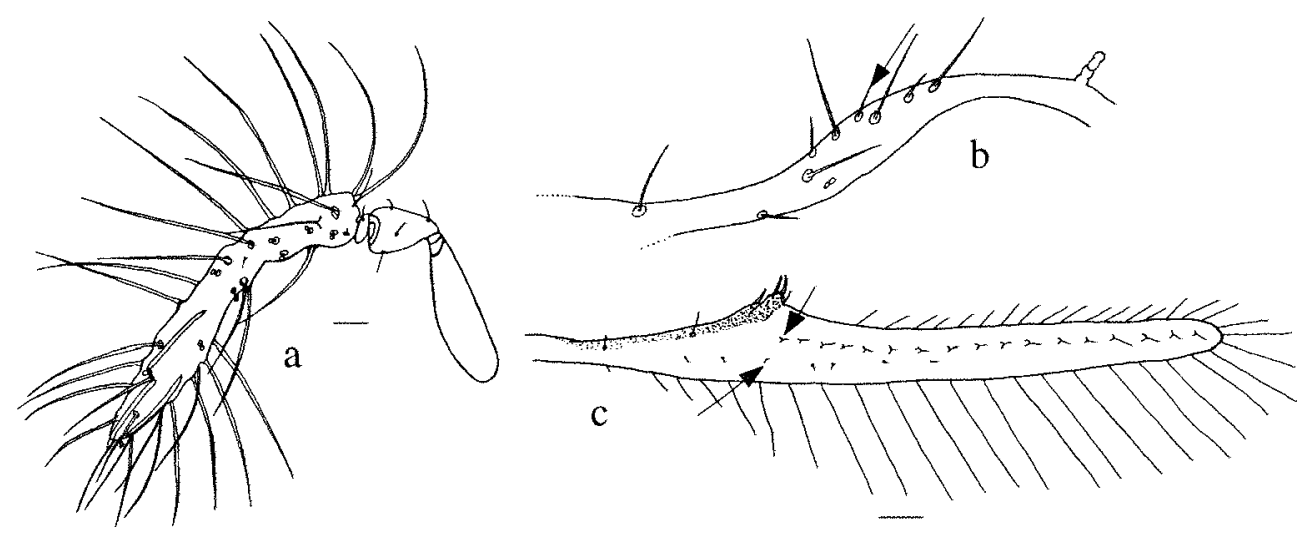

2. Lâmina dorsal sem lobos laterais 
2'. Lânina dorsal com distintos lobos laterais, ultrapassando as margens da cápsula genital (a); processo intervolselar distinto, curto e com reentrância apical (b). T. maniçobai
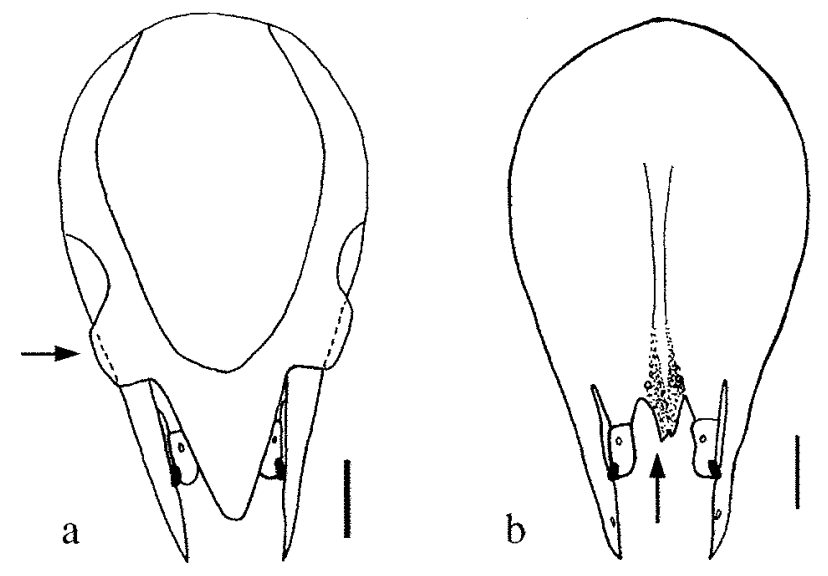

3. Lâmina dorsal larga em todo seu comprimento, não se estreitando significativamente da base para o ápice (a); carena dorsal presente (b). 4

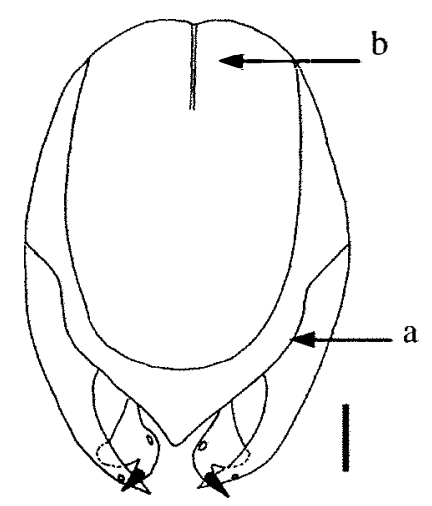

3'. Lâmina dorsal estreita em todo seu comprimento ou com base mais larga que o ápice; carena dorsal ausente. 10

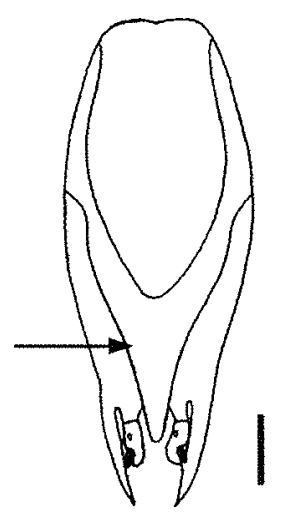


4. Volselas com projeções quitinizadas na margem lateral (forma de unha)

T. guariquensis

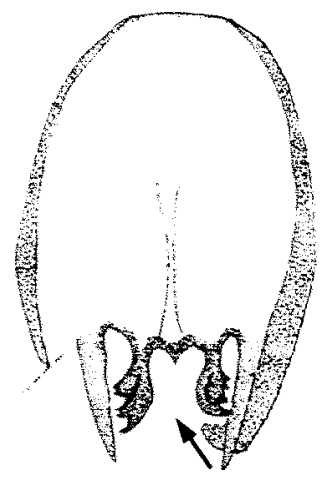

Figura de Velasquez de Rios \& Teran (1994)

4'. Volselas sem projeções quitinizadas

5. Parâmeros arqueados (a); volselas curvadas (b); cápsula genital grande (largura maior que 0,6 vezes o comprimento da cápsula genital). 6

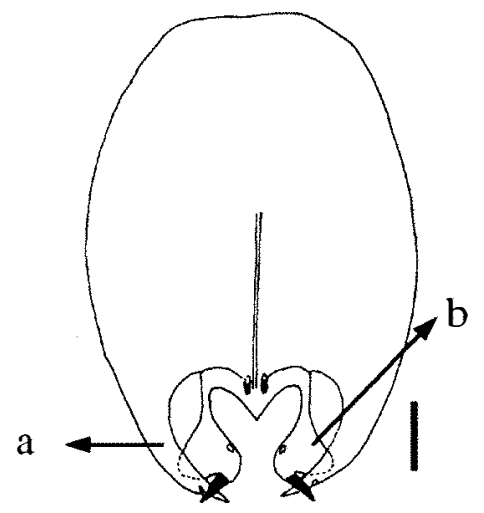

5'. Parâmeros não arqueados (a); cápsula genital pequena e ovalada (largura menor que 0,6 vezes o comprimento da cápsula genital) .8

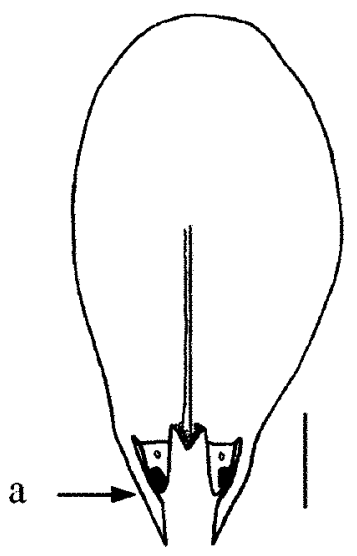


6. Lâmina dorsal com profunda fenda na linha mediana (a); volselas modificadas (b), ultrapassando os parâmeros posteriormente (c).

T. nomlaki

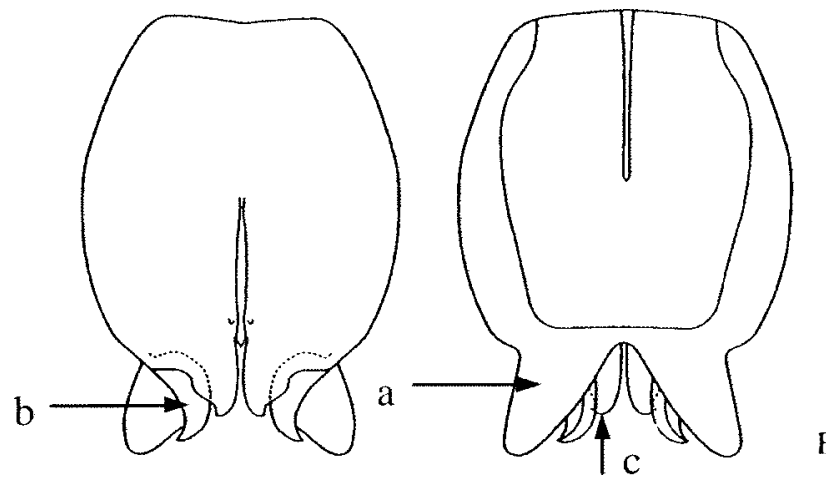

Figuras de Pinto (1998)

6'. Lâmina dorsal sem fenda

7. Volselas com acentuada reentrância lateral, formando um distinto lobo (a); parâmeros dilatados e arqueados (b); processo intervolselar muito curto (c); processos ventrais distintamente tubulares (d)

.T. atopovirilia
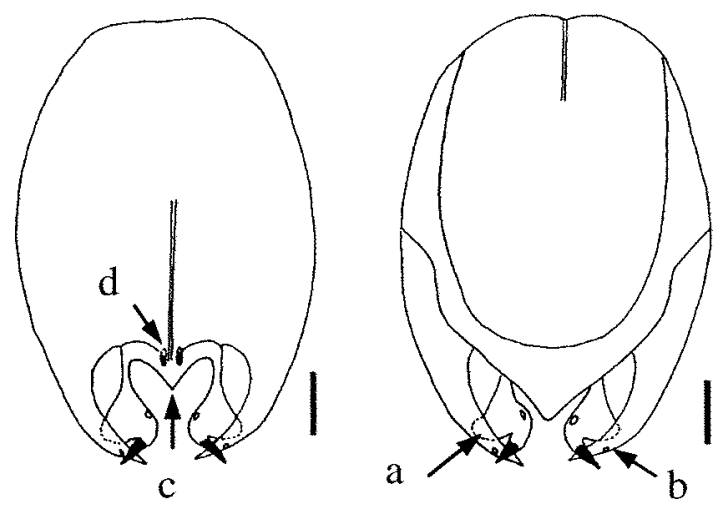

7'. Volselas curvadas com o ápice pontiagudo e espinho apical longo e estreito (a); parâmeros arqueados (b); processo intervolselar praticamente inexistente (c)

T. acacioi
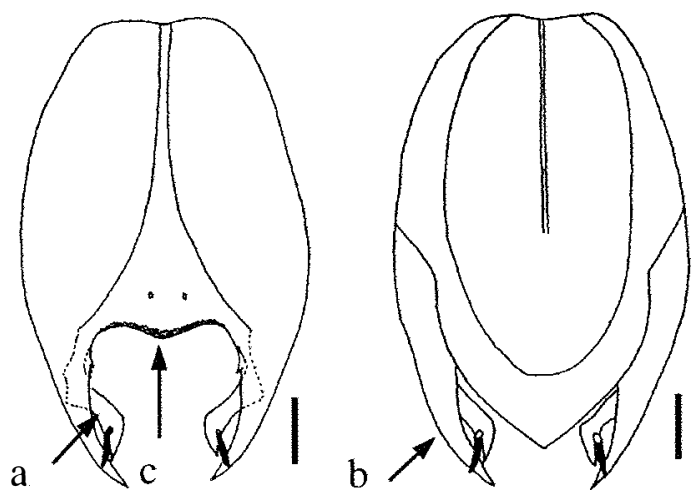
8. Lâmina dorsal tão ou mais larga que a cápsula genital (a), encobrindo as volselas (b) e o processo intervolselar (c)

T. fasciatum
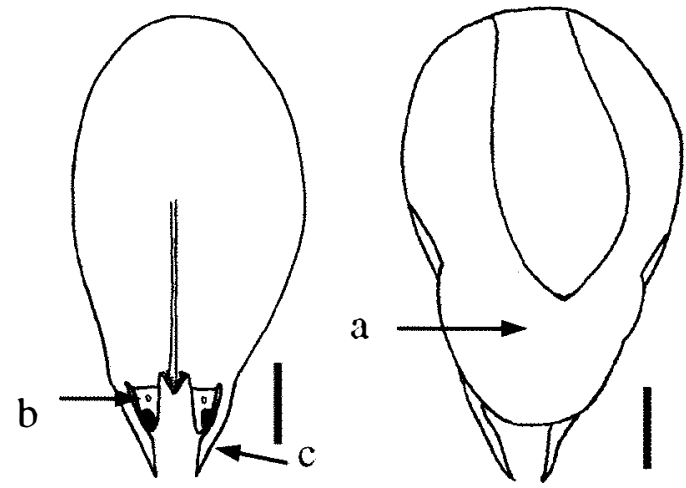

8'. Lâmina dorsal não abrangendo toda a largura da cápsula genital

9. Volselas modificadas com distinto lobo lateral (a); processo intervolselar subtriangular, cerca de metade do comprimento das volselas (b); extensão posterior da lâmina dorsal larga tanto no ápice quanto na base (c).

T. bennetti
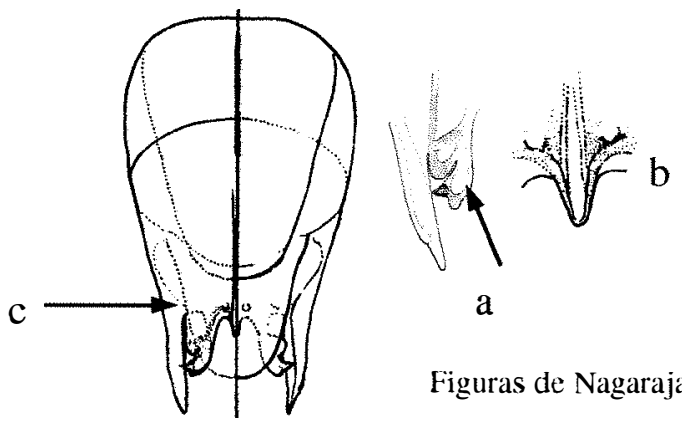

Figuras de Nagaraja \& Nagarkatti (1973)

9'. Volselas não modificadas (a); processo intervolselar diminuto, não alcançando as volselas (b); extensão posterior da lâmina dorsal mais estreita no ápice (c) Trichogramma sp. n. 3
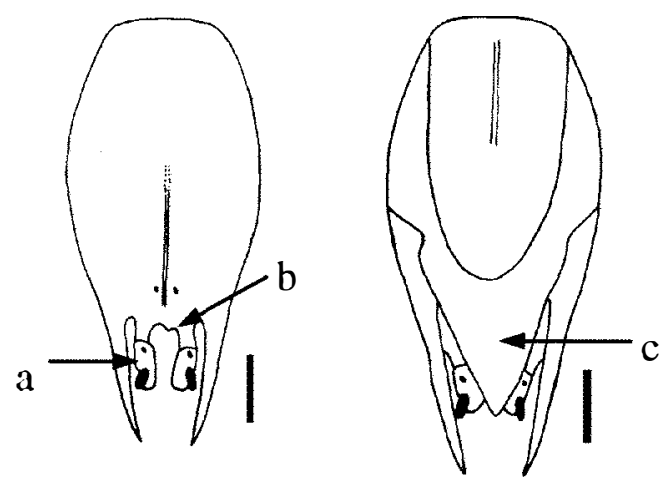

10. Lâmina dorsal com a base mais larga que o ápice 
10'. Lâmina dorsal com aspecto lingüiforme, extensão posterior distintamente estreita e longa, ápice arredondado; cápsula genital escurecida.

Trichogramma sp. n. 5
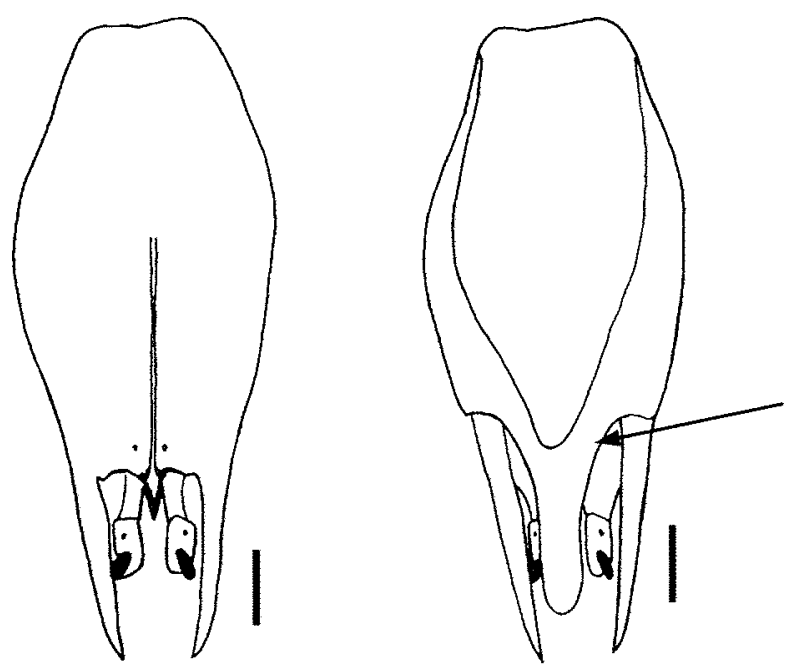

11. Lâmina dorsal sem reentrância basal

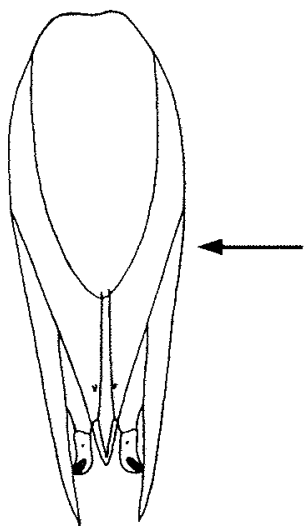

11'. Lâmina dorsal com reentrância basal.

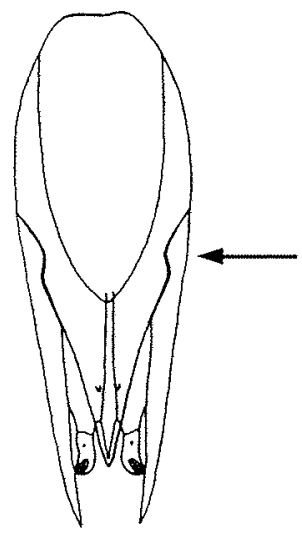

12'. Processo intervolselar não robusto. 


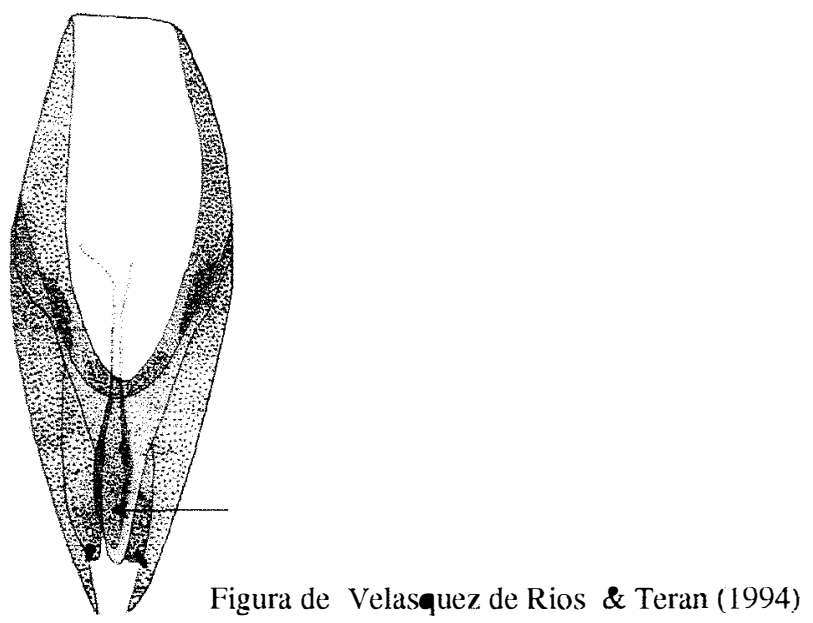

13. Processos ventrais dilatados e situados na base do processo intervolselar (a); processo intervolselar curto (b); cerdas anteriores do escutelo longas (CSAE > 0,005 $\mathrm{mm})(\mathrm{c})$ Trichogramma sp. n. 6
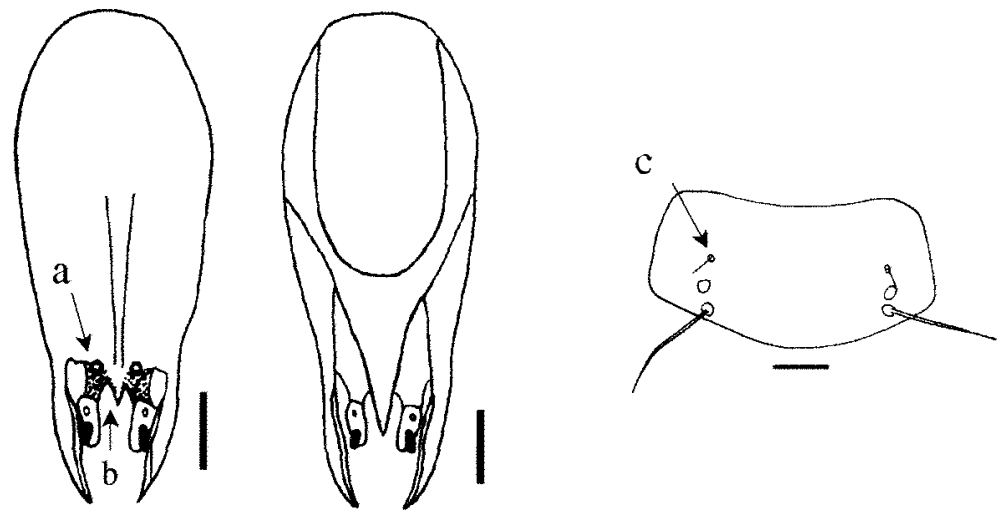

13'. Processos ventrais não dilatados e próximos da base do processo intervoselar (a); processo intervolselar mais alongado (b); cerdas anteriores do escutelo curtas, i.e., $\mathrm{CSAE} \leq 0,005 \mathrm{~mm}(\mathrm{c})$

Trichogramma sp. n. 7
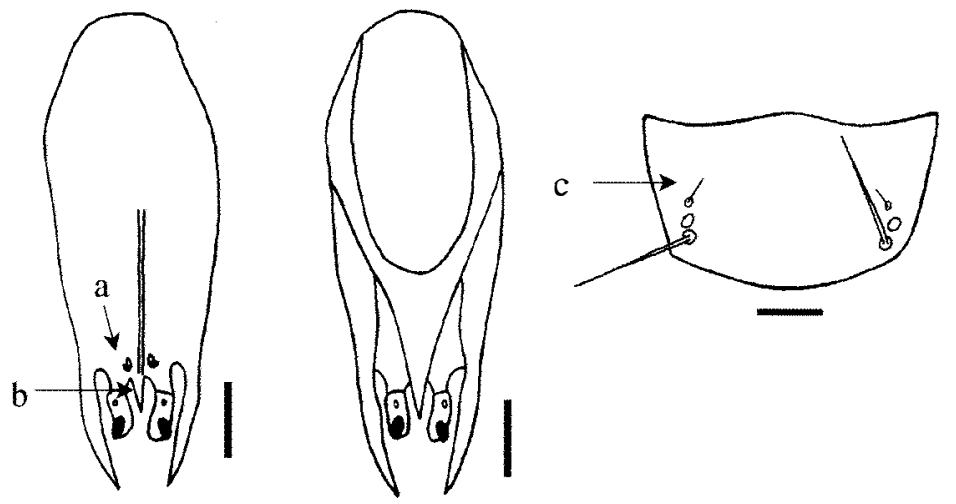
14. Cápsula genital com acentuada constrição ao nível do processo intervolselar.

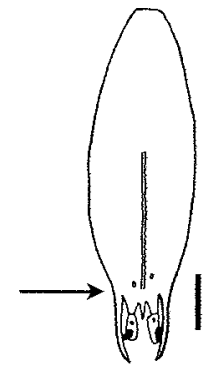

14’. Cápsula genital sem acentuada constrição ao nível do processo intervolselar.......16

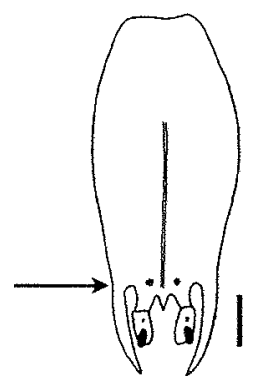

15. Lados da cápsula genital estreitam-se abruptamente no nível do processo intevolsear (a); parâmeros retos (b).

T. nerudai

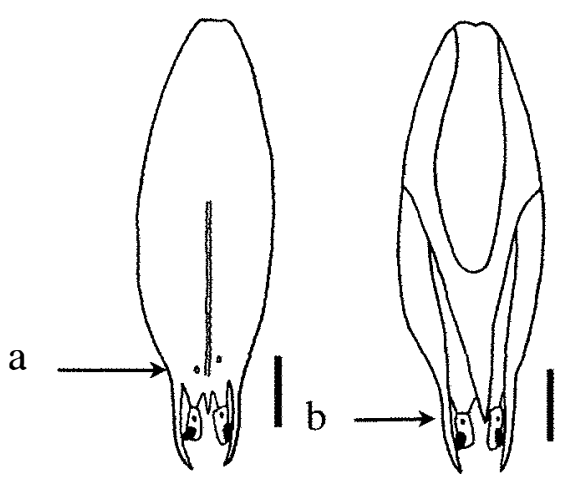

15'. Lados da cápsula genital estreitam-se mais gradualmente no nível do processo intevolsear (a); parâmeros arqueados (b).

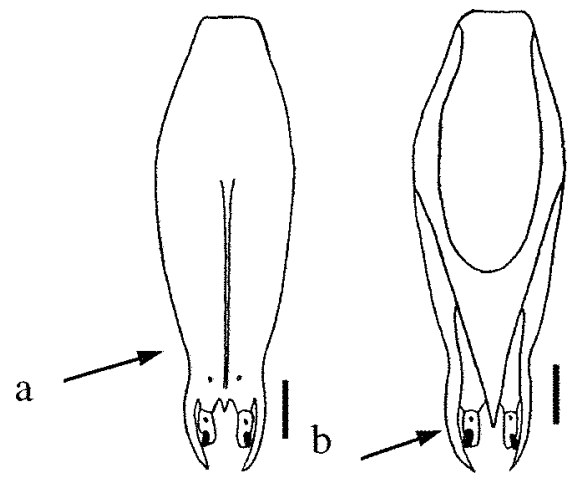


16. Processo intervolselar curto (alcançando ou não a base das volselas).

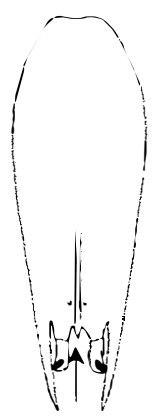

16'. Processo intervolselar longo (ultrapassando a base das volselas)

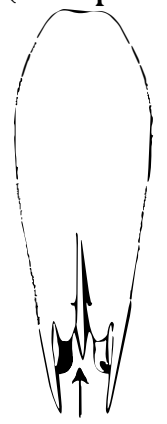

17. Asa posterior com a fileira posterior de cerdas da alongada, com 10 ou mais cerdas, a última cerda alcançando o ápice da asa (a); processos ventrais muito próximos da base do processo intervolselar (b).

T. rojasi
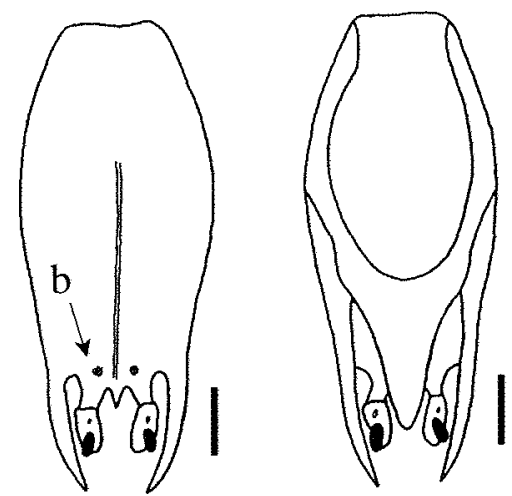

\section{a}

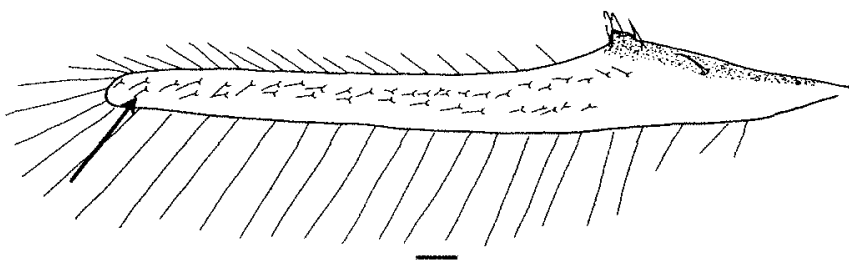

17'. Asa posterior com a fileira posterior de cerdas com menos de 10 cerdas, a última cerda alcançando ou não a metade do comprimento da fileira mediana

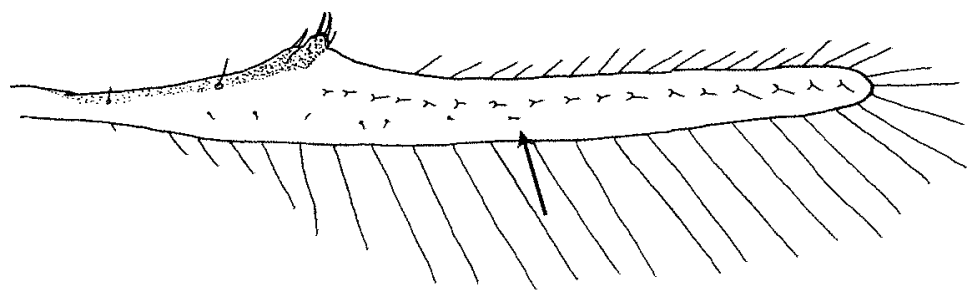


18. Lâmina dorsal curta, com o ápice arredondado, alcançando ou não a base das volselas.

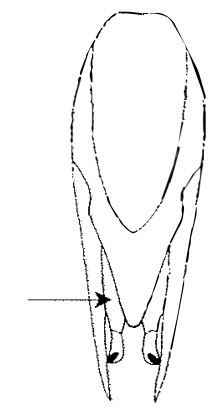

18'. Lâmina dorsal longa, com o ápice pontiagudo ou arredondado, alcançando ou não o ápice das volselas. 20

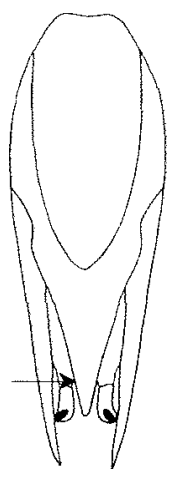

19. Cerdas anteriores do escutelo longas (a); processo intervolselar com o ápice pontiagudo (b); processos ventrais afastados da base do processo intervoselar (c); cápsula genital escurecida.

.Trichogramma sp. n. 11
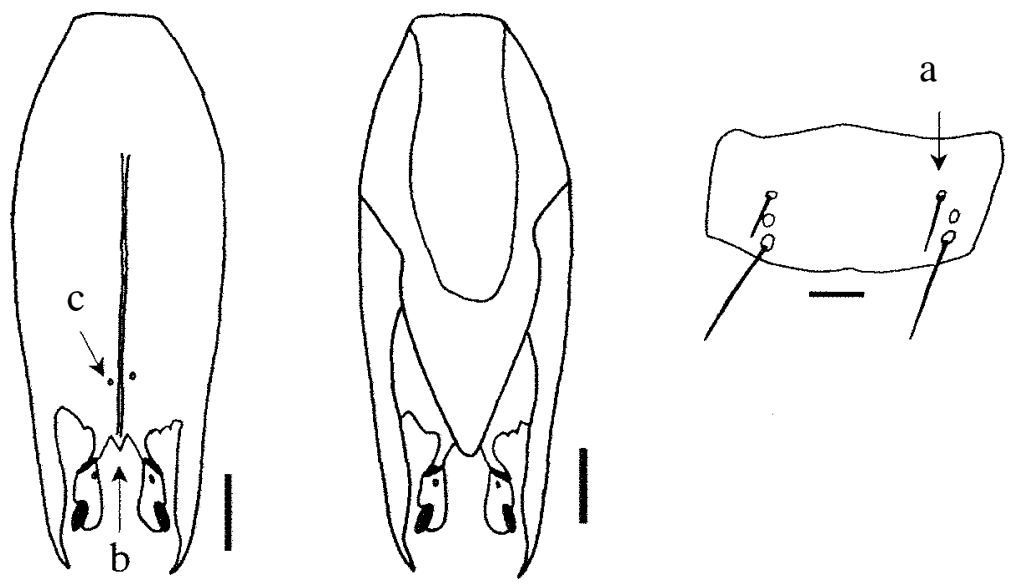

19'. Cerdas anteriores do escutelo curtas (a); processo intervolselar com o ápice bífido ou pontiagudo (b); processos ventrais próximos da base do processo intervoselar e afastados entre si (c); cápsula genital não-escurecida.

Trichogramma sp. n. 12 

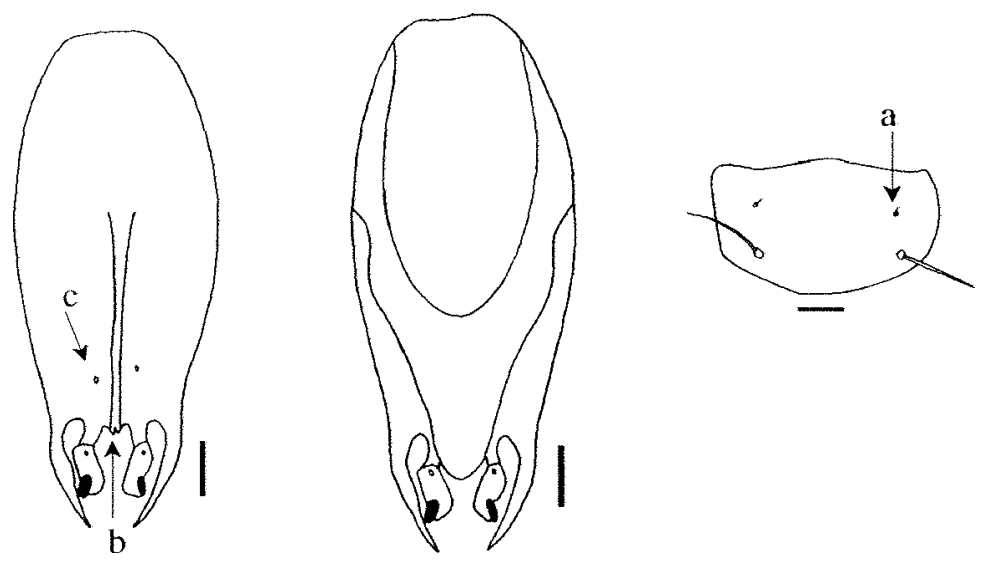

20. Processos ventrais mais dilatados situados na base do processo intervolselar (a); cerdas anteriores do escutelo alongadas (b)

Trichogramma sp. n. 1
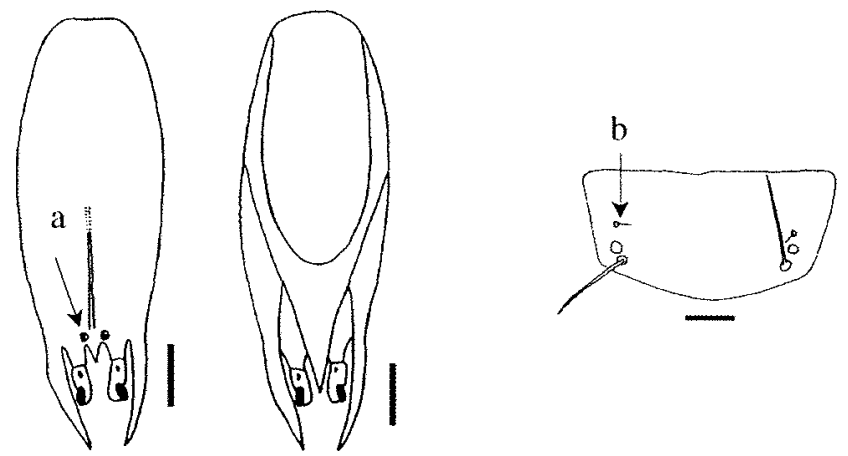

20'. Processos ventrais não dilatados e afastados da base do processo intervoselar......21

21. Cerdas da franja da asa anterior Iongas, cerca de 0,6 vezes o comprimento da tíbia posterior.

T. lopezandinensis

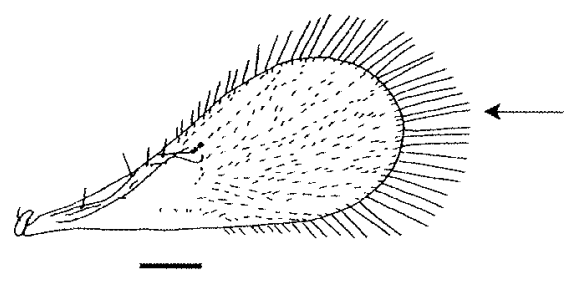

21'. Cerdas da franja da asa anterior curtas, menor que 0,3 vezes o comprimento da tíbia posterior.

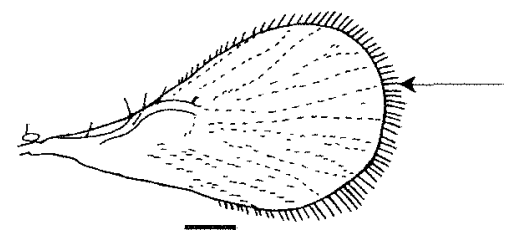


22. Carena ventral curta, com limite anterior pouco definido, de difícil visualização (a); sensilo basicônico subgloboso, fórmula 1-2-2-0-1-1; cerdas anteriores do escutelo distintas e escuras; cápsula genital escurecida.

T. lasallei
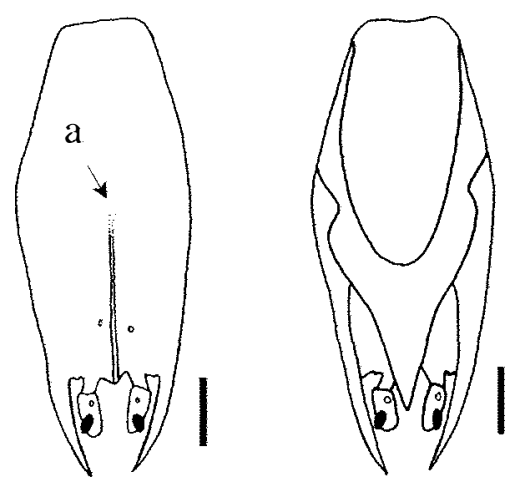

22'. Carena ventral longa e distinta.

23. Carena ventral distinta, longa, atingindo cerca de $2 / 3$ do comprimento da cápsula genital (a); sensilos basicônicos ovalados, fórmula 2(1)-2(1)-2-0(1)-1; cerdas anteriores do escutelo curtas, de difícil visualização (b).

T. bruni
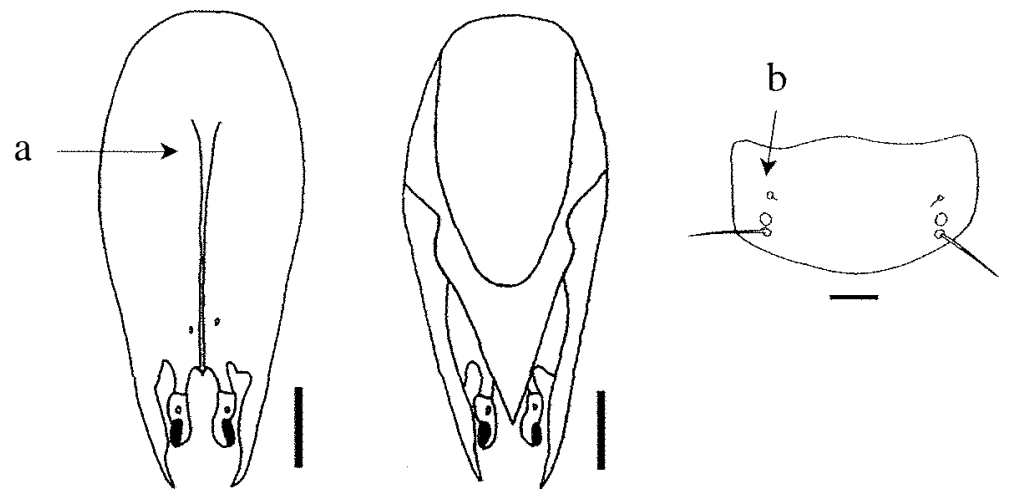

23'. Carena ventral longa e ultrapassando metade da cápsula genital (comumente associado a Euselasia sp. em eucalipto).

T. maxacalii
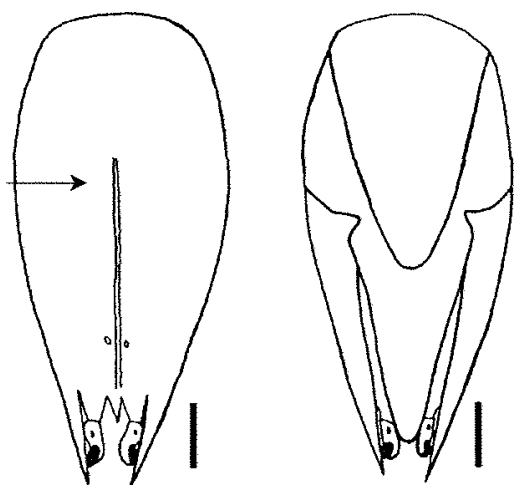
24. Cerdas do flagelo longas com o ápice uniformemente afilado $(\mathrm{CSF} / \mathrm{LF}>2.5)$

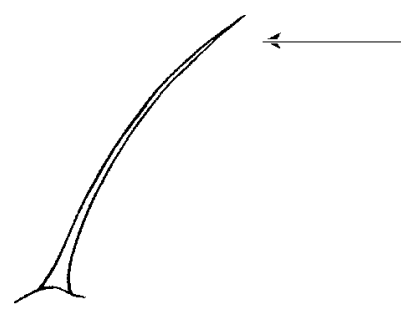

24'. Cerdas do flagelo curtas ( $\mathrm{CSF} / \mathrm{LF} \leq 2,5)$ com o ápice abruptamente afilado.

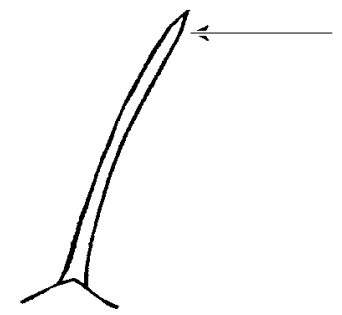

25. Carena ventral estreita e alongada, estendendo-se até a metade da cápsula genital (a); ápice do sensilo placóideo terminal estendendo-se 1/3 além do ápice do flagelo (oeste do Canadá e Estados Unidos, apenas um relato na Venezuela).

T. minutum

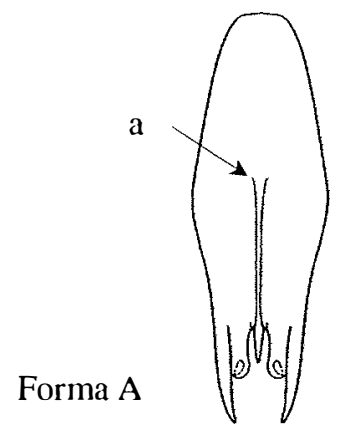

Forma B
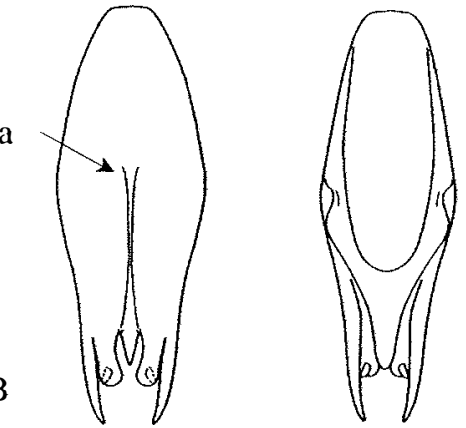

Figura de Pinto (1998)

25'. Carena ventral curta, não alcançando a metade da cápsula genital (a); ápice do sensilo placóideo terminal estendendo-se 1/4 além do ápice do flagelo; extensão posterior da lâmina dorsal geralmente mais fracamente esclerotizada, com o ápice da extensão posterior de difícil visualização em microscópio óptico (b); cerdas flageliformes mais longas (amplamente distribuída na região Neotropical).

T. pretiosum
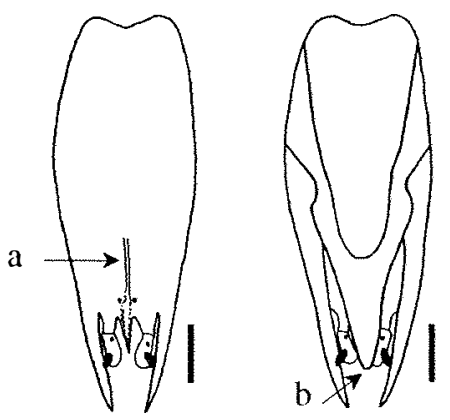
26. Processo intervolselar robusto, longo, pontiagudo ou truncado no nível do ápice das volselas (a); carena ventral curta $(0,04 \pm 0,004)$, pouco desenvolvida, não se estendendo além da metade da cápsula genital (b); fileira posterior de cerdas da asa posterior alongada, estendendo-se quase até o ápice da asa posterior (c).

T. fuentesi
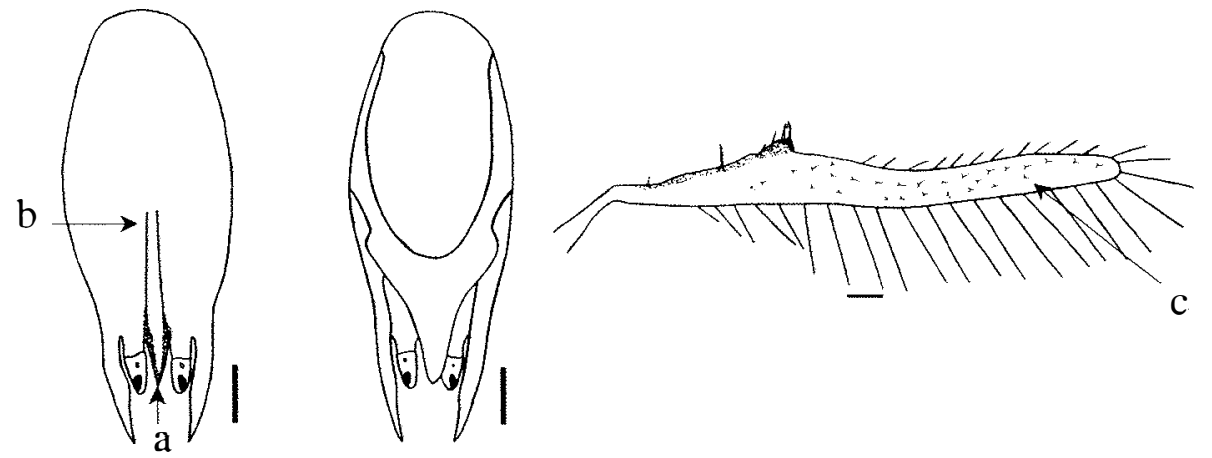

26'. Processo intervolselar longo, alcançando ou não o ápice das volselas

.27

27. Extensão posterior da lâmina dorsal não alcançando o ápice das volselas

.28

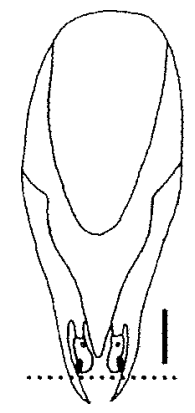

27'. Extensão posterior da lâmina dorsal aproximadamente no mesmo nível ou ultrapassando o ápice das volselas, se no mesmo nível, processo intervolselar próximo ou no nível ou além das volselas 31

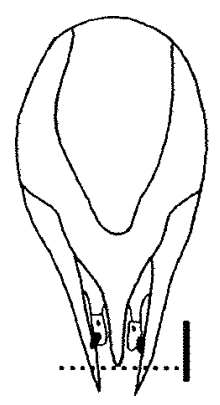

28. Processo intervolselar longo geralmente com o ápice pontiagudo; se truncado, a carena ventral ultrapassa a metade da cápsula genital.

28'. Processo intervolselar longo com ápice arredondado ou truncado; se truncado a carena ventral não ultrapassa a metade da cápsula genital 
29. Processo intervolselar no mesmo nível ou ultrapassando um pouco o ápice da lâmina dorsal (a); lâmina dorsal com reentrância basal mais suave (b) (associado a lepidópteros de hábitat florestal)

.T. bertii
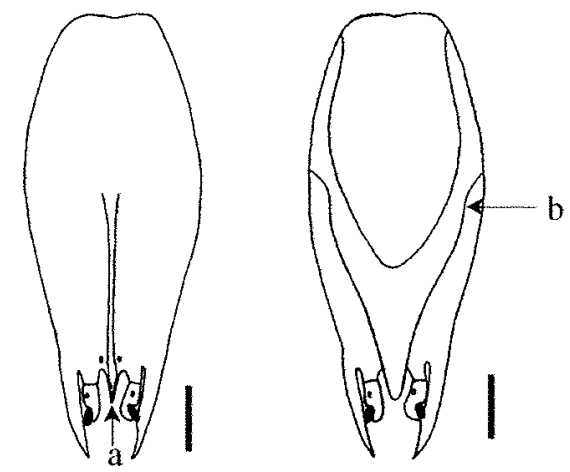

29'. Processo intervolselar mais curto, nunca ultrapassando o ápice da lâmina dorsal (a); lâmina dorsal com reentrância basal mais acentuada (b); sensilos basicônicos proeminentes e globosos (comumente associado a lepidópteros de importância agrícola). T. exiguum
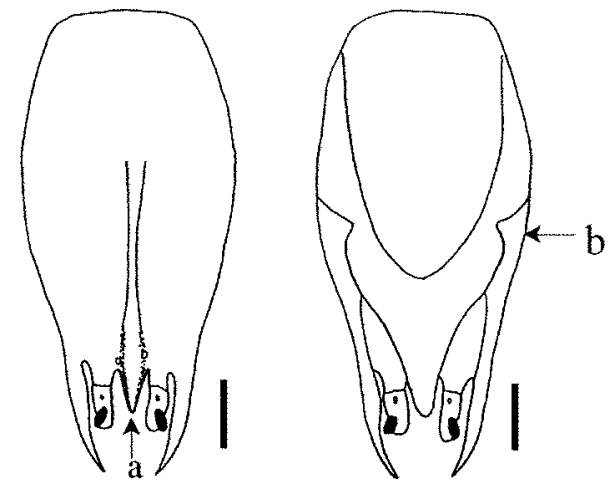

30. Processo intervolselar, largo e truncado no ápice (a); carena ventral não ultrapassa a metade da cápsula genital (b); lâmina dorsal com a extensão posterior estreita e com o ápice arredondado no mesmo nível do processo intervolselar(c)

T. marandobai

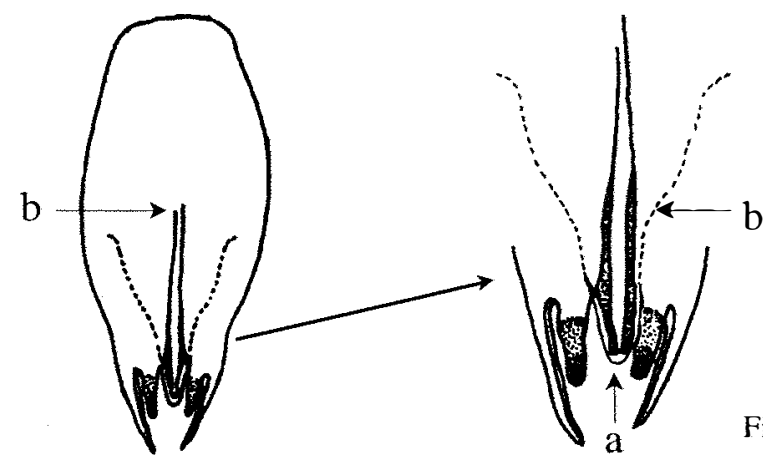

Figuras de Brun et al. (1986) 
30'. Processo intervolselar com o ápice arredondado (comumente associado a Erinnyis ello, em mandioca).

T. demoraesi
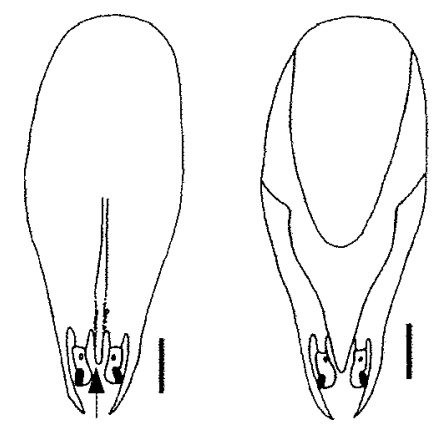

31. Antena com flagelo relativamente curto; os segmentos do flagelo completamente fundidos um ao outro e com a clava; sensilos basicônicos proeminentes e subglobosos; abertura dorsal alongada, estreitando-se apicalmente (a); largura da lâmina dorsal após a reentrância basal, consideravelmente menor que a base, lados afilando-se gradualmente com aspecto lingüiforme (b)...................................................T. stampae

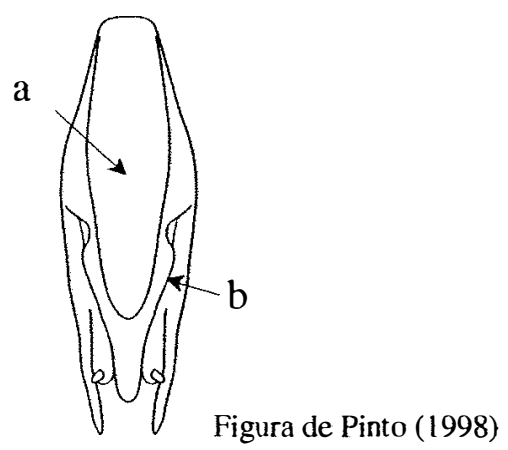

31'. Antena com flagelo não completamente fundido; sensilo basicônico com tamanho e número reduzido; lâmina dorsal de outra forma (comumente associada a Diatraea saccharalis, em cana-de-açúcar).

32

32. Cápsula genital larga (maior que $0,50 \pm 0,02 \mathrm{~mm}$ ). T. dissimilis
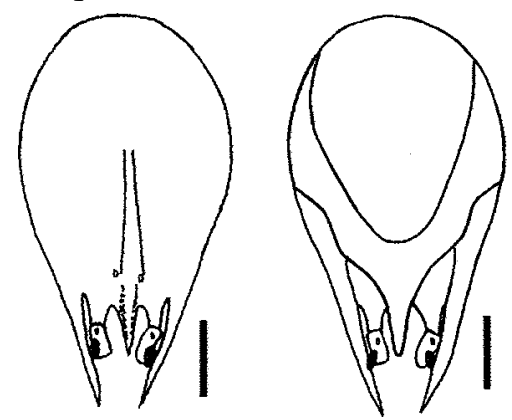

32'. Cápsula genital mais estreita (menor que 0,50 $\pm 0,02 \mathrm{~mm}$ ) 
33. Processo intervolselar no nível ou ultrapassando um pouco as volselas.........T. galloi
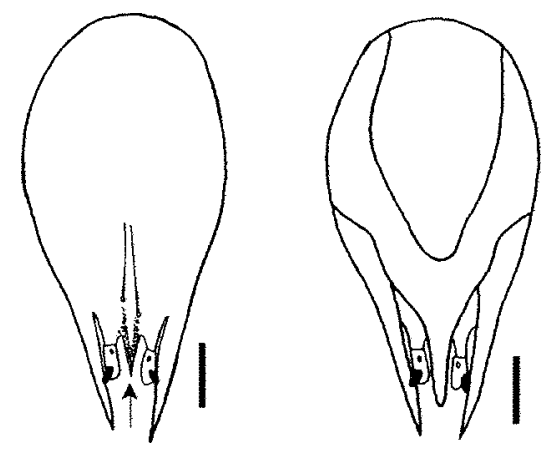

33'. Processo intervolselar não alcançando o nível das volselas

34. Lâmina dorsal com lados mais retos

T. jalmirezi
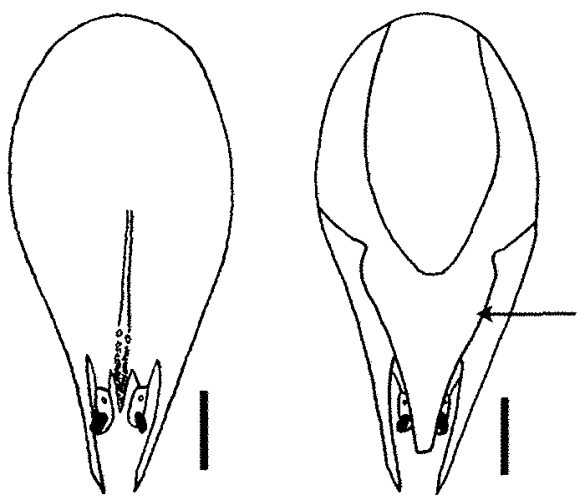

34'. Lâmina dorsal com lados mais sinuosos.

T. distinctum
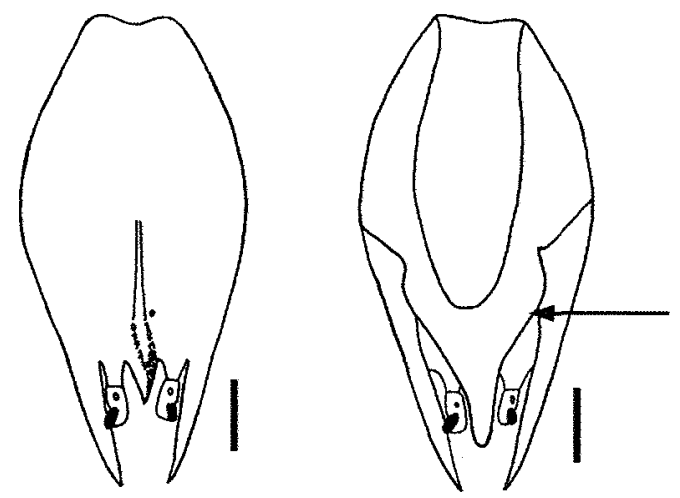


\subsection{Adendo ao catálogo de espécies de Trichogramma da América do Sul}

As informações da literatura, acrescida das amostras coletadas e recebidas para identificação, foram adicionadas ao catálogo das espécies de Trichogramma para a América do Sul (Zucchi \& Monteiro, 1997) (Tabela 7). Nesta tabela, exceto para os três registros marcados com $\left({ }^{*}\right)$, todos os demais correspondem à espécimes depositados na coleção da ESALQ.

Tabela 7. Registros acrescentados ao catálogo das espécies de Trichogramma, insetos hospedeiros e plantas associadas em países sul-americanos.

\begin{tabular}{|c|c|c|c|c|}
\hline Espécies & Insetos hospedeiros & Plantas associadas & Paises & Referências/Coletores \\
\hline \multicolumn{5}{|l|}{ Trichogramma } \\
\hline sp. aff pintoi & - & - & Brasil-SP & R. B. Querino \\
\hline T. acacioi & Nipteria panacea & Abacateiro & Brasil-ES & Pratissoli \& Fornazier (1999) \\
\hline T. acacioi & Anticarsia gemmatalis & Soja & Brasil-PR & Foerster et al. (2000) \\
\hline 1. acacioi & Euselasia sp. & - & Brasil-SP & R. B. Querino \\
\hline T. acacioi & Hamadryas feronia & Dalechampia sp. & Brasil-SP & J. A. Cerignoni \\
\hline T. atopovirilia & Anticarsia gemmatalis & Soja & Brasil-PR & Foerster \& Avanci (1999) \\
\hline T. atopovirilia & Spodoptera frugiperda & Milho & Brasil-SP & Beserra (2000) \\
\hline T. atopovirilia & - & - & Colombia & Pinto (1998) \\
\hline T: bruni & Bonagota cranaodes & - & Brasil-RS & M. S. Garcia \\
\hline T. bruni & Heliconius erato phyllis & Passiflora sp. & Brasil-SP & J. A. Cerignoni \\
\hline T. bruni & Hamadryas feronia & Dalechampia sp. & Brasil-SP & J. A. Cerignoni \\
\hline T. bruni & Erosina hyberniata & Acnistus arborescens & Brasil-SP & R. B. Querino \\
\hline T. brumi & Mechanistis lysimnia & Solanum agrarium & Brasil-SP & R. B. Querino \\
\hline T. demoraesi & - & - & Peru & M. Whu P. \\
\hline T. dissimilis & Sitotogra cerealella & - & Bolivia & E. Coloque \\
\hline T. exiguum & Argyrotaenia sphaleropa & Videira & Uruguai & Basso et al. (1999) \\
\hline T. fasciatum & Peridroma saucia & Agave sisalana & Equador & J.C. Monje \\
\hline T. fasciatum & - & - & Equador & Benzing, 1999* \\
\hline T. fasciatum & - & - & Venezuela & Pinto (1998)* \\
\hline T. galloi & Diatraea saccharalis & Cana-de-açúcar & Peru & M. Whu P. \\
\hline T. lasallei & Anticarsia gemmatalis & Soja & Brasil-PR & Foerster et al. (2000) \\
\hline
\end{tabular}


Tabela 7. Registros acrescentados ao catálogo das espécies de Trichogramma, insetos hospedeiros e plantas associadas em países sul-americanos.

\begin{tabular}{|c|c|c|c|c|}
\hline Espécies & Insetos hospedeiros & Plantas associadas & País & Coletores/coleção \\
\hline T: lasallei & Diatraea saccharalis & - & Uruguai & C. Basso \\
\hline I. nerudai & Tiula Absoluta & Tomateiro & Chile & R. Trincado \\
\hline I. pretiosium & Sphingidae & Beringela & Brasil-PE & E. J. Marques \\
\hline T. pretiosum & Bonagota cranaodes & Macieira & Brasil-RS & M. S. Garcia \\
\hline I. pretiosum & Bonagota cranaodes & Macieira & Brasil-SC & L.B. Monteiro \\
\hline T. pretiosum & Danaus plexippus erippus & Asclepias curassavia & Brasil-SP & J. A. Cerignoni \\
\hline T. pretiosum & Hamadryas feronia. & Dalechampia sp. & Brasil-SP & J.A. Cerignoni \\
\hline T.pretiosum & Trichoplusia oxygramma & Bacharis sp. & Brasil-SP & R. B. Querino \\
\hline T. pretiosum & - & - & Equador & Benzing, 1999* \\
\hline I. pretiosum & - & - & Peru & M. Whu P. \\
\hline I. sp.n.7 & - & - & Brasil-SP & R. B. Querino \\
\hline T. sp.n. 1 & - & - & Brasil-SP & R. B. Querino \\
\hline T. sp.n. 11 & Heliconius eralo phyllis & Passiflorasp. & Brasil-SP & J. A. Cerignoni \\
\hline I. sp.n. 12 & Calpode ethilius & Canna sp. & Brasil-AL & I. M.M. Lima \\
\hline I. sp.n. 3 & - & - & Brasil-SP & R. B. Querino \\
\hline T. sp.n. 5 & - & - & Brasil-SP & R. B. Querino \\
\hline I. sp.n. 6 & - & - & Brasil-SP & R. B. Querino \\
\hline T. sp.n. 9 & - & - & Brasil-SP & R. B. Querino \\
\hline
\end{tabular}

* coleção da ESALQ

Com base nas coletas realizadas, na coleção da ESALQ e dados compilados da literatura, 36 espécies estão registradas para a América do Sul (Figura 66), incluindo as oito novas espécies discutidas neste trabalho.

No Brasil, ocorrem 24 espécies de Trichogramma, dentro as quais T. lasallei e as oito novas espécies constituem novos registros (Quadro 2). Portanto, o Brasil é o país com o maior número de espécies, seguido pela Venezuela, Colômbia e Peru. Não há registro de espécies para Guiana Francesa e Suriname. O Peru apresenta o maior número de espécies introduzidas, com registro de oito espécies (Whu \& Valdivieso, 1999). 


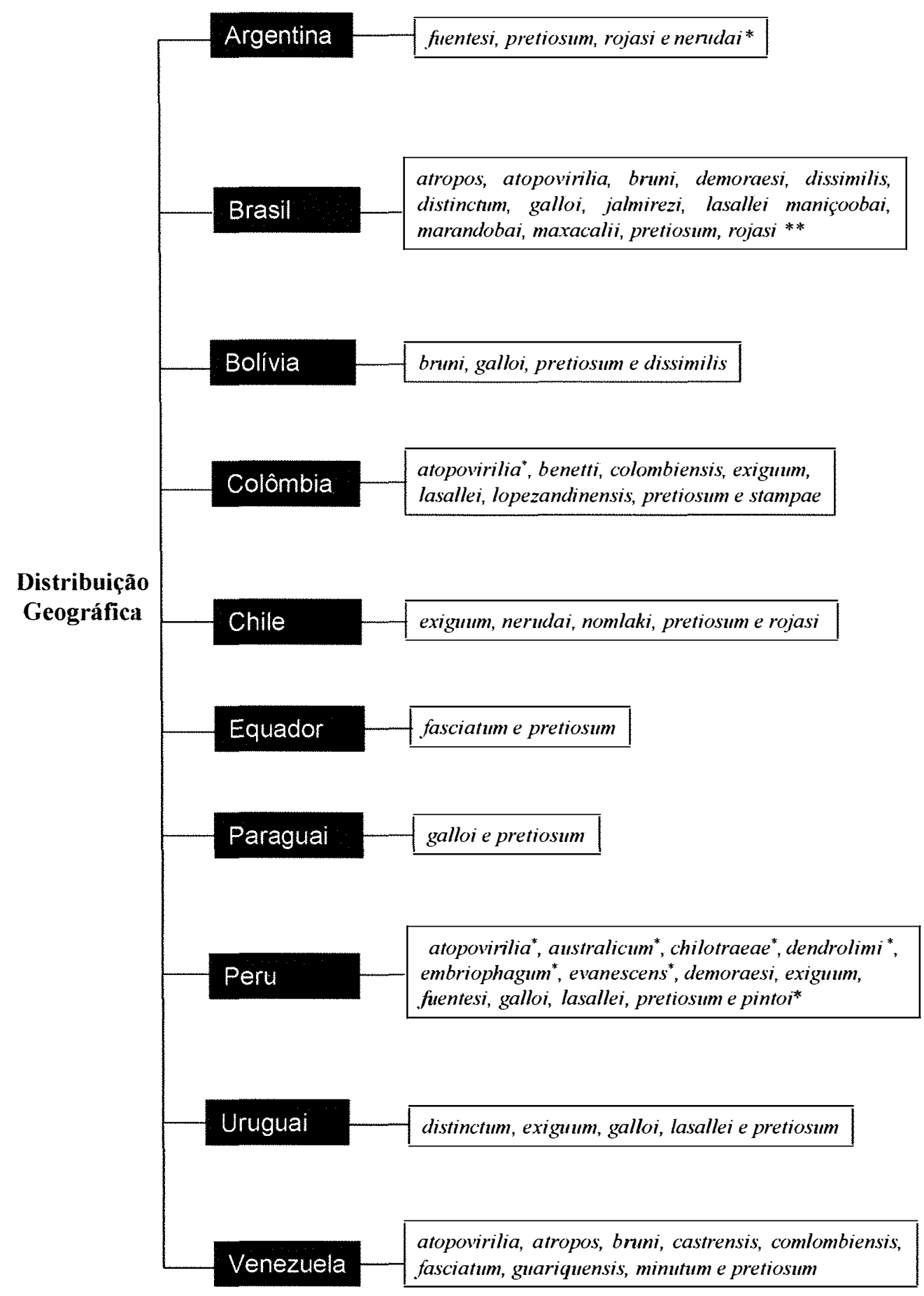

\footnotetext{
*espécies introduzidas

** incluindo oito novas espécies e $T$. bertii (não formalmente descrita)
}

Figura 66 - Espécies de Trichogramma da América do Sul. 
T. pretiosum está assinalado em todos os países com registros de Trichogramma. No Brasil, é a espécie mais amplamente distribuída, com registros nas regiões CentroOeste, Nordeste, Sudeste e Sul (Quadro 2).

A distribuição de Trichogramma no Brasil não é ainda bem conhecida. Os levantamentos têm sido direcionados em regiões próximas de locais com programas de controle biológico com Trichogramma e às culturas de importância econômica. O maior número de registro de espécies encontra-se na região Sudeste. Nas demais regiões permanece praticamente desconhecida a diversidade de espécies. Para a região Norte, não há nenhum registro.

O conhecimento da diversidade e distribuição de Trichogramma na América do Sul é ainda incipiente, não se conhece a diversidade de espécies. Os levantamentos têm sido restritos principalmente às culturas de importância econômica e pouco se conhece sobre as espécies que ocorrem em ambientes florestais e nativos.

Da mesma forma, o conhecimento sobre os hospedeiros de Trichogramma são também superficiais. A grande parte das espécies está associada a hospedeiros de importância econômica, pertencente em quase sua totalidade a ordem Lepidoptera.

Dentre os lepidópteros, a família Noctuidae é a que apresenta o maior número de espécies parasitadas por Trichogramma, incluindo as principais pragas de importância agrícola, por exemplo, Alabama argillacea em algodoeiro, Anticarsia gemmatalis em soja, Helicoverpa zea e Spodoptera frugiperda em milho (Figura 67).

Vários lepidópteros silvestres foram também parasitados por Trichogramma, como Heliconius erato phyllis, Hamadryas feronia e Mechanitis lysimnia, principalmente por espécies que preferem hábitats florestais, como T. bruni e T. acacioi. 


\begin{tabular}{|c|c|c|c|}
\hline Espécies & Estados & Cidades & Referências* \\
\hline \multirow{6}{*}{ T. acacioi } & Espírito Santo & Venda Nova do Imigrante & Pratissoli \&Fornazier (1999) \\
\hline & São Paulo & Itatinga & R.B. Querino \\
\hline & São Paulo & Piracicaba & J.A. Cerignoni \\
\hline & São Paulo & São Simão & E. Bernardi \\
\hline & Minas Gerais & Jaboticatubas & Brun, Moraes \& Soares (1984) \\
\hline & Paraná & Curitiba & Foerster et al. (2000) \\
\hline \multirow{3}{*}{ T. atopovirilia } & Minas Gerais & Lavras & P. Tironi \\
\hline & São Paulo & Piracicaba & Beserra (2000) \\
\hline & Paraná & Curitiba & Foerster \& Avanci (1999) \\
\hline \multirow{4}{*}{ T. bruni } & São Paulo & Itatinga & R. B. Querino \\
\hline & São Paulo & Piracicaba & J.A. Cerignoni \\
\hline & São Paulo & Sorocaba & C. Wilcken \\
\hline & Rio Grande do Sul & Vacaria & M. S. Garcia \\
\hline \multirow{4}{*}{ T. demoraesi } & São Paulo & Atibaia & Coleção da ESALQ \\
\hline & $\overline{\text { São Paulo }}$ & Piracicaba & R.B. Querino \\
\hline & Minas Gerais & Lavras & G.A. Carvalho \\
\hline & Espírito Santo & Itapemirim & D. Pratissoli \\
\hline \multirow{6}{*}{ T. dissimilis } & São Paulo & Araras & J.R.de Araújo \\
\hline & São Paulo & Macatuba & Coleção da ESALQ \\
\hline & São Paulo & Pradópolis & Coleção da ESALQ \\
\hline & São Paulo & Pirassununga & Coleção da ESALQ \\
\hline & São Paulo & Valparaíso & J.R. Barros \\
\hline & Mato Grosso do Sul & Rio Brilhante & Coleção da ESALQ \\
\hline T. distinctum & Pernambuco & Carpina & Coleção da ESALQ \\
\hline \multirow{3}{*}{ T. galloi } & São Paulo & Araras & Coleção da ESALQ \\
\hline & São Paulo & Piracicaba & Coleção da ESALQ \\
\hline & Rio de Janeiro & Conceição de Macabu & Coleção da ESALQ \\
\hline T. jalmirezi & Rio de Janeiro & Macaé & Coleção da ESALQ \\
\hline T. lasallei & Paraná & Curitiba & Coleção da ESALQ \\
\hline \multirow{2}{*}{ T. manicobai } & São Paulo & Campinas & W. Reis \\
\hline & Minas Gerais & Lavras & D. Pratissoli \\
\hline \multirow{2}{*}{ T. maxacalii } & São Paulo & Mogi-Guaçu & Coleção da ESALQ \\
\hline & Rio Grande do Sul & Guaiba & D. Bressan \\
\hline
\end{tabular}




\begin{tabular}{|c|c|c|c|}
\hline Espécies & Estados & Cidades & Referências* \\
\hline \multirow{18}{*}{ T.pretiosum } & São Paulo & Botucatu & Coleção da ESALQ \\
\hline & São Paulo & Anhembi & R.B.Querino \\
\hline & São Paulo & Piracicaba & D. Pratissoli \\
\hline & São Paulo & Jaboticabal & Coleção da ESALQ \\
\hline & São Paulo & Jaguariúna & L.A.de Sá \\
\hline & São Paulo & Santo Antonio da Posse & Coleção da ESALQ \\
\hline & Minas Gerais & João Monlevade & D. Pratissoli \\
\hline & Minas Gerais & Lavras & G.A. Carvalho \\
\hline & Minas Gerais & Viçosa & A.H.R. Gonring \\
\hline & Minas Gerais & Sete Lagoas & M. Michereff F. \\
\hline & Mato Grosso do Sul & Rio Brilhante & Coleção da ESALQ \\
\hline & Mato Grosso do Sul & Chapadão do Ceú & P.S.M. Botelho \\
\hline & Mato Grosso do Sul & Dourados & P.E. Degrande \\
\hline & Mato Grosso do Sul & Rondonopólis & P. E. Degrande \\
\hline & Mato Grosso do Sul & Naviraí & P. E. Degrande \\
\hline & Espírito Santo & Afonso Claúdio & D. Pratissoli \\
\hline & Espírito Santo & Conceição do Castelo & D. Pratissoli \\
\hline & Espírito Santo & Venda Nova do Imigrante & D. Pratissoli \\
\hline \multirow{15}{*}{ T. pretiosum } & Espírito Santo & River & D. Pratissoli \\
\hline & Espírito Santo & Alto Peçanha & D. Pratissoli \\
\hline & Espírito Santo & Alegre & D. Pratissoli \\
\hline & Rio de Janeiro & São José do Ubá & J.L. Blackmen \\
\hline & Distrito Federal & Brasília & M.A. Medeiros \\
\hline & Goiás & Goiânia & Coleção da ESALQ \\
\hline & Goiás & Cachoeira Dourada & D. Pratissoli \\
\hline & Goiás & Sidrolândia & P.S.M. Botelho \\
\hline & Paraná & Curitiba & Hohmann et al. (1989) \\
\hline & Paraná & Maringá & Coleção da ESALQ \\
\hline & Paraná & Porecatu & P.R. Cansioni \\
\hline & Paraná & Guarapuava & V. Pietrowski \\
\hline & Santa Catarina & Fraiburgo & L.B. Monteiro \\
\hline & Rio Grande do Sul & Vacaria & M. S. Garcia \\
\hline & Ceará & Iguatu & F.S. Ramalho \\
\hline
\end{tabular}




\begin{tabular}{|l|l|l|l|}
\hline \multicolumn{1}{|c|}{ Espécies } & \multicolumn{1}{|c|}{ Estados } & \multicolumn{1}{c|}{ Cidades } & \multicolumn{1}{c|}{ Referências } \\
\hline \multirow{3}{*}{ T. pretiosum } & Paraiba & Campina Grande & S.Micheletti \\
\cline { 2 - 4 } & Paraíba & Patos & Embrapa-algodão \\
\cline { 2 - 4 } & Paraiba & Juarez Távora & Embrapa-algodão \\
\cline { 2 - 4 } & Pernambuco & Recife & E.J. Marques \\
\hline T. rojasi & Paraná & Curitiba & Polaszek \& Foerster (1997) \\
\hline
\end{tabular}

* dados que não há informação do coletor referidos da Coleção da ESALQ; todas as espécies estão depositadas nessa coleção

Quadro 2 - Distribuição geográfica de Trichogramma no Brasil.

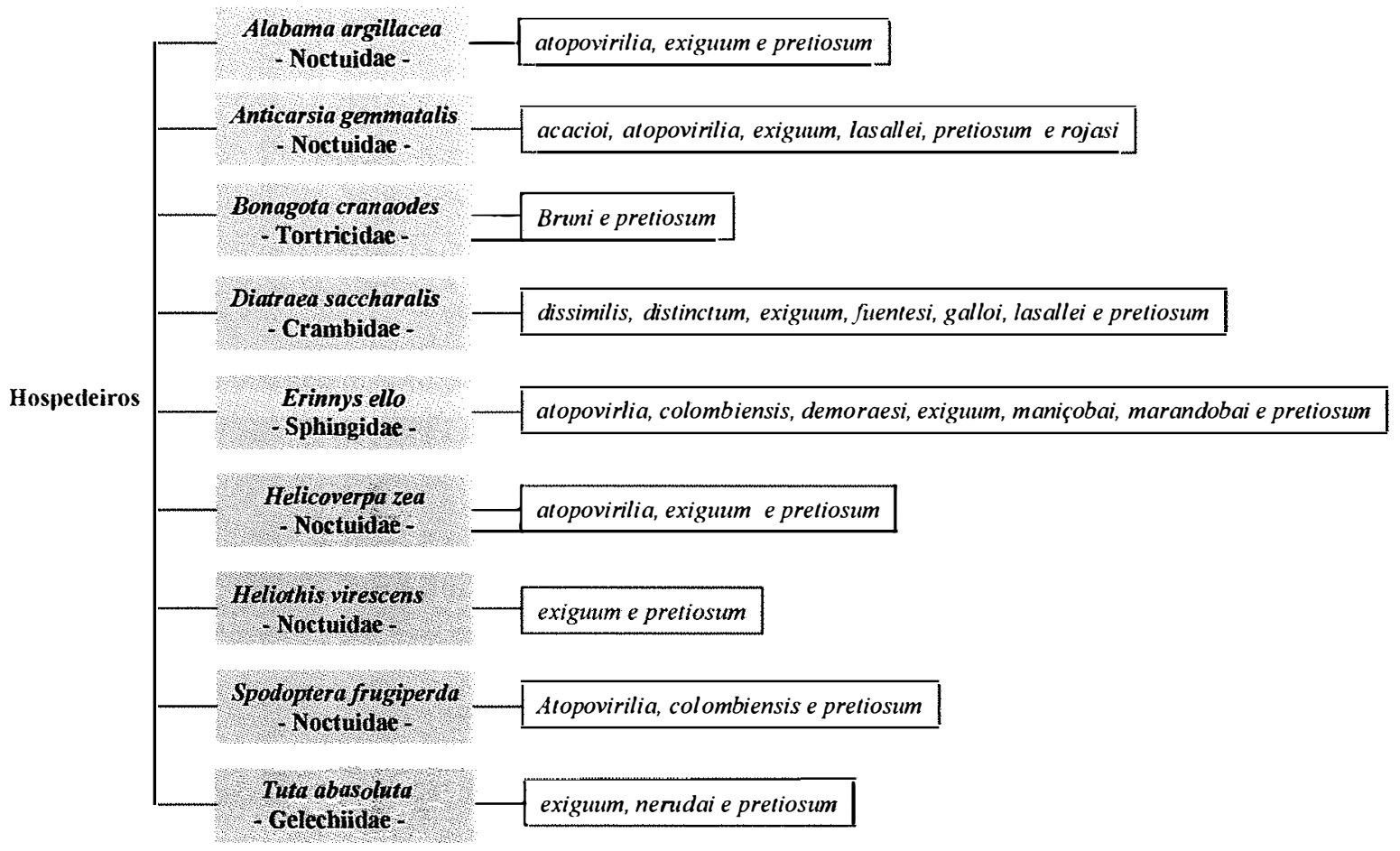

Figura 67 - Espécies de Trichogramma associadas a lepidópteros de importância econômica. 


\section{CONCLUSÕES}

- Na América do Sul, estão registradas 36 espécies de Trichogramma.

- Trichogramma pretiosum é a espécie mais amplamente distribuída na América do Sul.

- Trichogramma bruni apresenta acentuada variação intra-específica. A influência do ambiente (hábitat + hospedeiro) e a variação individual são responsáveis pela plasticidade observada na cápsula genital dessa espécie.

- A morfometria multivariada é útil para evidenciar diferenças sutis entre as espécies.

- A armadilha de suç̧ão é útil na coleta de Trichogramma em ambiente de difícil coleta dos ovos do hospedeiro. 


\section{REFERÊNCIAS BIBLIOGRÁFICAS}

ADAMS, D.C.; FUNK, D.J. Morphometric inferences on sibling species and sexual dimorphism in Neochlamisus bebbianae leaf beetles: multivariate applications of the thin-plate spline. Systematic Biology, v.46, n. 1, p.180-194, 1997.

ALMEIDA, R.P. de; CIOCIOLA JÚNIOR, A.I.; STOUTHAMER, R. Wolbachia-induced parthenogenesis: the first report in a Brazilian Trichogramma pretiosum population. Proceedings of the Experimental and Applied Entomology, v.12, p.41-44, 2001.

BAI, B.; LUCK, R.R.; FORSTER, L.; STEPHENS, B.; JANSSEN, J.A.M. The effect of host size on quality attributes of the egg parasitoid, Trichogramma pretiosum. Entomologia Experimentalis et Applicata, v.64, p.37-48, 1992.

BASSO, C.; PINTUREAU, B.; GRILLE, G. Taxonomic study of two Trichogramma species from Uruguay (Hymenoptera: Trichogrammatidae). Boletin de Sanidad Vegetal Plagas, v.25, n.3, p.372-382, 1999.

BENZING, A. Egg parasitoid in the andes of Ecuador. Braunschweig: Federal Biological Research Centre for Agriculture and Forestry, 1998. 1v. (Egg Parasitoid News, 10). 
BESERRA, E.B. Biologia, etologia e capacidade de parasitismo de Trichogramma spp. visando ao controle biológico de Spodoptera frugiperda (J. E. Smith, 1797). Piracicaba, 2000. 132p. Tese (Doutorado) - Escola Superior de Agricultura "Luiz de Queiroz", Universidade de São Paulo.

BLACKITH, R.E.; REYMENT, R.A. Multivariate morphometrics. London: Academic Press. 1971. 1v.

BOOKSTEIN, F.L. "Size and shape": a comment on semantics. Systematic Zoology, v.38, p.173-180, 1989.

BOOKSTEIN, F.L. Morphometrics tools for landmarks data: geometry and biology. New York: Cambridge University Press, 1991. 1v.

BOOKSTEIN, F.L. Biometrics, biomathematics and the morphometric synthesis. Bulletin of Mathematical Biology, v.58, p.313-365, 1996.

BOOKSTEIN, F.L.; CHERNOFF, B.; ELDER, B.; HUMPHRIES, J.; SMITH, G.; STRAUSS, R. Morphometric in evolutionary biology. Philadelphia: Academic of Natural Sciences, 1985. 1v. (Special Publication, 15).

BREEUWEER, J.A.J.; WERREN, J.H. Microorganisms associated with chromosome destruction and reproductive isolation between two insect species. Nature, v.346, p. $558-560,1990$.

BRUN, P.G.; MORAES, G.W.G.; SOARES, L.A. Três espécies novas de Trichogrammatidae parasitóides de lepidópteros desfolhadores da mandioca e do eucalipto. Pesquisa Agropecuária Brasileira, v.19, p.805-810, 1984. 
BRUN, P.G.; MORAES, G.W.G.; SOARES, L.A. Trichogramma marandobai sp.n. (Hymenoptera: Trichogrammatidae) parasitóide de Erinnyis ello (Lepidoptera: Sphingidae) desfolhador da mandioca. Pesquisa Agropecuária Brasileira, v.21, n.12, p.1245-1248, 1986.

CAVALCANTI, M.J.; LOPES, P.R.D. Análise morfométrica multivariada de cinco espécies de serranidae (Teleostei, Perciformes). Acta Biológica Leopoldensis, v.15, n.1, p.53-64, 1993.

CIOCIOLA JÚNIOR, A.I.; ZUCCHI, R.A.; STOUTHAMER, R. Molecular key to seven brazilian species of Trichogramma (Hymenoptera: Trichogrammatidae) using sequences of the ITS2 region and restriction analysis. Neotropical Entomology, v.30, n.2, p.259-262, 2001.

CIOCIOLA JÚNIOR, A.I.; ALMEIDA, R.P. de; ZUCCHI, R.A.; STOUTHAMER, R. Detecção de Wolbachia em uma população telítoca de Trichogramma atopovirilia Oatman \& Platner (Hymenoptera: Trichogrammatidae) via PCR com o Primer Específico wsp. Neotropical Entomology, v.30, n.3, p.489-491, 2001.

CÔNSOLI, F.L. Criação in vitro de Trichogramma galloi Zucchi, 1988 e Trichogramma pretiosum Riley, 1879 (Hymenoptera: Trichogrammatidae): desenvolvimento de um ovo artificial e aprimoramento das dietas artificiais. Piracicaba, 1997.153p. Tese (Doutorado) Escola Superior de Agricultura “Luiz de Queiroz", Universidade de São Paulo.

DEBACH, P. Uniparental, sibling and semi-species in relation to taxonomy and biological control. Israel Journal of Entomology, v.4, p.11-27, 1969.

DE SANTIS, L. Catálogo de los himenopteros calcidoideos de América do Sur de los Estados Unidos. La Plata: Comisión de Investigaciones Científicas de la Provincia de Buenos Aires, 1979. 488p. (Publicación Special). 
DE SANTIS, L. Catálogo de los himenopteros brasileños de la serie parasitica incluindo Bethyloidea. Curitiba: UFPR, 1980. 395 p.

DE SANTIS, L. Catálogo de Los himenopteros calcidoideos de América do sur de los Estados Unidos - Primer Suplemento. Revista Peruana de Entomologia, v.24, n.I, p.1-38, 1981 .

DOUTT, R.L.; VIGGIANI, G. The classification of the Trichogrammatidae (Hymenoptera: Chalcidoidea). Proceedings of the California Academy of Sciences, v.35, n.20, p.477-586, 1968.

FLANDERS, S.E. The validity of Trichogramma pretiosum. Annals of the Entomological Society of America, v. 61, p.1122-1124, 1968.

FOERSTER, L.A.; AVANCI, M.R. Egg parasitoids of Anticarsia gemmatalis Huber (Lepidoptera: Noctuidae) in soybeans. Anais da Sociedade Entomológica do Brasil, v.28, n.3, p.545-548, 1999.

FOERSTER, L.A.; AVANCI, M.R.F.; MARTIN, J.M.R.; CAÑETE, C. L. Egg parasitoids of Anticarsia gemmatalis (Lep.; Noctuidae) on soybeans in Brazil. In: INTERNATIONAL CONGRESS OF ENTOMOLOGY, 21., Foz do Iguaçu, 2000. Resumos. Foz do Iguaçu: EMBRAPA SOJA/SEB, 2000. p.385.

GALÁN, M.; RODRIGUEZ, J. Registro de Trichogramma rojasi Nagaraja y Nagarkatti (Hymenoptera: Trichogrammatidae) para Cuba. Revista Biologia (Havana), v.5, p.177-181, 1991.

GALÁN, M.; RODRIGUEZ, J. Caracterizacion morfometrica de Trichogramma Weswood (Hymenoptera: Trichogrammatidae). Revista de Protección Vegetal, v.8, p.157-165, 1993. 
GRENIER, S.; GRILLE, G.; BASSO, C.; PINTUREAU, B. Effects of the host species and the number of parasitoids per host on the size of some Trichogramma species (Hymenoptera: Trichogrammatidae). Biocontrol Science and Technology, v.11, p. $21-26,2001$.

HASSAN, S.A. Strategies to select Trichogramma species for use in biological control. In: WAJNBERG, E.; HASSAN, S.A. (Ed.). Biological control with egg parasitoids. Wallingford: CAB International, 1994. cap.3, p.55-71.

HERATY, J.M.; WOOLLEY, J.B.; DARLING, D.C. Phylogenetic implications of the mesofurca in Chalcidoidea (Hymenoptera), with emphasis on Aphelinidae. Systematic Entomology, v.22, p.45-65, 1997.

HOHMANN, C.L.; SILVA, S.M.T.; SANTOS, W.J. Lista preliminar de Trichogrammatidae encontrados no Paraná. Anais da Sociedade Entomológica do Brasil, v.18, p.203-206, 1989.

HUMPHRIES, J.M.; BOOKSTEIN, F.L.; CHERNOFF, B.; SMITH, G.R.; ELDER, R. L.; POSS, S.G. Multivariate discrimination by shape in relation to size. Systematic Zoology, v.30, p.291-308, 1981.

INTERNATIONAL code of zoological nomenclature. 4 ed. London: ITZN/British Museum/UCP, 2000.

KAZMER, D.J.; LUCK, R.F. Female body size, fitness and biological control quality: field experiments with Trichogramma pretiosum. Les Colloques de I'INRA, v.56, p. $37-40,1991$. 
LAROCA, S.; MIELKE, O.H.H. Ensaio sobre ecologia de comunidade em Sphingidae na Serra do Mar, Paraná, Brasil (Lepidoptera). Revista Brasileira de Biologia, v.35, n.l, p.1-19, 1975.

LASALLE, J. Parasitic hymenoptera, biological control and biodiversity. In: LASALLE, J.; GAULD, I.D. (Ed). Hymenoptera and biodiversity. Wallingford: CAB International; IOBC, 1993. cap.8, p.197-215.

MARCUS, L.F. Traditional morphometrics In: MICHIGAN MORPHOMETRICS WORKSHOP, Michigan, 1990. Proceedings. Ann. Arbor: University of Michigan Museum of Zoology, 1990. p.77-122, (Special Publication, 2).

MARCUS, L.F.; BELlO, E.; GARCIA-VALDECASAS, A. (Ed.). Contributions to morphometrics. Madrid: Museu Nacional de Ciencias Naturales, 1993. lv. (Monografia, 8).

MARSTON, N.; ERTLE, L.R. Host influence on the bionomics of Trichogramma minutum. Annals of the Entomological Society of America, v.66, n.5, p.1155$1162,1973$.

MEER, M.M.M.van. Phylogeny and host-symbiont interactions of thelytoky inducing Wolbachia in Hymenoptera. Wageningen, 1999. 118p. Thesis $(\mathrm{PhD})-$ Wageningen Agricultural University.

MONJE, J.C. Present significance of Trichogramma spp. (Hymenoptera: Trichogrammatidae) for the control of sugarcane borers in Americas. Mitteilungen der Deutschen Gesellschaft für allgemeine und angewandte Entomologie, v.27, p.287-290, 1995.

MONTEIRO, L.R.; REIS, S.F. dos. Princípios de morfometria geométrica. Ribeirão Preto: Holos Editora, 1999. 198p. 
NAGARAJA, H. On some new species of Indian Trichogramma (Hymenoptera: Trichogrammatidae). Oriental Insects, v.7, n.2, p.275-290, 1973.

NAGARAJA, H. Descriptions of new Trichogrammatidae (Hymenoptera) from Brasil. Revista Brasileira de Biologia, v.43, p.37-44, 1983.

NAGARAJA, $H$. Recent advances in biosystematics of Trichogramma and Trichogrammatoidea (Hymenoptera: Trichogrammatidae). Proceedings of the Indian Academy of Sciences, v.96, p.469-477, 1987.

NAGARAJA, H.; NAGARKATTI, S. A key to some new world species of Trichogramma (Hymenoptera: Trichogrammatidae) with descriptions of four new species. Proceedings of the Entomological Society of Washington, v.75, n.3, p.288-297, 1973.

NAGARKATTI, S. Studies on the shootborer Hypsipyla grandella (Zeller) (Lepidoptera, Pyralidae) XVII. A new species of Trichogramma (Hymenoptera: Trichogrammatidae). Turrialba, v.23, p.233-235, 1973.

NAGARKATTI, S. A new species of Trichogramma (Hymenoptera: Trichogrammatidae) parasitic on Papilio spp. in Japan. Oriental Insects, v.8, n.3, p. 391-393, 1974.

NAGARKATTI, S. Two new species of Trichogramma (Hymenoptera: Trichogrammatidae) from the USA. Entomophaga, v.20, p.245-248, 1975.

NAGARKATTI, S.; FAZALUDDIN, M. Biosystematic studies on Trichogramma species (Hymenoptera: Trichogrammatidae). Systematic Zoology, v.22, p.103-117, 1973. 
NAGARKATTI, S.; NAGARAJA, H. Biosystematics studies on Trichogramma species: experimental hybridization between Trichogramma australicum Girault, $T$. evanescens Westwood and T. minutum Riley. CIBC Technical Bulletin, v.10, p.8196, 1968.

NAGARKATTI, S.; NAGARAJA, H. Redescriptions of some Knowns species of Trichogramma (Hymenoptera: Trichogrammatidae) showing the importance of the male genitalia as a diagnostic character. Bulletin Entomological Research, v.61, p.13-31, 1971 .

NAGARKATTI, S.; NAGARAJA, H. Biosystematics of Trichogramma and Trichogrammatoidea species. Annual Review of Entomology, v.22, p.157-176, 1977.

NASCIMENTO, F.M. Análises morfométricas em duas espécies do complexo Anastrepha fraterculus (Wiedemann) (Diptera: Tephritidae) e inferências genéticas a partir do cruzamento interespecífico. São Paulo, 2000. 98p. Dissertação (Mestrado) Instituto de Biociências, Universidade de São Paulo.

OATMAN, E.R.; PINTO, J.D.; PLATNER, G.R. Trichogramma (Hymenoptera: Trichogrammatidae) of Hawaii. Pacific Insects, v.24, p.1-24, 1982.

ORREGO, C.; AGUDELO-SILVA, F. Genetic variation in the parasitoid wasp Trichogramma (Hymenoptera: Trichogrammatidae) revealed by DNA amplification of a section of the nuclear ribosomal repeat. Florida Entomologist, v.76, p.519-524, 1993.

PARRA, J.R.P.; ZUCCHI, R.A.; SILVEIRA NETO; HADDAD, M.L. Biology and themal requirements of Trichogramma galloi and $T$. distinctum Zucchi, on two altematives hosts. Les colloques de I 'INRA, v.56, p.81-84, 1991. 
PERKINS, R.C.L. Parasites of insects attacking sugar cane. Report of the work of the Experiment Station of The Hawaiian Sugar Planters Association, 1912, p.5-19. (Entomology Series, 10).

PINTO, J.D. Novel taxa of Trichogramma from the New World tropics and Australia (Hymenoptera: Trichogrammatidae). Journal of the New York Entomological Society, v.100, n.4, p.621-633, 1992.

PINTO, J.D. Taxonomia de Trichogrammatidae (Hymenoptera) com ênfase nos gêneros que parasitam Lepidoptera. In: PARRA, J.R.P.; ZUCCHI, R.A. (Ed.). Trichogramma e o controle biológico aplicado. Piracicaba: FEALQ, 1997a. cap.1, p.13-40.

PINTO, J.D. Trichogrammatidae. In: GIBSON, G.A.P.; HUBER, J.T.; WOOLLEY, J. B. (Ed.). Annotated keys to the Genera of Nearctic Chalcidoidea (Hymenoptera). Ottawa: NRC Research Press, 1997b. cap. 22, p.726-752.

PINTO, J.D. Trichogrammatoidea brasiliensis (Ashmead) - new combination for a species historically placed in Trichogramma (Hymenoptera: Trichogrammatidae). Proceedings of the Entomological Society of Washington, v.99, n.4, p.593-596, 1997c.

PINTO, J.D. Systematics of the north american species of Trichogramma Westwood (Hymenoptera: Trichogrammatidae). Washington: Entomological Society of Washington, 1998. 287 p. (Memoirs, 22).

PINTO, J.D.; OATMAN, E.R. Description of three new Trichogramma (Hymenoptera: Trichogrammatidae) from New Zealand and their relationship to New World species. Proceedings of the Entomological Society of Washington, v.98, p.396-406, 1996. 
PINTO, J.D.; STOUTHAMER, R. Systematics of the Trichogrammatidae with emphasis on Trichogramma. In: WAJNBERG, E.; HASSAN, S. A. (Ed.). Biological control with egg parasitoids. Wallingford: $\mathrm{CAB}$ International; IOBC, 1994. cap.1, p. 1-36.

PINTO, J.D.; OATMAN, E.R.; PLATNER, G.R. The identify of two closely related and frequently encountered species of new world Trichogramma (Hymenoptera: Trichogrammatidae). Proceedings of the Entomological Society of Washington, v. 85, n.3, p. $588-593,1983$.

PINTO, J.D.; PLATNER, G.R.; OATMAN, E.R. Clarification of the identify of several common species of north american Trichogramma (Hymenoptera: Trichogrammatidae). Annals of the Entomological Society of America, v.71, n.2, p.169-180, 1978.

PINTO, J.D.; PLATNER, G.R.; SASSAMAN, C.A. An electrophoretic study of two closely related species of North American Trichogramma, T. pretiosum and T. deion (Hymenoptera: Trichogrammatidae). Annals of the Entomological Society of America, v.86, p.702-709, 1993.

PINTO, J.D.; STOUTHAMER, R.; PLATNER, G.R. A new cryptic species of Trichogramma (Hymenoptera: Trichogrammatidae) from the Mojave Desert of California as determined by morphological, reproductive and molecular data. Proceedings of the Entomological Society of Washington, v.99, p.238-247, 1997.

PINTO, J.D.; KAZMER, D.J.; PLATNER, G.R.; SASSAMAN, C.A. Taxonomy of the Trichogramma minutum complex (Hymenoptera: Trichogrammatidae): Allozymic variation and its relationship to reproductive and geographic data. Annals of the Entomological Society of America, v.85, p.413-4222, 1992. 
PINTO, J.D.; STOUTHAMER, R.; PLATNER, G.R.; OATMAN, E.R. Variation in reproductive compatibility in Trichogramma and its taxonomic significance (Hymenoptera: Trichogrammatidae). Annals of the Entomological Society of America, v.84, n.1, p.37-46, 1991.

PINTO, J.D.; VELTEN, R.K.; PLATNER, G.R.; OATMAN, E.R. Phenotypic plasticity and taxonomic character in Trichogramma (Hymenoptera: Trichogrammatidae). Annals of the Entomological Society of America, v.82, p.414-425, 1989.

PINTUREAU, B. Enzymatic analysis of the genus Trichogramma (Hym.: Trichogrammatidae) in Europe. Entomophaga, v.38, p.411-431, p.1993a.

PINTUREAU, B. Morphometric analysis of the genus Trichogramma Westwood (Hymenoptera: Trichogrammatidae) in Europe. The Canadian Entomologist, v.125, p.367-378, 1993 b.

PINTUREAU, B. Phylogenetic study of the european species of the genus Trichogramma Westwood (Hymenoptera: Trichogrammatidae). Entomological (Trends in Agricultural Science), v.2, p.141-150, 1994.

PINTUREAU, B.; BABAULT, M. Systématique des espèces africaines des genres Trichogramma Westwood et Trichogrammatoidea Girault (Hym., Trichogrammatidae). Les Colloques de l'INRA, v.43, p.97-120, 1988.

PINTUREAU, B.; GERDING, M.; CISTERNAS, E. Description of three new species of Trichogrammatidae (Hymenoptera) from Chile. The Canadian Entomologist, v.131, p.53-63, 1999. 
POLASZEK, A.; FOERSTER, L.A. Telenomus cyamophylax, n.sp. (Hymenoptera: Scelionidae) attacking eggs of the velvetbean caterpillar, Anticarsia gemmatalis Hüber (Lepidoptera: Noctuidae). Anais da Sociedade Entomológica do Brasil, v. 26, n. 1, p. $177-181,1997$.

PRATISSOLI, D.; FORNAZIER, M.J. Ocorrência de Trichogramma acacioi Brun, Moraes \& Soares (Hym.: Trichogrammatidae) em ovos de Nipteria panacea ThierryMieg (Lep.: Geometridae), um geometrídeo desfolhador do abacateiro. Anais da Sociedade Entomológica do Brasil, v.28, n.2, p.347-349, 1999.

QUEDNAU, W. Uber die identitat der Trichogramma arten und einiger ihrer okotypen (Hymenoptera: Chalcidoidea, Trichogrammatidae). Mitteilungen aus der Biologischen Bundesanstalt fur Land und Fortwirstschaft, v.100, p.11-50, 1960.

QUERINO, R.B.; ZUCCHI, R.A.; CIOCIOLA JR., A.I. CAÑETE, C. L. FOERSTER, L.A. Characterization of three species of the genus Trichogramma. In: INTERNATIONAL CONGRESS OF ENTOMOLOGY, 21., Foz do Iguaçu, 2000. Resumos. Foz do Iguaçu: EMBRAPA SOJA/SEB, 2000. p.411.

REIS, S.F. dos. Morfometria e estatística multivariada em biologia evolutiva. Revista Brasileira de Zoologia, v.5, n.4, p.571-580, 1988.

REYMENT, R.A.; BLACKITH, R.E.; CAMPBELL, N.A. Multivariate morphometrics. New York: Academic Press, 1981. 233 p.

ROHLF, F.J. Relative warps analysis and an example of its application to mosquito wings. In: MARCUS, L.F.; BELLO, E.; GARCIA-VALDECASAS, A. (Ed.). Contributions to morphometrics. Madrid: Museu Nacional de Ciencias Naturales, 1993. p.131-159. (Monografia). 
ROHLF, F.J. Morphometric spaces, shape components, and the effects of linear transformations. In: MARCUS, L.F.; CORTI, M.; LOY, A.; NAYLOR, G.J.P.; SLICE, D. E. (Ed.). Advances in morphometrics. New York: NATO ASI, 1996. p.117-129. (Ser. A life Science, 284).

ROHLF, F.J. Program TPSSMALL. Stony Brook: State University of New York, Department of Ecology and Evolution, 1997.1v.

ROHLF, F.J. On applications of geometric morphometrics to studies of ontogeny and phylogeny. Systematic biology, v.47, p.147-158, 1998a.

ROHLF, F.J. Program TPSRELW. Stony Brook: State University of New York Department of Ecology and Evolution, 1998b.lv.

ROHLF, F.J. Program TPSDIG. Stony Brook: State University of New York, Department of Ecology and Evolution, 2000.1v.

ROHLF, F.J.; BOOKSTEIN, F.L. Proceedings of the Michigan Morphometric Workshop. s.l.: University of Michigan Museum of Zoology, 1991.380p. (Special Publication, 2).

ROHLF, F.J.; MARCUS, L.F. A revolution in morphometrics. Trends Ecology Evolution, v.8, p.129-132, 1993.

ROHLF, F.J.; SLICE, D. Extensions of the procrustes method for the optimal superimposition of marcos anatômicos. Systematic Zoology, v.39, n. 1, p.40-59, 1990.

ROHLF, F.J.; LOY, A.; CORTI, M. Morphometric analysis of old world Talpidae (Mammalia, Insectivora) using partial-warp scores. Systematic Biology, v.45, p.344$362,1996$. 
RUIZ, E.R.; KORYTKOWSKI, C.A. Contribucion al conocimiento de los Trichogrammatidae (Hymenoptera: Chalcidoidea) del Peru. Revista Peruana de Entomologia, v.22, n.1, p.1-8, 1979.

SARMIENTO, M.C.E. Una nueva especie de Trichogramma (Hymenoptera: Trichogrammatidae) de los Andes de Colombia. Revista Colombiana de Entomologia, v.19, n. 1, p.3-5, 1993.

SAS INSTITUTE. SAS/STAT user's guide, version 6. 4 ed. Cary, 1990.

SILVA, I.M.M.S. Identification and evaluation of Trichogramma parasitoids for biological control. Wageningen, 1999. 151p. Thesis ( $\mathrm{PhD})$ - Wageningen Agricultural University.

SILVA, I.M.M.S.; VAN KAN, F.J.P.M.; VAN LENTEREN, J.C.; STOUTHAMER, R. Analysis of Portuguese Trichogramma spp. (Hym., Trichogrammatidae) using ITSrDNA and RAPDs. Les Colloques de I'INRA, v.73, p.37-39, 1995.

SILVEIRA NETO, S.; NAKANO, O; BARBIN, D. Manual de ecologia dos insetos. São Paulo: Agronômica Ceres, 1976.419p.

SOROKINA, A.P. Key to species of the genus Trichogramma Westw. (Hymenoptera: Trichogrammatidae) of the world fauna. Moscow: Kolos Publishing House, 1993. 77p.

SOUTHWOOD, T.R.E. Ecological methods. New York: Chapman and Hall, 1992. 524p.

STONE, J. R. Landmark-based thin-plate spline relative warps analysis of grastropod shells. Systematic Biology, v.47, n.2, p.254-263, 1998.

STOUTHAMER, R. The use of sexual versus asexual wasps in biological control. Entomophaga, v.38, n.1, p.3-6, 1993. 
STOUTHAMER, R.; LUCK, R.F. Influence of microbe-associated parthenogenesis on the fecundity of Trichogramma deion and $T$. pretiosum. Entomologia Experimentalis et Applicata, v.67, p. 183-192, 1993.

STOUTHAMER, R.; WERREN, J.H. Microbes associated with parthenogenesis in wasps of the genus Trichogramma. Journal of Invertebrate Pathology, v.61, p.6-9, 1993.

STOUTHAMER, R.; BREEUWER, J.A.J.; LUCK, R.F.; WERREN, J.H. Molecular identification of microorganisms associated with parthenogenesis. Nature, v.361, p.66681993.

STOUTHAMER, R.; PINTO, J.D.; PLATNER, G.R.; LUCK, R.F. Taxonomic status of thelytokous forms of Trichogramma (Hymenoptera: Trichogrammatidae). Annals of the Entomological Society of America, v.83, p.475-481, 1990.

STOUTHAMER, R.; HU, J.; VAN KAN, F.J.P.M.; PLATNER, G.; PINTO, J.D. The utility of internally transcribed spacer 2 DNA sequences of the nuclear ribosomal gene for distinguishing sibling species of Trichogramma. BioControl, v.43, p.421440, 1999.

STOUTHAMER, R.; LUCK, R.F.; PINTO, J.D.; PLATNER, G.R.; STEPHENS, B. Non-reciprocal cross-incompatibility in Trichogramma deion. Entomological Experimentalis et Applicata, v.80, p.481-489, 1996.

THORPE, R.S. Biometric analysis of geographic variation and racial affinities. Biological Review, v.51, p.407-452, 1976. 
TORRE C., S. L. de la. Revisión de los Trichogramma de cuba, con la descripción de tres nuevos especies y una variedad. Habana: Universidad de la Habana, 1980. $36 \mathrm{p}$.

VELASQUEZ DE RIOS, M.; COLMENARES, O. Análisis morfométrico de dos espécies de Trichogramma (Hymenoptera: Trichogrammatidae) utilizando la metodología de componentes principales. Boletín de Entomología Venezolana, v.14, n.2, p.191-200, 1999.

VELASQUEZ DE RIOS, M.; TERAN, J. Description of the species of the Trichogramma genus (Hymenoptera: Trichogrammatidae) in Venezuela. Les Colloques I'INRA, v.73, p.41-46, 1995.

VIGGIANI, G. Ricerche sugli Hymenoptera Chalcidoidea XXVIII. Studio morfologico comparativo dell'armatura genitale esterna maschile dei Trichogrammatidae. Bollettino del Laboratorio di Entomologia Agraria 'Filippo Silvestri' de Portici, n.29, p.81-222, 1971.

VIGGIANI, G.; LAUDONIA, S. Le specie italiane di Trichogramma Westwood (Hymenoptera: Trichogrammatidae), con un commento sullo stato della tassonomia del genere. Bolletino del Laboratorio di Entomologia Agraria 'Fillipo Silvestri', v.46, p.107-124, 1989.

VINCENT, D.L.; GOODPASTURE, C. Three new species of Trichogramma (Hymenoptera: Trichogrammatidae) from North America. Proceedings of the Entomological Society of Washington, v.88, p.491-501, 1986.

VOEGELÉ, J. Découverte et description de deux nouvelles espèces de Trichogramma du groupe Euproctidis, Trichogramma brassicae et T. pintoi. Annales de la Societé Entomologique de France, v. 18, p.163-166, 1982. 
VOEGELÉ, J.; PINTUREAU, B. Caractérization morphologique des groupes et espèces du genre Trichogramma Westwood. Les Colloques de I'INRA, v.9, p.45-75, 1982.

VOEGELÉ, J.; POINTEL, J.G. Une nouvelle espèces de Trichogramme, Trichogramma maxacalii (Hymenoptera: Trichogrammatidae). Annales de la Societé Entomologique de France, v. 16, n.4, p.599-603, 1980.

WHU, M.; VALDIVIESO, L. Distribución y comportamiento de ocho especies de Trichogramma y Trichogrammatoidea (Hymenoptera: Trichogrammatidae) en el Perú. Revista Peruana de Entomologia, v.41, p.61-68, 1999.

ZELDITCH, M. L.; FINK, W. L.; SWIDERSKI, D. L. Morphometrics, Homology, and Phylogenetics: quantified characteres as synapomorphies. Systematic Biology, v.44, n.2, p.179-189, 1995.

ZEROVA, M.D.; FURSOV, V.N. A catalogue of species the genus Trichogramma Westwood of the world (Hymenoptera: Trichogrammatidae). Institute of Zoology of the Science Academy of the Ukranian SSR, v.89, n.4, 1989. $52 \mathrm{p}$

ZUCCHI, R.A. Taxonomia de espécies de Trichogramma (Hymenoptera: Trichogrammatidae) associadas a algumas pragas (Lepidoptera) no Brasil. Piracicaba, 1985. 77 p. Tese (LivreDocência) - Escola Superior de Agricultura “Luiz de Queiroz", Universidade de São Paulo.

ZUCCHI, R.A. New species of Trichogramma (Hymenoptera: Trichogrammatidae) associated with sugar cane borer Diatraea saccharalis (F.) (Lepidoptera: Pyralidae) in Brazil. Les Colloques de I'INRA, v. 43, p.133-140, 1988.

ZUCCHI, R.A.; MONTEIRO, R.C. New records of hosts and distribution of Trichogramma species in Brasil. Les Colloques de I'INRA, v.73, p.51-53, 1995. 
ZUCCHI, R.A.; MONTEIRO, R.C. O gênero Trichogramma na América do Sul. ln: PARRA, J.R.P.; ZUCCHI, R.A. (Ed.). Trichogramma e o controle biológico aplicado. Piracicaba: FEALQ, 1997. cap.2, p.41-66.

ZUCCHI, R.A.; QUERINO, R.B. L. Towards a database for Trichogramma species, their hosts and plant association in the South America. In: INTERNATIONAL CONGRESS OF ENTOMOLOGY, 21., Foz do Iguaçu, 2000. Resumos. Foz do Iguaçu: EMBRAPA SOJA/SEB, 2000. p.201.

ZUCCHI, R.A.; PARRA, J.R.P.; SILVEIRA NETO, S. Trichogramma species associated with some Lepidopterous pest in Brazil. Les Colloques de I'INRA, v.56, p.131-134, 1991.

ZUCCHI, R.A.; PINTO, J.D.; MONTEIRO, R.C. Some records on the Trichogramma species associated with Diatraea in The New World (Hym., Trichogrammatidae - Lep., Pyralidae). In: INTERNATIONAL CONGRESS OF ENTOMOLOGY, 20, Firenze, 1996. Resumos. Firenze: s.ed., 1996. p.639. 
APÊNDICE 

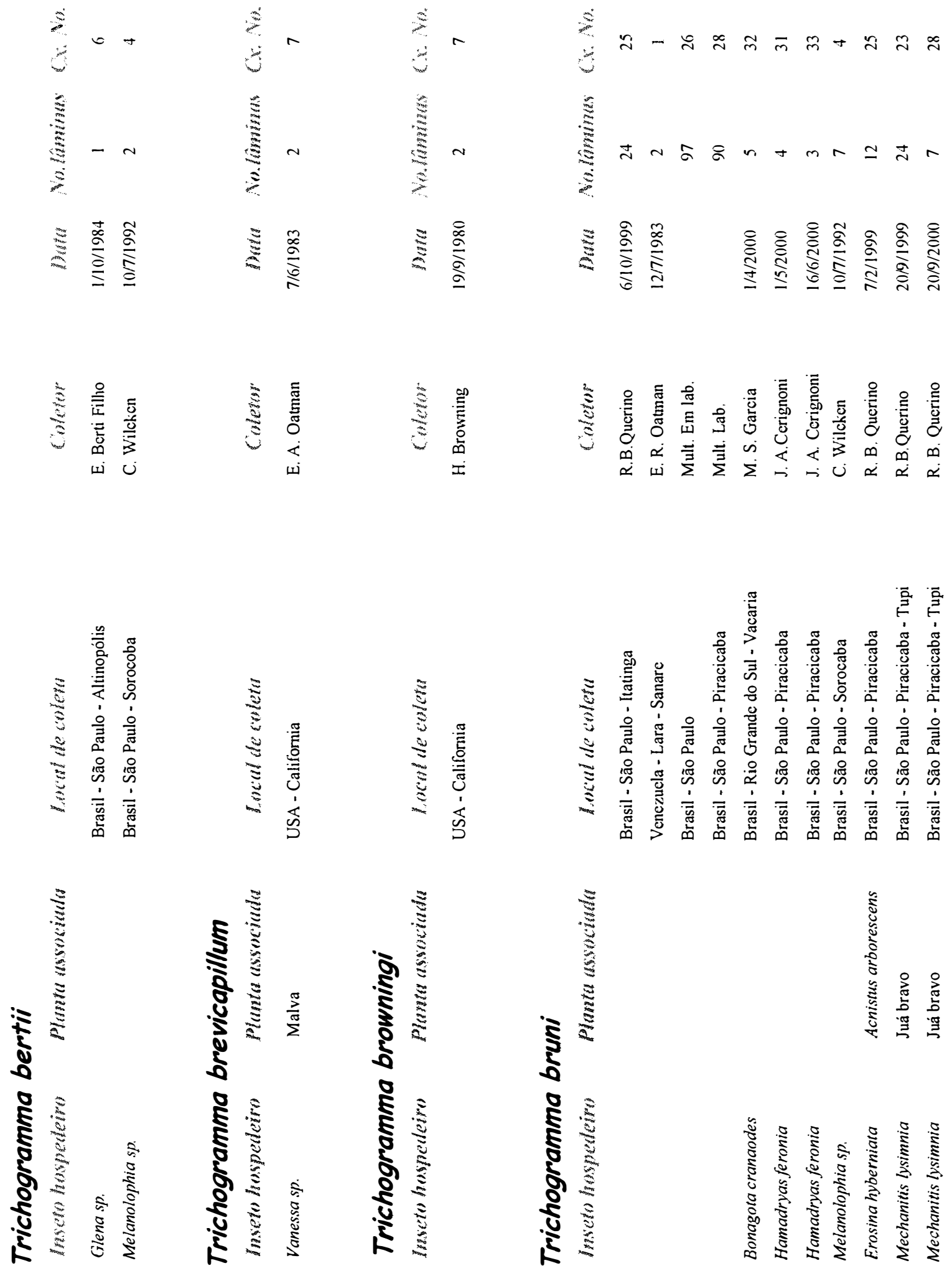

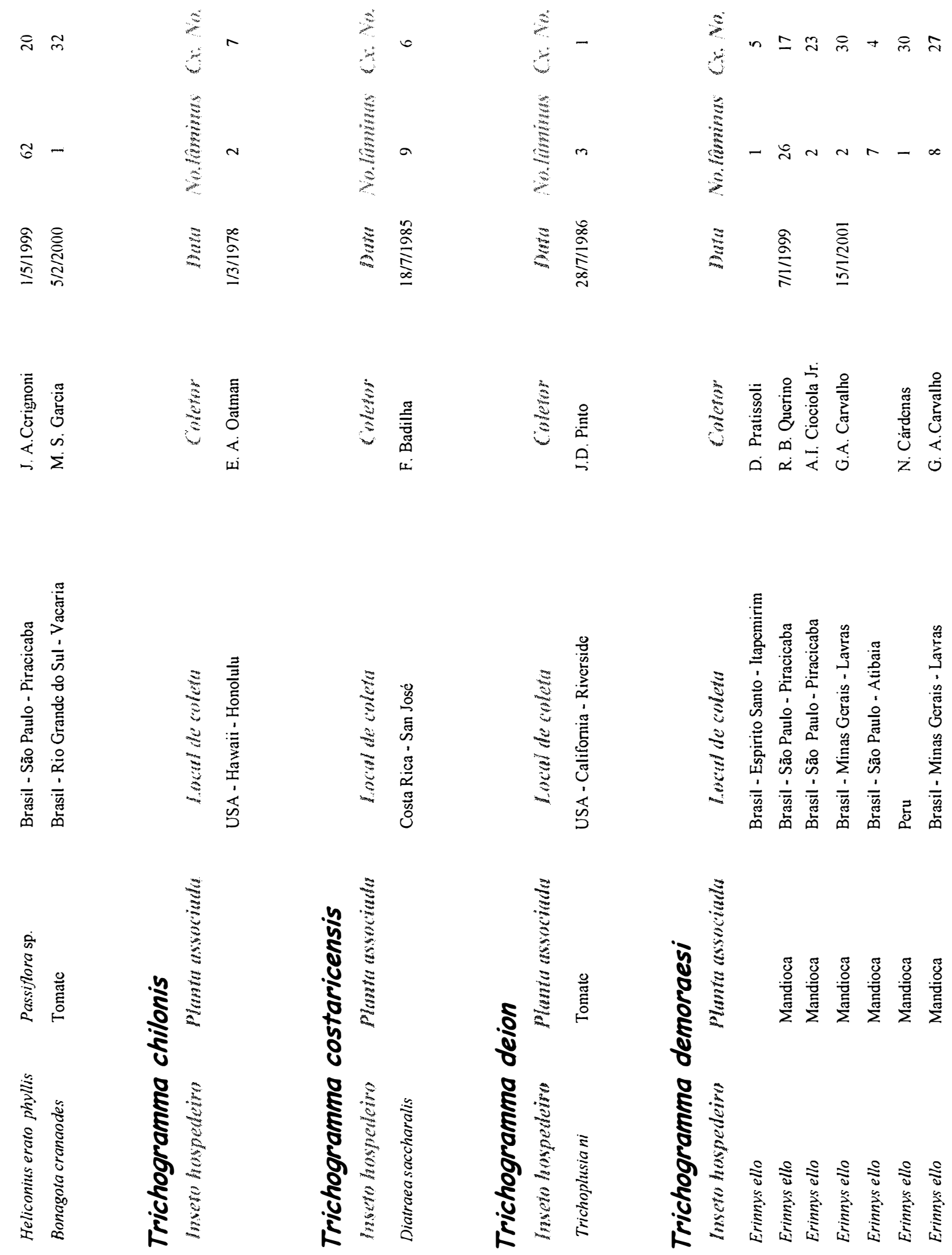

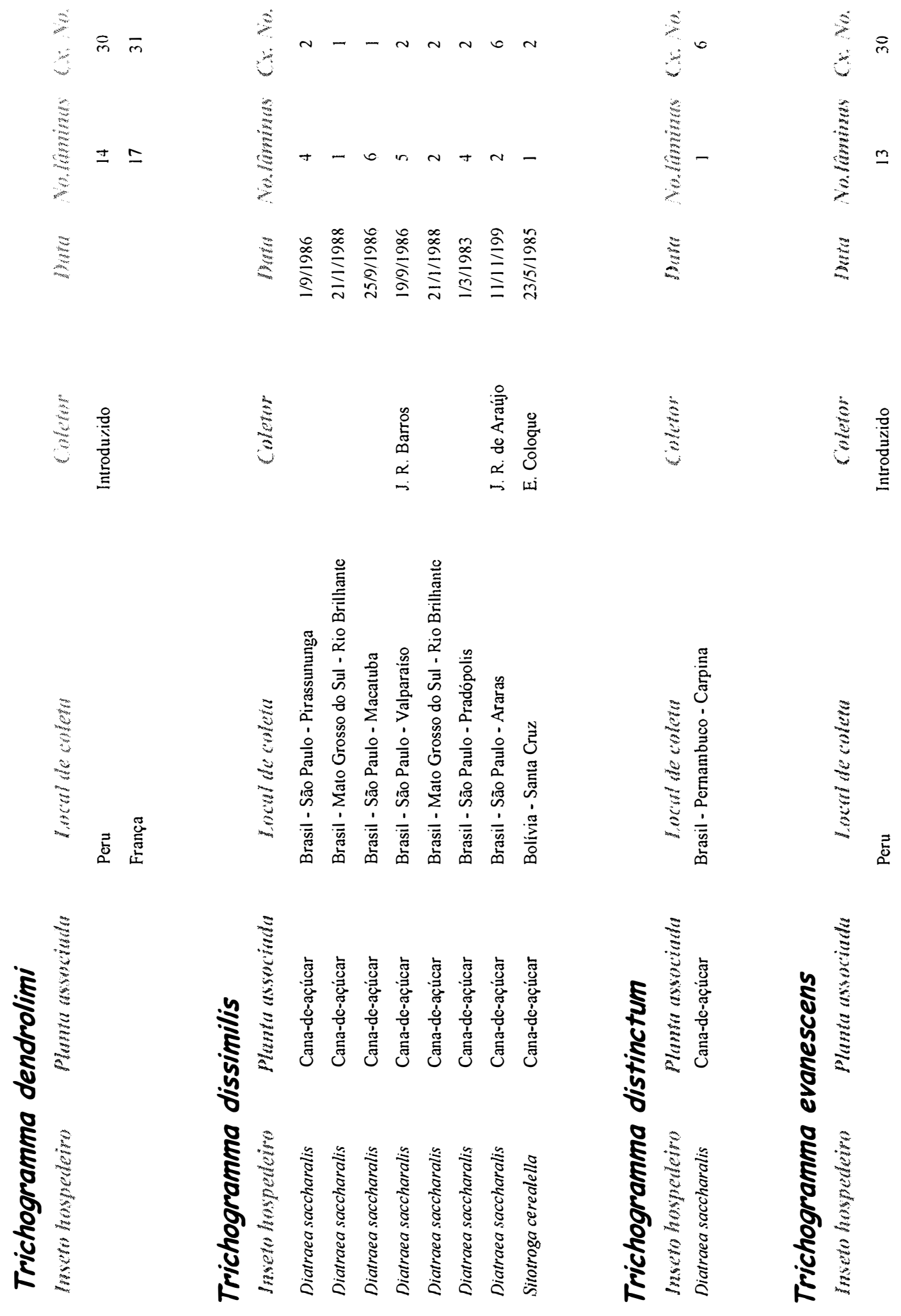


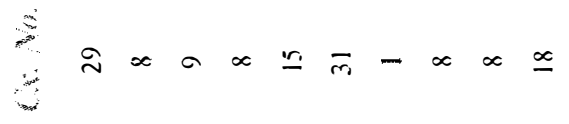

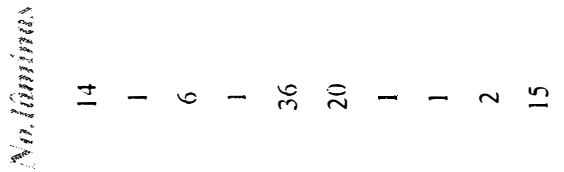

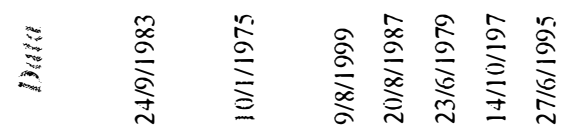

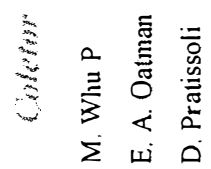

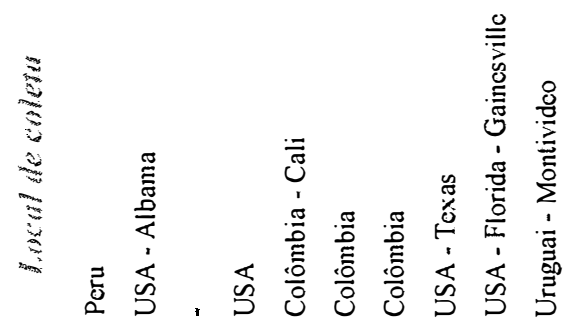

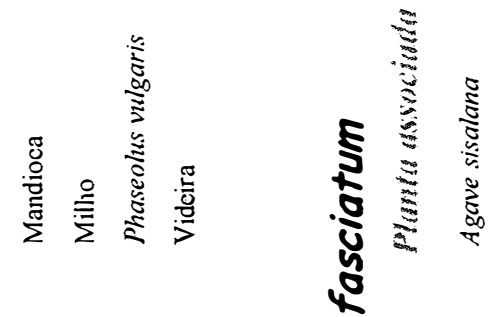

$\stackrel{\substack{5 \\ \Xi}}{\sum_{0}^{0}}$

2

$\frac{\sqrt{3}}{3} \approx$

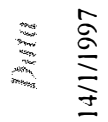

$\Xi$

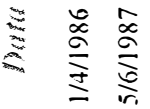

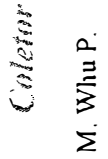

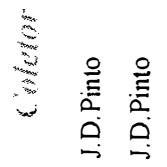
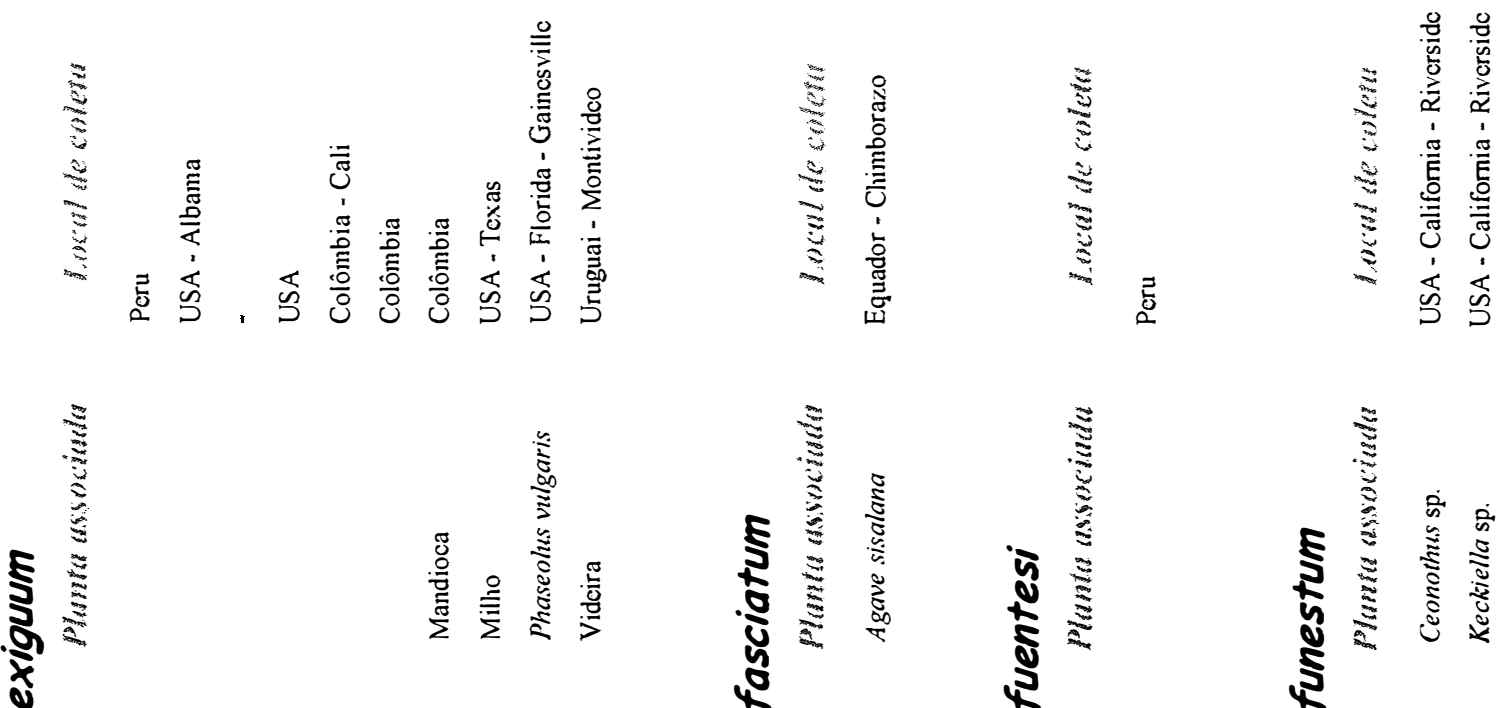

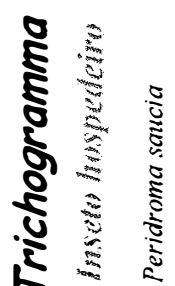
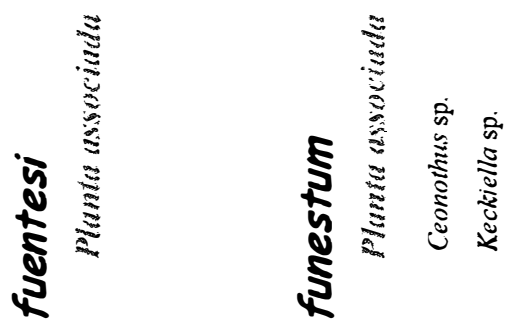

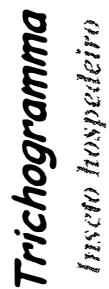
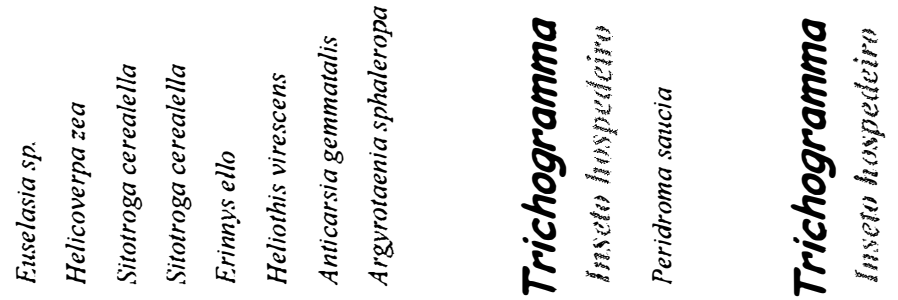

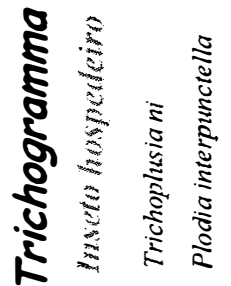




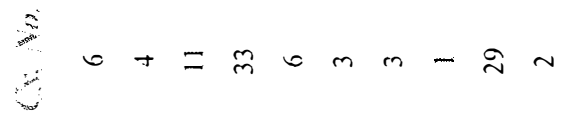

鳏

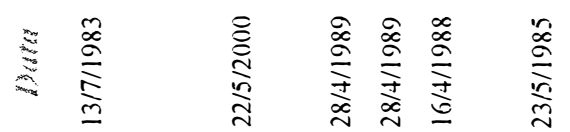

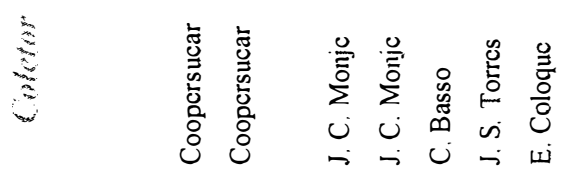

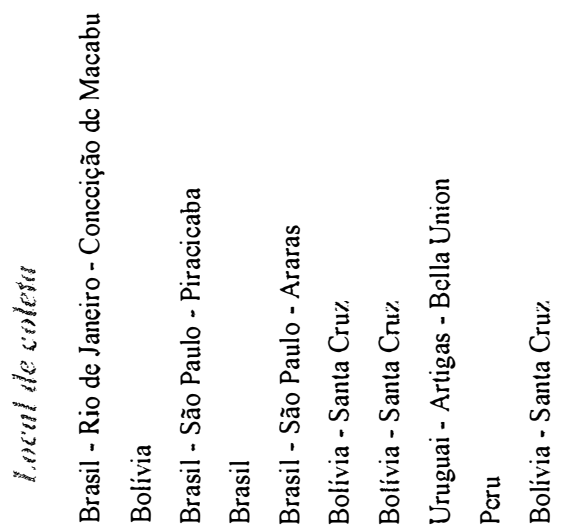

章-

$\underset{\substack{\infty \\ i \infty}}{i \infty}$

$\frac{N}{\infty} \frac{N}{\infty}$

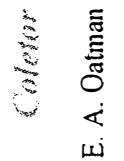

1

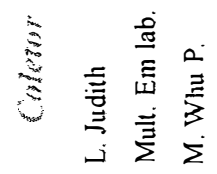

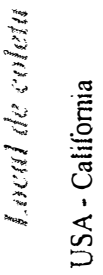

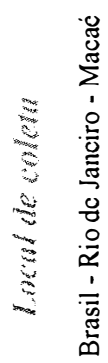
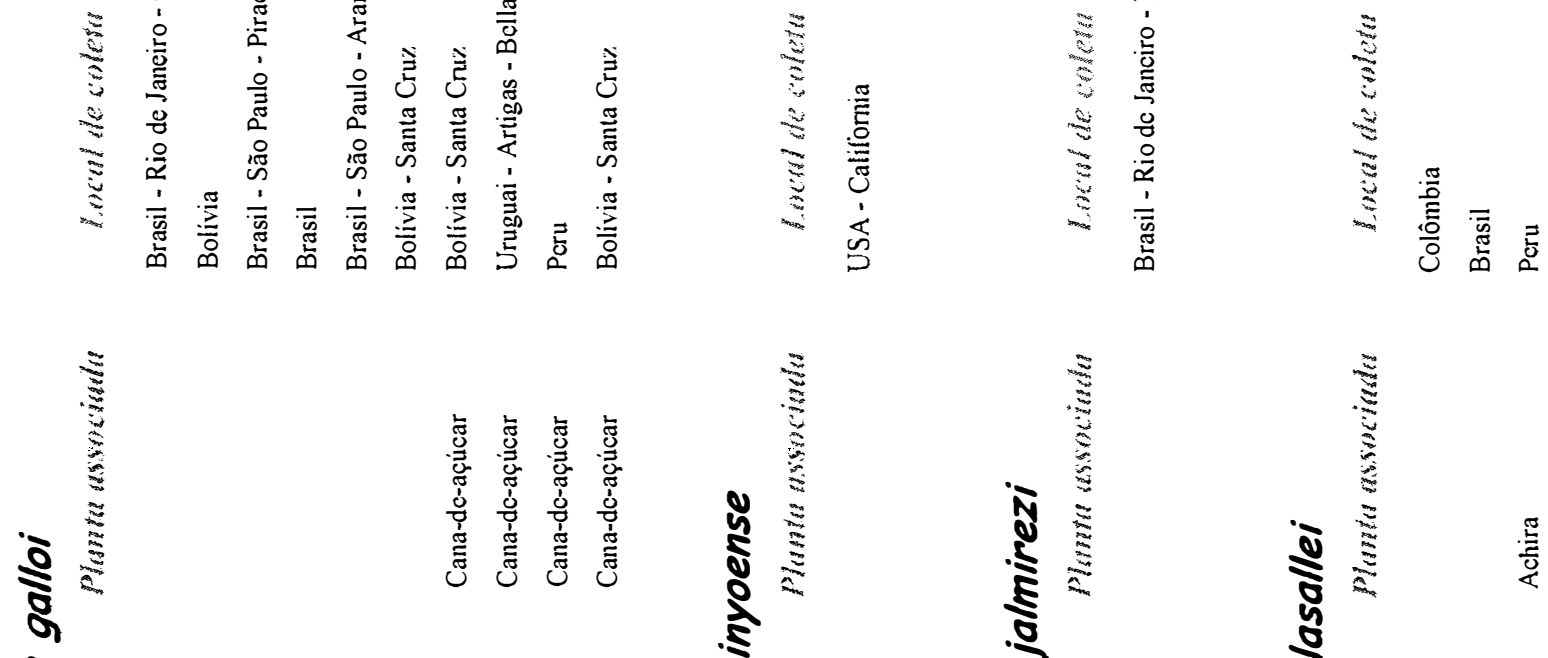

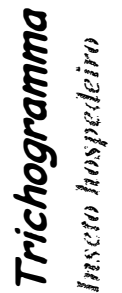

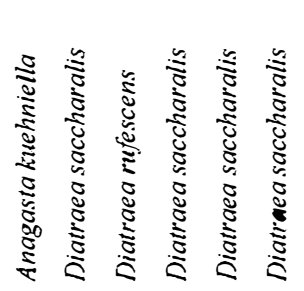

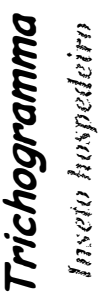
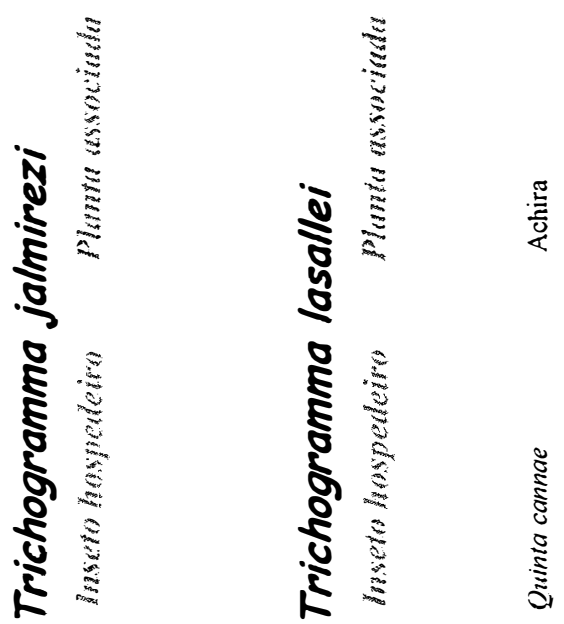

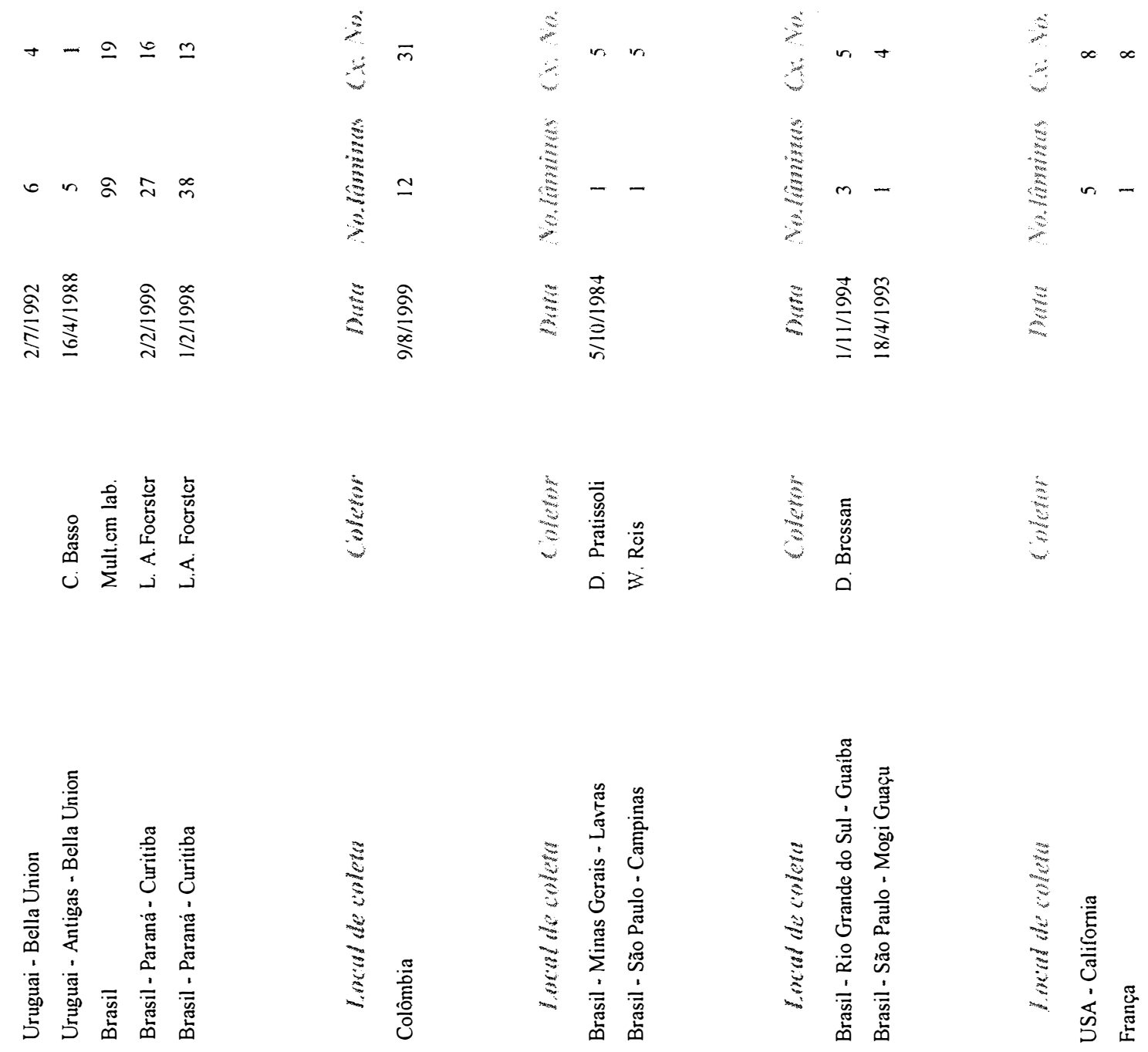

毫
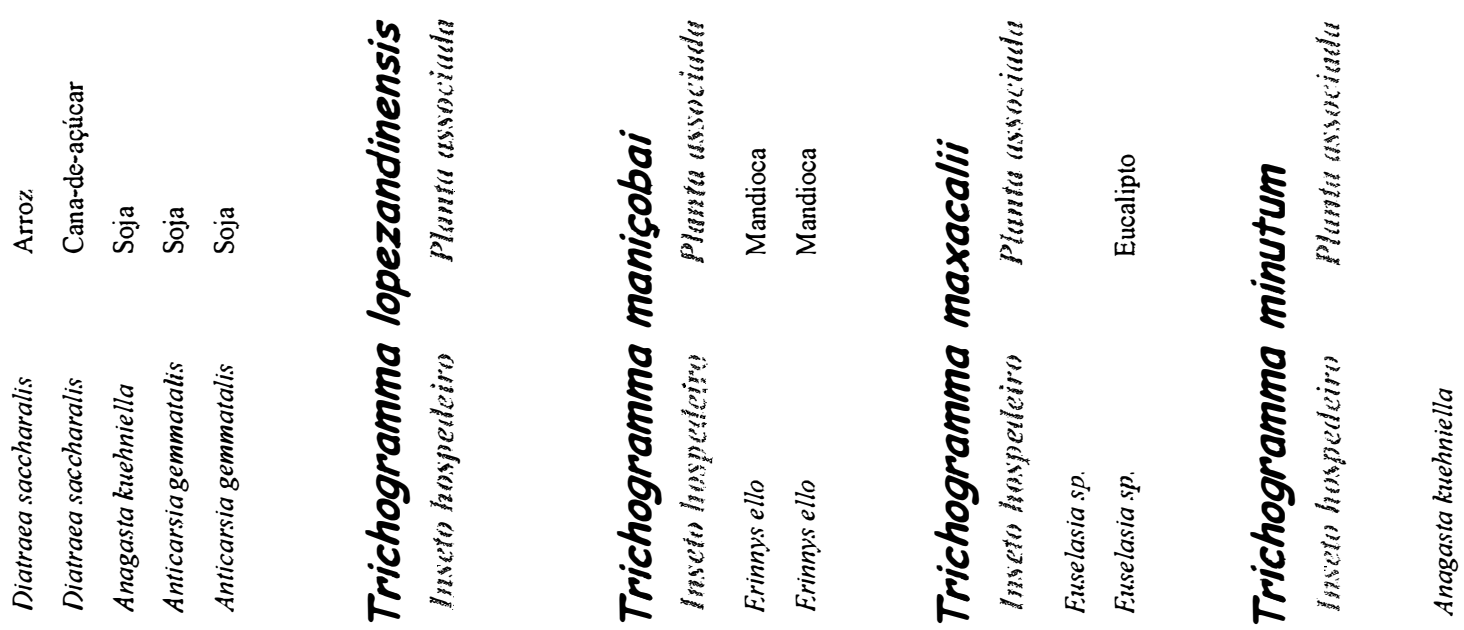

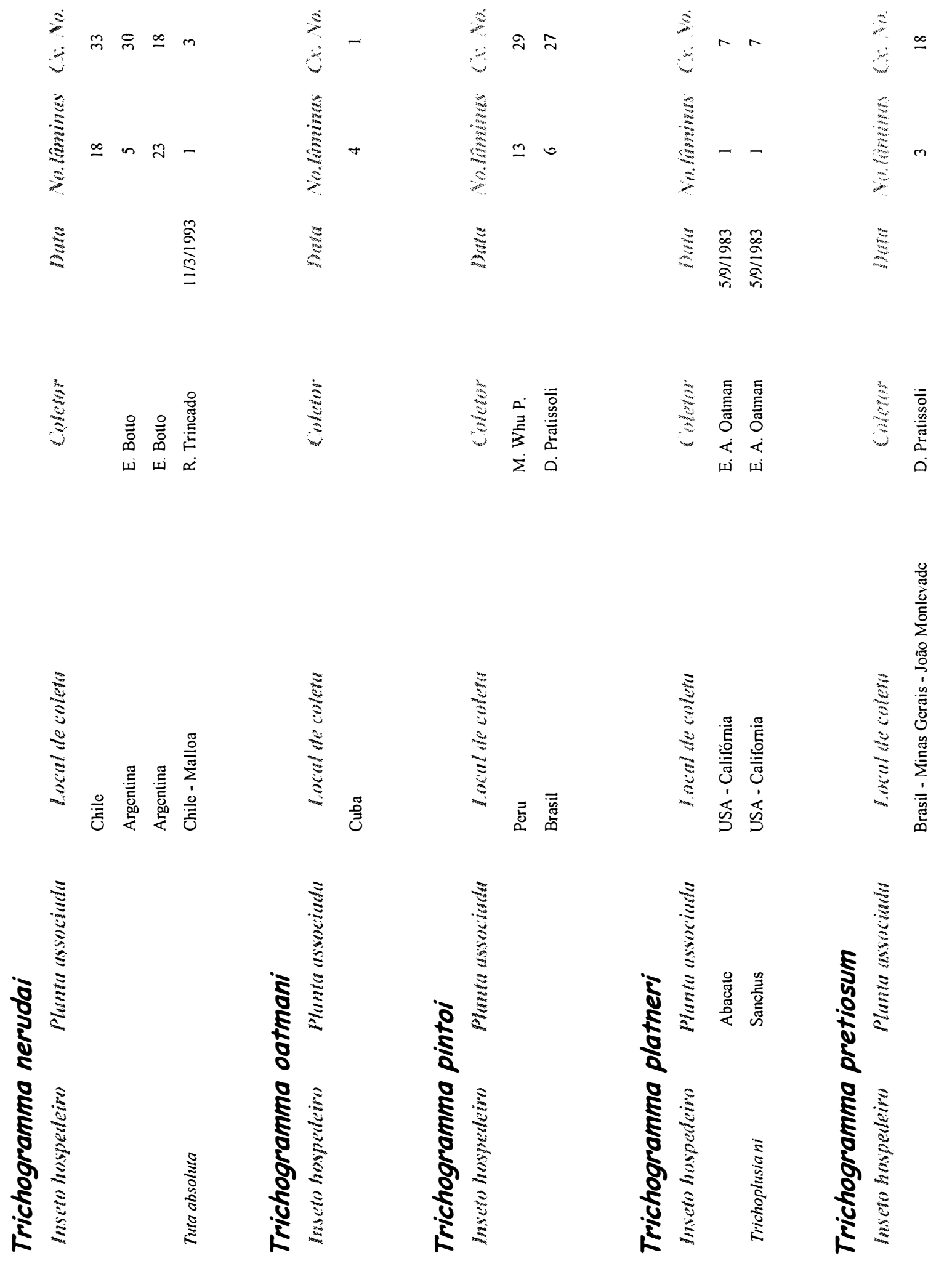


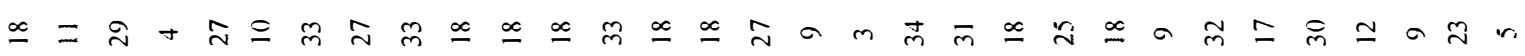

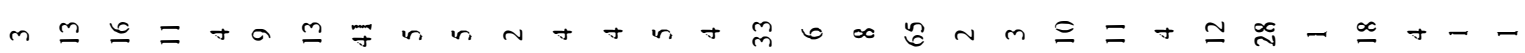

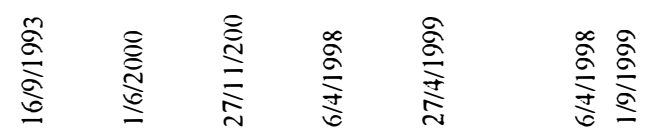

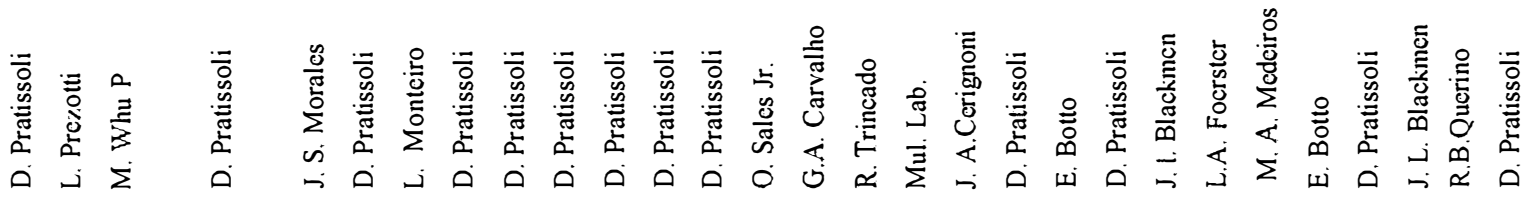

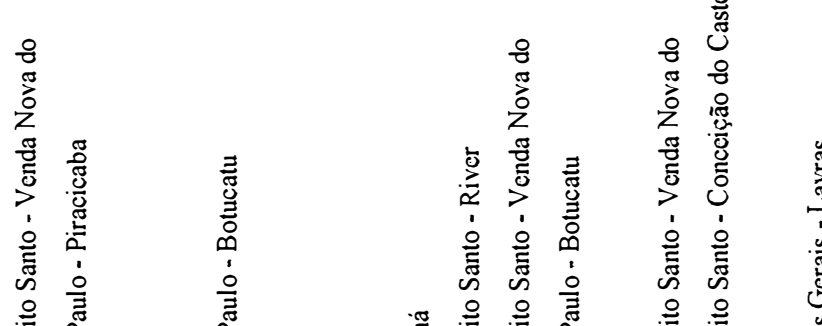

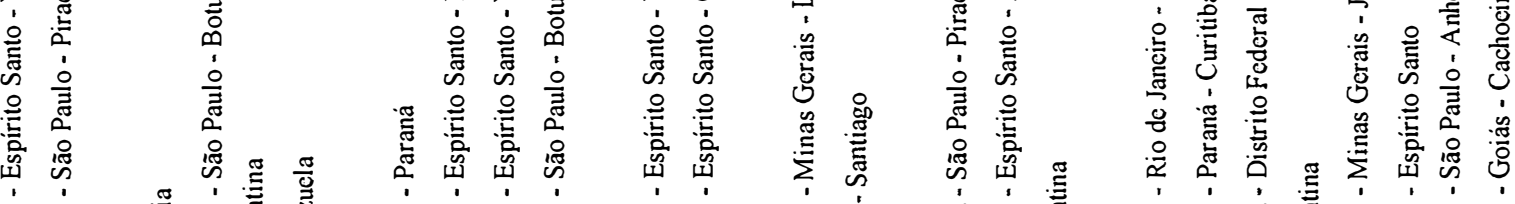

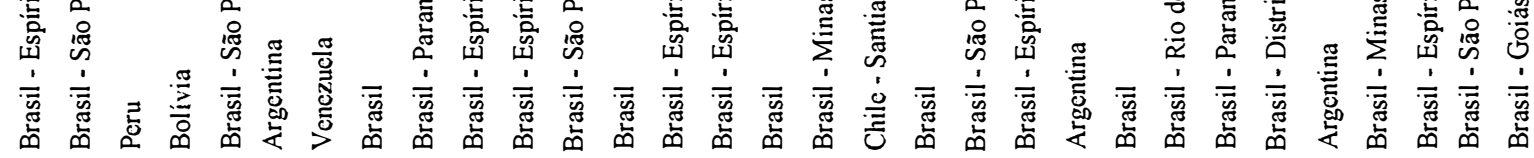




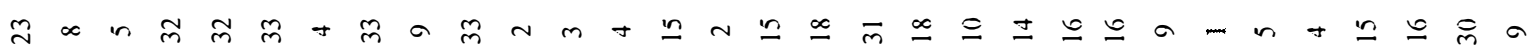

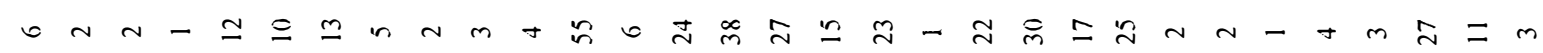

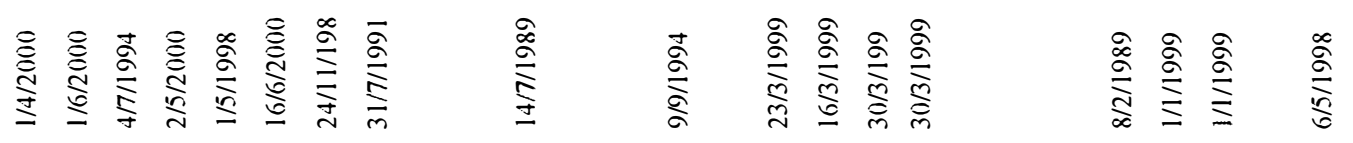

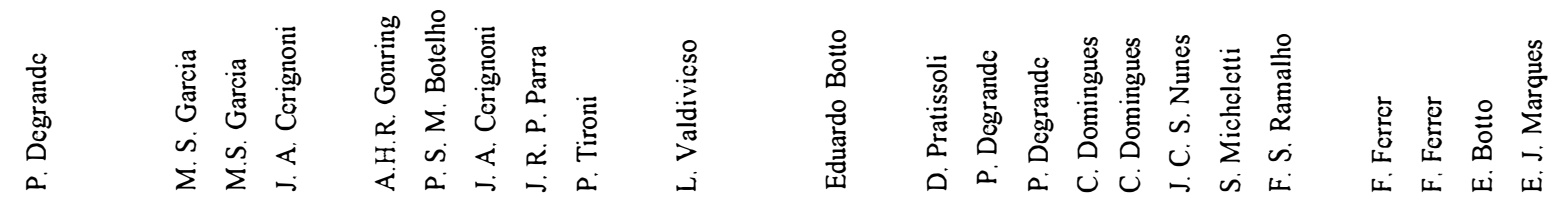

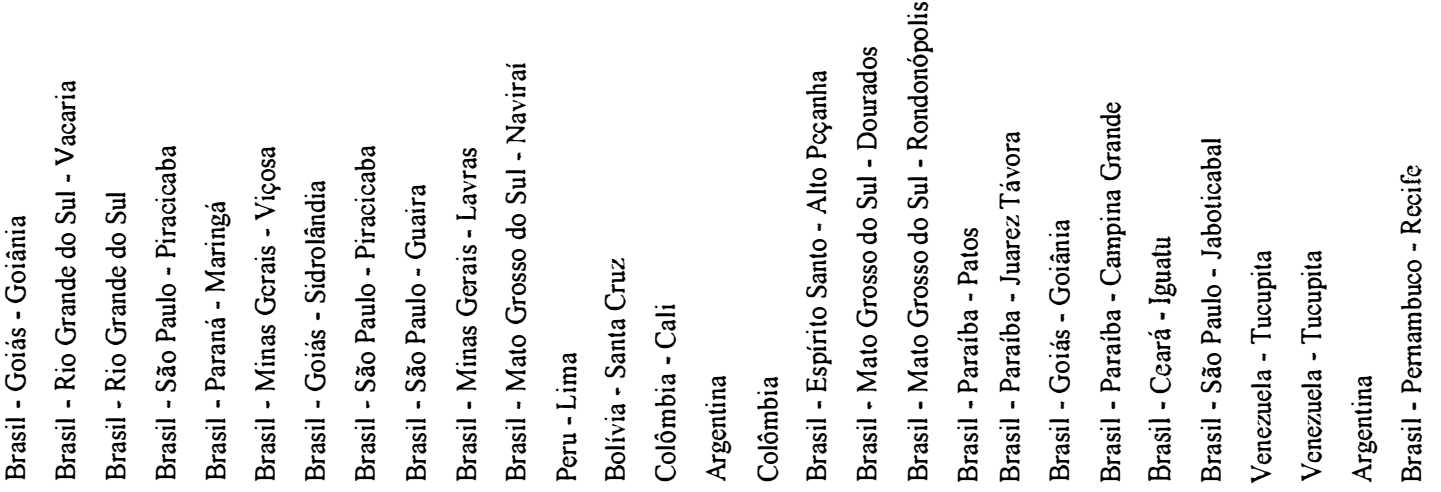

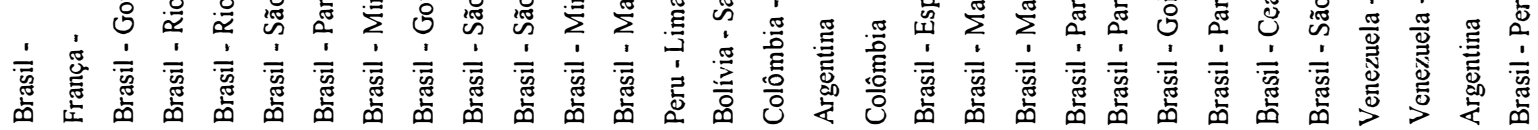
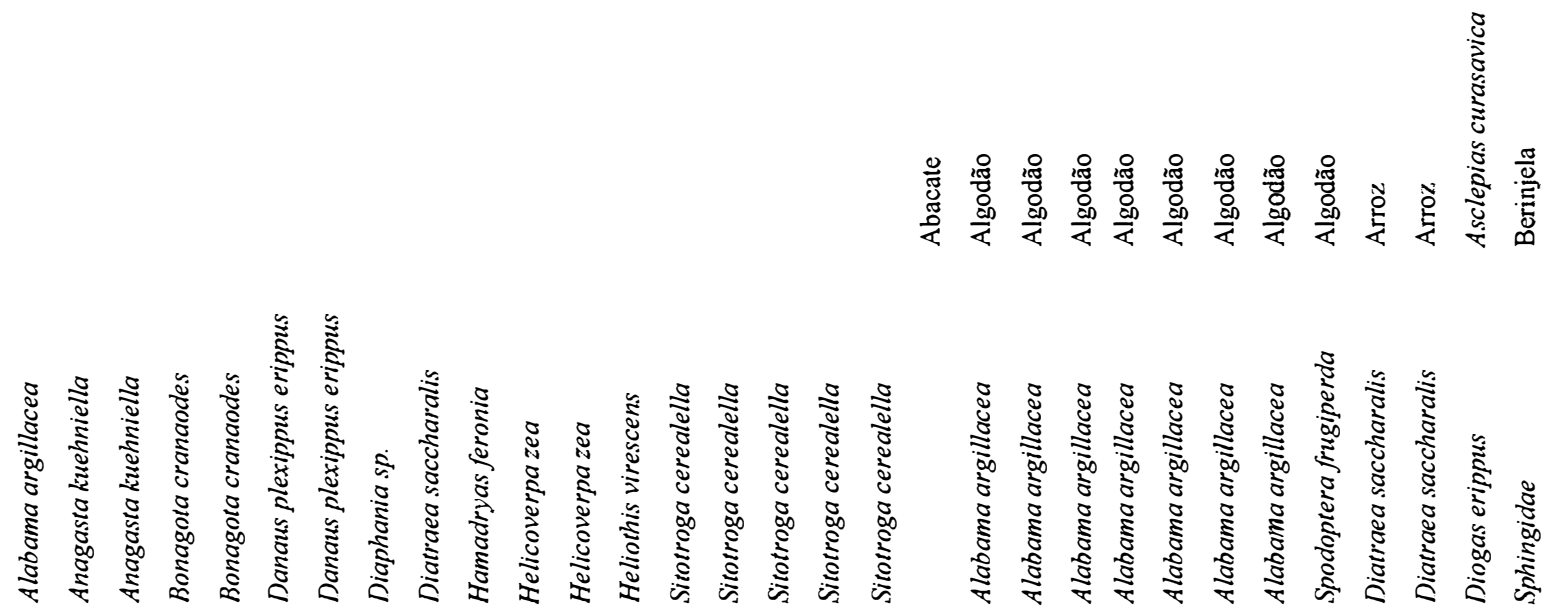


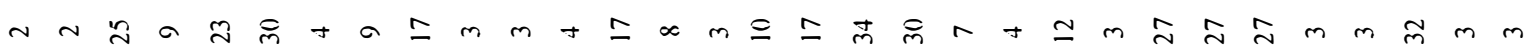

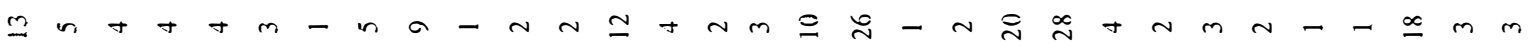

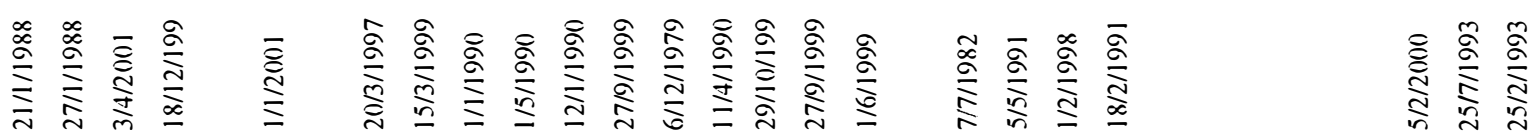

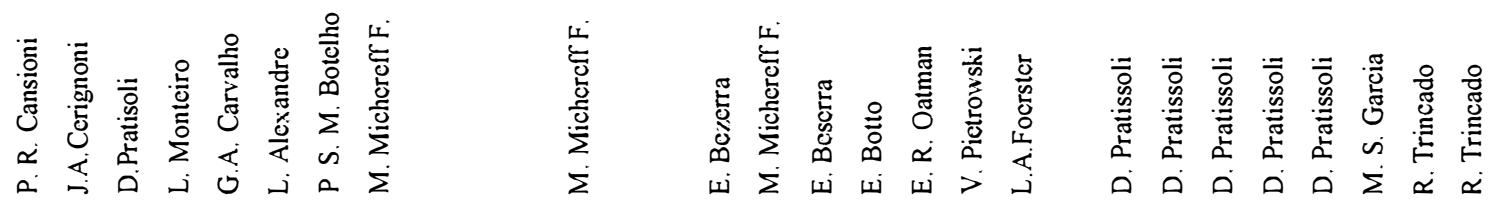

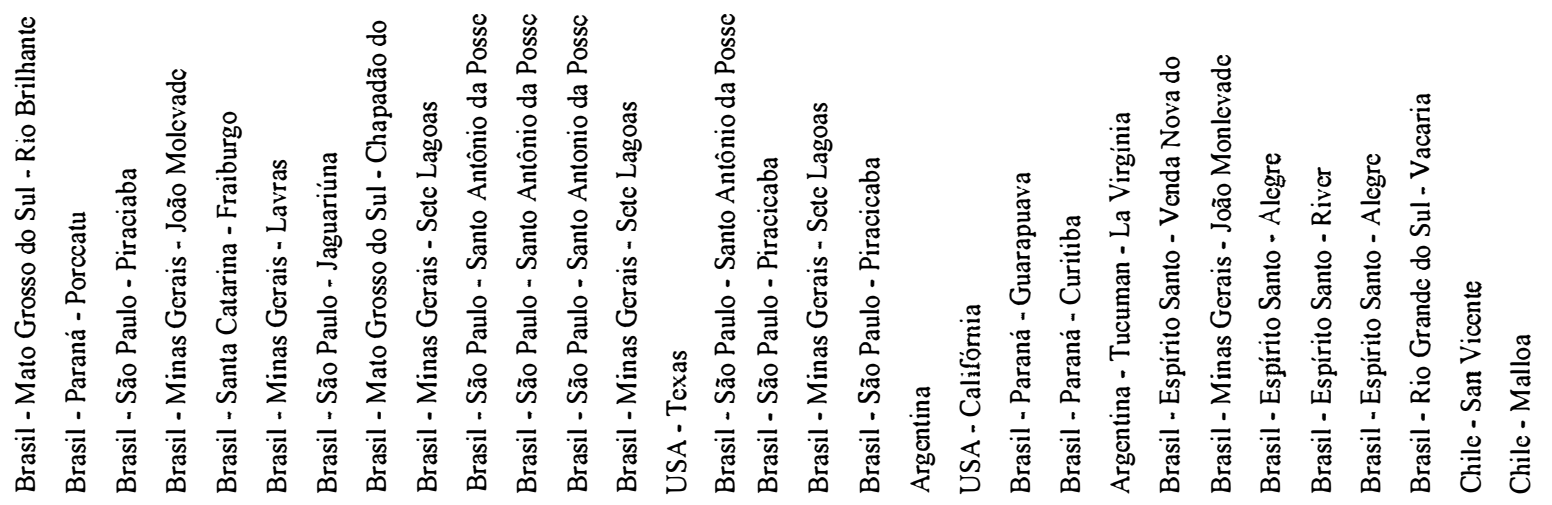

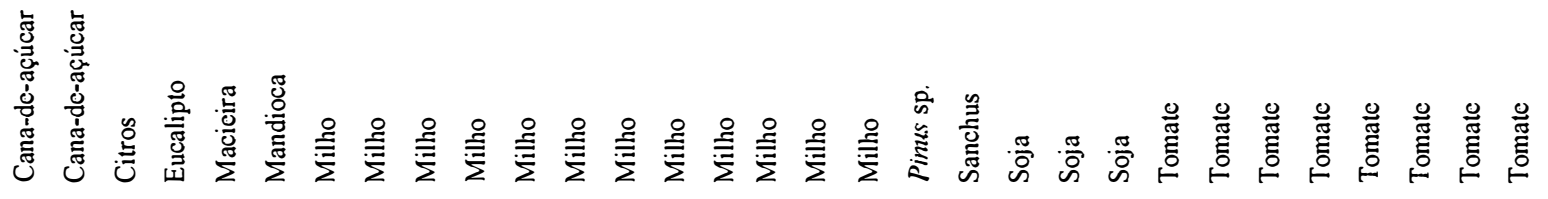

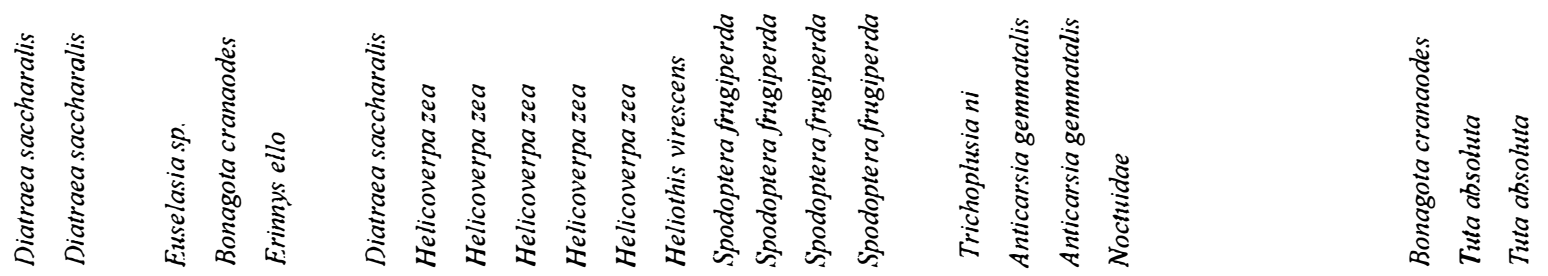




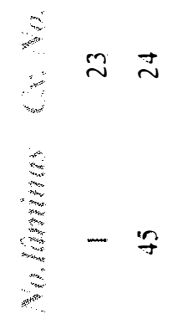

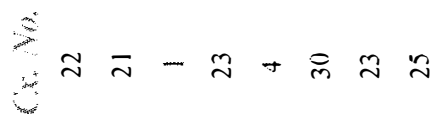

$\sum_{i}^{\infty} r$

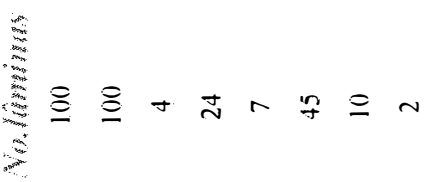

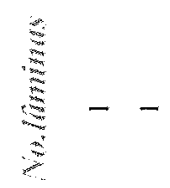

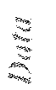

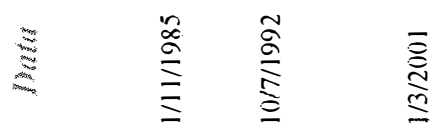

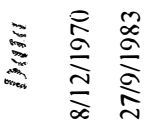

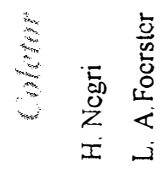

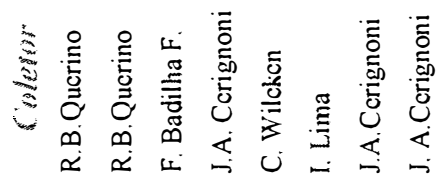

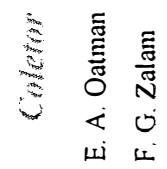
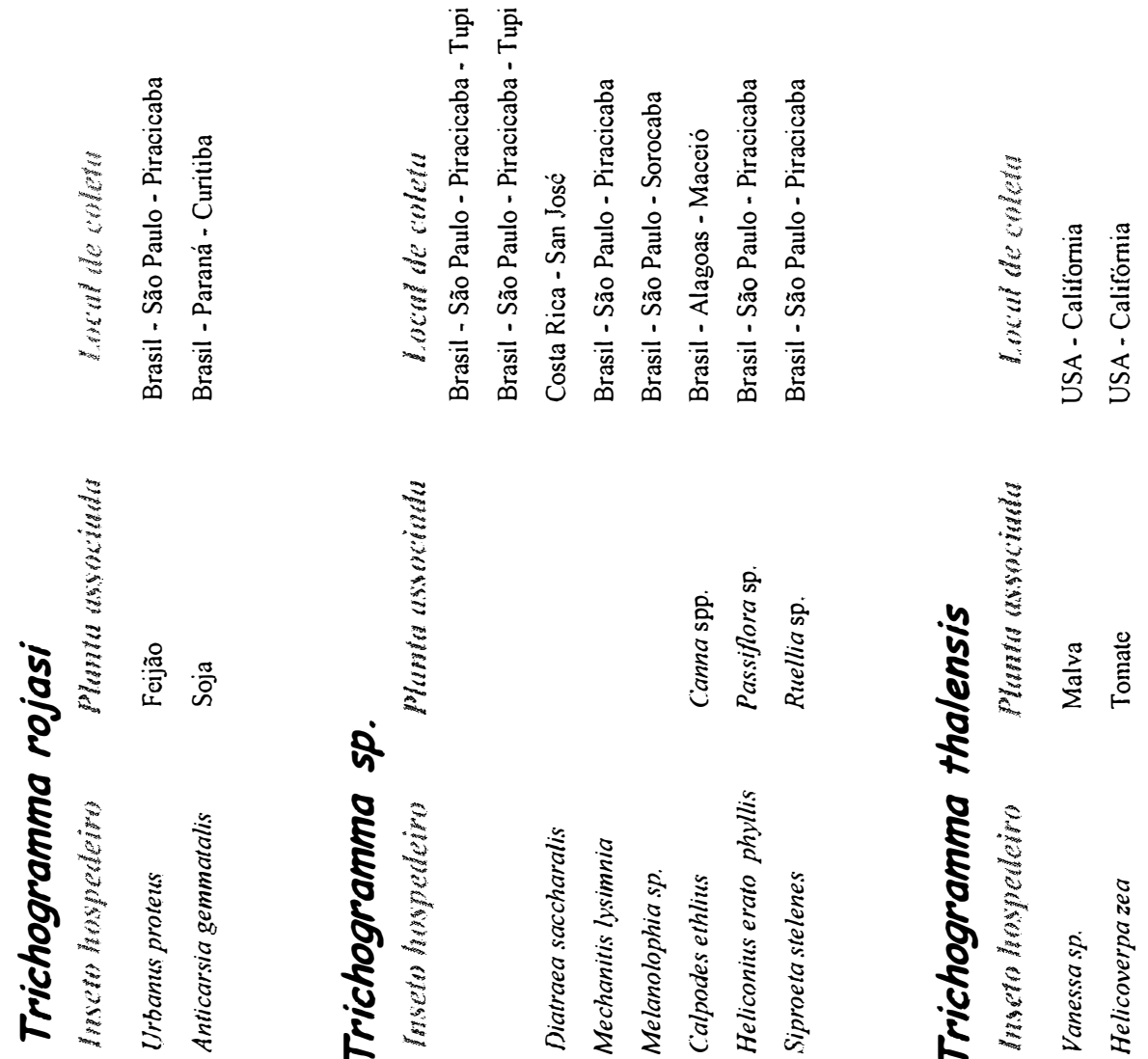

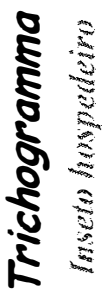

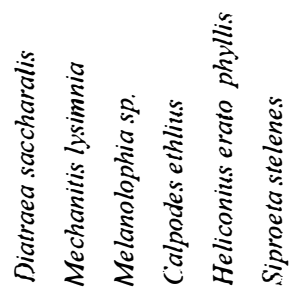

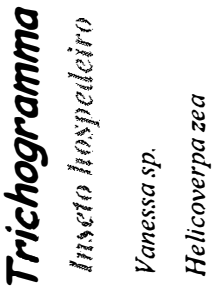


APÊNDICE 2 


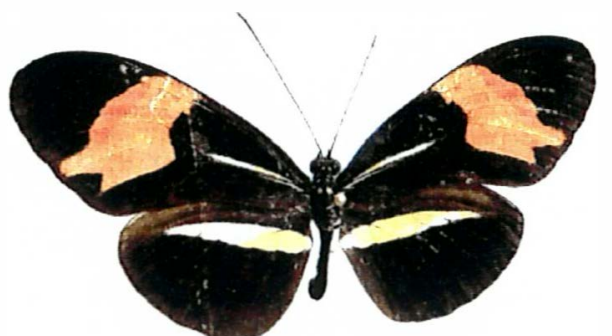

Heliconius erato phyllis

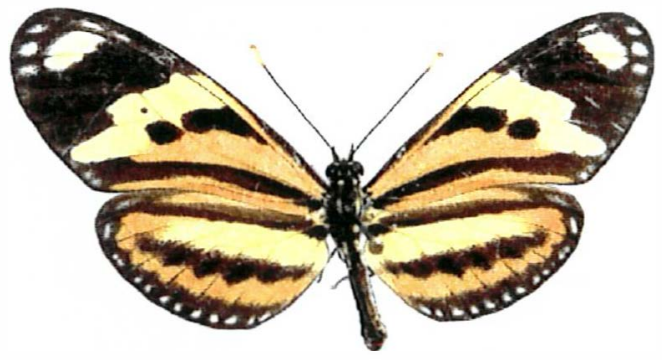

Eueides isabella dinasa

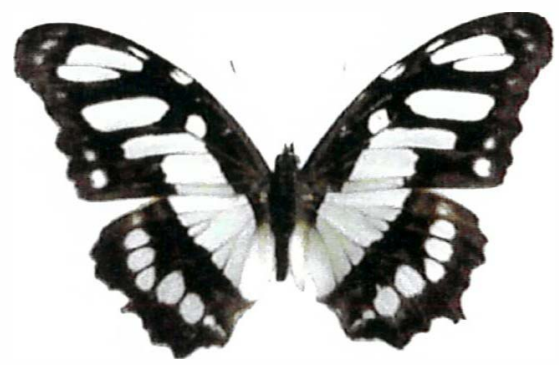

Siproeta stelene

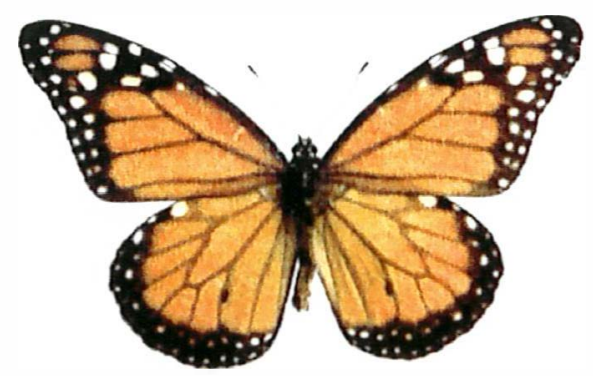

Danaus plexipus erippus

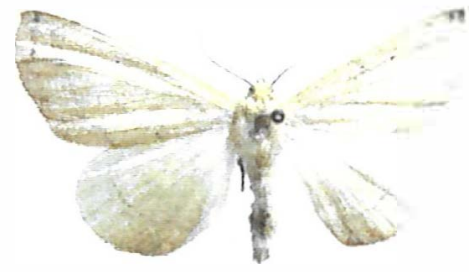

Erosina hyberniata

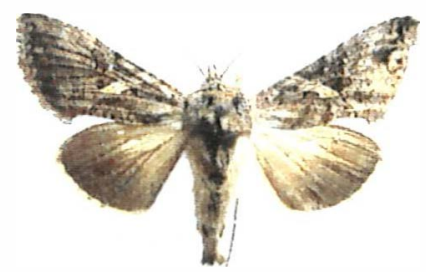

Trichoplusia oxygramma

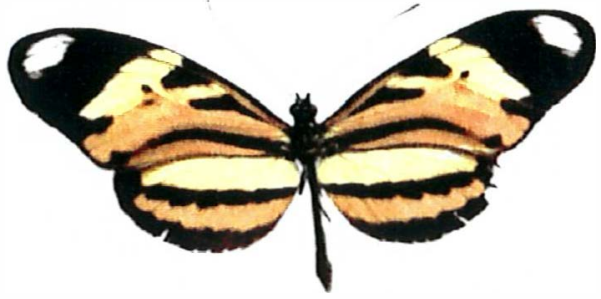

Heliconius ethilla narcaea

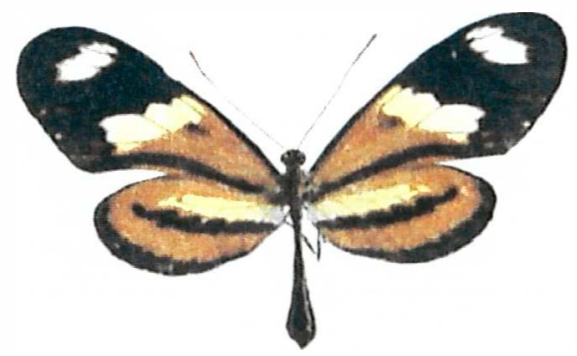

Mechanitis /ysimnia

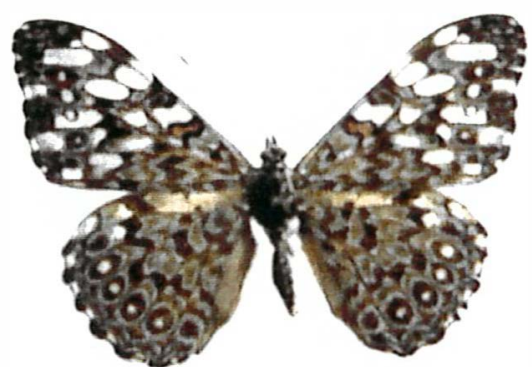

Hamadryas feronia

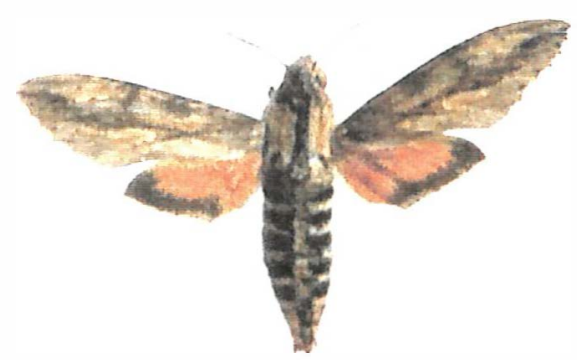

Erinnyis ello

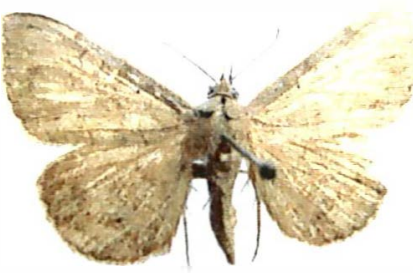

Anticarsia gemmatalis

Figura A - Espécies hospedeiras de Trichogramma coletados em campo. 


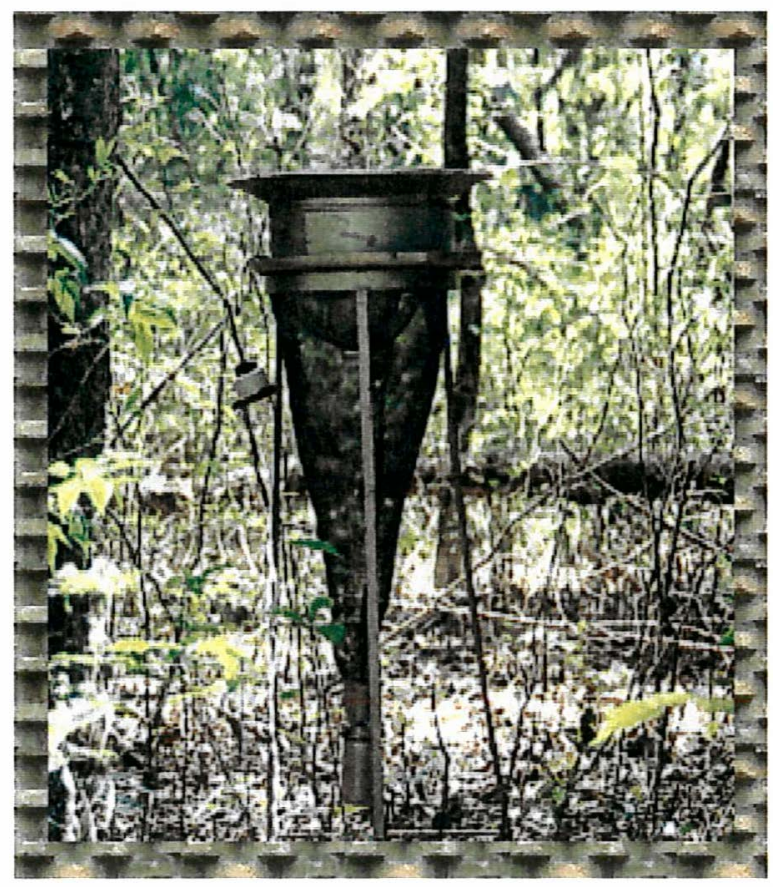

Armadilha de sucção

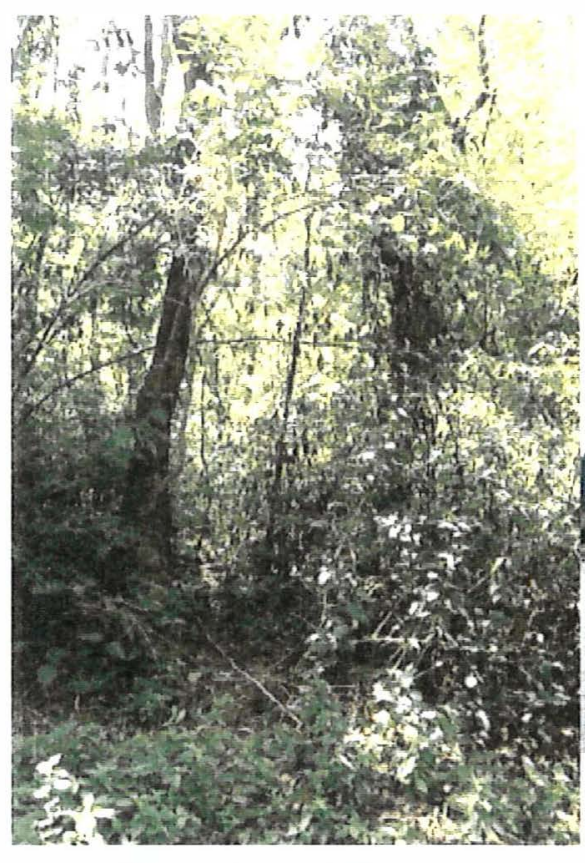

Local de instalação

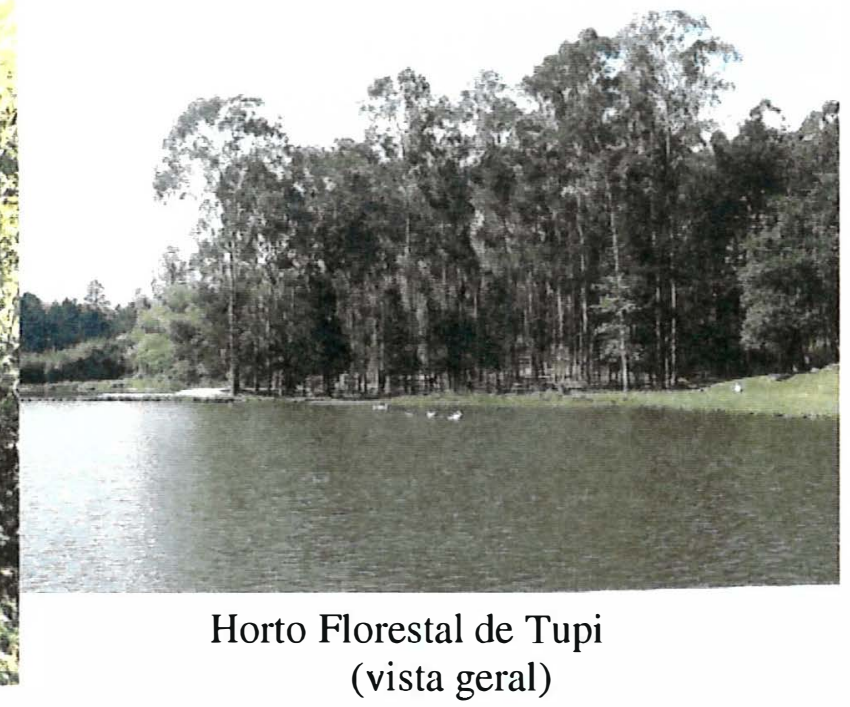

Figura B - Armadilha de sucção e aspecto do Horto Florestal de Tupi 